\title{
PHYSICAL PROCESSES AND ZOOPLANKTON \\ DISTRIBUTION IN THE GREAT SOUTH CHANNEL: OBSERVATIONAL AND NUMERICAL STUDIES
}

by

Ari Wenkart Epstein

A.B. Harvard College

Submitted in partial fulfillment of the requirements for the degree of

Doctor of Philosophy

at the

MASSACHUSETTS INSTITUTE OF TECHNOLOGY

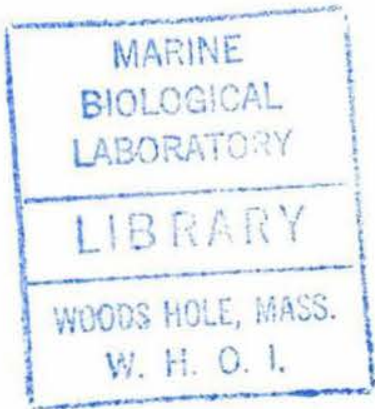

and the

WOODS HOLE OCEANOGRAPHIC INSTITUTION

June 1995

(C) Ari W. Epstein 1995

The author hereby grants to MIT and to WHOI permission to reproduce and to distribute copies of this thesis document in whole or in part.

Signature of Author

$>$

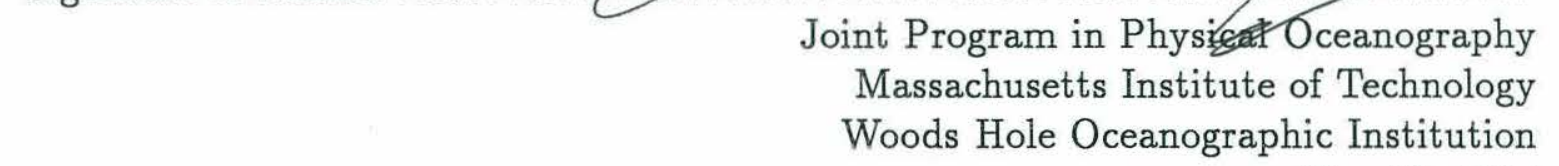

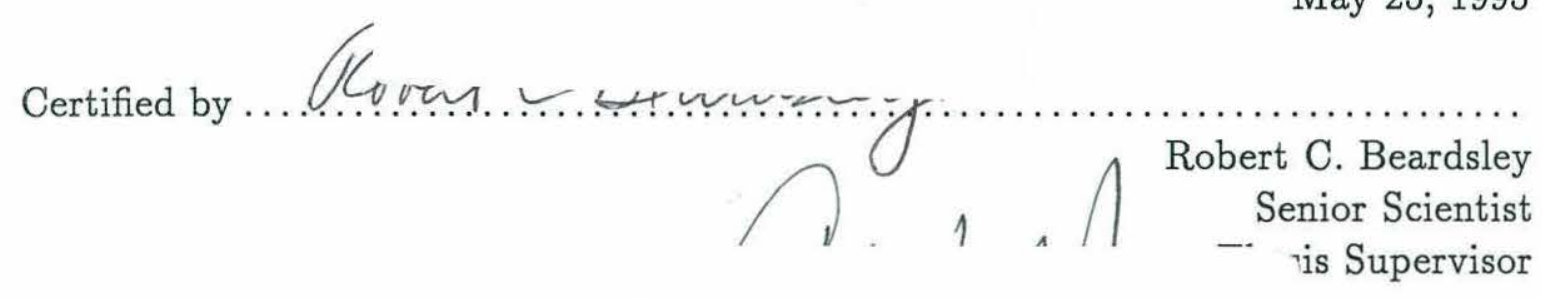

May 25, 1995

Accepted by

Carl Wunsch

Chairman, Joint Committee for Physical Oceanography

Massachusetts Institute of Technology

Woods Hole Oceanographic Institution 


\title{
PHYSICAL PROCESSES AND ZOOPLANKTON DISTRIBUTION IN THE GREAT SOUTH CHANNEL: OBSERVATIONAL AND NUMERICAL STUDIES \\ by \\ Ari Wenkart Epstein
}

Submitted in partial fulfillment of the requirements for the degree of Doctor of Philosophy at the Massachusetts Institute of Technology and the Woods Hole Oceanographic Institution

May 25, 1995

\begin{abstract}
This thesis addresses the question, "How do small-scale physics and biology combine to produce dense aggregations of certain species of zooplankton in the Great South Channel (GSC) of the Gulf of Maine?" The thesis consists of three relatively independent parts: an observational study made while following two right whales as they fed on dense patches of the copepod Calanus finmarchicus in the northern GSC; a detailed description of a tightly integrated set of biological and physical observations made in the GSC by means of a new instrument, the Video Plankton Recorder (VPR); and a two-dimensional Eulerian numerical model that simulates one way in which a physical flow field, combined with a biological behavior pattern, may produce dense plankton patches at a convergent front.

Part I: Data from a wide variety of instruments was combined to produce a coherent picture of the physical and biological environment near two feeding right whales observed in June, 1989. Instruments included a CTD (with transmissometer), a MOCNESS net system, a $150-\mathrm{kHz}$ ADCP, and a towed acoustic plankton profiler operating at 120 and $200 \mathrm{kHz}$. Acoustic data were intercalibrated with net-tow data and with "noise" in the transmissometer signal in order to estimate copepod abundance in the plankton patches on which the whales were feeding. One of the whales was observed to reverse course when copepod abundance dropped below about $1.5-4.5 \times 10^{3}$ copepods $/ \mathrm{m}^{3}$, which is consistent with independent estimates of the density of copepods necessary for a right whale to gain more energy from the prey it ingests than it loses to the extra hydrodynamic drag it experiences while feeding.

Part II: The VPR is a towed underwater microscope designed to image plankton non-invasively with sufficient resolution to obtain information on the spatial distribution of organisms on scales ranging from millimeters to hundreds of kilometers. CTD instrumentation mounted on the VPR makes it possible to correlate biological and hydrographic data with great precision. This study reports data from one transect
\end{abstract}


made across the GSC in May, 1992. The data show close correlations between hydrographic features (such as fronts, plumes and water masses) and broad-scale plankton distribution. In addition, it was possible to correlate the fine-scale (order tens of meters) patchiness in plankton distribution with the local stability of the water column (as indicated by gradient Richardson number). In one case, biological data provided an aid in determining the origin of one of the observed water masses.

Part III: This chapter presents a two-dimensional Eulerian numerical model that shows how depth-keeping swimming behavior on the part of an organism, combined with a convergent flow field at a surface front, can create dense patches of the organism. In this model a steady-state flow field and vertical diffusivity field are prescribed, along with the initial distribution of the plankton. The plankton swim vertically with speeds that depend only on depth, but the form of that depth-dependence may take into account such factors as the vertical variation in light level or in the concentration of some prey organism. An analysis of various nondimensional parameters associated with the model illustrates the roles played in determining the final structure of the patch by such factors as diffusion, water velocity and details of the animals' swimming behavior. Output from the model is compared with data taken at a dense plankton patch observed near a front in the northern Great South Channel in early June, 1989.

Thesis Supervisor:

Robert C. Beardsley

Senior Scientist

Woods Hole Oceanographic Institution 


\section{Acknowledgements}

I am extremely grateful to my advisor, Bob Beardsley, for his wisdom, support and encouragement over the past several years. Despite his remarkably busy schedule he has always made himself available to me, and I'm sure he has given me far more time than he could spare. I would like to thank him for encouraging me to take on such an unusual project, and for helping me to pull the various aspects of it together when they threatened to fly apart. On a more personal side, working with Bob has made an otherwise very difficult time much easier; I've always felt better coming out of his office than I felt going in.

I would also like to thank the other members of my Thesis Committee: Cabell Davis, Glenn Flierl, Paola Malanotte-Rizzoli, and Dave Mountain. They have been very generous with their time and expertise, and have been a continuous source of encouragement and good humor. I am also grateful that they were willing to tell me I wasn't quite done yet, even though I thought I was; they were right.

I would like to thank Scott Gallager, who was not a member of my Committee but might as well have been, for allowing me to work on VPR data with him and for helping me to understand what was going on biologically. Rocky Geyer very generously gave me access to all of his model code and helped me to understand how it worked. I am grateful to Jim Price for chairing my thesis defense, and for the useful comments and suggestions he made on my thesis draft. I would also like to thank SCOPEX co-workers Karen F. Wishner, Michael C. Macaulay, and Robert D. Kenney, who, together with Bob, Chen, and myself, are co-authors of the paper on which Chapter 2 is based, and Andy Solow, who, together with Cabell, Scott, Bob and myself, is a co-author of the paper on which Chapter 3 is based.

Thanks to Bill Williams for sharing the data and m-files necessary to make various plots of the Great South Channel and for sharing his analysis of data from EN237 VPR casts 20 and 21. Alison Macdonald supplied many extremely helpful doses of $\mathrm{IAT}_{\mathrm{E}} \mathrm{X}$ wizardry. Jack Cook, of WHOI Graphic Services, drafted many of the figures in Chapter 2 and then (as part of the Project That Wouldn't Die) helped me get them into a format that a Unix box could understand. Anne-Marie Michael, Abbie Alvin, Ronni Schwartz, Changsheng Chen and Dick Limeburner have helped me in a million various ways. Faculty in the MIT Physical Oceanography Group have been very generous in permitting me access to their computer resources, and Linda Meinke has helped me sort out whatever fights I was having with those computers, always with extremely good cheer.

I would like to thank my classmates for all the good arguments, and especially Bingjian Ni, who sometimes let me sleep on the couch in our office (when I could beat 
him to it). Kate Deyst, Brian McCue, and Shelley Zak have now seen me through two theses (and innumerable other crises) with constant love and friendship; I promise not to make them do it again. I also want to thank my family, some of whom know what it's like to try to get a Ph.D., and others of whom are willing to pretend they do.

Finally, I cannot possibly give enough thanks to my wonderful wife, Joan Silberlicht Epstein, for her love, support and good penmanship. I promise to try in the future to keep my "thought balloons" from crowding her out of the house.

My first three years in the Joint Program were paid for by the Office of Naval Research under an ONR Fellowship. I would also like to acknowledge subsequent support from the National Science Foundation under grant OCE 93-13671 and the National Oceanic and Atmospheric Administration under grants NA36GP0374 and NA26GP0431.

The SCOPEX field work reported here was supported by the National Science Foundation and the U.S. Department of Interior Minerals Management Service through NSF grants OCE 87-13988 and OCE 91-01034 to R. Beardsley and C. Chen, grants OCE 87-11847 and OCE 89-15610 to K. Wishner, grants OCE 8711851 and OCE 89-15610 to R. Kenny, and grants OCE 89-040247 and OCE 89-15844 to M. Macaulay. Support for A. Epstein during the analysis phase of the SCOPEX work was provided by the National Oceanic and Atmospheric Administration under Grant NA36GP0374. The final preparation of the SCOPEX manuscipt was supported by NSF under grant OCE 93-15713 with help from J. Cook and A.-M. Michael. The authors of the paper on which Chapter 2 is based thank the many individuals who helped make SCOPEX a successful field experiment. In particular, we acknowledge the encouragement and strong support of $\mathrm{H}$. Winn, who served with $\mathrm{K}$. Wishner as SCOPEX co-coordinator; P. Wiebe, who provided valuable input concerning the interpretation of acoustic data; A. and E. Durbin, who kindly shared their measurements of copepod size and energy content; A. Leising, who shared his unpublished results on copepod swarming; and the crews of the R/V Endeavor and Marlin.

The authors of the paper on which Chapter 3 is based thank Andy Girrard, Ben Moten and Philip Alatalo for help in processing the video images, and Bob Elder and Craig Lewis for their efforts at sea in keeping the VPR in the water. This research was supported by NOAA MER Grant NA16RC0515-02, NSF GLOBEC Grant OCE 9313671, and ONR Grant N00014-93-1-0602.

This is contribution number 38 of the U.S. GLOBEC program, funded jointly by the NSF and NOAA. 


\section{Contents}

$\begin{array}{ll}\text { Abstract } & 3\end{array}$

$\begin{array}{lr}\text { Acknowledgements } & 5\end{array}$

$\begin{array}{lll}1 \text { Introduction } & 10\end{array}$

1.1 Following the Whales . . . . . . . . . . . . . 12

1.2 A Closer Look . . . . . . . . . . . . . . . . . . . . . . . 13

1.3 A Numerical Approach . . . . . . . . . . . . . . . . . . . . . 14

1.4 Specific Contributions . . . . . . . . . . . . . . . . 14

2 Spatial Variability in Zooplankton Abundance near Feeding Right Whales in the Great South Channel 16

2.1 Abstract . . . . . . . . . . . . . . . . 16

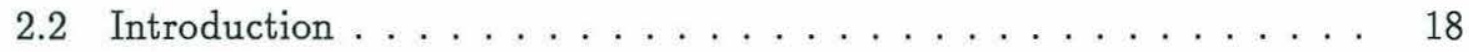

2.3 The Sampling Program . . . . . . . . . . . . . . . . . . 20

2.4 The Observations . . . . . . . . . . . . . . . . . . . . . . . . 29

2.4.1 Intercomparison Between 200-kHz and MOCNESS Biomass Estimates . . . . . . . . . . . . . . . . 30

2.4.2 Comparison Between Light Transmission and 200-kHz Biomass Estimates . . . . . . . . . . . . . . . 34 
2.4 .3 Tow-yo $5 \ldots \ldots \ldots \ldots \ldots \ldots \ldots \ldots$. . . . . . . 40

2.4 .4 Tow-yo $6 \ldots \ldots \ldots \ldots \ldots \ldots \ldots \ldots \ldots$

2.4.5 The Next Morning . . . . . . . . . . . . . 46

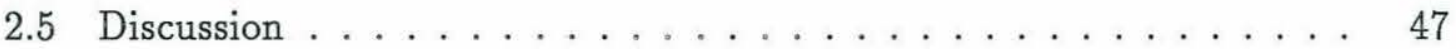

3 High-Resolution Observations of Plankton Spatial Distributions Correlated with Hydrography in the Great South Channel 51

3.1 Abstract . . . . . . . . . . . . . . . 51

3.2 Introduction . . . . . . . . . . . . . . . 53

3.3 Physical Setting . . . . . . . . . . . . . . . . 55

3.4 Sampling Techniques $\ldots \ldots \ldots \ldots \ldots \ldots \ldots$

3.4.1 The Video Plankton Recorder (VPR) . . . . . . . . . 57

3.4.2 Data Processing . . . . . . . . . . . . . . . . . . . 59

3.4.3 Richardson Numbers . . . . . . . . . . . . . . . . . . . . 62

$3.5 \quad$ Results . . . . . . . . . . . . . . . . 63

3.5.1 General Hydrography . . . . . . . . . . . . . . . . . . 63

3.5.2 T-S and Water-Type Analysis . . . . . . . . . . 66

3.5.3 Water Column Stability _. . . . . . . . . . . . . . 74

3.5.4 Distribution and Abundance of Plankton . . . . . . . 75

$3.5 .5 \quad$ T-S-P Diagrams . . . . . . . . . . . . . . . . . 98

3.6 Discussion . . . . . . . . . . . . . . . . . . . . . . . . . . . 99

3.7 Conclusions . . . . . . . . . . . . . . . . . . . . 110

4 Flow-Induced Aggregation of Zooplankton at a Front: a Two-Dimensional Eulerian Numerical Model 112

4.1 Introduction . . . . . . . . . . . . . . . . . . . 112

4.2 The Small-Scale Subduction Mechanism . . . . . . . . . . . 114 
4.3 Aggregation Near a Front Observed during SCOPEX . . . . . . 116

4.4 The Model . . . . . . . . . . . . . . . . . . . . . . . 122

4.5 Velocity Fields and Sample Runs . . . . . . . . . . . . 128

4.6 Parameter Space . . . . . . . . . . . . . . . . . . 133

4.6.1 The Diffusion Length Scale. . . . . . . . . . . . . 136

4.6.2 Nondimensional Parameters . . . . . . . . . . . . . . 144

4.6 .3 Regime Diagrams . . . . . . . . . . . . . . . . . 159

4.7 Curved Fronts . . . . . . . . . . . . . . . . . . . 166

4.7.1 Comparison between Model Results and SCOPEX Data . . . 170

4.8 Conclusion . . . . . . . . . . . . . . . . . . . . . . . . . . . 172

5 Conclusion 174

5.1 Individual Plankton Patches . . . . . . . . . . . . . . 174

5.2 One Transect in Detail . . . . . . . . . . . . . . . . 176

5.3 Model of a Mechanism . . . . . . . . . . . . . . . . . . 178

5.4 Questions . . . . . . . . . . . . . . . . . . . . . 181

A Horizontal and Vertical Diffusion $\quad 184$

A.1 Homogeneity of Vertical Diffusion . . . . . . . . . . . . . . 184

A.2 Horizontal Diffusion . . . . . . . . . . . . . . . . 185

B The One- and Two-dimensional QUICK Algorithms 188

$\begin{array}{ll}\text { References } & 191\end{array}$ 


\section{Chapter 1}

\section{Introduction}

The Great South Channel of the Gulf of Maine (see Figure 1.1) is a complex place, both physically and biologically. Physically, it is at the intersection of a number of distinct hydrographic systems: the shallow, well-mixed water of Georges Bank, characterized by rapid tidal currents and a strong mean anticyclonic circulation (Hopkins and Garfield, 1981; Flagg, 1987); the stratified waters of the western Gulf of Maine, fed by inflow from the Scotian Shelf and the rivers of northern New England (Hopkins and Garfield, 1979); and the shallow water lying over Nantucket Shoals and along outer Cape Cod (Limeburner and Beardsley, 1982). At the Channel's southern end, beyond its 70-meter-deep sill, is the sharp drop-off in topography that marks the boundary between the continental shelf and slope (Butman and Beardsley, 1987; Flagg, 1987). Biologically, the area surrounding the Great South Channel is a region of strong primary production (O'Reilly et al., 1987) and correspondingly high populations of zooplankton (Bigelow, 1926; Davis, 1987) and higher predators. Water flows in both directions through the Great South Channel-typically into the Gulf of Maine on the eastern side of the Channel and out of the Gulf on the western side-carrying with it a large variety of organisms. 


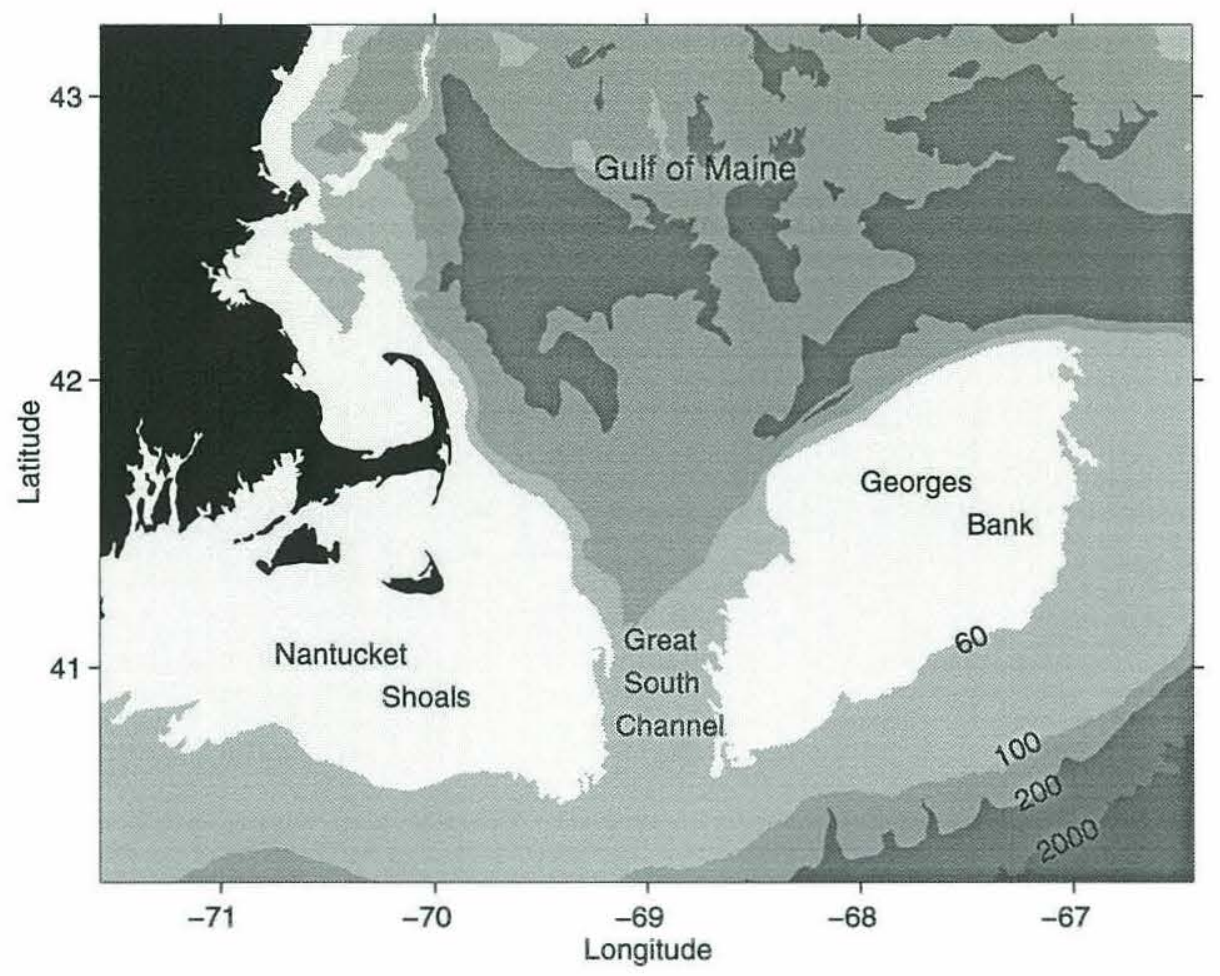

Figure 1.1: The Great South Channel region; contours are in meters.

How do these physical and biological systems interact? More specifically, how do small-scale physical mechanisms, combined with biological behavior, influence the distribution of various species in and near the Great South Channel? The question is an intricate one, and this thesis focuses on only one part of it: how do small-scale physics and biology combine to produce dense aggregations of certain zooplankton species in the northern part of the Great South Channel?

The answer, to the extent that I can give one, is in the form of three relatively independent studies. The first, presented in Chapter 2, concentrates on dense patches of the copepod Calanus finmarchicus that are a characteristic feature of the northern Great South Channel in the late spring and early summer. The second study, presented in Chapter 3, discusses in detail a tightly integrated set of biological and physical observations made in the Great South Channel by means of a new instrument, the Video Plankton Recorder (VPR). The third, presented in Chapter 4, 
describes a numerical model designed to simulate one way in which physics and biology may combine to produce dense accumulations of organisms at a convergent front. The studies are linked by a common theme-attempts to understand the role of smallscale physical phenomena in determining the distribution of zooplankton in the Great South Channel-and by the possibility of combining the complementary methods of all three studies: of using the VPR to gather detailed information concerning the biological and physical environment of Calanus patches in the Great South Channel, and of using that information in an attempt to model the mechanisms that may have caused those patches to form.

\subsection{Following the Whales}

Every spring, most (and perhaps all) of the right whales known to exist in the North Atlantic migrate to the Great South Channel, where they feed on dense patches of Calanus for about two months. The existence of these patches is extremely important to the whales: right whales feed by swimming with their mouths open, filtering prey out of the water with their baleen. If there is not a sufficient concentration of prey, a whale can lose more energy (to increased hydrodynamic resistance) by attempting to feed than it gains from the food it does ingest. The South Channel Ocean Productivity Experiment, or SCOPEX, was a study of these whales and of the plankton patches they feed on.

In SCOPEX, research vessels steamed behind whales as they fed, measuring physical and biological properties of the water in which the animals were feeding. Chapter 2 describes the information gathered while following two whales on June 3 and 4, 1989. Acoustic instruments, nets, and a CTD-mounted transmissometer were used to estimate the density of copepods in the patches, one patch's approximate size, the rate at which one whale swam while feeding, and the minimum prey concentrations 
at which the other whale was willing to feed. Estimates of this critical concentration agree well with previous estimates based on right whales' metabolic requirements. One important feature of the study was the intercalibration of acoustic, net-tow and light-transmission data. The instuments concerned sample at different vertical and horizontal resolutions, with different degrees of specificity, and over extremely different volumes of water (from the roughly $25 \mathrm{~cm}^{3}$ sampled by the transmissometer to the roughly $1000 \mathrm{~m}^{3}$ sampled by a net). Nevertheless, by comparing and combining data appropriately, it was possible to produce a coherent description of the physical and biological environment in which the whales were feeding, using what would otherwise have been too sparse a dataset.

\subsection{A Closer Look}

Chapter 3 describes a much more detailed dataset. Until recently, many questions concerning the interactions between biology and physics in the ocean have been essentially impossible to address observationally. Conventional physical and biological oceanographic instruments sample on such different temporal and spatial scales, and with such differing degrees of coverage, that it is generally either very difficult or impossible to form a detailed understanding of the specific physical environment in which an organism or group of organisms exists. The Video Plankton Recorder (VPR) addresses this problem by making detailed physical measurements while capturing highly magnified images of individual organisms on videotape. The physical and biological data can then be combined to produce an integrated description of the organisms and their environment.

The study presented in Chapter 3 is one example of such an integrated description. This chapter describes data taken during a transect made across the northern Great South Channel in May, 1992. From that dataset, it has been possible to pro- 
duce high-resolution plots of the distribution of a number of organisms and classes of organisms, and to correlate the distribution patterns of various kinds of plankton with the distribution of water masses and water types encountered during the section. In one case, biological data have helped to provide a means of deciding whether a certain band of water was flowing into or out of the Gulf of Maine, and hence shed light on certain kinematic features of the flow field.

\subsection{A Numerical Approach}

Chapter 4 takes a close look at one mechanism that may lead to the creation of dense patches of plankton, such as some of those observed in the Great South Channel. The mechanism requires the existence of a convergent flow field at a surface front, combined with depth-keeping swimming behavior on the part of the plankton. This chapter describes a patch observed during SCOPEX that may have been formed by this mechanism, and presents a two-dimensional, Eulerian numerical model of the mechanism, combining the effects of advection, diffusion, and vertical swimming.

Runs of the model under various conditions illustrate ways in which dense patches can be formed by this mechanism, and help to illuminate the role played by such parameters as diffusion, water velocity, and certain details of the animals' swimming behavior in determining the final shape of the patches and the degree of concentration achieved. Output from the model is compared to the SCOPEX data.

\subsection{Specific Contributions}

Chapters 2 and 3 represent the work of a number of investigators in a variety of disciplines, and they have been submitted for publication as multiple-authored 
papers. It is therefore incumbent upon me, as the author of this thesis, to identify my contribution to each paper. In such intensely collaborative work, it is not always possible to determine who is responsible for precisely which aspects of the outcome, or even to assign responsibility for some components to any single individual. Nevertheless, in this section I shall try to describe the parts of each study for which I am directly responsible.

For Chapter 2, I carried out the interpretation (and some processing) of the acoustic dataset (gathered by M.C. Macaulay), especially as it related to the lighttransmission data. Following earlier work by R. C. Beardsley and C. Chen, I developed techniques for interpreting light-transmission data in terms of the concentration of copepods and for comparing that data to the acoustic dataset, and I then carried out the analysis and interpretation of the light-transmission data. I also performed some processing of the CTD data, again building on work done by C. Chen. In addition, I was responsible for interpreting ADCP data in order to estimate the swimming speed of the whale named Stars and the size of the Calanus patch in which it was feeding.

For Chapter 3, I was the investigator primarily responsible for processing, interpreting and describing hydrographic data (including VPR/CTD and ADCP data). I also wrote the custom m-files used for "binning" VPR data (assigning time and depth bins to the observed organisms and estimating the concentration of organisms in each bin) and for analyzing VPR/CTD data in terms of individual legs; these m-files are now in use by other investigators working with data from the VPR (e.g., Benfield et al., submitted; Norrbin et al., submitted). In addition, I was responsible for gridding all datasets and for producing the interpolated and binned data required for T-S-P plots. 


\section{Chapter 2}

\section{Spatial Variability in Zooplankton}

\section{Abundance near Feeding Right}

\section{Whales in the Great South}

\section{Channel}

\subsection{Abstract}

On 3 June 1989, during SCOPEX '89, two right whales were observed to be feeding close to the surface at separate sites in the Great South Channel of the Gulf of Maine. ${ }^{1}$ The R/V Marlin deployed and monitored a radio tag on one whale, and underway measurements were made near each whale from the R/V Endeavor to investigate the small-scale spatial structure of water properties and zooplankton abun-

\footnotetext{
${ }^{1}$ This chapter has been submitted to Deep-Sea Research for publication, in slightly different form, as: "Spatial Variability in Zooplankton Abundance near Feeding Right Whales in the Great South Channel", by Robert C. Beardsley, Ari W. Epstein, Changsheng Chen, Karen F. Wishner, Michael C. Macaulay, and Robert D. Kenney.
} 
dance in the upper water column near the whales. These measurements included two CTD tow-yos, zooplankton sampling with a MOCNESS, continuous vertical profiling of currents with a $150-\mathrm{kHz}$ ADCP, and continuous vertical profiling of zooplankton concentration with a towed acoustic profiler operating at 120 and $200 \mathrm{kHz}$.

The whales were feeding on a relatively homogeneous mixture of primarily two stages (copepodite IV and V) of a single copepod species (Calanus finmarchicus), which was most abundant in the upper 10-20 $\mathrm{m}$ of the water column above the seasonal pycnocline. Simple descriptions of the spatial structure of copepod abundance in patches traversed by the whales were developed based on MOCNESS samples, acoustic backscatter, and light transmission. In particular, a high correlation was found between MOCNESS biomass measurements and certain $200-\mathrm{kHz}$ acoustic biomass estimates, which enabled the acoustic data to be interpreted solely in terms of copepod abundance. Acoustic measurements made in a copepod patch while closely following one whale indicated mean and peak copepod biomasses of 6.0 and $28.4 \mathrm{~g} / \mathrm{m}^{3}$ (corresponding to mean and peak concentrations of $8.7 \times 10^{3}$ and $4.1 \times 10^{4}$ copepods $/ \mathrm{m}^{3}$ ) in the 4-10 $\mathrm{m}$ depth band, where the whale was probably feeding. With a mean energy content of $10^{-3} \mathrm{kcal} /$ copepod, that whale's mean energy intake rate was $3.8 \times 10^{4}$ $\mathrm{kcal} / \mathrm{hr}$. The whale was observed to reverse course and turn back into the patch when it swam into a region of lower copepod abundance, with biomass less than roughly $1-3 \mathrm{~g} / \mathrm{m}^{3}$ or $1.5-4.5 \times 10^{3}$ copepods $/ \mathrm{m}^{3}$. This concentration is consistent with independent estimates of the minimum prey concentration required for a right whale to regain the energy it expends when it feeds.

The next morning, one of the whales was found to be skim-feeding on a Calanus finmarchicus patch in which a bucket sample gave a copepod biomass of $256 \mathrm{~g} / \mathrm{m}^{3}$ or $3.3 \times 10^{5}$ copepods $/ \mathrm{m}^{3}$. If this one sample approximated the mean abundance of the patch, then the whale had a mean energy intake of $1.4 \times 10^{5} \mathrm{kcal} / \mathrm{hr}$. At this rate, it could consume its daily basal metabolic energy requirement in roughly nine minutes, 
and its annual requirement in roughly two days (assuming continuous feeding at a mean speed of $1.2 \mathrm{~m} / \mathrm{s}$ as determined from the ADCP measurements). Although physical advection on regional and smaller scales appears to be an important element in the processes that cause such dense patches to form in this region during late spring, the lack of a clear linkage between the small-scale physical and biological data reported here suggest that some non-physical, species-specific animal behavior like swarming must be partially responsible for creating the very densest copepod patches observed during SCOPEX '89.

\subsection{Introduction}

The primary food of the North Atlantic right whale, Eubalaena glacialis, is the copepod Calanus finmarchicus (Matthews, 1938; Tomlin, 1957; Omura et al., 1969; Nemoto, 1970; Watkins and Schevil, 1976, 1979; Scott et al., 1985; Kenney et al., 1986; Gaskin, 1987, 1991; Wishner et al., 1988; Murison and Gaskin, 1989; Mayo and Marx, 1990). This copepod overwinters in a dormant stage (primarily copepodite V) throughout the western Gulf of Maine, especially in the deep basins, and matures and reproduces in early spring. The young develop through the onset of the seasonal thermocline and the spring phytoplankton bloom into late-stage copepodites and adults by late spring. Right whales feed by swimming with their mouths open, using their baleen to filter prey out of the water (Nemoto, 1970; Watkins and Schevill, 1976, 1979; Pivorunas, 1979; Mayo and Marx, 1990). This process requires more energy than the whale would expend by swimming with its mouth closed, because of the additional drag. In menhaden, a planktivorous fish which feeds in a very similar fashion, the energy cost of mouth-open swimming is about 2.5 times that of swimming with the mouth closed at the same speed (Durbin and Durbin, 1993). Since the number of copepods consumed per unit time (and hence the amount of energy 
available in the form of food) varies with the concentration of copepods in the water, there must be some minimum or critical concentration of copepods below which it is not energetically favorable for the whale to feed. Mayo and Goldman (1992) estimate this critical concentration to be $4 \times 10^{3}$ copepods $/ \mathrm{m}^{3}$, within the range of peak concentrations detected in the Gulf of Maine but 1-2 orders of magnitude greater than many of the other samples of copepods collected from various locations in the Gulf of Maine in late spring. This critical concentration, moreover, represents merely a break-even point: the point at which the whale gains energy, rather than losing it, by attempting to feed. In order to maintain itself, the whale requires more than this break-even concentration. Analysis by Kenney et al. (1986), based on standard mammalian metabolic models and copepod energy density values from Comita et al. (1966) and CETAP (1982), suggests that the whale must routinely feed in patches containing concentrations between $3 \times 10^{5}$ and $1 \times 10^{6}$ copepods $/ \mathrm{m}^{3}$ in order to survive. For physical and biological reasons that are not well understood, extremely dense aggregations of late stage Calanus finmarchicus (which have nearly maximum food value for the right whale) occur in the northern Great South Channel (GSC) region of the western Gulf of Maine in late spring (Wishner et al., 1988, 1995), making it an ideal feeding ground. It is thus not surprising that each spring a large fraction, perhaps the majority, of the western North Atlantic right whale population (estimated at between 300 and 350 individuals) migrates to this region to feed (Kenney et al., 1995).

The South Channel Ocean Productivity Experiment (SCOPEX) was conducted in the spring of 1988 and 1989 in part to identify and study the physical and biological processes that help create and sustain these dense patches of zooplankton, and to observe the behavior of right whales in the Great South Channel and relate it to the distribution of their prey organisms during this period (Kenney and Wishner, 1995). The main 1989 field program (SCOPEX '89) involved two research vessels (the R/V Marlin and the R/V Endeavor) and an aircraft. The aircraft was 
used primarily to locate right whales in the GSC area and to provide a synoptic view of the distribution and abundance of whales in the broader region; the Marlin was used for detailed study of the whales' behavior; and the Endeavor was used to make environmental measurements both near the whales and on larger scales within the GSC. These measurements included (a) hydrographic and current profiling with the R/V Endeavor's NBIS Mark III CTD and 150-kHz RDI acoustic Doppler current profiler (ADCP), respectively, (b) acoustic profiling for zooplankton distribution and biomass with a towed Biosonics Model 101, 120- and 200-kHz acoustic fin (Macaulay et al., 1995), and (c) biological sampling with MOCNESS [a multiple opening and closing net and environmental sampling system (Wiebe et al., 1976, 1985)] and other towed nets (Wishner et al., 1995).

SCOPEX ' 89 was conducted during May and June of 1989. A series of smallscale physical/biological surveys, diel stations, and other studies were made between 18 May 1989 and 6 June 1989, followed by a regional CTD/ADCP survey to determine the larger-scale circulation and water-property structure in the northern GSC. This survey (Chen et al., 1995) showed that by early June of 1989, the near-surface plume of relatively fresh water normally found each spring off Cape Cod had pushed east far into the northern GSC (see Figure 2.1). The majority of right-whale sightings during this period occurred in the eastern frontal zone of this plume, where the densest aggregations of late-stage Calanus finmarchicus were also observed (Wishner et al., 1995). We will present here a simple description and synthesis of the observations made near two of these whales.

\subsection{The Sampling Program}

At approximately 1400 Eastern Daylight Time (EDT) 3 June, the last scheduled day of the R/V Marlin's cruise, the R/V Endeavor rendezvoused with the Marlin 


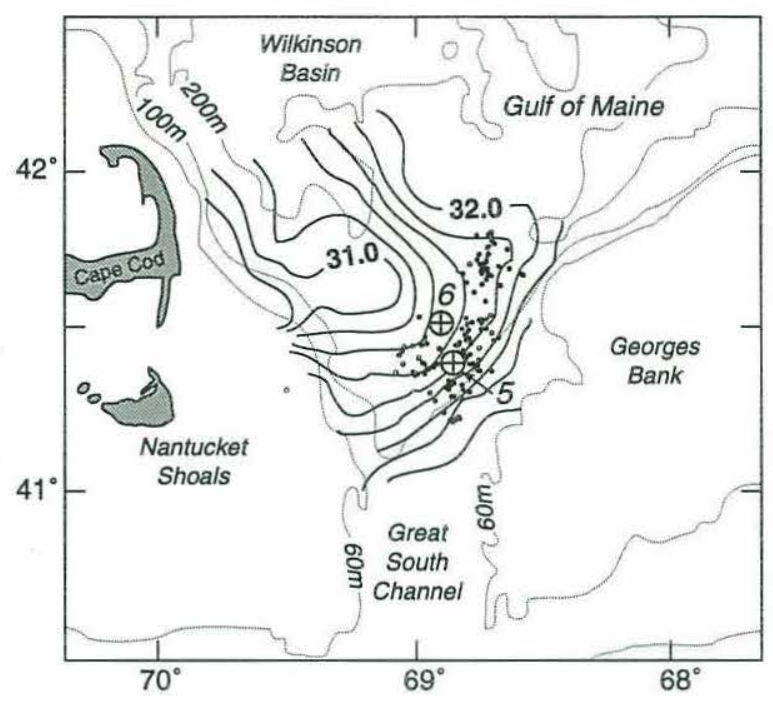

Figure 2.1: Map of the Great South Channel region, showing the near-surface $(2 \mathrm{~m})$ salinity pattern observed during 6-12 June, 1989, and the distribution of right whale sightings made during the three-week period 22 May-11 June, 1989. Note how almost all the whale sightings are clustered in the leading front associated with the low-salinity plume moving east from Cape Cod. The two circled crosses show the locations of tow-yos 5 and 6, where the observations around feeding right whales on 3 and 4 June described in this paper were made. The 60-, 100-, and 20-m isobaths are shown for reference. This figure is adapted from Chen et al. (1995) and Kenney et al. (1995).

near $41.4^{\circ} \mathrm{N}, 68.8^{\circ} \mathrm{W}$, in order to exchange some equipment between ships (Table 2.1).

As the Marlin steamed westward toward port, the Endeavor then began a small-scale local survey, towing the dual-frequency acoustic fin at 1-2 knots in order to map the local distribution of zooplankton. The fin was towed off the port stern quarter at a depth of $0.5-1.0 \mathrm{~m}$, and useful acoustic data were generally obtained at depths deeper than about $4 \mathrm{~m}$. At approximately 1500 EDT, investigators on the Endeavor sighted a feeding right whale. The whale was not photographed, so its identity is unknown; in the context of this paper we shall call it "Whale A". [Right whales can be identified uniquely by markings on their heads and bodies (Kraus et al., 1986), and sighting histories for all identified individuals are maintained in a catalog at the New England Aquarium (Crone and Kraus, 1990).] 


\begin{tabular}{|c|c|c|}
\hline Date & Time & Description of Activity \\
\hline \multirow[t]{17}{*}{ June 3: } & 1400 & Endeavor rendezvous with Marlin near $41.4^{\circ} \mathrm{N}, 68.8^{\circ} \mathrm{W}$. \\
\hline & 1429 & Endeavor starts sampling near Whale $A$ with acoustic fin. \\
\hline & 1615 & $\begin{array}{l}\text { Endeavor starts tow-yo } 5 \text { Leg } 1 \text { (CTD 139) and shallow MOC- } \\
\text { NESS } 43 \text { following feeding Whale A. }\end{array}$ \\
\hline & 1643 & Marlin deploys radio tag on Stars, begins monitoring dive time. \\
\hline & 1656 & Endeavor finishes Leg 1 of tow-yo 5, MOCNESS 43. \\
\hline & 1715 & Marlin starts zooplankton tow near Stars. \\
\hline & 1717 & Endeavor starts Leg 2 of tow-yo 5. \\
\hline & 1815 & $\begin{array}{l}\text { Endeavor finishes Leg } 2 \text { of tow-yo } 5 \text {, steams northwest toward Marlin } \\
\text { and Stars. }\end{array}$ \\
\hline & 1940 & Endeavor makes visual contact with Stars. \\
\hline & $1945-2100$ & Ships steam together behind or near Stars. \\
\hline & 2015 & $\begin{array}{l}\text { Endeavor starts tow-yo } 6 \text { (CTD 140) and shallow MOCNESS } 44 \text { fol- } \\
\text { lowing Stars (feeding). }\end{array}$ \\
\hline & 2020 & $\begin{array}{l}\text { Behavior of Stars begins to change. Eventually she becomes nearly } \\
\text { motionless at the surface (and perhaps asleep). }\end{array}$ \\
\hline & 2043 & Endeavor finishes MOCNESS 44. \\
\hline & 2045 & Stars rests at surface for $6.47 \mathrm{~min}$. \\
\hline & 2100 & Marlin departs for home, continues to monitor radio tag. \\
\hline & 2143 & Marlin stops monitoring radio tag. \\
\hline & 2227 & Endeavor finishes tow-yo 6 . \\
\hline
\end{tabular}

Table 2.1: Time-table of observations made near right whales during June 3-4, 1989. Time is Eastern Daylight Time (EDT), which differs from Greenwich Mean Time (GMT) by four hours $(\mathrm{GMT}=\mathrm{EDT}+$ four hours). Table continues on next page. 


\begin{tabular}{|c|c|c|}
\hline Date & Time & Description of Activity \\
\hline \multirow{10}{*}{ June 4: } & 2323 & Endeavor starts deep MOCNESS 45 . \\
\hline & 2355 & $\begin{array}{l}\text { Endeavor finishes MOCNESS } 45 \text {, continues tracking Stars by radio } \\
\text { (with limited success) through the night. }\end{array}$ \\
\hline & 0407 & Stars passes within about $100 \mathrm{~m}$ of Endeavor. \\
\hline & 0523 & $\begin{array}{l}\text { Endeavor sights Stars skim-feeding near the surface; Endeavor begins } \\
\text { following Stars closely as she feeds. }\end{array}$ \\
\hline & 0750 & Endeavor takes 10 liter surface bucket sample near Stars. \\
\hline & 0820 & Endeavor takes XBT 12 near Stars. \\
\hline & 0836 & Endeavor loses sight of Stars. \\
\hline & 0900 & Dense fog rolls in, making further visual tracking impossible. \\
\hline & $0900-1130$ & $\begin{array}{l}\text { Endeavor receives only intermittent signals from radio tag; no good } \\
\text { data recorded. }\end{array}$ \\
\hline & 1130 & Endeavor departs for next work area. \\
\hline
\end{tabular}

Table 2.1 continued: Time-table of observations made near right whales during June 3-4, 1989 .

While following about $200 \mathrm{~m}$ behind this whale, the Endeavor carried out a combined CTD tow-yo (tow-yo 5) and shallow horizontal MOCNESS tow (MOCNESS 43). The CTD fish was equipped with a Sea Tech 25-cm pathlength transmissometer and Sea Tech in-situ fluorometer and rigged with a simple steering vane attached to the rosette sampler to keep the sensors oriented into the flow. The CTD was lowered off the starboard side and yo-yoed between about $2 \mathrm{~m}$ and $60 \mathrm{~m}$ every six minutes with a lowering speed of about $20 \mathrm{~m} / \mathrm{min}$. Only the downcast data were analyzed. The $1 \mathrm{~m}^{2}$ MOCNESS (with nine 335- $\mu$ mesh nets) was deployed over the stern as usual and towed at about $10-\mathrm{m}$ depth and at about $1.5 \mathrm{kt}(0.83 \mathrm{~m} / \mathrm{s})$ to maintain the optimal $45^{\circ}$ net angle. About $130 \mathrm{~m}^{3}$ of water were filtered through each MOCNESS net. There were two legs in tow-yo 5. The first leg (leg 1) coincided with MOCNESS 43 as the Endeavor steamed southward, following the whale as it fed on a large patch of Calanus finmarchicus. At 1710 Whale $A$ appeared to reach the edge of the patch and reversed course. After completing MOCNESS 43 and passing out 
of the patch, the Endeavor also reversed course and began leg 2 steaming northward, again following Whale $A$. Leg 2 was completed at 1815 EDT.

At 1614 EDT, while Endeavor was engaged in tow-yo 5, the Marlin, at that time about $14 \mathrm{~km}$ WNW of Endeavor, sighted a right whale known as "Stars", one of the best known individuals in the western North Atlantic right whale population (Figure 2.2). (At that time Stars, an eight-year-old female approximately 11-12 m long, was easily recognizable by, among other features, a length of rope entangled in her baleen.) Observers on the Marlin noted dense patches of copepods and krill near the surface, and they observed that flushing the heads also brought up large numbers of copepods. Marlin informed Endeavor of its observations by radio, and at 1643 attached a VHF radio tag to Stars in order to monitor her behavior. When the Endeavor had completed tow-yo 5, it steamed toward Marlin and Stars, arriving within sight of Stars at about 1940 EDT (Figure 2.2).

The two ships then steamed slowly together, following Stars. A schematic of the Marlin and the Endeavor with acoustic fin, CTD, and MOCNESS simultaneously deployed while following Stars is shown in Figure 2.3. At 2015 (approximately sundown), the Endeavor began a combined CTD tow-yo (tow-yo 6) and shallow (0-5 m) horizontal MOCNESS tow (MOCNESS 44) following Stars. From the time Marlin had first sighted Stars, the whale's behavior had been characterized by a sequence of short dives (15-60 seconds in duration) and very short surfacings, with occasional dives as long as 2 or 3 minutes (Figures 2.4 and 2.5). For much of the time she was visible just below the surface, feeding. At about 2020, just after sundown, she began to surface for longer intervals, and at 2030 she made the longest dive in the sequence (about four minutes). She then stopped feeding and rested on or near the surface, perhaps sleeping for an hour or so. At 2043 the Endeavor completed MOCNESS 44 but continued the CTD tow-yo following Stars. At 2100 Marlin departed for port, still monitoring the radio tag attached to Stars, and at 2143 Marlin ceased monitoring. 


\section{Path of Endeavor and Hypothetical Water Particles on June 3 and 4, 1989}

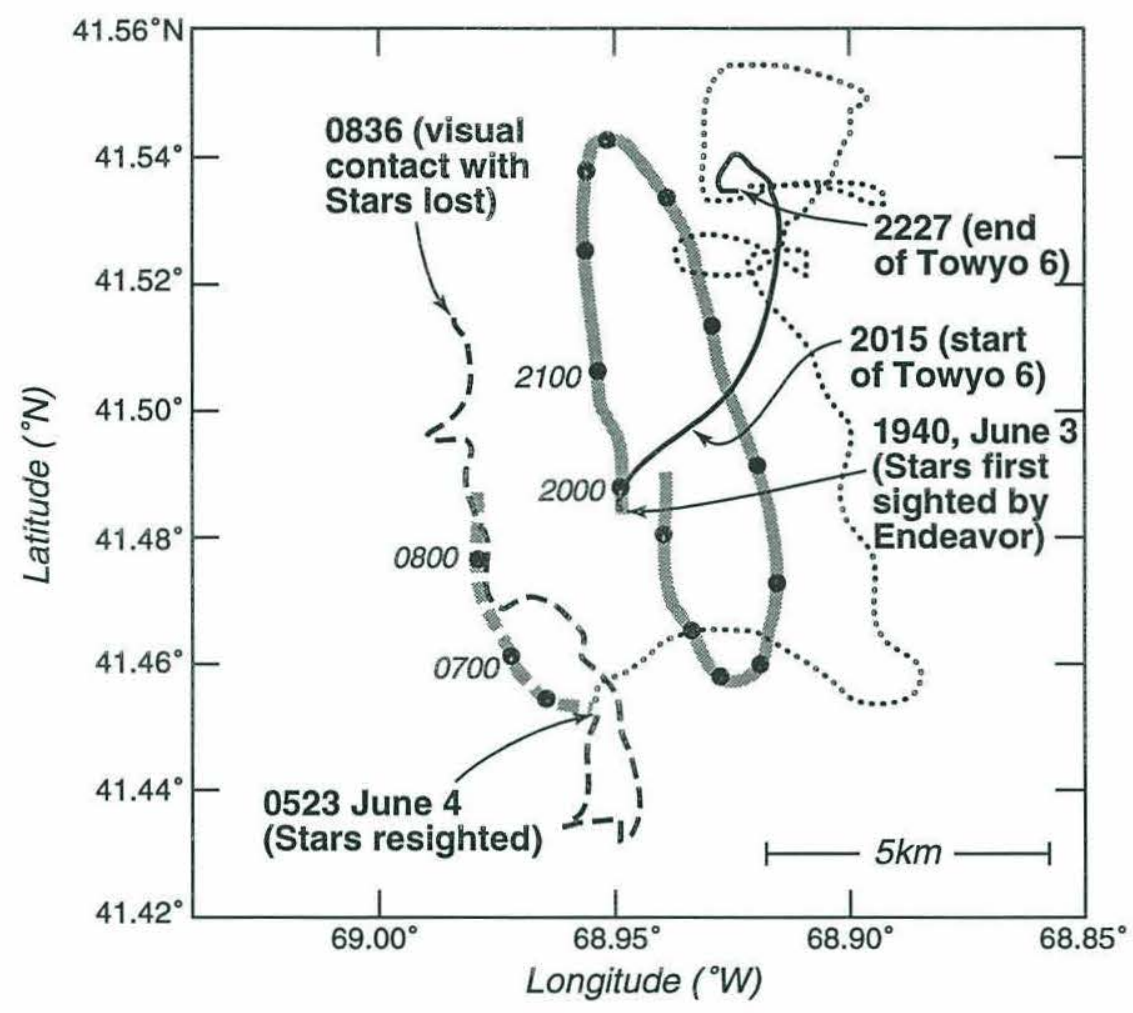

Figure 2.2: Map showing path of the R/V Endeavor between 1940 on 3 June and 0835, 4 June as it tracked Stars. The path of the Endeavor between first sighting Stars at 1940 and the end of towyo 6 at 2227 is shown as a dark solid curve. A dotted curve is used to show the path as Endeavor conducted MOCNESS 45 and attempted to track Stars through the night. At 0523, 4 June, the Endeavor spotted Stars again and followed her closely until about 0836, following the path shown by the dark dashed curve. Also shown are the paths of two hypothetical water particles constructed using the Endeavor 7-m ADCP data. The trajectory of the first particle (shown as a broad solid curve) starts at the same location and time where Stars was first sighted on 3 June by Endeavor. This particle moves in a elongated elliptical path oriented approximately north-south, indicative of the strong semi-diurnal tidal current in this region. The solid dots along this path indicate a time interval of one hour, with the times of the first two dots given. The second particle starts at the same location and time where Stars was re-sighted on 4 June. Over the approximately three-hour period that Stars was tracked (the time interval between dots is again one hour), this second particle moved northward along its primarily tidal trajectory, shown by a broad dashed curve. It is interesting to note that Stars was spotted at 0523 on 4 June only $1.2 \mathrm{~km}$ west-southwest from where she would have been carried by the tidal current if she had just floated passively in the water. Earlier that morning at 0407 , she had been heard from the Endeavor just $0.9 \mathrm{~km}$ east of where the tidal current would have carried her. 


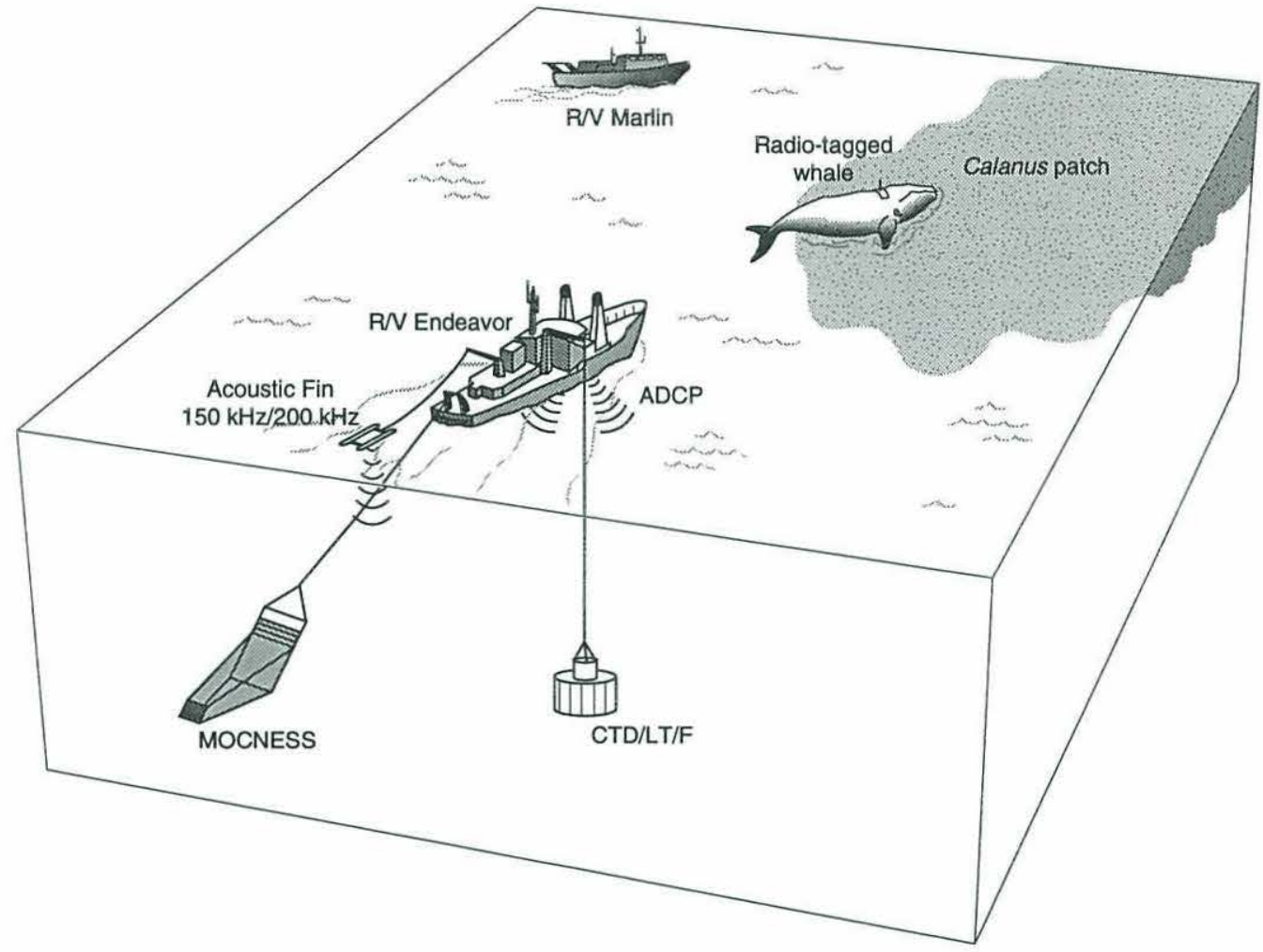

Figure 2.3: $\quad$ Schematic showing the R/V Marlin and R/V Endeavor sampling around the right whale Stars during tow-yo 6 on 3 June 1989. The Endeavor made simultaneous measurements with a CTD/light-transmission/fluorometer profiler, a towed dual-frequency acoustic profiler, MOCNESS, and the ship's ADCP. The Marlin observed the whale's eating and diving behavior both visually and by monitoring a VHF radio tag. 


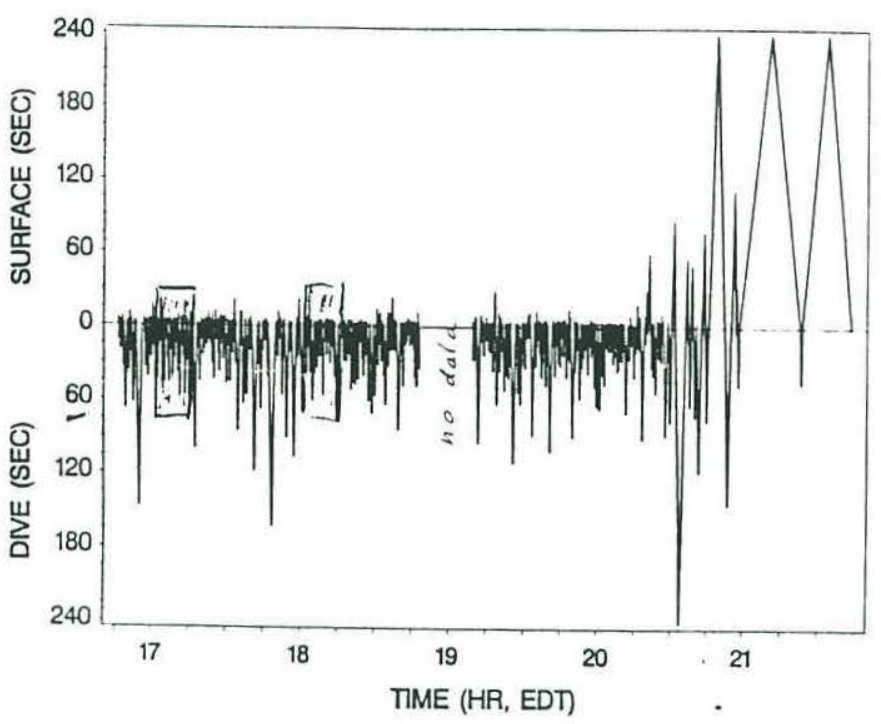

Figure 2.4: Detailed surface and dive data for radio-tagged right whale (Stars) on 3 June, 1989. Surface durations are shown by upward spikes and dive durations by downward spikes. Both are truncated at four minutes for clarity. The duration of the long dive at approximately 2035 was $4 \mathrm{~min}, 12 \mathrm{sec}$. The three long surfacings at the end of the sequence were $6 \mathrm{~min}, 72 \mathrm{sec} ; 24 \mathrm{~min}$, $24 \mathrm{sec}$; and $19 \mathrm{~min}, 48 \mathrm{sec}$, respectively. The two shaded boxes represent the segments expanded in Figure 2.5.

Using separate equipment, Endeavor continued monitoring the tag. At about 2230, Endeavor completed tow-yo 6, made one vertically stratified MOCNESS tow (MOCNESS 45$)$ to the bottom near Stars and then spent the rest of the night attempting to track Stars via the radio tag (with only partial success). At 0523 the next morning (sunrise occurred at 0508), Stars was observed skim-feeding in a large Calanus patch near $41.4^{\circ} \mathrm{N}, 68.9^{\circ} \mathrm{W}$. At 0750, Endeavor took a surface bucket sample to measure the zooplankton concentration in this patch. Visual contact with Stars was lost at 0836, and at about 0900 a dense fog rolled in, making further visual tracking impossible. Reception of the tag's radio signals became poor and intermittent, and at about 1130 Endeavor left the area to conduct other studies. 

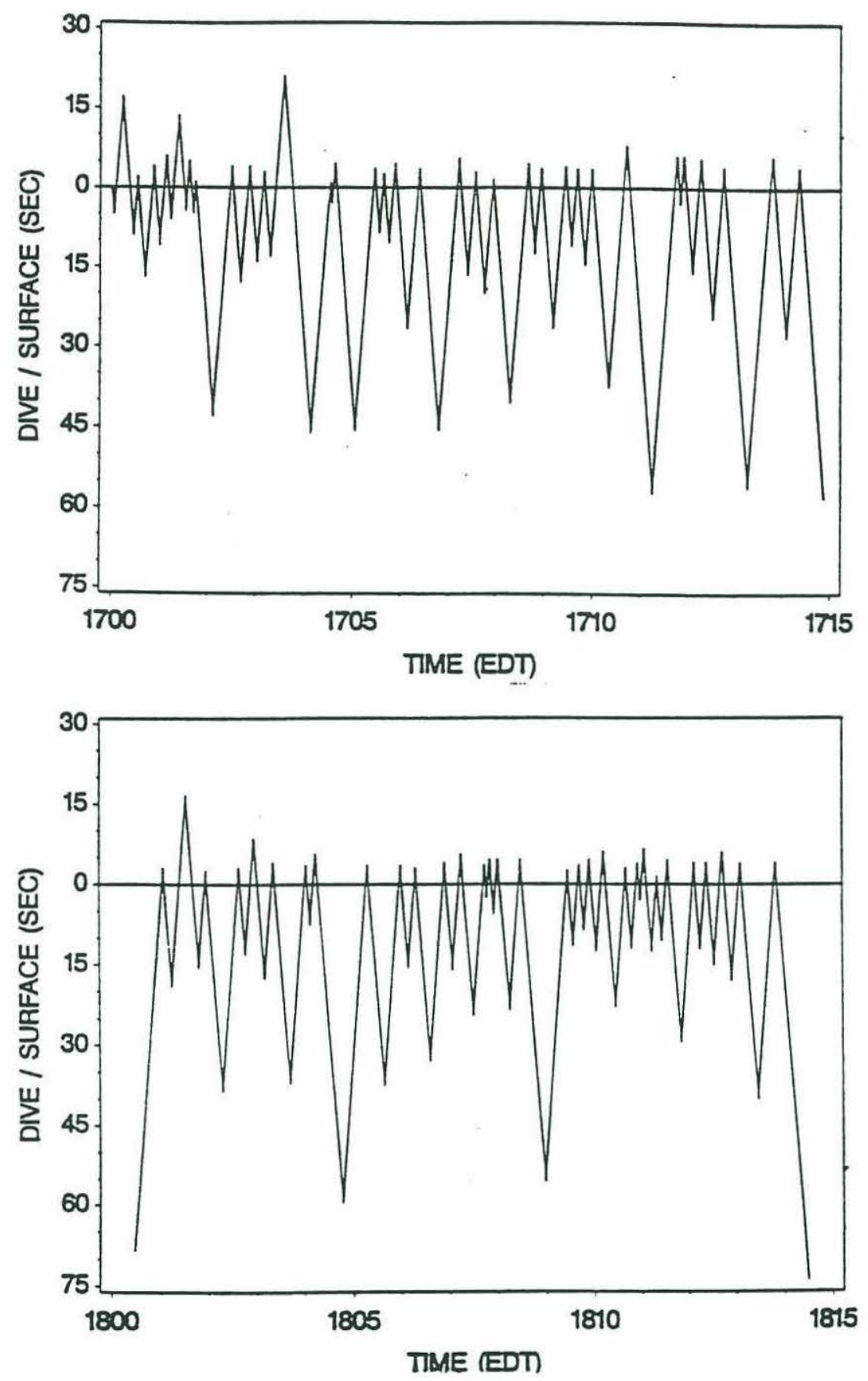

Figure 2.5: Expanded 15-minute examples of Stars dive and surface data on 3 June, 1989. 


\subsection{The Observations}

One objective of sampling the zooplankton distribution around Whale $A$ and Stars with acoustics and the MOCNESS simultaneously was to intercalibrate these techniques, so that if they provided good quantitative agreement, the acoustics could be used to obtain a continuous, high-resolution record of zooplankton abundance over time and space. The acoustic data were recorded in several formats. The 120 - and $200-\mathrm{kHz}$ data were processed separately on a PC into biomass estimates, averaging over 60 -second $\times 1$-m blocks, and recorded on disk. Some of this information was also displayed in real time aboard ship in order to help monitor and direct the ongoing sampling. During leg 1 of tow-yo 5, some raw $200-\mathrm{kHz}$ acoustic data was also recorded digitally for backup. After the 1989 field work was completed, the Biosonics unit was calibrated at the University of Washington Applied Physics Laboratory. The raw $200-\mathrm{kHz}$ data from tow-yo 5 were then processed into biomass estimates, averaging over 30 -second $\times 1$-m blocks, using optimum threshold and gain settings. Copepod biomass was computed using a conversion factor of $-36 \mathrm{db} / \mathrm{kg}$, based on previous work. [See Macaulay et al. (1995) for more details about the acoustic system and data processing.]

We found in subsequent analysis that only the 30 -second, $200-\mathrm{kHz}$ data provided good quantitative estimates of copepod biomass. The 60 -second, $200-\mathrm{kHz}$ data provided a useful qualitative picture of the vertical distribution of copepods and larger zooplankton (which were also observed in the 60 -second, $120-\mathrm{kHz}$ data), but the estimates of copepod biomass were reduced in places where the abundance of individuals was insufficient to produce measurable scatter (see Macaulay et al., 1995). As a result, only the limited time series of 30 -second, $200-\mathrm{kHz}$ data taken during tow-yo 5 has been used to intercalibrate with MOCNESS-derived biomass estimates. 
During tow-yos 5 and 6, we noticed extreme 'noise' in the profiles of light transmission made by the CTD. Apparently, the copepod concentrations were sufficiently dense that light transmission was noticeably reduced when one or more copepods moved through the beam. Subsequent comparison with the 30 -second, $200-\mathrm{kHz}$ biomass data (to be presented below) indicates that the amplitude of the light transmission 'noise' provides a crude quantitative measure of copepod concentration. Since light-transmission data were collected on each CTD cast during each tow-yo, we can use the light-transmission data to crudely map the copepod distribution during the tow-yos, even for those times when acoustic data are not available.

\subsubsection{Intercomparison Between 200-kHz and MOCNESS Biomass Estimates}

Figure 2.6A shows the zooplankton biomass field obtained from the 30 -second, $200-\mathrm{kHz}$ acoustic data during leg 1 of tow-yo 5, with the path of MOCNESS 43 superimposed. The acoustic biomass data is shown as a function of distance along the shiptrack (measured relative to the surface water) and depth to $25 \mathrm{~m}$. The zero biomass shown in the top $4 \mathrm{~m}$ is an artifact of the blanking of acoustic data near the transducer. Figure 2.6A shows a dense, patchy layer of copepods lying above a much denser and thicker layer of larger zooplankton (presumably euphausiids) centered near $20 \mathrm{~m}$. The mean copepod biomass between 4 and $10 \mathrm{~m}$ is about $6 \mathrm{~g} / \mathrm{m}^{3}$, while the larger zooplankton layer below the copepod layer has a maximum mean "biomass" of about $440 \mathrm{~g} / \mathrm{m}^{3}$ at $20 \mathrm{~m}$. (The large value of this number indicates the presence of some organism other than copepods, but it does not represent an actual estimate of biomass for that organism, since the conversion factor of $-36 \mathrm{~dB} / \mathrm{kg}$ is valid only for copepods.) 

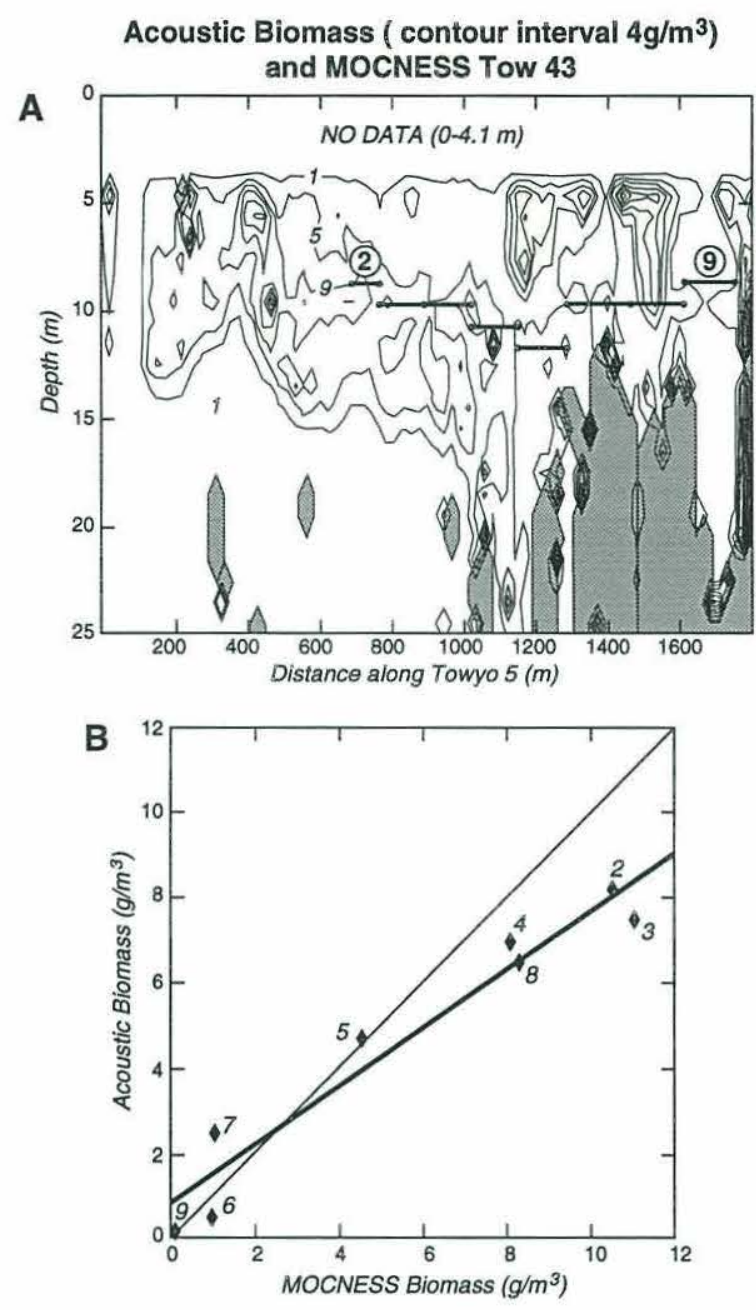

Figure 2.6: A: Contour plot of the $30-\mathrm{sec}, 200-\mathrm{kHz}$ acoustic biomass field for the first part of leg 1 of tow-yo 5. Although good data was collected to near the bottom, only acoustic data in the upper $25 \mathrm{~m}$ are displayed here, since the copepod layer was confined to the top $10-20 \mathrm{~m}$. The contour values $\left(1,5,9,13,17,21\right.$, and $\left.25 \mathrm{~g} / \mathrm{m}^{3}\right)$ were chosen to highlight the copepod biomass distribution. Biomass values above $25 \mathrm{~g} / \mathrm{m}^{2}$ are not contoured but shown in gray; these larger values correspond to the layer of larger zooplankton (presumably euphasiids) and some individual fish located below the copepod layer. Note that no acoustic data were collected in the top $4.1 \mathrm{~m}$, causing the blanking of that layer. Also no data were collected between 25 and $150 \mathrm{~m}$ along the transect. Superimposed is the smoothed trajectory of MOCNESS 43 , with nets 2 and 9 marked. This path has been shifted in time and depth to give the best correlation between the acoustic and MOCNESS biomass estimates: the path shown is the optimum one, giving a correlation coefficient of 0.971 . (The depth of both acoustic and MOCNESS data has also been shifted to give the best correlation between acoustic and light-transmission data.)

B: Comparison of the MOCNESS 43 biomass estimates with the biomass estimates the MOCNESS would have measured if it had sampled the $30-\mathrm{sec}, 200-\mathrm{kHz}$ biomass field shown above along the path that gives the best correlation between acoustic and MOCNESS data. The number at each value indicates the net number. Net 1 is not used since its oblique sample included the top $4 \mathrm{~m}$, where no acoustic data were taken. The slope of the least-squares best-fit line through the data is $0.69 \pm 0.17$; a perfect comparison would have a slope of 1 . 
Whale $A$ appeared to be feeding within the top $10 \mathrm{~m}$ of the surface, and so the MOCNESS was set to sample horizontally between 8 and $11 \mathrm{~m}$ after an initial oblique tow from the surface to $8 \mathrm{~m}$ (net \#1). The MOCNESS results are listed in Table 2.2. Although the average biomass measured during MOCNESS 43 was $6.2 \mathrm{~g} / \mathrm{m}^{3}$, essentially identical to the mean $5-10 \mathrm{~m}$ acoustic estimate, Figure 2.6A and Table 2.2 show such large spatial variation in copepod biomass that the two data sets must be aligned carefully before additional comparison.

The MOCNESS pressure sensor was not very accurate and had an unknown offset, and the depth at which the acoustic fin was towed is not known precisely; in addition, the MOCNESS and acoustic systems used different PC clocks for data acquisition and were towed from different positions on the ship with different amounts of wire out. To compensate for these factors, we chose to shift the MOCNESS biomass data in time and depth relative to the acoustic biomass data to find the best correlation. The sensitivity of the correlation coefficient to this shifting is shown in Table 2.3. The best fit occurs with a time shift of 60 seconds (two acoustic time bins) and a depth shift of $1 \mathrm{~m}$ (one acoustic depth bin); these values are reasonable considering the relative positions of the acoustic fin and MOCNESS and the low tow speed. Figure 2.6B shows the MOCNESS data plotted against biomass values the MOCNESS would have found if it had sampled the acoustic field as shown in Figure $2.6 \mathrm{~A}$ (with the optimal shift). The agreement is quite good, with a correlation coefficient equal to 0.971 , significantly different from zero above the $99.9 \%$ level. The linear regression slope is $0.68 \pm 0.17$ ( $95 \%$ confidence limit), suggesting that the 200 $\mathrm{kHz}$ system may tend to underestimate copepod biomass at the larger values in this application, although more samples are needed to substantiate this suggestion. The overall good agreement between the MOCNESS and 200-kHz biomass estimates in this comparison seems due in part to the fact that the zooplankton population being sampled in the top $10 \mathrm{~m}$ was almost entirely a mixture of two stages (CIV and CV) of a single copepod species (Calanus finmarchicus) (Table 2.2). 


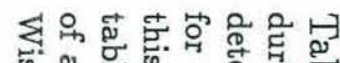

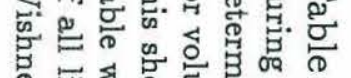

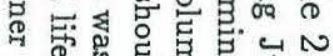
용

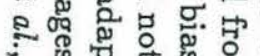

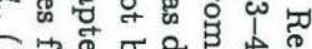
응ํ. 浣 $\checkmark \Omega$

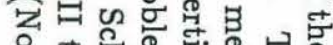
웅요유. .

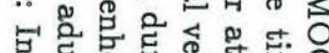

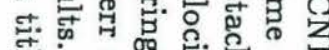

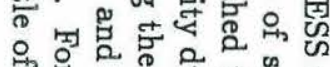

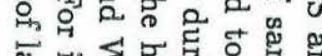

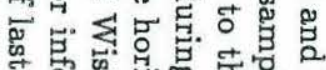
염

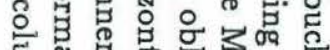

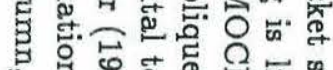
입 유유.

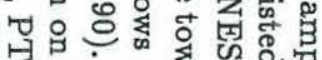
分 0 औ

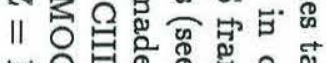

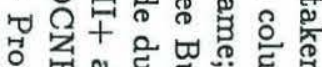

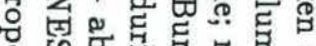

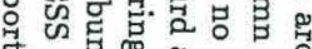

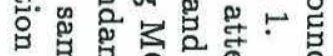

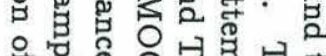
的会宫军实 o o क M

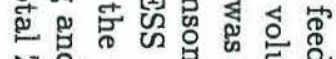

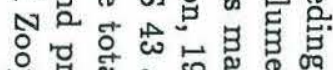

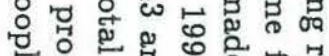
웅

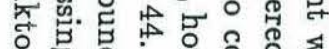
品品舟

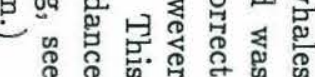

\begin{tabular}{|c|c|c|c|c|c|c|c|c|c|c|c|c|c|}
\hline $\begin{array}{c}\text { MOC } \\
\text { No. }\end{array}$ & $\begin{array}{l}\text { Net } \\
\text { No. }\end{array}$ & $\begin{array}{l}\text { Mini- } \\
\text { mum } \\
\text { Pres. } \\
\text { (dbars) }\end{array}$ & $\begin{array}{l}\text { Maxi- } \\
\text { mum } \\
\text { Pres. } \\
\text { (dbars) }\end{array}$ & $\begin{array}{c}\text { Vol- } \\
\text { ume } \\
\text { Filtered } \\
\left(\mathrm{m}^{3}\right)\end{array}$ & $\begin{array}{c}\text { Total } \\
\text { Biomass } \\
\left(\mathrm{mg} / \mathrm{m}^{3}\right)\end{array}$ & $\begin{array}{l}\text { Copepod } \\
\text { Biomass } \\
\left(\mathrm{mg} / \mathrm{m}^{3}\right)\end{array}$ & $\begin{array}{l}\text { CIII+ } \\
\text { Abund. } \\
\left(\# / \mathrm{m}^{3}\right)\end{array}$ & $\begin{array}{l}\text { CIII } \\
\text { Abund. } \\
\left(\# / \mathrm{m}^{3}\right)\end{array}$ & $\begin{array}{l}\text { CIV } \\
\text { Abund. } \\
\left(\# / \mathrm{m}^{3}\right)\end{array}$ & $\begin{array}{c}\text { CV } \\
\text { Abund. } \\
\left(\# / \mathrm{m}^{3}\right)\end{array}$ & $\begin{array}{c}\text { F } \\
\text { Abund. } \\
\left(\# / \mathrm{m}^{3}\right)\end{array}$ & $\begin{array}{c}\text { M } \\
\text { Abund. } \\
\left(\# / \mathrm{m}^{3}\right)\end{array}$ & $\begin{array}{l}\text { Cal. fin- } \\
\text { marchicus } \\
\text { PTZ }\end{array}$ \\
\hline 43 & 1 & 0 & 10 & 197.9 & 11080 & 11080 & 22744 & 497 & 14203 & 8045 & 0 & 0 & 1.00 \\
\hline 1619 & 2 & 8 & 9 & 81.2 & 10526 & 10526 & 24434 & 349 & 11344 & 12217 & 349 & 175 & 1.00 \\
\hline 1648 & 3 & 9 & 10 & 121.2 & 11045 & 11045 & 12687 & 37 & 6139 & 6325 & 149 & 37 & 1.00 \\
\hline \multirow[t]{6}{*}{ Tow-yo 5} & 4 & 9 & 10 & 119.2 & 8082 & 8082 & 12686 & 70 & 6850 & 5697 & 70 & 0 & 0.99 \\
\hline & 5 & 9 & 11 & 129.6 & 4499 & 4499 & 7777 & 0 & 3854 & 3889 & 35 & 0 & 0.99 \\
\hline & 6 & 10 & 11 & 138.9 & 932 & 932 & 1525 & 4 & 487 & 1015 & 11 & 8 & 1.00 \\
\hline & 7 & 9 & 10 & 166.1 & 1017 & 1022 & 1264 & 5 & 263 & 987 & 9 & 0 & 1.00 \\
\hline & 8 & 8 & 10 & 141.4 & 8342 & 8342 & 9343 & 0 & 1023 & 8097 & 222 & 0 & 1.00 \\
\hline & 9 & 8 & 9 & 144.3 & 84 & 70 & 98 & 3 & 43 & 51 & 1 & 0 & 0.82 \\
\hline 44 & 1 & 0 & 2 & 151.2 & 5243 & 5243 & 10804 & 429 & 78166 & 2576 & 18 & 0 & 1.00 \\
\hline 2018- & 2 & 0 & 2 & 98.9 & 8916 & 8916 & 15569 & 848 & 11813 & 2908 & 0 & 0 & 0.97 \\
\hline 2043 & 3 & 0 & 2 & 100.0 & 7918 & 7918 & 19746 & 849 & 15429 & 3468 & 0 & 0 & 1.00 \\
\hline \multirow[t]{6}{*}{ Tow-yo 6} & 4 & 1 & 2 & 112.2 & 6872 & 6872 & 14921 & 1027 & 11297 & 2598 & 0 & 0 & 0.98 \\
\hline & 5 & 1 & 5 & 114.8 & 7518 & 7518 & 18925 & 1219 & 15012 & 2694 & 0 & 0 & 0.99 \\
\hline & 6 & 1 & 5 & 99.2 & 4290 & 4290 & 12530 & 660 & 9712 & 2158 & 0 & 0 & 1.00 \\
\hline & 7 & 1 & 2 & 100.9 & 1678 & 1677 & 5684 & 431 & 4343 & 894 & 0 & 16 & 1.00 \\
\hline & 8 & 1 & 4 & 100.6 & 2408 & 2402 & 6022 & 723 & 4204 & 1095 & 0 & 0 & 1.00 \\
\hline & 9 & 3 & 5 & 99.6 & 3549 & 3174 & 7230 & 738 & 5295 & 1197 & 0 & 0 & 1.00 \\
\hline 45 & 2 & 87 & 138 & 202.7 & 501 & 452 & 452 & 2 & 114 & 291 & 17 & 27 & 0.91 \\
\hline 2323- & 3 & 46 & 86 & 261.1 & 197 & 158 & 120 & 0 & 14 & 66 & 35 & 5 & 0.79 \\
\hline 2355 & 4 & 19 & 46 & 123.3 & 989 & 868 & 501 & 11 & 219 & 238 & 30 & 4 & 0.99 \\
\hline \multirow[t]{5}{*}{ (Night) } & 5 & 16 & 19 & 77.9 & 1810 & 1746 & 2591 & 25 & 1917 & 625 & 0 & 25 & 1.00 \\
\hline & 6 & 12 & 16 & 80.8 & 2262 & 2193 & 4546 & 15 & 3005 & 1495 & 31 & 0 & 1.00 \\
\hline & 7 & 7 & 12 & 95.9 & 4730 & 4684 & 11740 & 1038 & 9174 & 1529 & 0 & 0 & 1.00 \\
\hline & 8 & 2 & 7 & 76.9 & 220 & 115 & 285 & 49 & 189 & 47 & 0 & 1 & 0.99 \\
\hline & 9 & 0 & 3 & 113.7 & 428 & 109 & 253 & 45 & 157 & 52 & 0 & 0 & 0.83 \\
\hline $\begin{array}{l}\text { Bucket } \\
\text { Sample } \\
(0750)\end{array}$ & - & - & - & 0.01 & 256100 & 256100 & 331200 & 3200 & 180000 & 140000 & 800 & 7200 & 0.99 \\
\hline
\end{tabular}




\begin{tabular}{|c|c|c|c|}
\hline & \multicolumn{3}{|c|}{$\Delta z(\mathrm{~m})$} \\
\hline & 0 & 1 & 2 \\
\hline \multirow{5}{*}{$\begin{array}{c}\Delta t \\
(\mathrm{sec})\end{array}$} & .63 & .68 & .26 \\
\hline & .88 & .94 & .71 \\
\hline & .90 & .97 & .76 \\
\hline & .88 & .96 & .74 \\
\hline & .84 & .94 & .71 \\
\hline
\end{tabular}

Table 2.3: Table of correlation coefficients between MOCNESS 43 (nets 2-9) and the 30-sec $200 \mathrm{kHz}$ biomass estimates listed as a function of time and depth shifts between the two data sets. The time and depth increments used are $30 \mathrm{sec}$ and $1 \mathrm{~m}$. The best correlation occurred with a time shift of $60 \mathrm{sec}$ and a depth shift of $1 \mathrm{~m}$. The MOCNESS net 1 biomass datum is not included in this comparison since it was obtained on an oblique tow from the surface through a nearsurface layer not sampled with the $200 \mathrm{kHz}$ system.

This comparison gives confidence that the $200-\mathrm{kHz}$ system was measuring Calanus biomass accurately on small scales when processed in 30 -second blocks with optimal settings. Note how even the individual MOCNESS samples can average over some of the smaller peaks and holes in the acoustic biomass field shown in Figure 2.6, making a continuous acoustic record very valuable in determining small-scale variations in biomass. Next we will use the 30 -second, $200-\mathrm{kHz}$ biomass data to test the sensitivity of light transmission to copepod concentration.

\subsubsection{Comparison Between Light Transmission and 200-kHz Biomass Estimates}

The optical characteristics of pure seawater depend only weakly on temperature, salinity and pressure, so that variations in the light transmission of water in the ocean are caused primarily by the presence of biological organisms, their waste 
products, and other particulate material. During the CTD sampling conducted near Whale $A$ and Stars, we observed significant scatter in light-transmission profiles in the upper $30-40 \mathrm{~m}$ of the water column. This scatter had a distinctive feature: the maximum values of light transmission seemed to follow a relatively smooth curve, but in many depth ranges, lower values of light transmission seemed to be scattered randomly below that maximum (see Figure 2.7A for an example from cast 2 in tow-yo 5). This pattern suggests that the scatter was due not to changes in the amount of small particulate matter in the water, but rather to intermittent appearances of relatively large obstructions, which we believe to be individual copepods. The following simple argument attempts to quantify the process by which the presence of copepods could attenuate a transmissometer light beam.

Suppose the light beam from the transmissometer's source to its receiver is a cylinder of radius $R$ and length $L$. If we model the copepods as opaque cylinders of radius $r$ and length $h$, then the percentage of the beam light that is blocked by copepods, assuming that the copepods are spaced far enough apart that their shadows do not overlap, is given by

$$
B_{z}=100 \% \times\left(N_{z} \times 2 r h\right) /\left(\pi R^{2}\right)
$$

where $N_{z}$ is the number of copepods in the beam's path. $N_{z}$ is related to the concentration of copepods $C_{z}$ by

$$
N_{z}=C_{z} \times \pi \times R^{2} \times L
$$

so that the percentage of light blocked is given by

$$
B_{z}=100 \% \times C_{z} \times 2 r h \times L .
$$

For $L=25 \mathrm{~cm}$, the percentage of light blocked versus copepod concentration is plotted in Figure 2.8 for Calanus finmarchicus copepodite stages CIV and CV. This figure shows, for example, that for CIV, a concentration of $3.8 \times 10^{4}$ copepods $/ \mathrm{m}^{3}$ would 

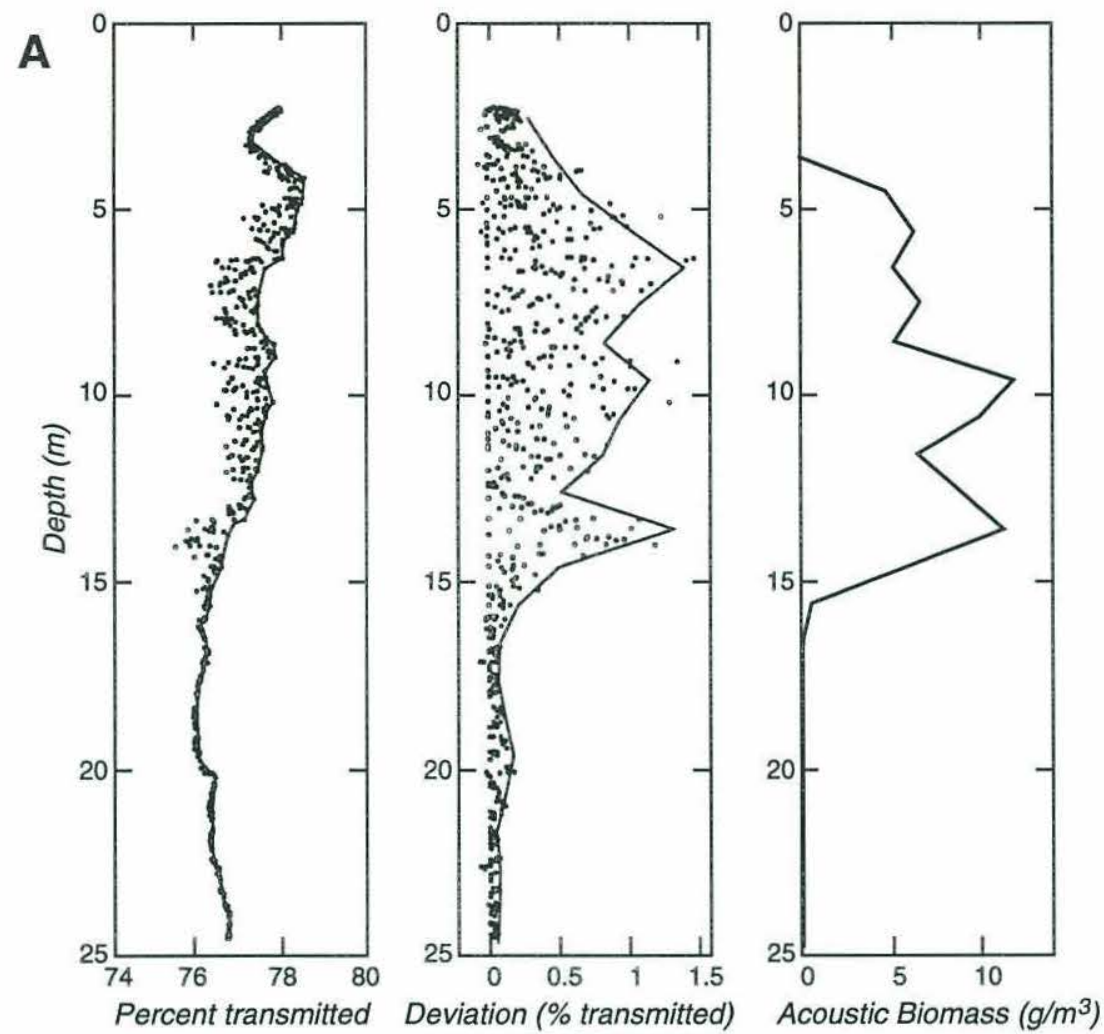

and $2 \times$ RMS Deviation
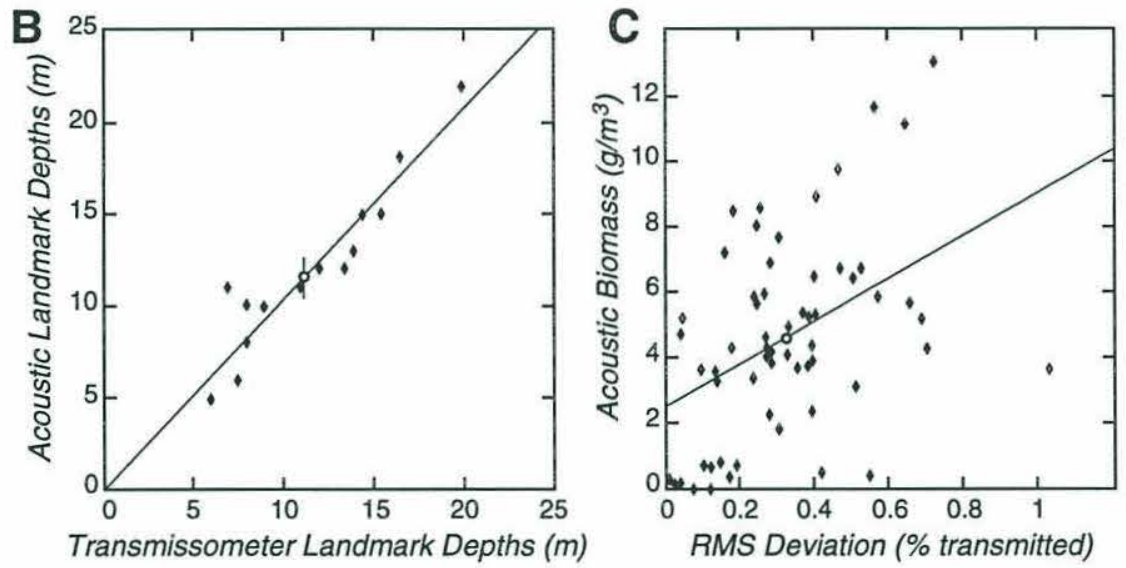

Figure 2.7: A: Raw profile of percent light transmission versus depth at cast 2 of tow-yo 5 (left panel). The curve connecting the maximum transmission represents the putative background profile. Profile of percent light-transmission deviation, i.e., the difference between the raw values and the background profile (center panel). The solid line represents twice the rms deviation calculated for 1 -m bins. Profile of $30-\mathrm{sec}, 200-\mathrm{kHz}$ acoustic biomass corresponding to station 2 (right panel).

B: Scatterplot of "landmark" depths (the depths of major qualitative features) in light-transmission deviation versus those in the acoustic biomass data. Slope of best-fit line through the origin is 1.04 \pm 0.21 ( $95 \%$ confidence).

C: Scatterplot of rms light transmission deviation versus acoustic biomass. Best fit line has correlation coefficient 0.44 , which is significant above the $99.9 \%$ level. Data shown are from all profiles where comparison is possible. 


\section{Percent Shadowing by Copepods}

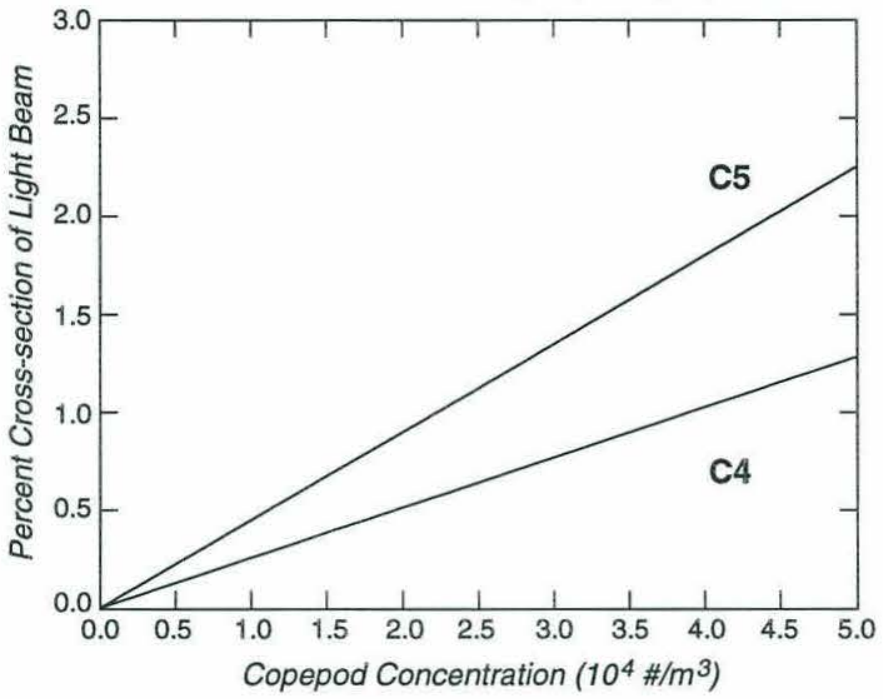

Figure 2.8: The percent cross-section of the transmissometer light beam that would be blocked as a function of copepod concentration for stages CIV and CV Calanus. To construct this figure, the copepod is modeled as a cylinder of length $L_{c}$ and width . $43 \times L_{c}$, where $L_{c}$ is the cephalothorax length. A. and T. Durbin (personal communication) report mean values of $L_{c}$ of $1.75 \mathrm{~mm}$ for stage CIV and $2.28 \mathrm{~mm}$ for stage CV based on measurements of the surface Calanus population during the May-June SCOPEX '89 Endeavor cruise.

reduce the amount of light transmitted by $1 \%$. In the light-transmission profile shown in Figure 2.7A, reductions as large as $1.5 \%$ are seen near 7 and $14 \mathrm{~m}$. If we assume that the composition of the copepod patch sampled in Figure 2.7A is similar to that found in the MOCNESS 43 tows, i.e., that the patch is roughly $42 \%$ CIV and $58 \%$ $\mathrm{CV}$, then a $1.5 \%$ reduction in transmitted light implies a copepod concentration of $4.1 \times 10^{4}$ copepods $/ \mathrm{m}^{3}$. This is about 1.7 times the maximum concentration found during MOCNESS 43. At this concentration, about 3 copepods would be in the light beam on the average, which suggests that the assumption that their shadows do not overlap is reasonable.

To further examine the hypothesis that scatter in the transmissometer data was due to obstruction of the light beam by copepods, we compared the scatter with 200$\mathrm{kHz}$ acoustic biomass estimates made at the same time. For each light-transmission profile, we subjectively drew a smooth curve to fit the maximum light transmission 
profile (on the assumption that this "background" profile would have matched most data points if not for the presence of copepods-see the example in Figure 2.7A). We then subtracted the raw data from this background profile to determine the deviation of the observed light transmission from the background, and calculated the root mean square (rms) deviation in 1-m depth bins. We then compared the rms deviation profiles to the contemporaneous $200-\mathrm{kHz}$ biomass profiles obtained during leg 1 of tow-yo 5 over the upper $25 \mathrm{~m}$, where we believe the acoustic instrument was observing primarily copepods.

As in the comparison between MOCNESS and acoustic data, we shifted the nominal depth of the acoustic data relative to that of the transmissometer data in order to account for uncertainty in the depth at which the acoustic system was deployed. The best correlation between acoustic and transmissometer data was given by a depth offset of $1 \mathrm{~m}$ (one acoustic depth bin). No time adjustment was necessary. (This offset, as well as the additional 1-m and 60-second offsets between MOCNESS and acoustic data are taken into account in Figures 2.6A and 2.9A). Figure 2.7B plots the depths at which major features - such as distinct peaks or the sharp drop-off of intensity at the base of the copepod layer - occur in the acoustic data versus the depths at which they occur in the transmissometer data. The two data sets correspond very well in this qualitative sense, with a correlation coefficient of 0.945 , significantly different from 0 above the $99.9 \%$ level. This qualitative agreement between rms transmissometer deviation and acoustic biomass estimate is illustrated in Figure 2.9B, where vertical profiles of the two quantities are compared.

The data do not correspond as well in a quantitative sense. Figure $2.7 \mathrm{C}$ shows the acoustic biomass estimate for each depth bin plotted versus the rms transmissometer deviation for the corresponding bin. The correlation coefficient 0.442 is significantly different from 0 above the $99.9 \%$ level, but the correlation is too weak to make it possible to use transmissometer data to predict biomass with much confi- 

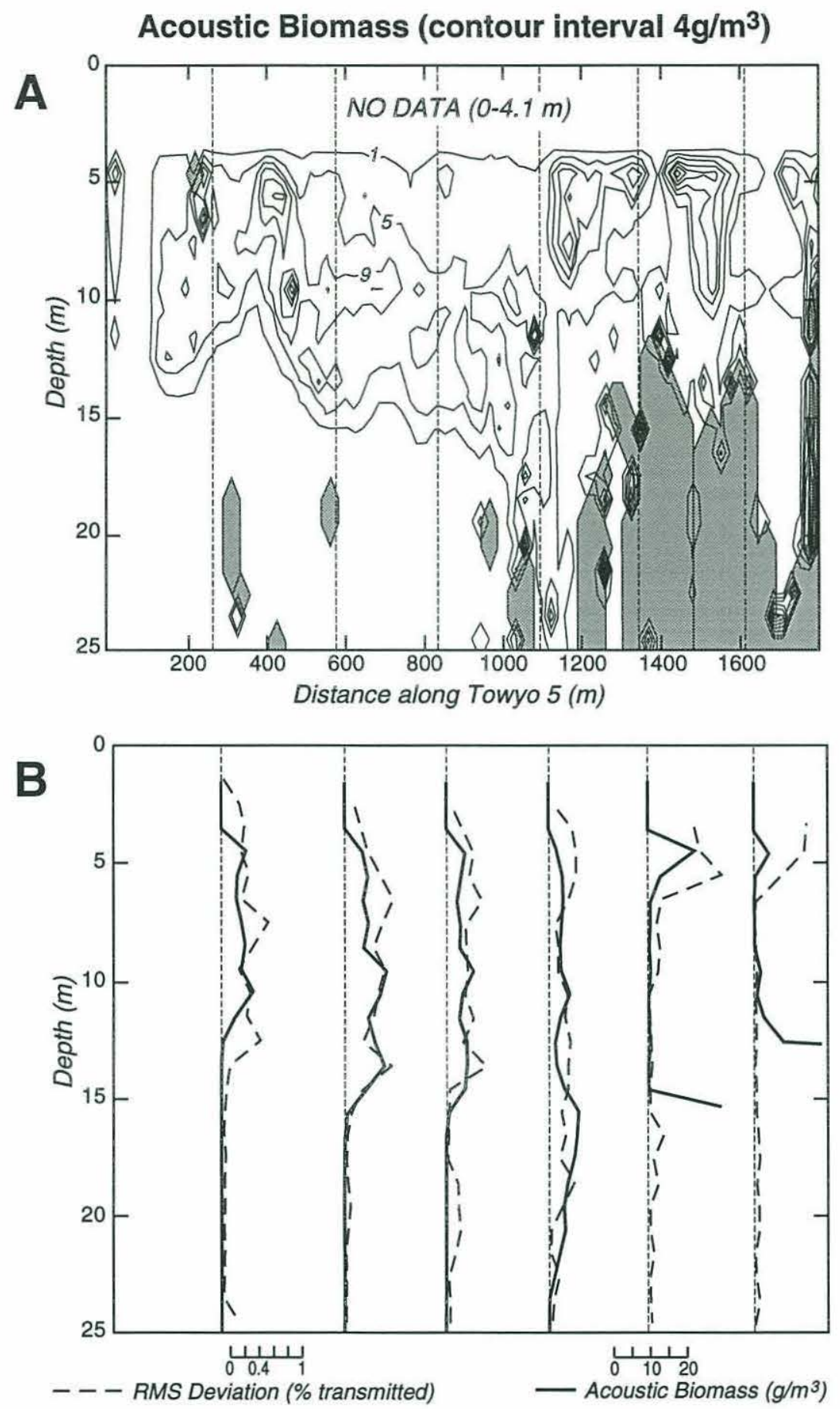

Figure 2.9: A: Contour plot of the $30-\mathrm{sec}, 200-\mathrm{kHz}$ acoustic biomass field for the first part of leg 1 of tow-yo 5 with the locations of CTD stations 1-6 shown as dashed vertical lines. The acoustic biomass field is as shown in Figure 2.6A.

B: Comparison of the percent rms light-transmission deviation profiles with acoustic biomass profiles measured along the lines shown above. The relative depth of the acoustic data has been shifted vertically to give the best correlation of the landmark depths shown in Figure 2.7B. 
dence. This is not unreasonable, given the patchiness of the copepod distribution (as shown in the acoustic data) and the large differences between the water volumes sampled with the two instruments. The acoustic profiler integrates, for 30 seconds, backscatter data from a relatively wide field (the size of which depends on the depth bin), while the transmissometer samples only the small volume within the light beam path for 2-3 seconds over a $1 \mathrm{~m}$ depth bin.

\subsubsection{Tow-yo 5}

As mentioned above, tow-yo 5 consisted of two legs, the first made following Whale A southward as it fed on a large patch of Calanus finmarchicus and the second made following the whale as it reversed course to turn back into the patch and continue feeding. During leg 1 , both 30 -second, $200-\mathrm{kHz}$ acoustic and MOCNESS 43 biomass data were collected, and the composite picture shown in Figure 2.6A provides our best description of the spatial structure of zooplankton near a feeding right whale. The qualitative agreement between acoustic biomass and rms light-transmission deviation described above makes it possible to use transmissometer data to get a crude idea of the copepod distribution during the rest of tow-yo 5 , for which 30 -second, $200-\mathrm{kHz}$ acoustic data do not exist. Figure 2.10 shows rms light-transmission deviation for all of tow-yo 5, with isopycnal surfaces shown superimposed. The break in the CTD casts between casts 9 and 10 (around 2500-3100 m along the transect) corresponds to the period when the ship reversed course between legs 1 and 2 . The deeper, lightly shaded areas represent dense patches of larger zooplankton (presumably euphausiids) detected in both the 30 -second and the 60 -second $200-\mathrm{kHz}$ acoustic data. These deeper patches were part of a dense layer of larger zooplankton which rose from near the bottom towards the surface during the day. 


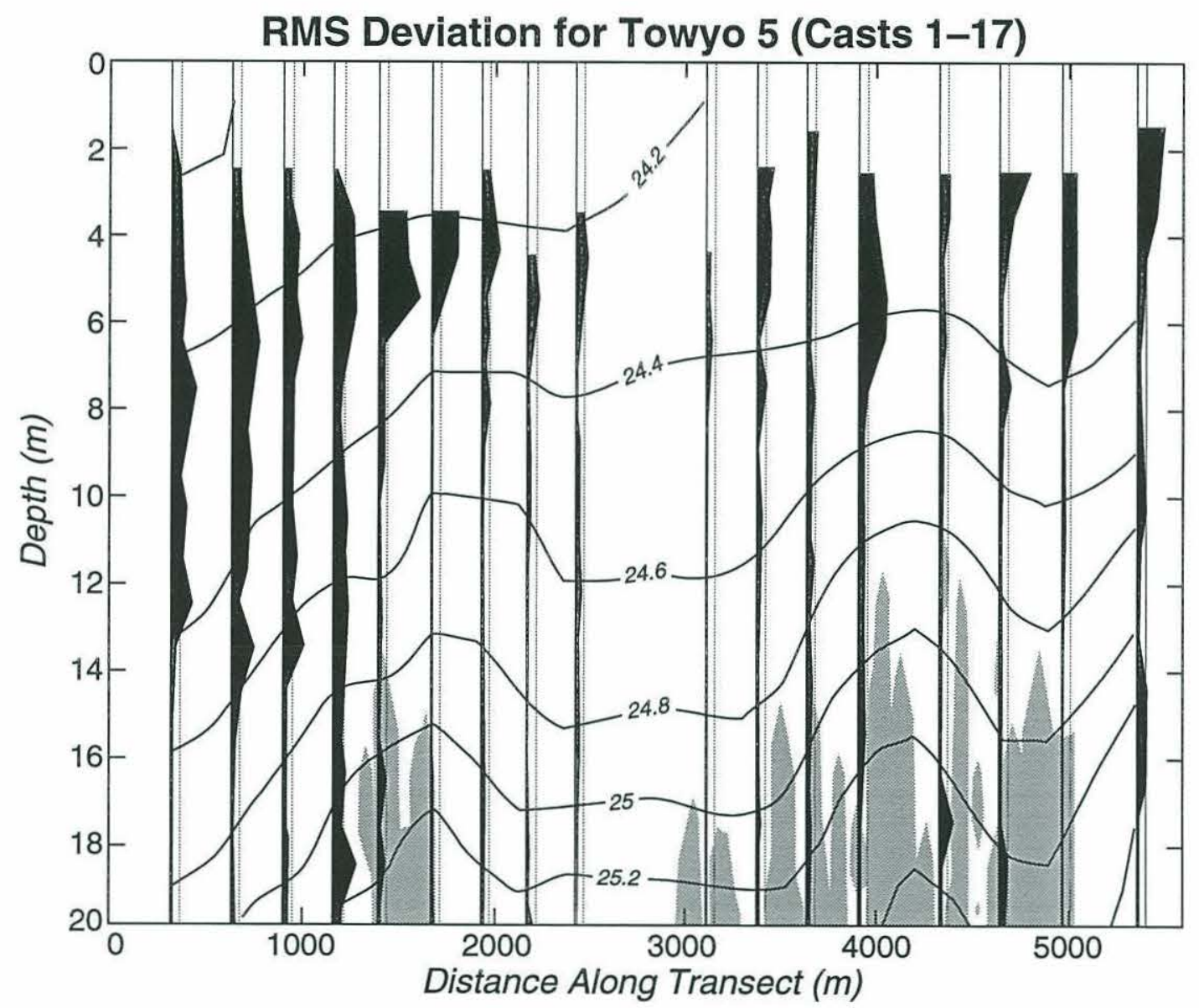

Figure 2.10: Profiles of percent rms light-transmission deviation plotted as a function of position along the entire tow-yo 5 transect. The dark shaded areas indicate the percent rms deviation measured during each CTD lowering while the lighter shaded areas denote regions where large (noncopepod) zooplankton were found in the acoustic data. Dotted lines indicate an rms deviation of $.2 \%$ transmission, the level below which light-transmission estimates of copepod biomass are essentially indistinguishable from zero due to curvature of the "background" light-transmission curve. Superimposed are isopycnals spanning the range of $\sigma_{t}$ from 24.0 to 25.4. The $\sigma_{t}$ labels appear in the gap separating leg 1 from leg 2 . 
The combined picture of zooplankton distribution shown in Figures 2.6, 2.9, and 2.10 indicates a thick layer of copepods extending down to about $15 \mathrm{~m}$ at the start of leg 1 . This layer then seems to become thinner, extending down to only about 6$7 \mathrm{~m}$, and the copepod concentration seems to decrease (as measured by the intensity of the rms transmissometer deviation and decrease in MOCNESS concentration) towards the end of leg 1. This thinning and weakening of the copepod layer corresponds roughly to the region where Whale A ceased feeding and reversed direction. During leg 2, which corresponds roughly to the region where the whale began feeding again, the copepod layer at first seems very weak, but gradually builds in intensity and remains near-surface. Since the top 3-4 $\mathrm{m}$ were not sampled by either acoustics or CTD during tow-yo 5, only the observation that Whale A was not skim-feeding indicates that the maximum copepod concentrations occurred beneath the top 0 $1 \mathrm{~m}$.

The distribution of copepods within this near-surface layer was clearly patchy, both horizontally and vertically. The horizontal average of the 30 -second, $200-\mathrm{kHz}$ acoustic biomass data shown in Figure 2.6A over a distance of about $1.5 \mathrm{~km}$ did not vary much with depth between the top depth sampled (about $4.1 \mathrm{~m}$ ) and $10 \mathrm{~m}$, and had a mean value of about $6.0 \mathrm{~g} / \mathrm{m}^{3}$ over this depth band. Based on MOCNESS 43 results (Table 2.2), the average copepod wet weight was $0.69 \pm 0.18 \mathrm{mg}$, so that the spatial mean concentration in the $4-10 \mathrm{~m}$ depth band was $8.7 \times 10^{3}$ copepods $/ \mathrm{m}^{3}$. Short gaps in the copepod layer occurred near 1400 and $1650 \mathrm{~m}$, creating one almost discrete patch roughly $250 \mathrm{~m}$ long with mean and maximum biomass estimates of 7.7 and $28.4 \mathrm{~g} / \mathrm{m}^{3}$, which correspond roughly to mean and peak concentrations of $1.1 \times 10^{4}$ and $4.1 \times 10^{4}$ copepods $/ \mathrm{m}^{3}$, respectively. Although the acoustic approach may tend to underestimate the larger biomass values (Figure 2.6B), the acoustic peak concentration of $4.1 \times 10^{4}$ copepods $/ \mathrm{m}^{3}$, observed at a depth of $4 \mathrm{~m}$ at $1450 \mathrm{~m}$, is about twice the peak concentration of $2.4 \times 10^{4}$ copepods $/ \mathrm{m}^{3}$ found in MOCNESS 43 (Table 2.2). This difference is due to both the longer horizontal sam- 
pling distance of the MOCNESS and to its ability to sample only one depth interval at a time.

The top 4-30 m of the water column was strongly stratified during tow-yo 5 (Figure 2.10). Salinity and temperature contributed roughly equally to the formation of the pycnocline, with the maximum vertical density gradient occurring between 12 and $20 \mathrm{~m}$ on average. The maximum spatially averaged Brunt Väisälä frequency was $N_{\max } \cong 2.3 \times 10^{-2} 1 / \mathrm{s}$. There was some shoaling of the near-surface isopycnals with time during tow-yo 5, suggesting that the thinning of the copepod layer during the tow-yo may be associated with the rising density field. There was little evidence of a surface mixed layer and the copepod layer did extend down through the near-surface stratification, although most of the copepod layer was located above the maximum vertical density gradient. The ADCP velocity data exhibited small but measurable variations (of order $2-7 \mathrm{~cm} / \mathrm{s}$ ) in both vertical and horizontal directions during towyo 5 , but no clear picture of horizontal convergence or vertical shear was found. The average vertical shear squared $S^{2}$ was about $3 \times 10^{-4} 1 / \mathrm{s}^{2}$, roughly uniform with depth over the top $30 \mathrm{~m}$, such that the local gradient Richardson number $\mathrm{Ri}=N^{2} / S^{2}$ was generally greater than 0.5 , indicating that active vertical mixing was not occurring in the copepod layer.

\subsubsection{Tow-yo 6}

About 1.7 hours after tow-yo 5 was completed, the Endeavor began a combined CTD tow-yo (tow-yo 6) and shallow horizontal MOCNESS tow (MOCNESS 44) following Stars. The start of tow-yo 6 was located about $18.4 \mathrm{~km}$ WNW from the end of tow-yo 5 and closer to the core of the fresh-water surface plume (Figures 2.1 and 2.2). As a result, the near-surface water was fresher, with a layer of relatively constant salinity in the top $5 \mathrm{~m}$. The surface water was stratified in temperature, with both 
temperature and salinity gradients maximum between about 10 and $18 \mathrm{~m}$ on average. The mean density gradient was also a maximum in this depth range (Figure 11), with a maximum Brunt-Väisälä frequency of $N_{\max } \cong 2.7 \times 10^{-2} 1 / \mathrm{s}$. The average vertical shear squared decreased from about $8 \times 10^{-4} 1 / \mathrm{s}^{2}$ near $9 \mathrm{~m}$ (the shallowest depth at which estimates of $S$ can be made) to about $4 \times 10^{-4} 1 / \mathrm{s}^{2}$, below $14 \mathrm{~m}$. As during tow-yo 5 , the local gradient Richardson number was generally greater than 0.5 , indicating a lack of active shear-induced mixing.

The MOCNESS was set to sample the top $5 \mathrm{~m}$ of the water column and found copepod biomass and concentrations similar to those found during tow-yo 5 (Table 2.2). The rms light-transmission deviation data showed a patchy distribution, with a thick layer of high copepod biomass extending down to a depth of $16 \mathrm{~m}$ throughout the tow-yo (Figure 2.11). The horizontal structure was also patchy, with maximum rms light-transmission deviations a bit larger than, but comparable to, those found in tow-yo 5. Although Stars slowed feeding at approximately 2020 (soon after the start of tow-yo 6) and completely stopped soon afterward (Figure 2.4), the light-transmission data indicate that the whale did not stop because of a lack of available copepod biomass.

Later that night, the Endeavor made a bottom-to-surface oblique MOCNESS tow (MOCNESS 45). Calanus finmarchicus were found in concentrations above $10^{3}$ copepods $/ \mathrm{m}^{3}$ only in the top $20 \mathrm{~m}$ (Table 2). Other net sampling conducted in this general region during the last week in May and the first week in June, 1989, indicated that Calanus finmarchicus remained concentrated near the surface and did not exhibit diel vertical migration behavior (Wishner et al., 1995). 


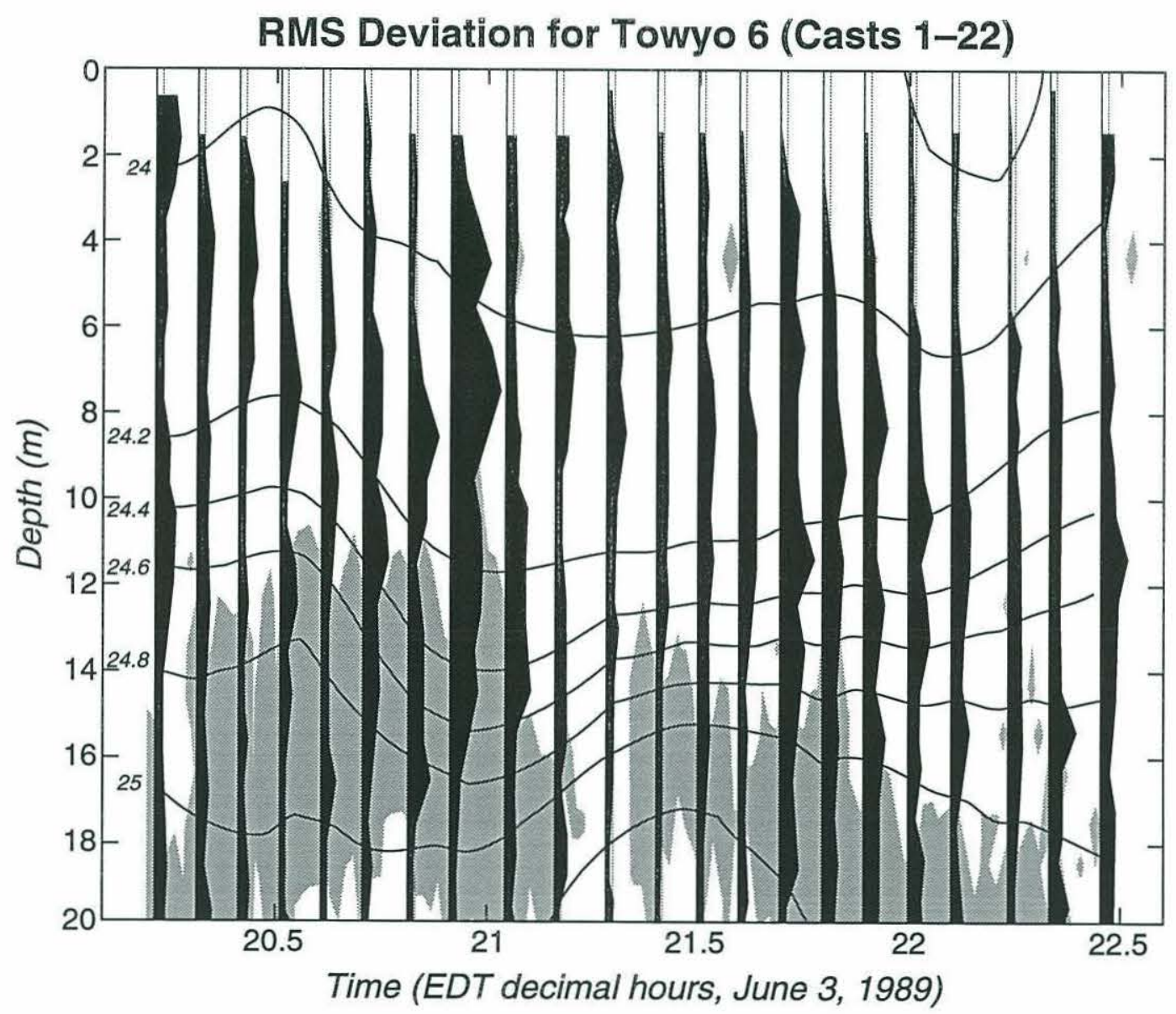

Figure 2.11: Profiles of percent rms light-transmission deviation plotted as a function of time along the entire tow-yo 6 transect. The dark shaded areas indicate the percent rms deviation measured during each CTD lowering while the lighter shaded areas denote regions where large (noncopepod) zooplankton were found in the acoustic data. Dotted lines indicate an rms deviation of $0.2 \%$ transmission, the level below which light-transmission estimates of copepod biomass are indistinguishable from zero. Superimposed are isopycnals spanning the range of $\sigma_{t}$ from 24.0 to 25.2. The $\sigma_{t}$ labels are shown to the left. 


\subsubsection{The Next Morning}

Sunrise the next morning was at 0508. At 0523, Stars was observed to be surface-feeding near $41.45^{\circ} \mathrm{N}, 68.96^{\circ} \mathrm{W}$, approximately $1.2 \mathrm{~km}$ west-southwest of where she would have been if only the tidal current had carried her from the location where she was first sighted by the Endeavor (Figure 2.2). She was then followed by the Endeavor and observed to continue to feed until about 0836 when visual contact was lost in fog near $41.51^{\circ} \mathrm{N}, 68.98^{\circ} \mathrm{W}$ (Figure 2.2). Stars first swam southward, then turned and swam northward as she was also carried northward by the current. The water near the whale was reddish due to high concentrations of Calanus finmarchicus very close to the surface. A surface bucket sample taken from the Endeavor near the whale had the highest copepod concentration found during SCOPEX ' 89 (Table 2.2). The copepod biomass estimate was $256 \mathrm{~g} / \mathrm{m}^{3}$ and the concentration of CIII and older Calanus was $3.3 \times 10^{5}$ copepods $/ \mathrm{m}^{3}$, both more than one order of magnitude larger than observed during sampling the previous evening around Stars.

During this period the Endeavor steamed slowly behind Stars, attempting to follow her within $0.5 \mathrm{~km}$ without crowding her (Figure 2.2). We can thus use the Endeavor 7-m ADCP data to estimate both Stars' swimming speed while feeding and the size of the Calanus patch. Over the three-hour period, the average speed of the Endeavor through the water (at $7 \mathrm{~m}$ ) was $1.22 \mathrm{~m} / \mathrm{s}$. If we neglect vertical shear and assume the uncertainty in relative position between the Endeavor and Stars was $0.5 \mathrm{~km}$ at each end of the path, the uncertainty in speed would be about $0.1 \mathrm{~m} / \mathrm{s}$. Thus, we estimate that the minimum mean speed of Stars during this feeding period was $1.2 \pm 0.1 \mathrm{~m} / \mathrm{s}$. This estimate is within the upper limit of $1.5 \mathrm{~m} / \mathrm{s}$ cited by Watkins and Schevill (1979) for right whales in this region. Since Stars was observed to feed throughout this period, the minimum north-south extent of the surface patch was $5.3 \mathrm{~km}$. We have no knowledge of the east-west extent of the patch. 


\subsection{Discussion}

The experimental strategy of using right whales to locate dense patches of their copepod food, Calanus finmarchicus, proved successful in SCOPEX '89. On 3 June, two right whales were found feeding near the surface. One whale (Whale A) was followed for about three hours, and the other (Stars) was tagged with a VHF radio transmitter and subsequently followed for about 16 hours, sometimes by a single vessel and sometimes by two vessels working together. Underway measurements were made in order to investigate the small-scale spatial structure of water properties, light transmission, and zooplankton in the upper water column near both whales.

If we take $1-3 \mathrm{~g} / \mathrm{m}^{3}$ as the minimum copepod biomass detectable with the light-transmission approach (based on Figure 2.7C), then during tow-yo 5 Whale $\mathrm{A}$ apparently stopped feeding when the concentration dropped below about $1.5-4.5 \times 10^{3}$ copepods $/ \mathrm{m}^{3}$. This value is consistent with Mayo and Goldman's (1992) estimate that the break-even prey concentration for a right whale (the concentration above which the whale gains more energy by feeding than it loses by swimming with its mouth open) is approximately $4 \times 10^{3}$ copepods $/ \mathrm{m}^{3}$. It is also reasonably consistent with Wishner et al.'s (1995) observations for the entire MOCNESS data set from all SCOPEX cruises of a minimum peak copepod abundance of $1.0 \times 10^{3}$ in 1988 and $9.7 \times 10^{3}$ in 1989 in areas where right whales were feeding.

The mean and peak copepod concentrations observed around Whale A during tow-yo 5 were $8.7 \times 10^{3}$ and $4.1 \times 10^{4}$ copepods $/ \mathrm{m}^{3}$, respectively. If we assume the mean energy value of each copepod is about $10^{-3} \mathrm{kcal}$, then the mean energy intake of Whale A during this period was roughly $3.8 \times 10^{4} \mathrm{kcal} /$ hour (assuming a swimming speed of $1.2 \mathrm{~m} / \mathrm{s}$ and a mouth area of $\left.1 \mathrm{~m}^{2}\right)$. At this rate, a whale would have to feed for approximately 5.5 hours just to satisfy its daily basal metabolism energy requirement of $2.1 \times 10^{5} \mathrm{kcal}$ (Kenney et al., 1986). Up to five times this amount 
may be required to sustain active metabolism and feeding (Kenney et al., 1986). It therefore seems that right whales must find even denser concentrations of copepods if they are to survive in the long term, especially since any food a right whale eats during the summer must provide it not only with its daily energy requirement but also with additional energy it will need for growth, reproduction, and metabolism during the three- to five-month winter period when it may not feed at all.

Denser concentrations of copepods are available in the GSC. The morning after tow-yos 5 and 6, Stars was found to be skim-feeding on a Calanus finmarchicus patch in which a bucket sample gave a concentration of $3.3 \times 10^{5}$ copepods $/ \mathrm{m}^{3}$. If this one sample approximated the mean concentration of this patch, then Stars had a mean energy intake of $1.4 \times 10^{6} \mathrm{kcal} / \mathrm{hr}$. At this rate, she could consume her daily basal metabolic energy requirement in roughly nine minutes, and her annual requirement in roughly two days (assuming continuous feeding). Clearly, finding such especially dense copepod patches in the GSC makes sense as a foraging strategy.

Leising (1994) has recently described some laboratory observations of copepod swarming which suggest that individual copepods attempt to "maintain a personal space only slightly larger (1.2-1.3 times) than their own body dimensions." This suggests that a crude estimate of the maximum copepod concentration that could have occurred during our June, 1989, SCOPEX observations was

$$
C_{\max }=\frac{1.41}{\left(N N D_{\min }\right)^{3}}=1.3 \times 10^{7} \text { copepods } / \mathrm{m}^{3}
$$

where the minimum nearest-neighbor distance $N N D_{\min }$ in $\mathrm{mm}$ is estimated from the average antenna length $\ell$ using

$$
N N D_{\min }=2.45 \ell-0.21
$$

(Leising, personal communication). The average antenna length is assumed equal to the average cephalothorax length (see Figure 2.8 caption), so that $\ell=2.0 \mathrm{~mm}$ and $N N D_{\min }=4.7 \mathrm{~mm}$. The resulting value of $C_{\max }$ is roughly 40 times the 
bucket-sample concentration, indicating how close the patch was to perfect feeding conditions for Stars. The average spacing between individual copepods in the bucket sample was only $16 \mathrm{~mm}$, contributing to the reddish hue of the sample and of the patch in the ocean.

One objective of SCOPEX was to examine several hypotheses about what processes might cause the formation of such dense copepod aggregations in late spring in the northern Great South Channel region (Kenney and Wishner, 1995). Three hypotheses were initially advanced. The advection hypothesis states that an interaction between the water flow and the behavior of the copepods (especially vertical migration and a preference for some depth band) passively concentrates the copepods. The productivity hypothesis states that the high copepod concentrations are due to high primary productivity in the area (i.e., a simple food chain response). The social behavior hypothesis states that a species-specific social behavior (e.g., swarming) creates the dense copepod aggregations.

Wishner et al. (1995) found that in the two years (1988 and 1989) examined during SCOPEX, the densest copepod aggregations were found near the front of the surface fresh water plume east of Cape Cod, suggesting that regional advection was important. Epstein et al. (1993; see also Chapter 4 of this thesis) have examined CTD and acoustic biomass data collected on the same Endeavor SCOPEX '89 cruise in a small-scale frontal feature in the surface plume, and suggested that the horizontal convergence associated with surface subduction, coupled with the copepods' tendency to maintain their depth near a fixed level near the surface, could explain a significant increase in the local near-surface copepod concentration. Thus, differential advection on regional and smaller scales, coupled with a specific copepod behavior, appear to be important processes in this region. Durbin et al. (1995b) found no evidence of localized higher primary productivity to support the productivity hypothesis. Since the biological and physical data reported in this paper do not suggest that the small- 
scale subduction concentration mechanism suggested by Epstein et al. (1993) was active either during or immediately prior to the measurements made on 3-4 June, we conclude that some non-physical, species-specific animal behavior (such as swarming or some other unknown physical mechanism) must be partially responsible for creating the very densest copepod patches observed during SCOPEX. 


\section{Chapter 3}

\section{High-Resolution Observations of}

\section{Plankton Spatial Distributions}

\section{Correlated with Hydrography in}

\section{the Great South Channel}

\subsection{Abstract}

The Video Plankton Recorder (VPR) is a towed underwater microscope designed to image plankton non-invasively with sufficient resolution to obtain information on the spatial distribution of major taxa and associated hydrography on scales of millimeters to hundreds of kilometers. ${ }^{1}$ During a 13-day cruise on Georges Bank in May, 1992, the VPR was tow-yoed at 4-6 kts while obtaining plankton images at 60

\footnotetext{
${ }^{1}$ This chapter has been submitted to Deep-Sea Research for publication, in slightly different form, as: "High-Resolution Observations of Plankton Spatial Distributions Correlated with Hydrography in the Great South Channel, Georges Bank", by Scott M. Gallager, Cabell S. Davis, Ari W. Epstein, Andy Solow, and Robert C. Beardsley.
} 
$\mathrm{Hz}$ and CTD data at $0.25 \mathrm{~Hz}$. A $150-\mathrm{kHz}$ shipboard ADCP recorded data on water velocities. Data from an eight-hour transect across the Great South Channel (GSC) were analyzed on a continuum of spatial scales from coarse-scale $(100 \mathrm{~km})$ to microscale (mm). Abundance was determined for 12 taxonomic groups including: invertebrate larvae (ophiopluteus, hydroid medusa: Obelia sp., anthozoa larvae: Cerianthus sp.), copepods (Calanus sp., Pseudocalanus sp.), pteropods (Limacina retroversa, Clione sp.), ctenophore (Mnemiopsis sp., Pleurobrachia sp.), larvacea (Oikopleura sp.), chaetognatha (Sagitta sp.), and diatom colonies (Chaetocerous socialis).

Species-specific plots of the positions of individual plankton in the water column and plots of the temperature and salinity at which the plankton were observed (temperature-salinity-plankton plots) showed that major taxonomic groups were patchy at coarse-scales because of their association with specific water masses of different origin, and because of the presence of temperature/density discontinuities (pycnocline and fronts). A thorough analysis of the T-S characteristics of the water masses encountered along the transect indicated that diatom colonies and ophiopluteus larvae of echinoderms were transported to the GSC in a band of cold water originating on the south flank of Georges Bank. Within this water, diatom colonies formed an intense patch at a mixing front reaching a density of $5 / \mathrm{ml}$. Within each water mass, fine-scale (tens of meters) plankton patchiness was associated with regions of vertical stability as indicated by the association of plankton with regions of high gradient Richardson numbers. Aggregation of plankton at the micro-scale occurred extensively for plankton capable of active swimming only, suggesting a dynamic interaction between biological and physical variables, rather than the dominance of one, at this spatial scale. On occasion, veliger larvae of Limacina retroversa were found in spawning patches at concentrations exceeding $600 / \mathrm{ml}$ within a few $\mathrm{cm}$ of the air/sea interface. The ability to observe and quantify such local concentrations of plankton, together with micro-scale physical information over large spatial scales, should shed new light on the dynamics of plankton populations in the world oceans. 


\subsection{Introduction}

Spatial variability in plankton distributions, and the mechanisms by which it is produced, have been discussed in the literature for decades (Bigelow, 1926; 1927; Hardy and Gunther, 1935; Cassie, 1959; McGowan, 1974). Most studies have been concerned with population abundances at the mesoscale (100-1000 km; Haury et al., 1976) where spatial integration over large distances by the sampling equipment used was appropriate for the questions being addressed. As advances in sampling technology paralleled an increasing interest in variability at smaller spatial scales, new equipment revealed smaller-scale plankton distributions to be invariably patchy (Cassie, 1959; 1960; Cushing, 1961). Moreover, patchy distributions of plankton have been found to covary with water column physics within reasonably large ( $>100 \mathrm{~km})$ spatial scales (Cassie, 1960; Steele, 1976; Denman and Powell, 1984).

Significant correlations between physical structure and biological activity can arise from both biological and physical sources. Biological sources include behavior in response to the chemical and biological composition of the water column (prey or nutrient localization) or to external environmental forcing (diurnal migration). Physical structuring of the water column can cause redistribution of biology through mixing, or it can isolate biological communities from neighboring water masses. Intrusion of water masses into an area carrying discrete populations has been documented at the mesoscale in a number of studies (e.g. McGowan, 1967; Wiebe et al, 1976). Examples of such intrusions are related to the distribution and formation of mesoscale eddies, such as Gulf Stream rings in the northwestern Atlantic, meanders and spin-offs from the loop current in the Gulf of Mexico (Maul et al., 1974), broad upwellings and plumes at the shelf break, and the outflow of major river systems. The result of such intrusions can be a significant contrast in biomass and species composition in the plankton over distances of hundreds of kilometers. Changes in community composi- 
tion over smaller scales (coarse-scale: $1-100 \mathrm{~km}$ and fine-scale: $1-1000 \mathrm{~m}$ ) are usually attributed to biological-physical interactions, such as accumulation of organisms at fronts and in convective cells due to swimming activity of the plankton (Mackas et al., 1988; Marine Zooplankton Colloquium, 1989). In coastal regions, however, it is often possible to find a number of water masses with specific physical properties interacting, mixing and forming a complex three-dimensional mosaic of interleaved water parcels over distances of just a few km (Neumann and Pierson, 1966). This is particularly true in areas of rapidly changing bathymetry and offshore shoals and banks (e.g. Flagg, 1987).

Given the high degree of variance in plankton biomass often observed at these coarse spatial scales, one can ask how much of the observed biological variance is due to the spatial redistribution or interaction between specific water parcels within such a mosaic, compared with the variance due to biological factors related to species-specific behavior. To address this question, samples must be taken for physical and biological variables synoptically and their sampling wavelength must be less than one half of the dominant wavelength of the expected changes in water mass and plankton distribution (Denman and Mackas, 1977). Conventional sampling gear precludes such an analysis since nets and pumps tend to integrate sample volumes over greater spatial scales than necessary to resolve vertical and horizontal boundaries of plankton distributions less than a few tens of meters. Particle counters, fluorometers, and active acoustic systems allow for rapid data acquisition and processing for particle abundance, size and chlorphyll levels, but without taxonomic information on the composition of the plankton.

With the advent of the Video Plankton Recorder (VPR)(Davis et al., 1992a,b), we are in a position to address some of these taxon-specific questions, and to study how the distribution of plankton correlates with physical parameters on scales from millimeters to hundreds of kilometers. The VPR is designed to sample non-invasively 
the micro-distribution and environment of individual plankton over relatively large spatial scales. Fragile forms such as gelatinous zooplankton and colonial phytoplankton are sampled optically in their natural orientation without damage, thus providing information not obtainable by conventional sampling equipment.

The study reported here was part of a pilot cruise in the Global Ocean Ecosystem Dynamics (GLOBEC) program being conducted on Georges Bank in the northwest Atlantic Ocean. The purpose of the GLOBEC Georges Bank program is to understand the mechanisms controlling the population size (and its variance in time and space) of key planktonic organisms critical to the fisheries of the region. To this end, the results of a VPR transect made across the Great South Channel (GSC) in May, 1992, are reported here, where we address the following questions: 1) What are the spatial scales for correlation between species-specific distributions of plankton and the prevailing hydrography in Great South Channel? 2) To what extent do water masses provide boundaries to planktonic communities? 3) What is the relationship between plankton abundance and the micro-scale distribution (patchiness) within a given water mass? and 4) How does water column stability influence plankton abundance on micro- to meso-scales?

\subsection{Physical Setting}

The Great South Channel (GSC) is a shallow channel (sill depth approximately $70 \mathrm{~m}$ ) linking the Gulf of Maine to the outer continental shelf and slope of New England (Figure 3.1). It is bounded on the east by Georges Bank, and on the west by Nantucket Shoals. The transect we describe here in detail (VPR 22) was made in the northern GSC, about 20 kilometers north of the channel sill. The transect was conducted on May 27-28, 1992, between 1620 and 0130 local time (EDT) and 


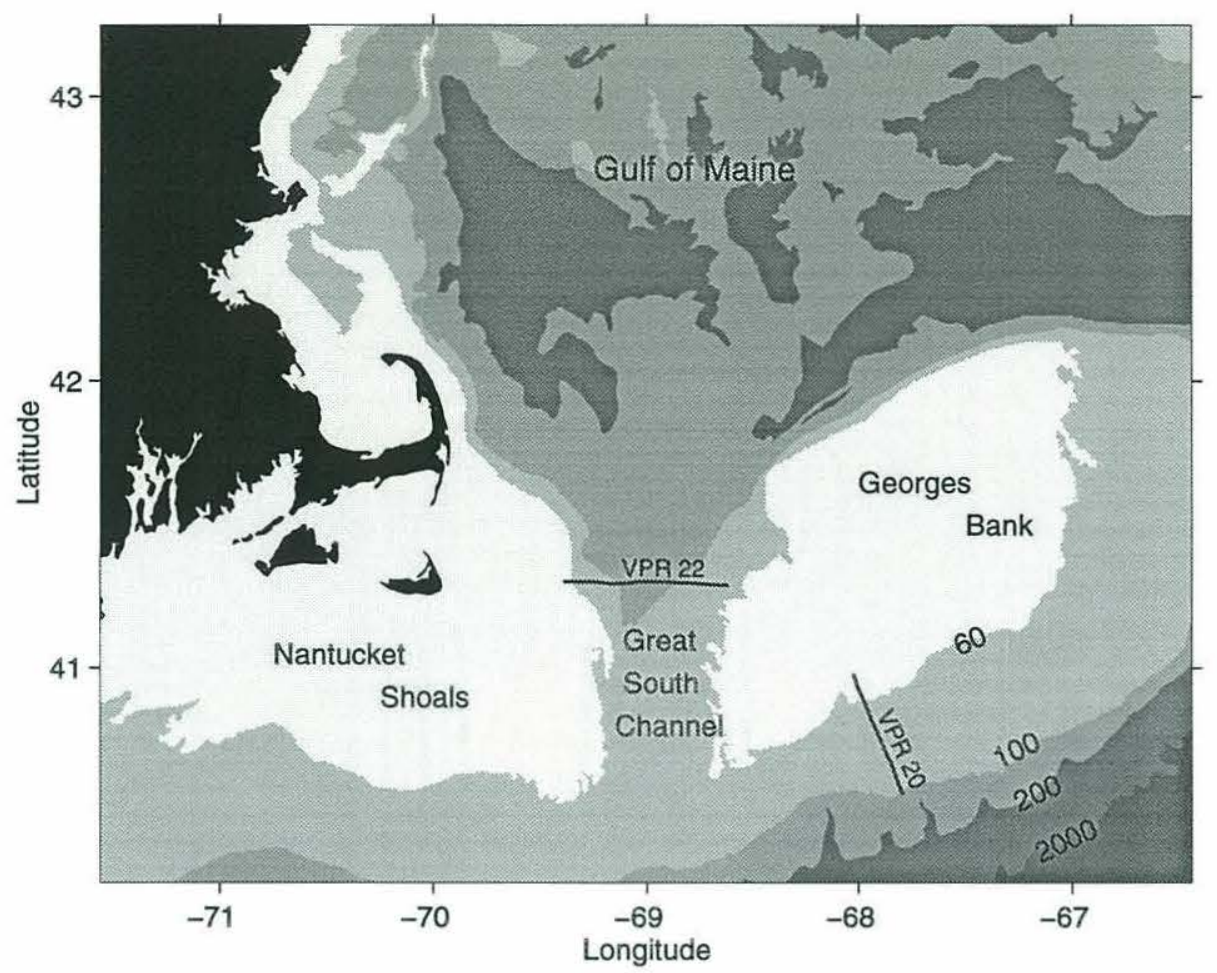

Figure 3.1: Overview of the research area with transects VPR 22 and VPR 20 marked.

extended westward $62 \mathrm{~km}$ from a starting point at $41^{\circ} 17.3^{\prime} \mathrm{N}, 68^{\circ} 36.80^{\prime} \mathrm{W}$. Bottom depth ranged from about $50 \mathrm{~m}$ on either side of the channel to $>150 \mathrm{~m}$ in the center.

The transect was made at the intersection of four distinct hydrographic regions: the Gulf of Maine, Georges Bank, Nantucket Shoals, and the outer continental shelf and slope. During late spring, the deep western Gulf of Maine is essentially a threelayer system, in which relatively fresh and warm Maine Surface Water overlies the cold Maine Intermediate Water, which itself overlies the warmer but more saline Maine Bottom Water (Hopkins and Garfield, 1979; Flagg, 1987). In contrast, water over the shallower cap of Georges Bank and over Nantucket Shoals tends to be locally well mixed by strong tidal currents (Hopkins and Garfield, 1981; Limeburner and Beardsley, 1982). In the late spring, a plume of relatively fresh water thought to originate in spring runoff from the Penobscot, Kennebec, Androscoggin and Merrimac Rivers is found off Cape Cod over the western flank of the northern GSC (Chen et al., 
1995; Limeburner and Beardsley, 1982); the runoff water is thought to travel along the northwestern rim of the Gulf of Maine as a buoyant plume, partially mixing with the surrounding water and reaching the northern GSC by mid-May. South of the transect we describe lies a region of relatively well-mixed water covering the sill of the GSC, and south of that a stratified region that marks the boundary between the continentalshelf water characteristic of the south flank of Georges Bank and water characteristic of the continental slope. The hydrography of the region as a whole is described by Flagg (1987) and Butman and Beardsley (1987). The northern GSC was studied in some detail during the South Channel Ocean Productivity Experiment (SCOPEX) (Kenney and Wishner, 1995; Wishner et al., 1988; Limeburner and Beardsley, 1989; Chen et al., 1995a,b; Durbin et al., 1995a,b,c); the transect we describe here was made in the southernmost region of the SCOPEX study area.

\subsection{Sampling Techniques}

\subsubsection{The Video Plankton Recorder (VPR)}

The VPR is a towed underwater video microscope with four concentric fields of view (FOV) (a full description of the VPR system is given in Davis et al., 1992a,b). For this particular cruise, the FOV and imaged volumes (iv) were set to the follow-

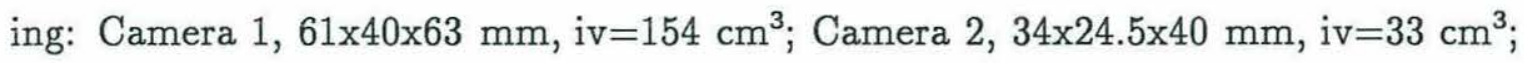
Camera 3, 12x9x20 mm, iv $=2.0 \mathrm{~cm}^{3}$; and Camera $4,6 \times 4.5 \times 23 \mathrm{~mm}$, iv $=0.62 \mathrm{~cm}^{3}$ (Figure 3.2). The unobtrusive nature of the VPR allows for non-invasive sampling of fragile plankton forms and organisms which may otherwise avoid the sampling gear (Davis et. al., 1992a,b). The collimated output from an $80 \mathrm{~W}$ xenon red filtered strobe was synchronized with the video cameras to provide a short ( $1 \mu \mathrm{sec})$ light pulse which was directed at an oblique angle to the cameras. Video data from each 

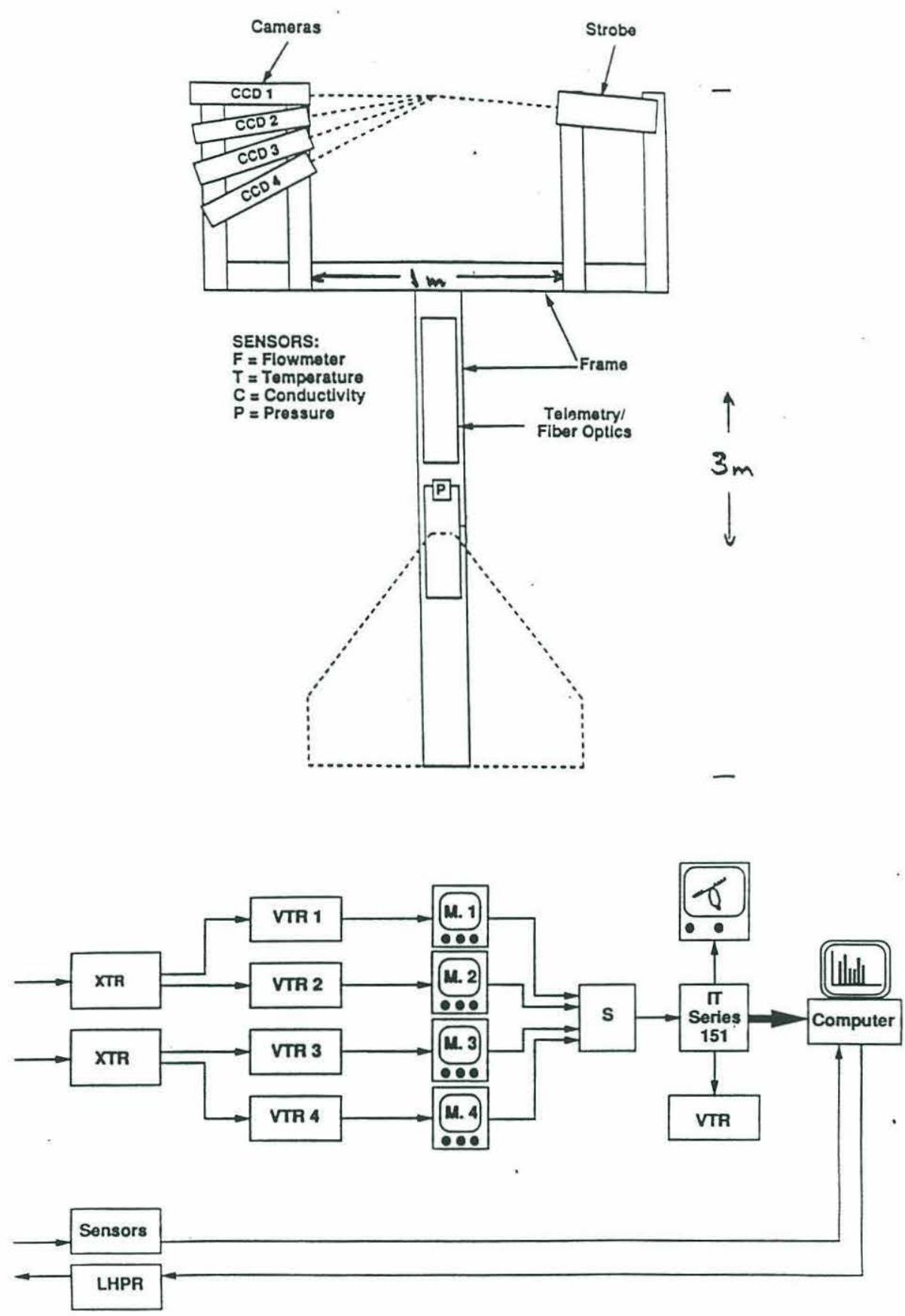

Figure 3.2: Schematic diagram of the Video Plankton Recorder (VPR) showing layout of the major underwater (top) and shipboard (bottom) components. Four CCD cameras, each having a different magnification, and the strobe are held on side-arm mounts $1 \mathrm{~m}$ apart. Video is transmitted to the surface via fiber-optic link. Serial communications are provided for CTD, transmissometer and fluorometer. On the surface, video from fiber optic cable is de-multiplexed, displayed, and recorded on SONY Betacam recorders. Although images were classified by hand in this study, a single channel may now be directed to a real-time image processor for focus detection and taxonomic identification of the plankton. 
of the four cameras was transmitted to the surface via fiber-optic cable at $60 \mathrm{~Hz}$ and recorded, along with time-code overlay, on high-resolution SONY Betacam SP recorders.

Temperature, salinity and pressure data were taken by Seabird sensors mounted on the VPR in flow directly behind the imaged volumes (Figure 3.2 ). Data were obtained at $10 \mathrm{~Hz}$ and averaged over four-second intervals before being transmitted to the surface. An estimate of the relative uncertainty or noise of the CTD sensors was made following deployment of the VPR at a constant depth $(4 \mathrm{~m})$ for $10 \mathrm{~min}$ in a well-mixed region of the Bank. The resulting standard deviations are \pm 0.046 for temperature, $\pm 0.017 \mathrm{psu}$ for salinity, and \pm 0.018 for $\sigma_{t}$. Unfortunately, the Seatech fluorometer and transmissometer normally mounted on the VPR were lost during a storm two days before this transect was made.

During transect VPR 22, the VPR was tow-yoed from the air/sea interface to within $10 \mathrm{~m}$ of the bottom except in the central portion of the transect, where it was lowered to about $92 \mathrm{~m}$. While the ship steamed in a westward direction at $\approx 2 \mathrm{~m} / \mathrm{s}$ (4 kts), tow-yos were produced by winching the cable in and out at a rate of about 0.2 $\mathrm{m} / \mathrm{s}$. The result was 37 saw-tooth tow-yo legs or 74 vertical profiles over a horizontal distance of $62 \mathrm{~km}$. At a sampling rate of $60 \mathrm{~Hz}$, Camera $2 \mathrm{FOV}$ provided nearly contiguous imaged volumes, while Camera 4 FOV provided non-overlapping imaged volumes at intervals of about $4 \mathrm{~cm}$.

\subsubsection{Data Processing}

Videotapes from two cameras (Cameras 2 and 4) were processed manually field-by-field. The operator scanned slowly ( 5 fields per second, fps) while looking for in-focus images of plankton. When a target was encountered, the time code and the taxonomic description for the sighting were entered into a database. In addition, size 
estimates (length and width) for a few taxonomic groups were recorded from Camera 4 images. The eight-hour transect required about 80 hours of video processing for each camera. (Processing of VPR images has recently been automated for near real-time analysis of taxonomic information.) Upon completion of the video database, Matlab m-files were developed to time-match each plankton sighting with the time in the CTD record and assign a depth, salinity, and temperature to each image. Accuracy of assigning depth and other variables using this procedure was estimated to be within $\pm 0.35 \mathrm{~m}$. Sources of error include offset between clocks in the video time code generator and CTD instruments $( \pm 0.25 \mathrm{~m})$ and error due to linear interpolation between CTD data points $( \pm 0.1 \mathrm{~m})$. Sightings of plankton, along with their assigned physical variables, were sorted to the following 12 major taxonomic groups: copepods (Calanus finmarchicus, Pseudocalanus sp., other copepods); pteropods ( $L i$ macina retroversa, Clione); Echinoderms (ophiopluteus larvae, metamorphosing juveniles); Hydrozoans (Obelia sp.); Ctenophores (Pleurobranchia sp.); Chaetognaths (Sagitta sp.); Larvaceans (Oikopleura sp.); diatoms (Chaetocerous socialis).

Coarse-scale visualization of the biological and physical data on identical spatial scales along the transect required some further processing. Both taxomonic and hydrographic data were interpolated to a regular grid of 300-s x 1-m ( $\approx 600$-m horizontal by $1-\mathrm{m}$ vertical) cells using software tools included in the GMT package (Wessel and Smith, 1991) and custom Matlab m-files. Plankton abundance was calculated as the number of individuals of a given taxon observed within each 1-m depth bin divided by the total volume sampled in that bin. For example, if 10 copepods were observed in Camera 4 as the VPR traversed a single 1-m depth bin, the abundance of copepods per liter for that bin would be $10 /[(0.0006)(60) t]$, where $t$ is the time in seconds between when the VPR entered and exited that particular depth bin. Plots of the uniformly gridded cells were completed in Matlab. 
To visualize the temperature $(\mathrm{T})$ and salinity $(\mathrm{S})$ in the physical environment of individual plankton within each taxon, and to create what have been called temperature-salinity-plankton (T-S-P) Plots (e.g. Michel and Foyo, 1976), T and S values associated with each plankton sighting were binned into cells at intervals of $0.05^{\circ} \mathrm{C}$ by $0.02 \mathrm{psu}$ (practical salinity units), respectively. The normalized plankton abundance was calculated by dividing the sum of the number of plankton of a given taxon in each cell by the total number of individuals of that taxon across the entire transect. To make a T-S-P plot, contour plots of normalized plankton abundance were made directly on a T-S grid. Contours were selected such that they encompassed $90 \%$ of the plankton in a given taxon.

To evaluate plankton distributions at the micro-scale, estimates of plankton patchiness were made independently of total plankton abundance using a pointprocess technique similar to that described by Davis et al. (1992b). The length of the transect within each $600 \times 1$-m grid cell traversed by the VPR was about $10 \mathrm{~m}$.

Along this transect, the number of plankton of each taxonomic group less than $1 \mathrm{~m}$ from each individual was calculated. The mean number of plankton within $1 \mathrm{~m}$ was then compared to a calculated expected mean number, assuming a random distribution of organisms along the VPR transect through that grid cell. The ratio of the observed to calculated mean number of plankton provided a patchiness index (PI) with values equal to one, greater than one, or less than one indicating random, aggregated, or uniform distributions, respectively. To determine when aggregated or uniform distributions were significantly different from random, 100 Monte Carlo simulations of randomly distributed plankton were produced within each grid cell and compared with the observed distributions. Values for PI along with the $95 \%$ confidence interval (two-tailed test) were plotted in a frequency histogram for each taxonomic group for which sufficient observations were available. To evaluate the relationship between plankton aggregation and physical gradients, those organisms 
that were significantly aggregated were plotted against the vertical gradient over 1 $\mathrm{m}$ in temperature, salinity, and $\sigma_{t}$ in which they were observed. Although the same approach could be used at smaller spatial scales if a sufficient number of observations were available, we use PI to describe patchiness at only the 1-m spatial scale here.

\subsubsection{Richardson Numbers}

A key factor in the formation of plankton patches is hypothesized to be the interaction between plankton swimming abilities and the dispersive forces of physical mixing (e.g., Davis et al., 1991). As an index of water-column stability, gradient Richardson numbers ( $\mathrm{Ri}$ ) were calculated for each grid cell using data on the potential density gradient and shear magnitude according to the definition:

$$
\mathrm{Ri}=\frac{-\frac{\mathrm{g}}{\rho} \frac{\partial \rho}{\partial z}}{\left(\frac{\partial u}{\partial z}\right)^{2}}
$$

where the numerator is an index of static density stability and the denominator is proportional to the turbulent kinetic energy production from vertical shear (Nuemann and Pierson, 1966). Rileq0.25 indicates that the water is susceptible to vertical mixing due to shear instability. Data from the onboard $150-\mathrm{kHz}$ Acoustic Doppler Current Profiler (ADCP) was averaged over 300-s horizontal intervals and 4-m verti-

cal intervals. Vertical shear $\left(\frac{\partial u}{\partial z}\right)$ was calculated by subtracting the velocity vectors in vertically adjacent bins and dividing by the distance between bin centers. Gradients in density $\left(\frac{\partial \rho}{\partial z}\right)$ were calculated from gridded density data smoothed by an eight-meter vertical running average. To enable direct comparison, plots of $\mathrm{Ri}$ were generated for the same grid cells as the biological and physical data. 


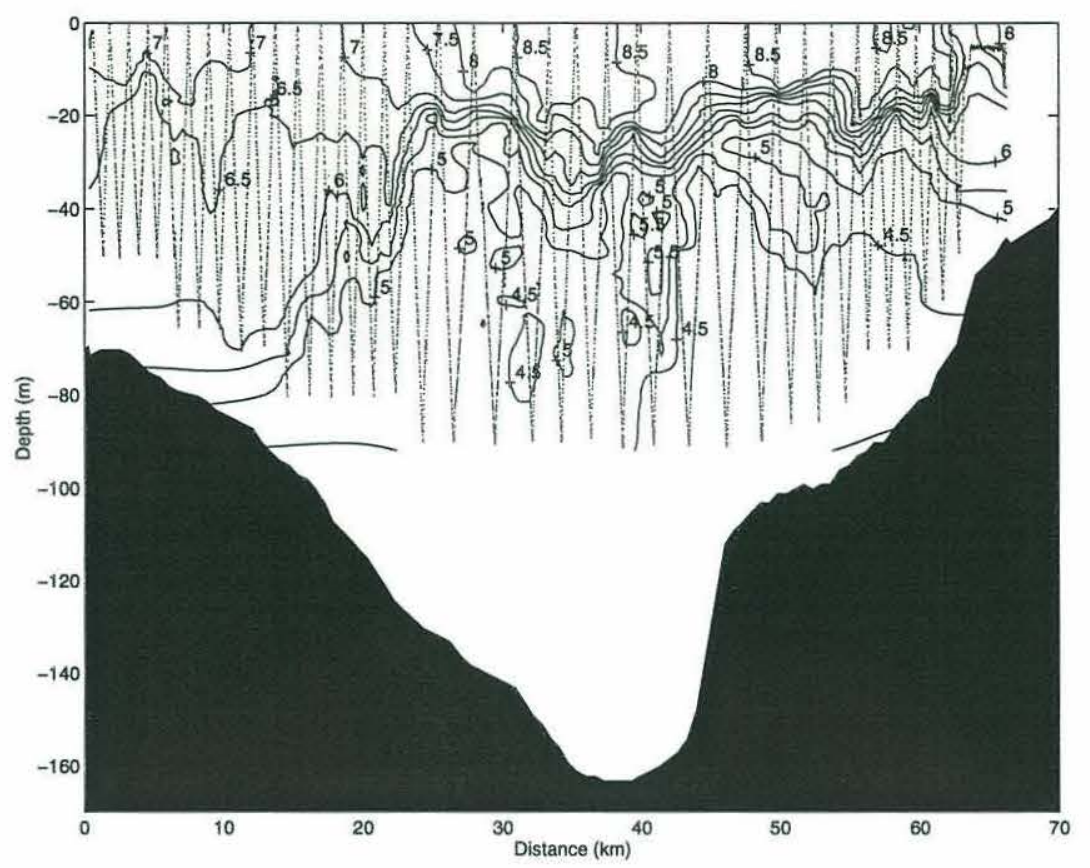

Figure 3.3: Part A. Temperature (C) contours across Great South Channel on 27-28 May, 1992. View is looking south, so that east-to-west is left-to-right. Each dot along the tow-yo path indicates 4 seconds of data.

\subsection{Results}

\subsubsection{General Hydrography}

The eastern end of transect VPR 22 lay in 70-m depth over the western flank of Georges Bank. Here the water was slightly stratified, primarily in temperature (Figure 3.3). Moving westward, a sharp horizontal temperature and density gradient, originating at the bottom, appeared about $15 \mathrm{~km}$ along the transect. A surface temperature and density front appeared about five $\mathrm{km}$ further along and joined the bottom-originating front four $\mathrm{km}$ later at about $20-\mathrm{m}$ depth. This junction formed a pycnocline that continued throughout the rest of the section. The meeting of surfaceand bottom-originating isopycnals is a typical signature of a tidal-mixing front (a front formed between a deeper stratified region and a shallower region where tidal 


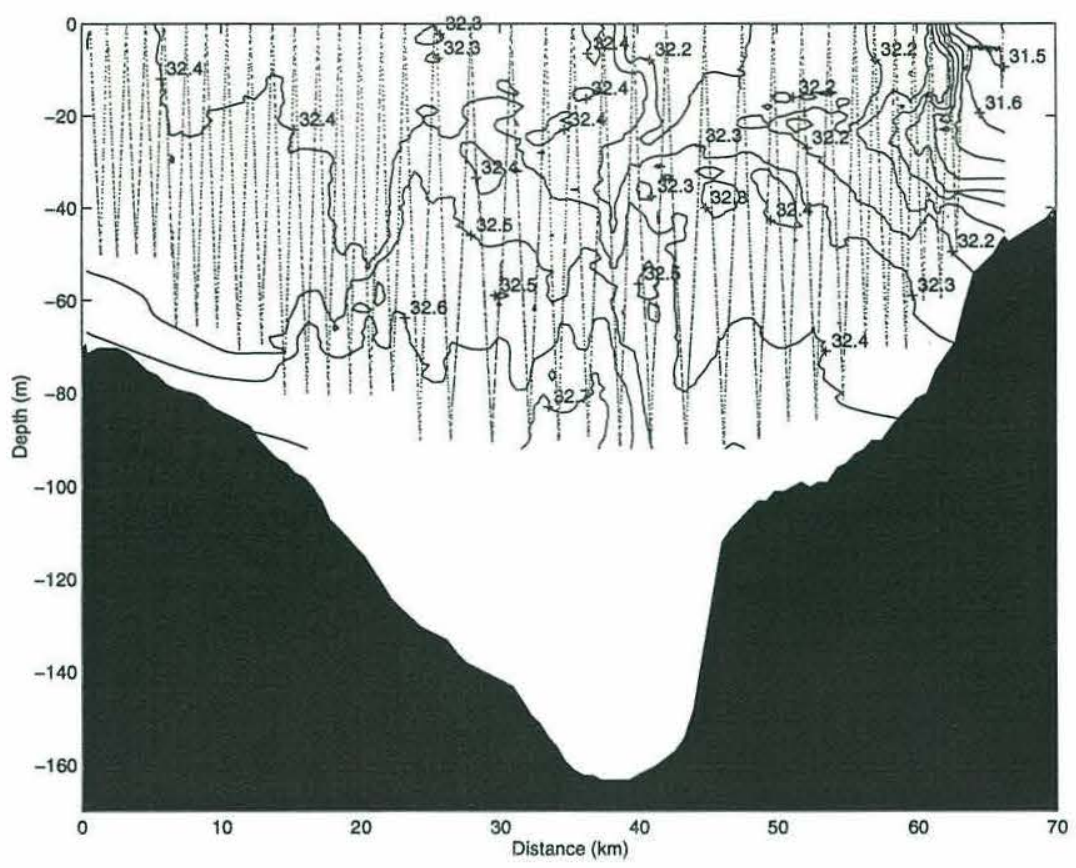

Figure 3.3 continued: Part B. Salinity (psu) contours across Great South Channel on 27-28 May 1992.

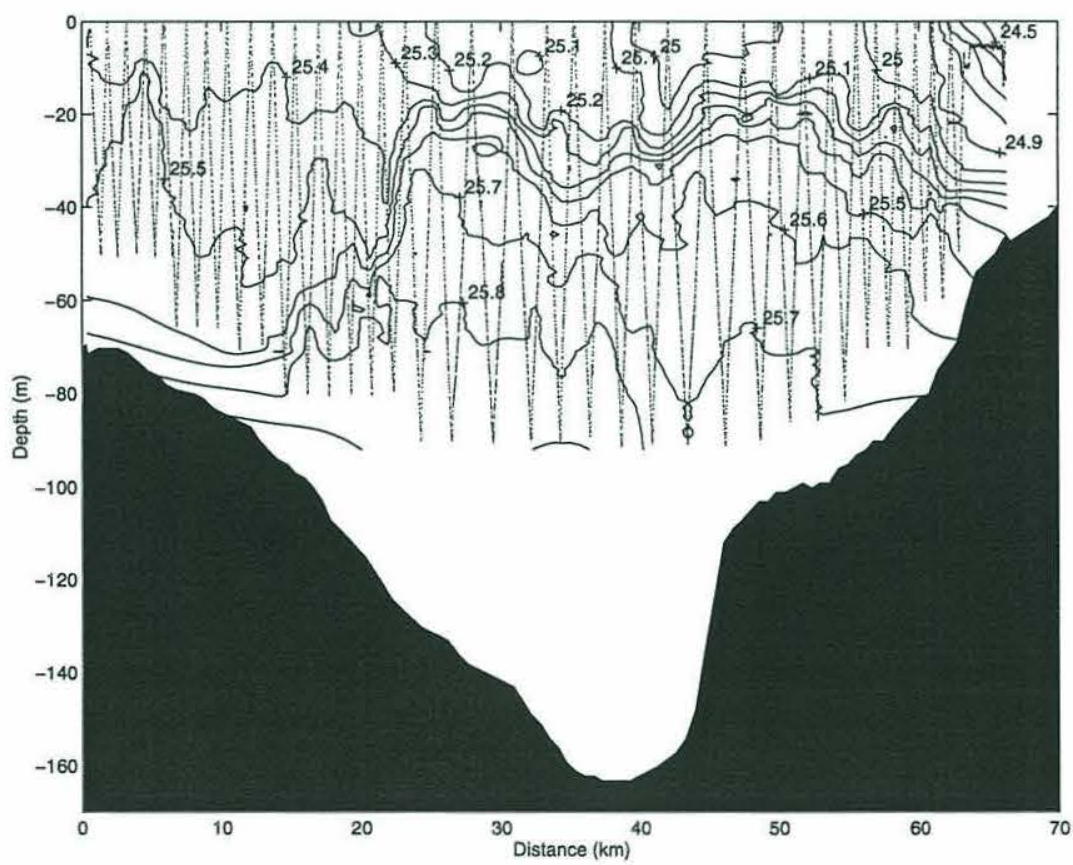

Figure 3.3 continued: Part C. Density $\left(\sigma_{t}\right)$ contours across Great South Channel on 27-28 May 1992. 
currents are sufficiently strong to mix the entire water column). In addition, the appearance of the surface front marked the first location in the transect where $\sigma_{t}$ varied by more than 0.5 in the upper $40 \mathrm{~m}$; a $\Delta \sigma_{t}$ of less than 0.5 in the upper $40 \mathrm{~m}$ is the criterion used by Garrett et al. (1978) in deciding whether to consider a region tidally well mixed. As we show below, however, a number of distinct water types, having discernible vertical structure, were found in the region to the east of this front, and so we do not believe the front to be a simple tidal-mixing front.

The bottom-originating portion of the front coincided with the appearance of the densest water observed in the transect $\left(\sigma_{t} \geq 25.8\right)$. This body of dense water extends westward at least $25 \mathrm{~km}$. (The dense water may extend further at depth, but we have information for only the top $92 \mathrm{~m}$, the maximum depth sampled by the VPR.) At depths generally above this dense water, but below the pycnocline, the temperature field was not smooth: there occurred a number of intrusions of water that were either cooler $\left(\mathrm{T}<4.5^{\circ} \mathrm{C}\right)$ or warmer $\left(\mathrm{T}>5^{\circ} \mathrm{C}\right)$ than the surrounding water. At the surface, regions of warm $\left(\mathrm{T}>8.5^{\circ} \mathrm{C}\right)$ water alternated with regions of slightly cooler but fresher, and hence less dense, water. This surface pattern extended from the surface temperature front nearly to the western end of the transect.

Between about 38 and $60 \mathrm{~km}$ along the transect lay a large body of cold ( $\mathrm{T} \leq$ $4.5^{C}$ ) water extending from at least $92-\mathrm{m}$ depth to as shallow as about $30 \mathrm{~m}$. This cold water was considerably fresher and less dense than the body of dense water immediately to its east. The body of cold water extended westward about $20 \mathrm{~km}$, until the bottom depth was about $60 \mathrm{~m}$. Above this cold water and below the surface water, the water became fresher toward the west, eventually reaching salinities as low as 31.7 psu. Near the end of the transect, these lower salinities were visible at the surface in a sharp surface salinity front. 


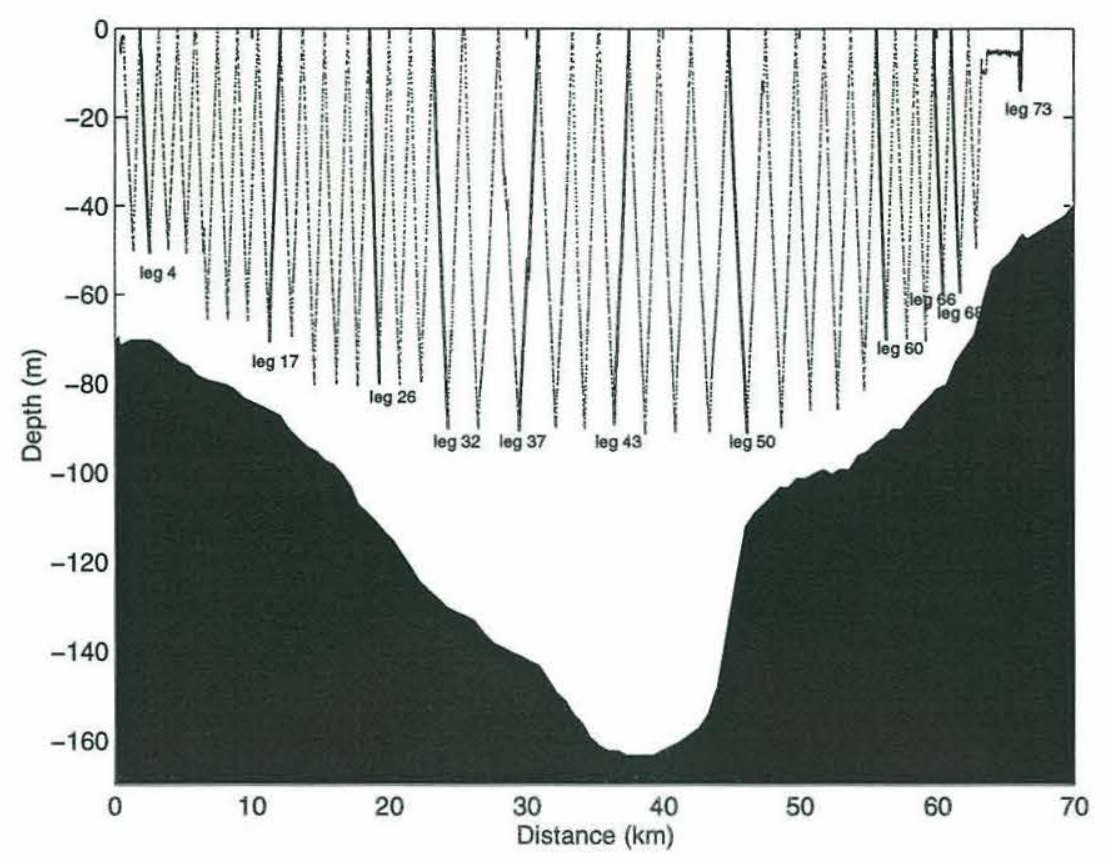

Figure 3.4: Tow-Yo track (dotted line) of the VPR across the Great South Channel with characteristic vertical legs (solid lines) indexed by leg number.

\subsubsection{T-S and Water-Type Analysis}

The short horizontal distances between vertical legs permitted an unusually detailed hydrographic analysis of the section. In our initial T-S analysis, we treated each of the transect's 74 vertical legs separately. To prevent our analysis from being biased by the varying amounts of time the VPR spent at different depths, we first projected the individual temperature and salinity data points for each vertical leg onto regularly-spaced depth intervals $(2 \mathrm{~m})$ using a sum of cubic splines calculated to fit the data optimally in a least-squares sense. In order to identify water types that were common to many legs, T-S diagrams were plotted for each leg and compared. The locations of representative legs along the transect are shown in Figure 3.4, and their T-S properties are given in Figure 3.5.

T-S data from all legs were compared in order to identify the clustering of T-S points that characterizes water masses. Properties of the water masses we have 


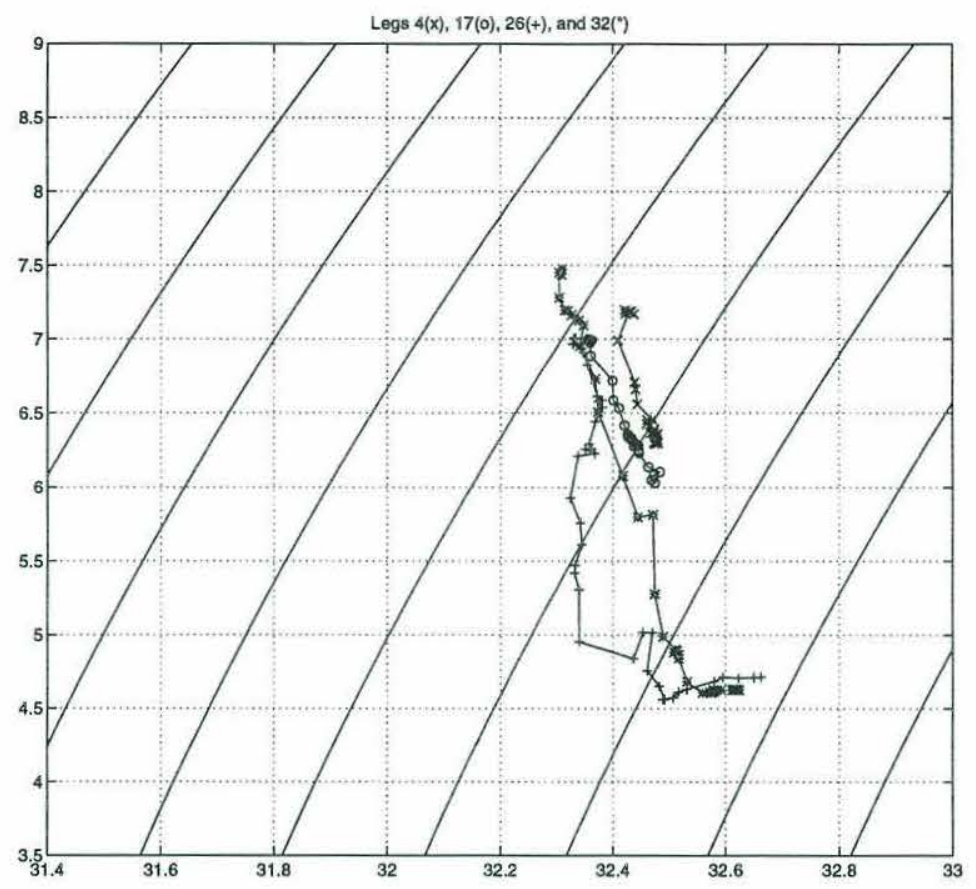

Figure 3.5: Part A. Temperature-salinity plots for representative legs shown in Figure 3.4. Legs $4,17,26$, and 32 are shown here.

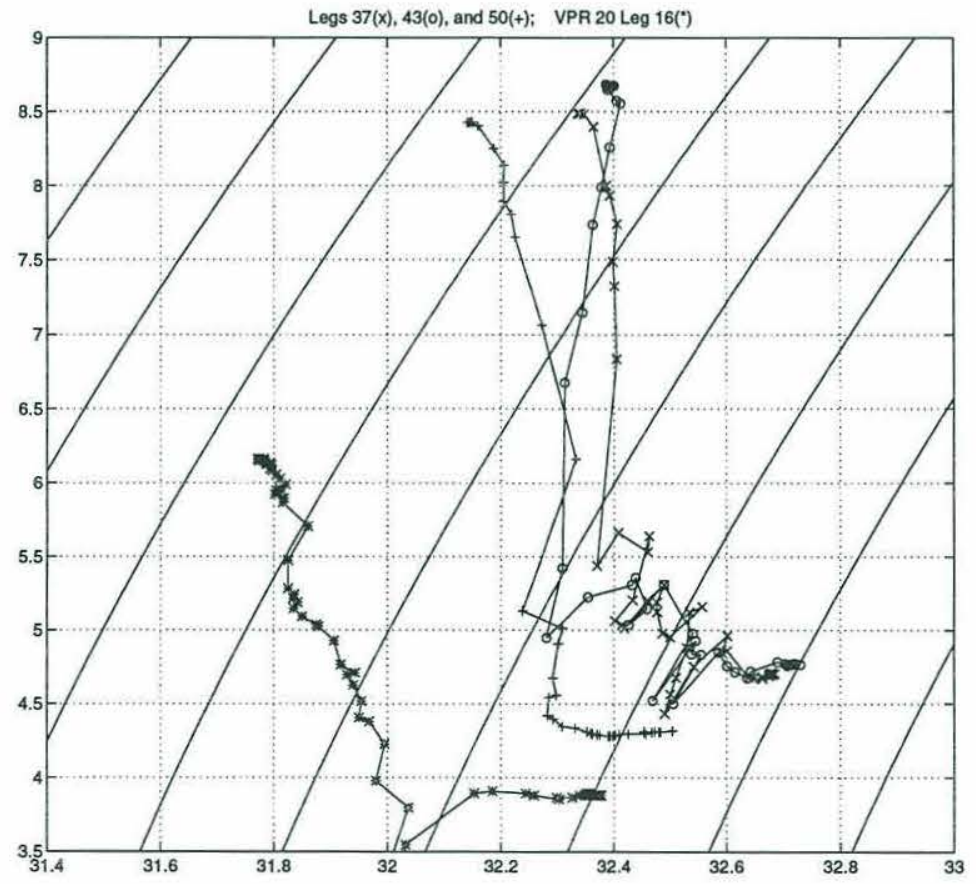

Figure 3.5 continued: Part B. Temperature-salinity plots for representative legs shown in Figure 3.4. Legs 37, 43, and 50 from VPR 22 and leg 16 from VPR 20 are shown here. 


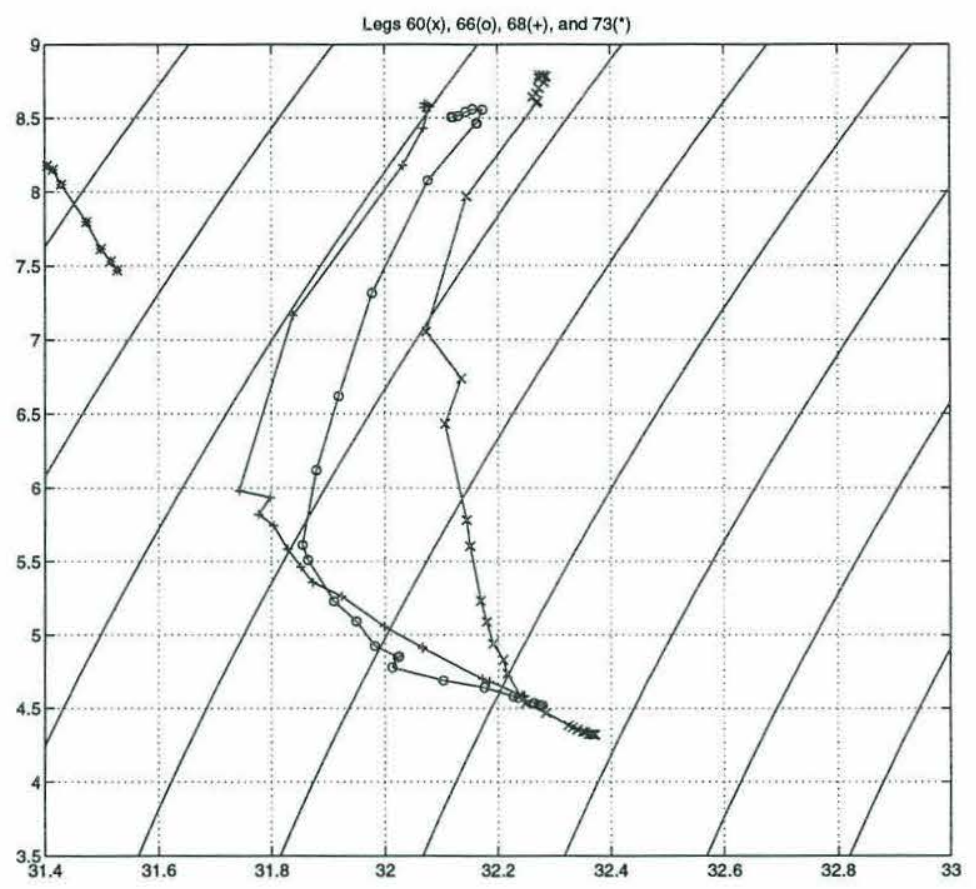

Figure 3.5 continued: Part C. Temperature-salinity plots for representative legs shown in Figure 3.4. Legs 60, 66, 68 and 73 are shown here.

identified are shown in Figure 3.6. Water masses were identified by finding locations on the T-S plot where many data points from a number of vertical legs clustered. In Figure 3.6, outlines of water-mass properties were in general drawn to include only those T-S points whose existence could not be explained by mixing between two (or several) identified water types. Using this composite T-S diagram, along with the T and S data for each vertical leg, we have created by hand a complete picture of the various water types encountered along the transect (Figure 3.7).

Some of the water types we have identified correspond to water types that are usually found in the GSC during the spring and summer. Others are probably quite transient, and may have existed in the GSC for only a relatively short period. Indeed, because the transect took a significant fraction of a tidal cycle to complete, and because tidal velocities are so high in the GSC, it is certain that Figure 3.7 does not represent a "snapshot" of the water types found at any one time in the GSC. 


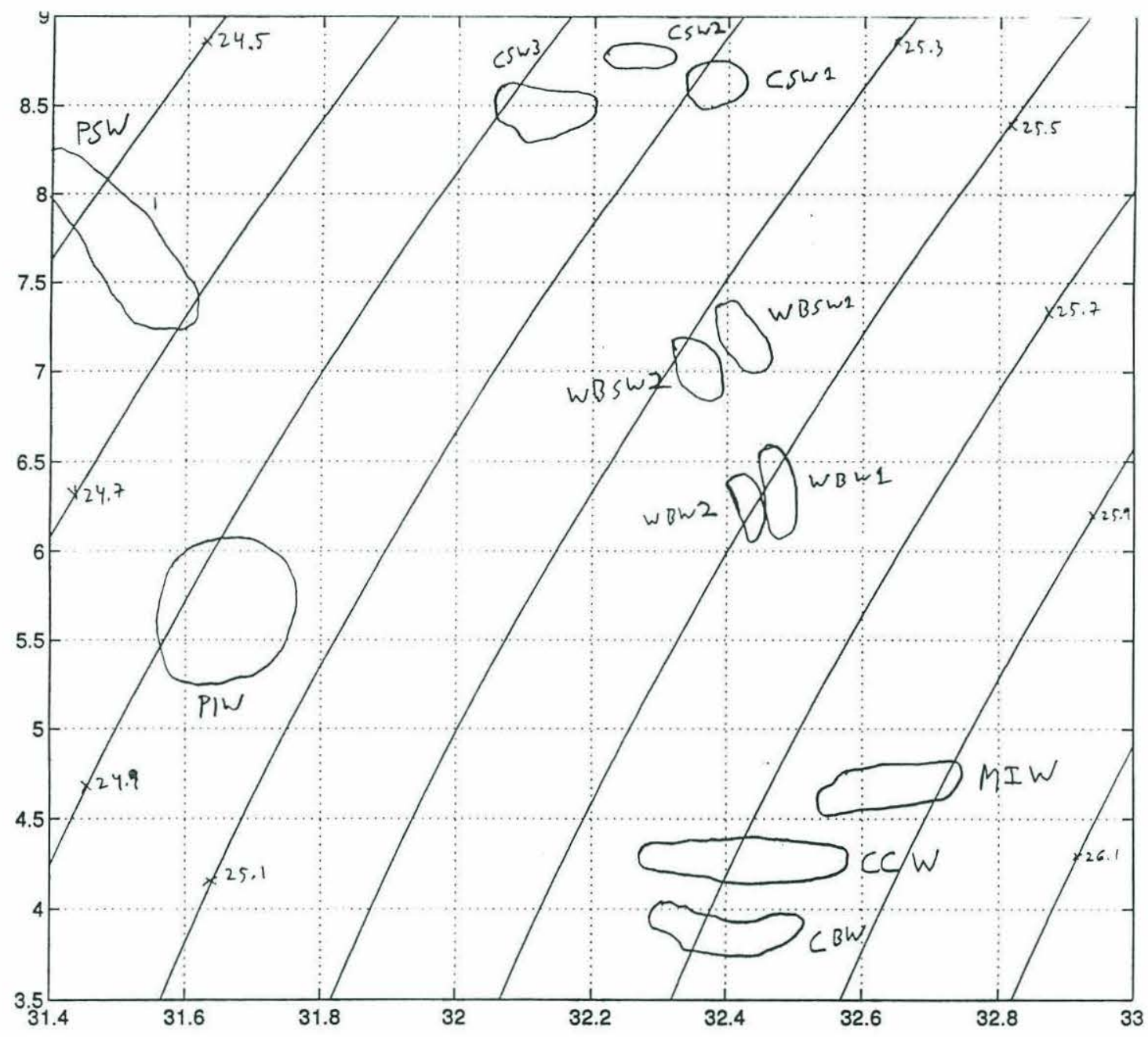

Figure 3.6: Identification of water masses based on T-S data from all 74 legs of transect VPR 22 across the Great South Channel. Outlines of water masses were drawn by hand. MIW: Maine Intermediate Water; SW: Surface Water; CCW: Cold Coastal Water; CBW: Cold Band Water; WBW1: Western Bank Water 1; WBSW1: Western Bank Surface Water 1; WBW2: Western Bank Water 2; WBSW2: Western Bank Surface Water 2; CSW1,2,3: Channel Surface Water 1,2,3; PSW: Plume Surface Water; PIW: Plume Intermediate Water. 


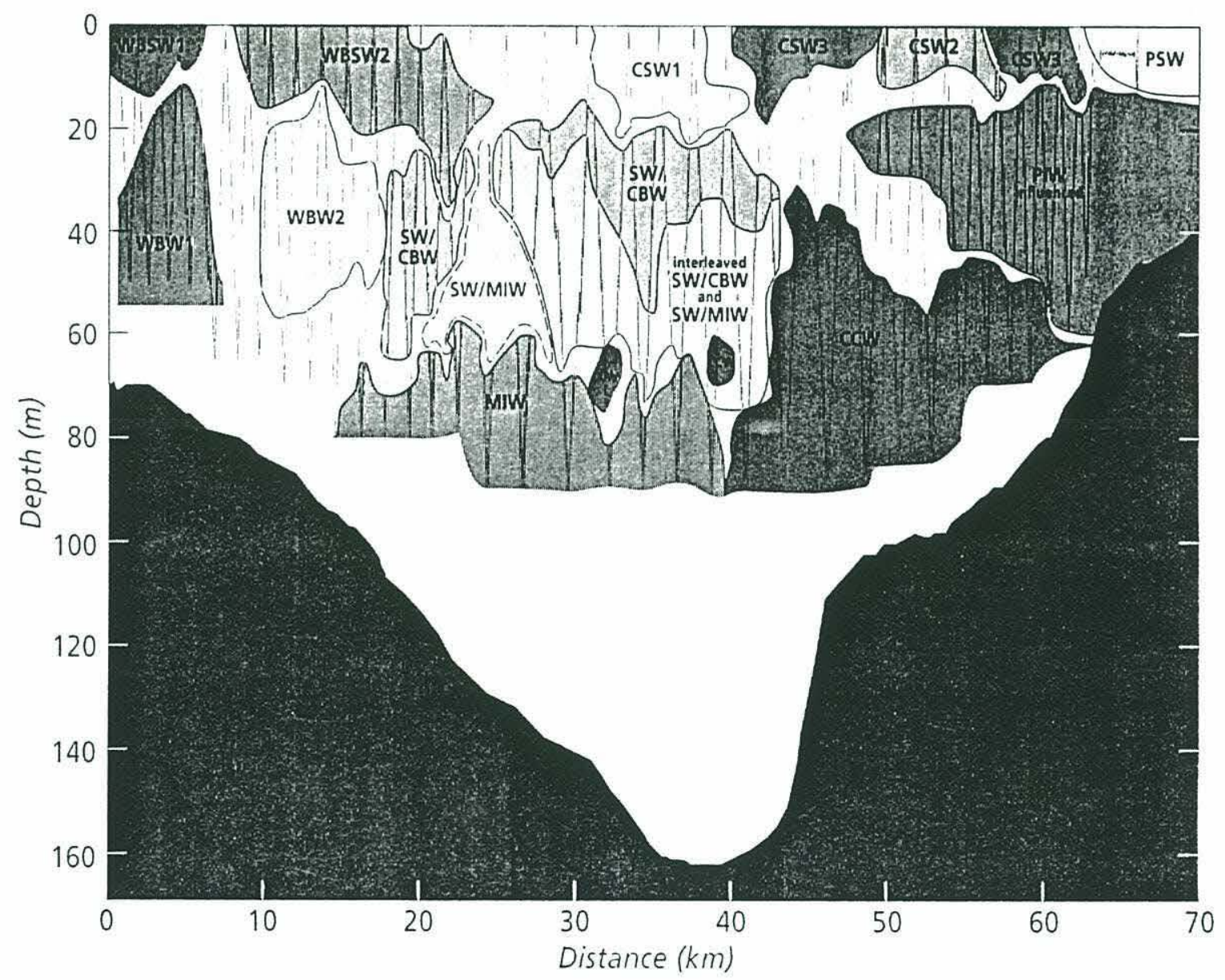

Figure 3.7: Composite diagram of the vertical and horizontal distribution of water masses across the GSC based on T-S properties of identified water masses. All codes are as given in Figure 3.6. 
Nevertheless, this figure gives a portrait of the water types that were present when and where the VPR was towed on this transect, and as such it is directly comparable with the biology observed at the same times and places. Characterizing distinct, distinguishable water types that were observed thus provides one way to correlate the physical and biological properties of the observed water.

The densest water in the section was the Maine Intermediate Water (MIW)(Figures 3.6 and 3.7). It occurred at depths below about $60 \mathrm{~m}$ between 15 and $40 \mathrm{~km}$ along the transect. Having a density generally above $25.8 \sigma_{t}$ units, the MIW shown here had salinities between about 32.5 and 32.75 psu and temperatures between about 4.5 and $4.8^{\circ} \mathrm{C}$. Above the MIW was a cone-shaped mass of water whose T-S properties suggest that it was formed by mixing between MIW and the overlying water. The VPR did not sample deep enough to encounter the Maine Bottom Water (MBW), a warmer but saltier water mass generally found below the MIW. It is also possible that this part of the GSC is too shallow to contain MBW.

The coldest water in the section $\left(\mathrm{T} \leq 4.5^{\circ} \mathrm{C}\right.$, S between about 32.3 and $32.6 \mathrm{psu}$ ), found over the western flank of the Great South Channel between 38 and $60 \mathrm{~km}$ along the transect, was similar in both position and T-S properties to cold subsurface tongues identified in May, 1976, and May, 1979, sections by Limeburner and Beardsley (1982). Chen et al. (1995) suggest that this cold tongue consists of water (perhaps originating as MIW) that has been freshened and cooled during winter along the shallow edge of the western Gulf of Maine, and which then flows southward under the developing seasonal thermocline along the coast into the northern GSC. For our purposes, we call this water Cold Coastal Water (CCW). A few intrusions of CCW were found in the central part of the section at depths of about $65 \mathrm{~m}$, just above the core of MIW.

At the far eastern end of the section (near the western edge of Georges Bank) we have identified four distinct water types, which we call Western Bank Water 1, 
Western Bank Surface Water 1, Western Bank Water 2 and Western Bank Surface Water 2 (WBW1, WBSW1, WBW2, WBSW2). Although WBW1 and WBW2 are quite similar to each other, as are WBSW1 and WBSW2, we identify them as separate water types because data points for the relevant vertical legs cluster in distinct groups on T-S diagrams (Figure 3.5a), and because the horizontal transition between these water types is very rapid (it occurs within about $2 \mathrm{~km}$ ). In both the surface water and the intermediate-depth water, the water to the east (WBW1 and WBSW1) was saltier and generally slightly warmer than the water to the west (WBW2 and WBSW2). The T-S properties of all of these water types could be produced by mixing between MIW and the surface waters found in central and western portions of this section (discussed below). This is what one might expect, since water over the western section of Georges Bank is thought to be formed by tidal mixing between MIW and surface water in the Gulf of Maine (Flagg, 1987; Hopkins and Garfield, 1981).

Surface water in the central and western portions of the section was warmer and fresher than the surface water to the east. It consisted of two parcels of warm water $\left(\mathrm{T}>8.5^{\circ} \mathrm{C}\right)$, interspersed among two parcels of slightly colder, fresher water. The easternmost parcel of warm water, which occurred in the center of the section (between about 30 and $40 \mathrm{~km}$ along transect), we call Channel Surface Water 1 (CSW1). The other parcel of warm water, which occurred between about 50 and $55 \mathrm{~km}$ along the transect, we call Channel Surface Water 2 (CSW2). The parcels of colder water, which were essentially identical to each other in their T-S properties, we call Channel Surface Water 3 (CSW3). CSW3 was found between 40 and $50 \mathrm{~km}$ and between 55 and $62 \mathrm{~km}$ along the transect.

The near-surface water at the far western end of the transect was considerably fresher ( $\mathrm{S}<31.6 \mathrm{psu}$ ) than water anywhere else in the transect. The physical location and T-S properties of this fresh water lead us to believe that it marks the southern extreme of the surface fresh-water plume that forms off of Cape Cod each spring due 
to runoff into the western Gulf of Maine, as described by Limeburner and Beardsley (1982) and Chen et al. (1995). We call this fresh water Plume Surface Water (PSW).

The fresh surface plume's influence can be seen at intermediate depths as well. Beginning at about $48 \mathrm{~km}$ along the transect, water at depths between about 15 and $50 \mathrm{~m}$ became markedly fresher than the water above or below it, growing increasingly fresh toward the west. T-S plots of the relevant vertical legs (Figure $3.5 \mathrm{C}$ ) show clear evidence of mixing with some intermediate-depth water having salinity between about 31.55 and 31.75 psu and temperature between about 5.25 and $6^{\circ} \mathrm{C}$. We have designated this water Plume Intermediate Water (PIW). The PIW itself was not directly sampled by the VPR. In Figure 3.7 we have indicated the region where T and S were influenced by mixing with PIW.

Analysis of the remaining portions of the section (the areas labeled "SW/CBW" and the area labeled "Interleaved SW/CBW and SW/MIW") is somewhat more complicated, and relies in part on biological information provided by the VPR. The areas labeled "SW/CBW" contained water that seems to be the product of mixing between the overlying surface water and some cold $\left(\mathrm{T}<5^{\circ} \mathrm{C}\right)$ water having salinity between 32.3 and 32.5 psu (Figure 3.5A). The area labeled "Interleaved SW/MIW and SW/CBW" seems to consist of layers of surface water mixed with that same cold water, interleaved with layers of surface water mixed with MIW (Figure 3.5B). Further interpretation of these results will be discussed after section 3.5.4, which describes the biological results. (For the sake of clarity, however, we note here that the initials CBW stand for Cold Band Water; we believe the source of the water in question to be in the Cold Band that flows southwestward along the south flank of Georges Bank.) 


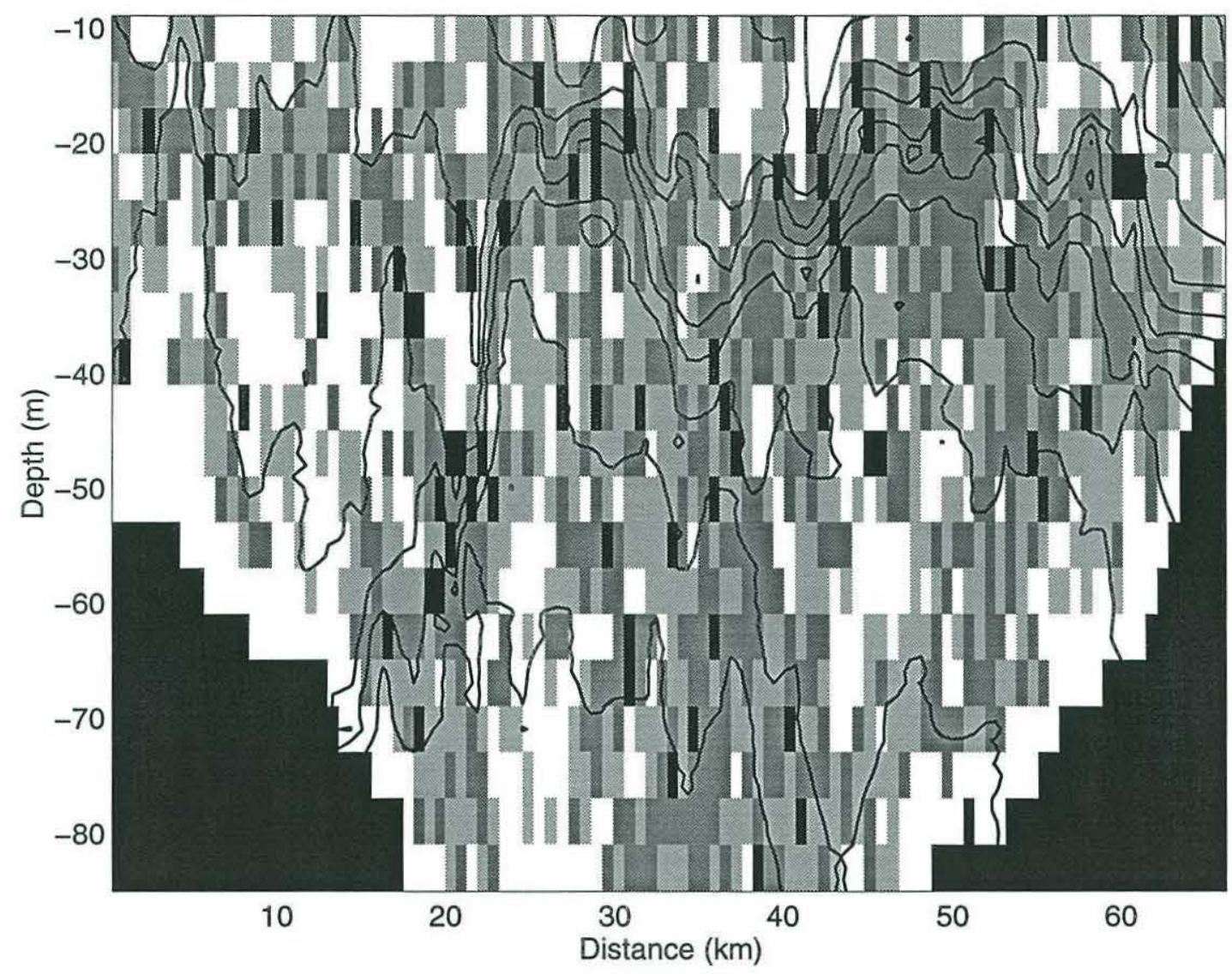

Figure 3.8: Gradient Richardson Number across the Great South Channel calculated at intervals of $4 \mathrm{~m}$ depth by $600 \mathrm{~m}$ horizontal distance. White areas indicate $\mathrm{Ri} \leq 0.25$; light gray areas indicate $.25<\mathrm{Ri} \leq 1$; dark gray areas indicate $1<\mathrm{Ri} \leq 10$; and black areas indicate bottom topography or $10<\mathrm{Ri}$. Contours of $\sigma_{t}$ are overlaid for reference.

\subsubsection{Water Column Stability}

Richardson number is plotted as a function of depth and distance across the transect in Figure 3.8. In general, regions of high Richardson number (high static stability) tended to occur in areas of strong stratification, as would be expected. Gradient Richardson number exhibited high spatial variability due to high variability in the measured values of shear. On the whole, water masses exhibited smaller values of Richardson number (i.e., reduced stability) within the body of the water mass and away from interfaces with other water masses. Closer to the boundaries between water masses, $\mathrm{Ri}$ tended to increase rapidly, suggesting greater vertical stability. This 
was true for both vertical and horizontal boundaries. (Note relatively high Ri values between MIW and CCW at about 40 meters along the transect.)

\subsubsection{Distribution and Abundance of Plankton}

Identification of plankton to major taxonomic group, and to genus in many cases, was possible from video images recorded by Camera 4 (FOV $=6 \times 4.5 \mathrm{~mm})$. Features such as the number and shape of the seta on the antenuals of Calanus finmarchicus, the number of whorls in the shells of Limacina retroversa, and the number and length of arms of echinoid ophiopluteus larvae were used to characterize individuals from the images. After some experience was gained in making plankton identifications from Camera 4, the larger FOV of Camera $2(34 \times 24.5 \mathrm{~mm})$ was used to identify plankton for estimates of abundance and distribution. Two exceptions to this were for the diatom colonies Chaetocerous socialis and for Limacina retroversa, which were too numerous at certain times to count from Camera 2. Distributions and abundances for each of the taxa will be discussed separately in order of region of occurrence and abundance.

\section{Hydrozoa (Figure 3.9A)}

Hydroid colonies and their free-swimming medusa (Obelia sp.) were strikingly confined to the well-mixed region of the bank. The western boundary of the hydroid distribution was distinctly marked by the roughly parabolically-shaped mixing front separating WBW2, MIW, and CBW. On the bank, few hydroids were found above $10 \mathrm{~m}$ where the Western Bank Surface Water masses 1 and 2 (WBSW1 and WBSW2) were identified. Maximum concentration approached 0.6/1 in the region of WBW1. 

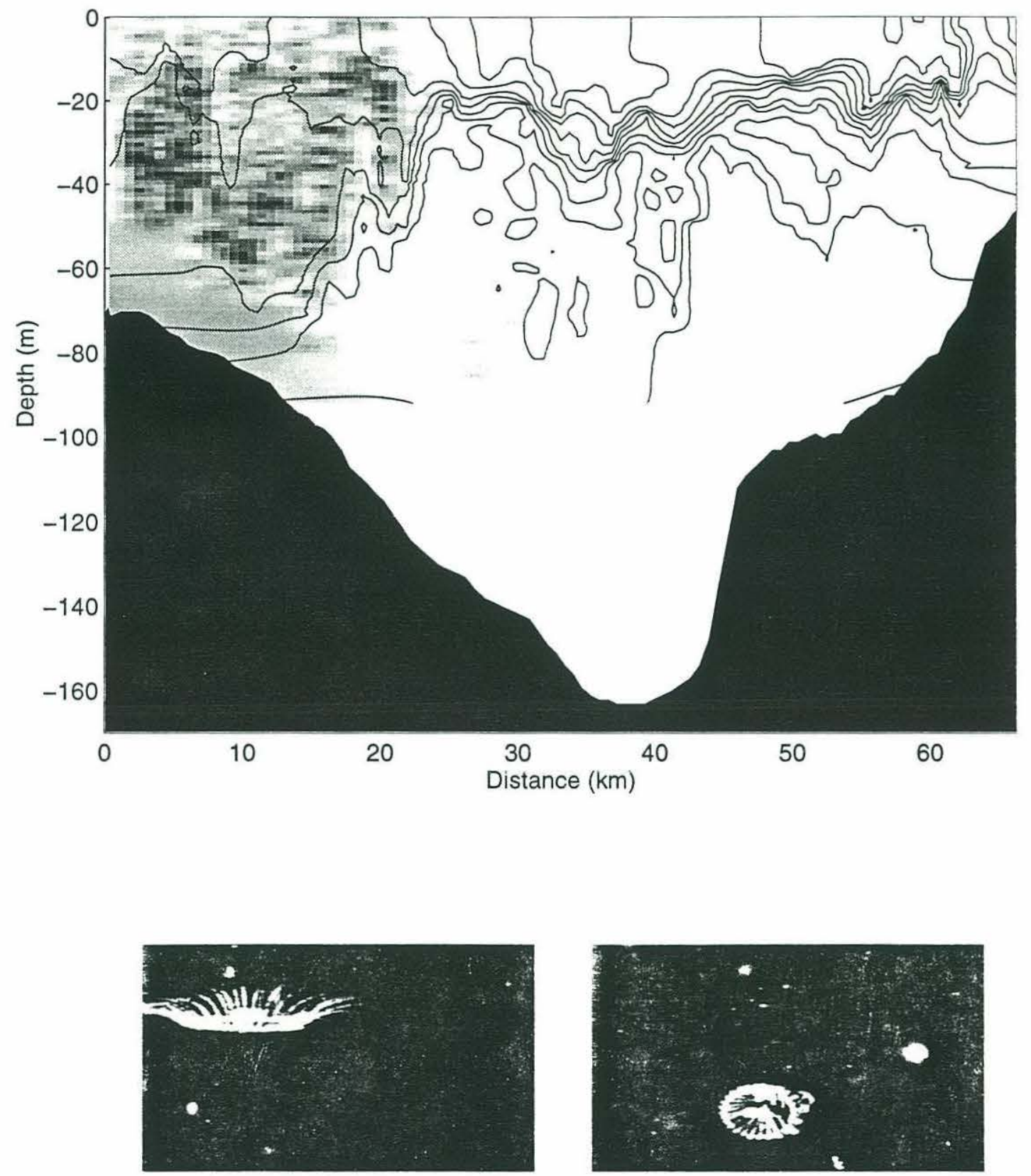

Figure 3.9: Part A. Distribution (above) and two representative images extracted from the video tapes (below) of plankton identified along transect VPR 22. For parts A, B, E, F, H, I, J, K, L, and M, data are from Camera 2 (FOV: $34 \times 24.5 \mathrm{~mm}$ ); for parts $C, D$, and $G$, data are from Camera 4 (FOV: $6 \times 4.4 \mathrm{~mm}$ ). All images are from Camera 4. Temperature contours at $0.5^{\circ} \mathrm{C}$ intervals, as in Figure 3.3A, are plotted for reference. Shown here: Hydroid medusa Obelia sp. 

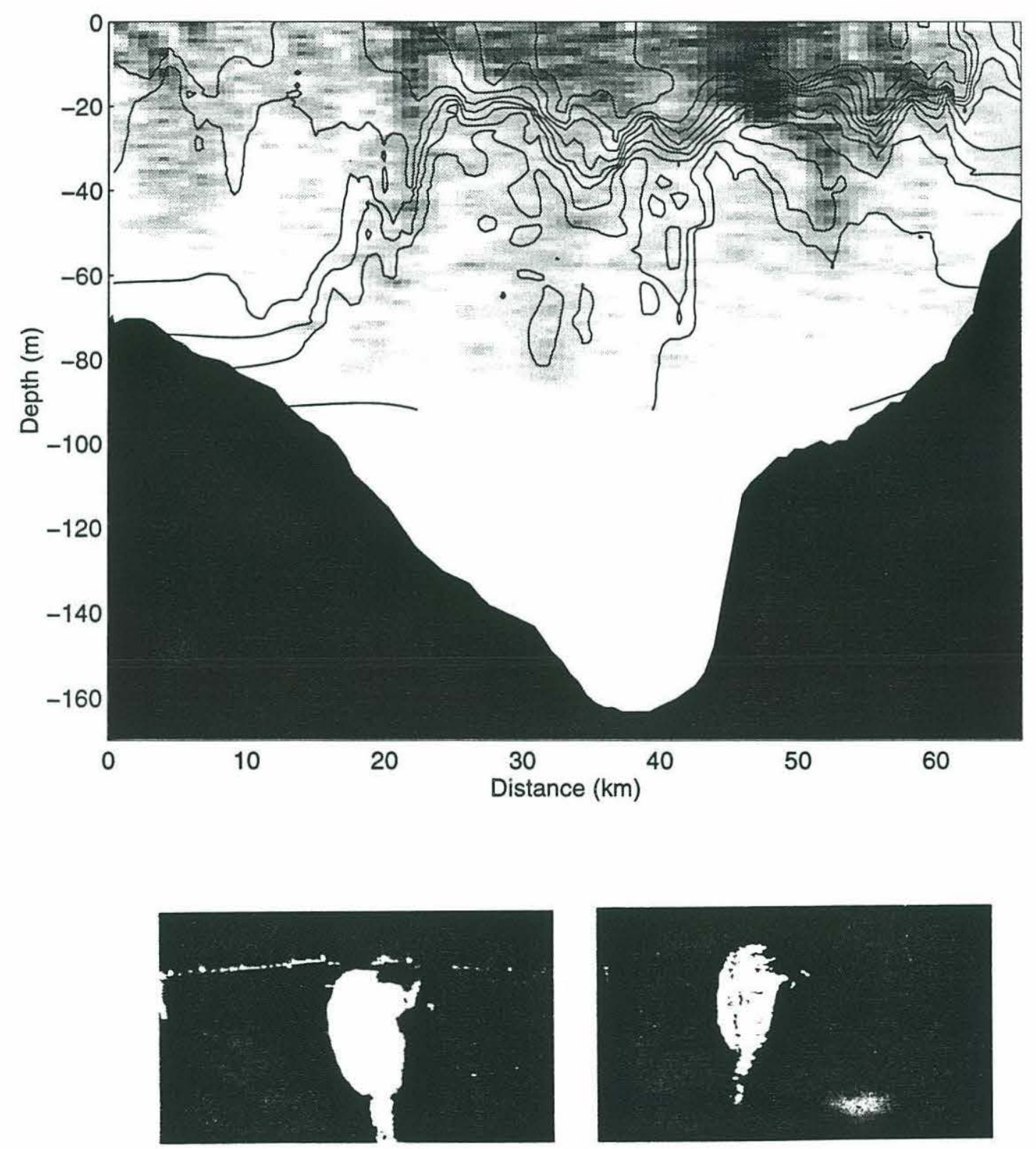

Figure 3.9 continued: Part B. Calanus finmarchicus CIV and adults. 

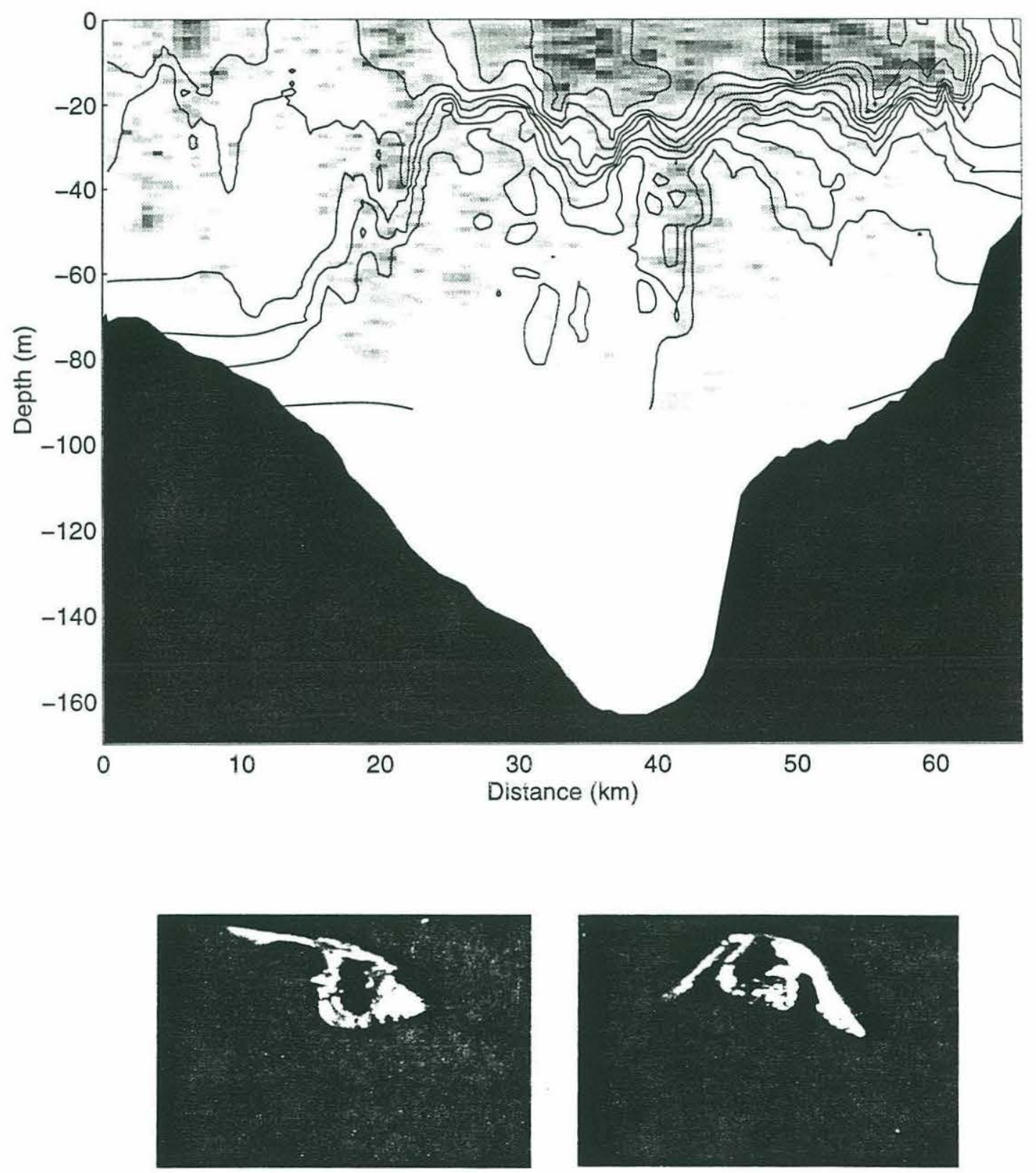

Figure 3.9 continued: Part C. Pteropod Limacina retroversa. 

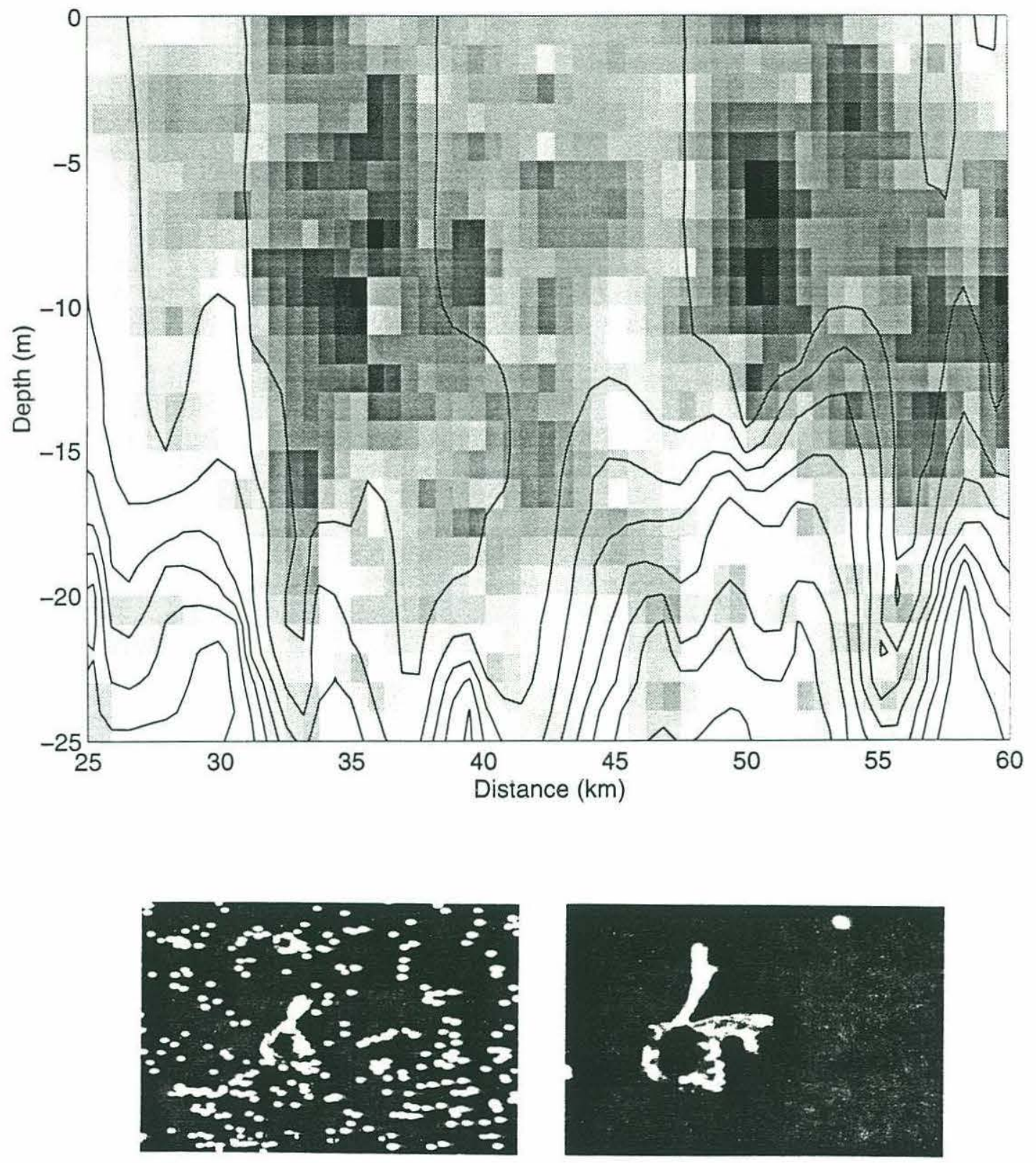

Figure 3.9 continued: Part D. Two patches of $L$. retroversa located above the thermocline plotted on an enlarged scale. Note bounding of patches by $8.5^{\circ} \mathrm{C}$ temperature contour and the cloud of veligers being released by a pteropod in the bottom left image. 

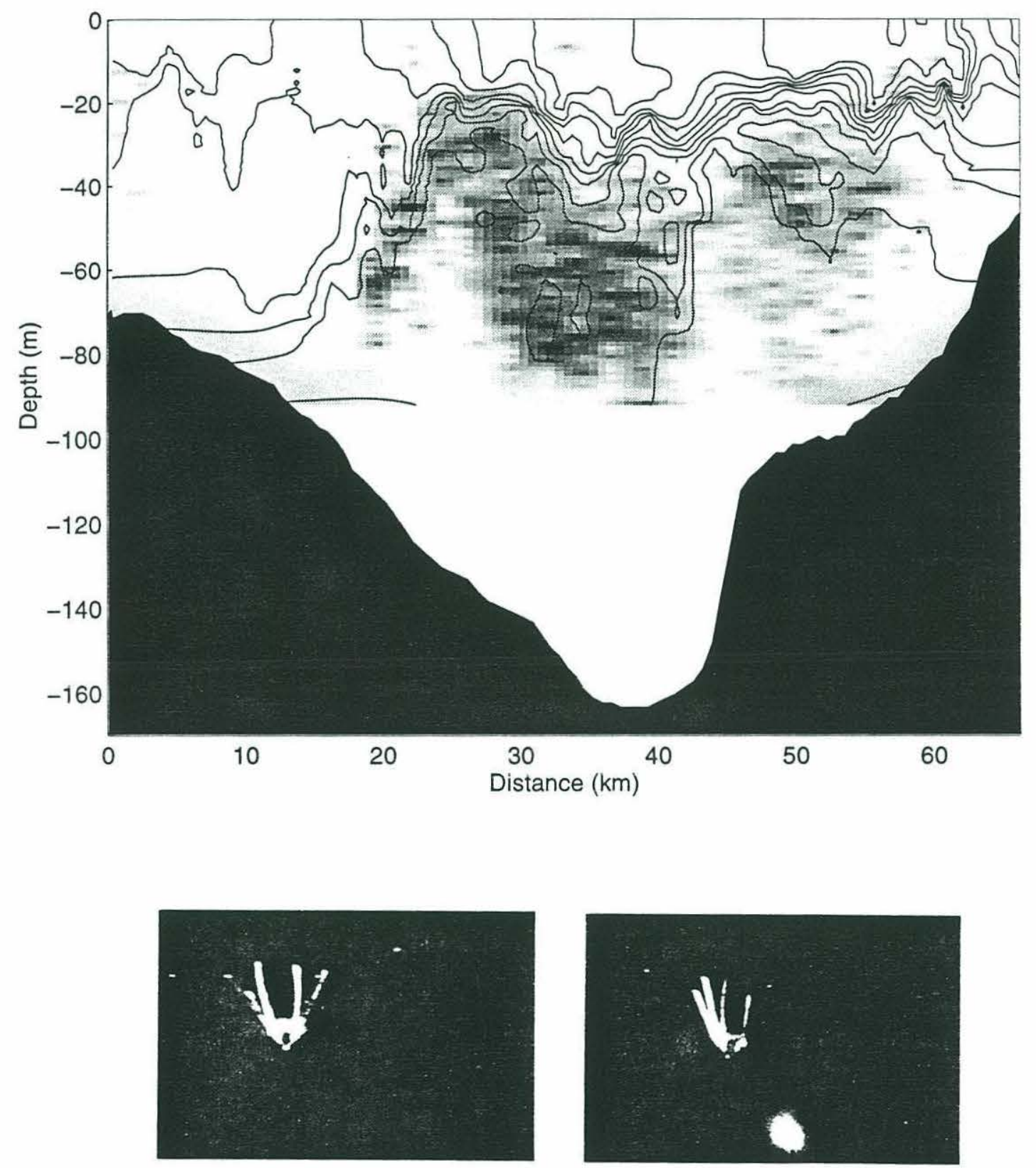

Figure 3.9 continued: Part E. Ophiopluteus larvae. 

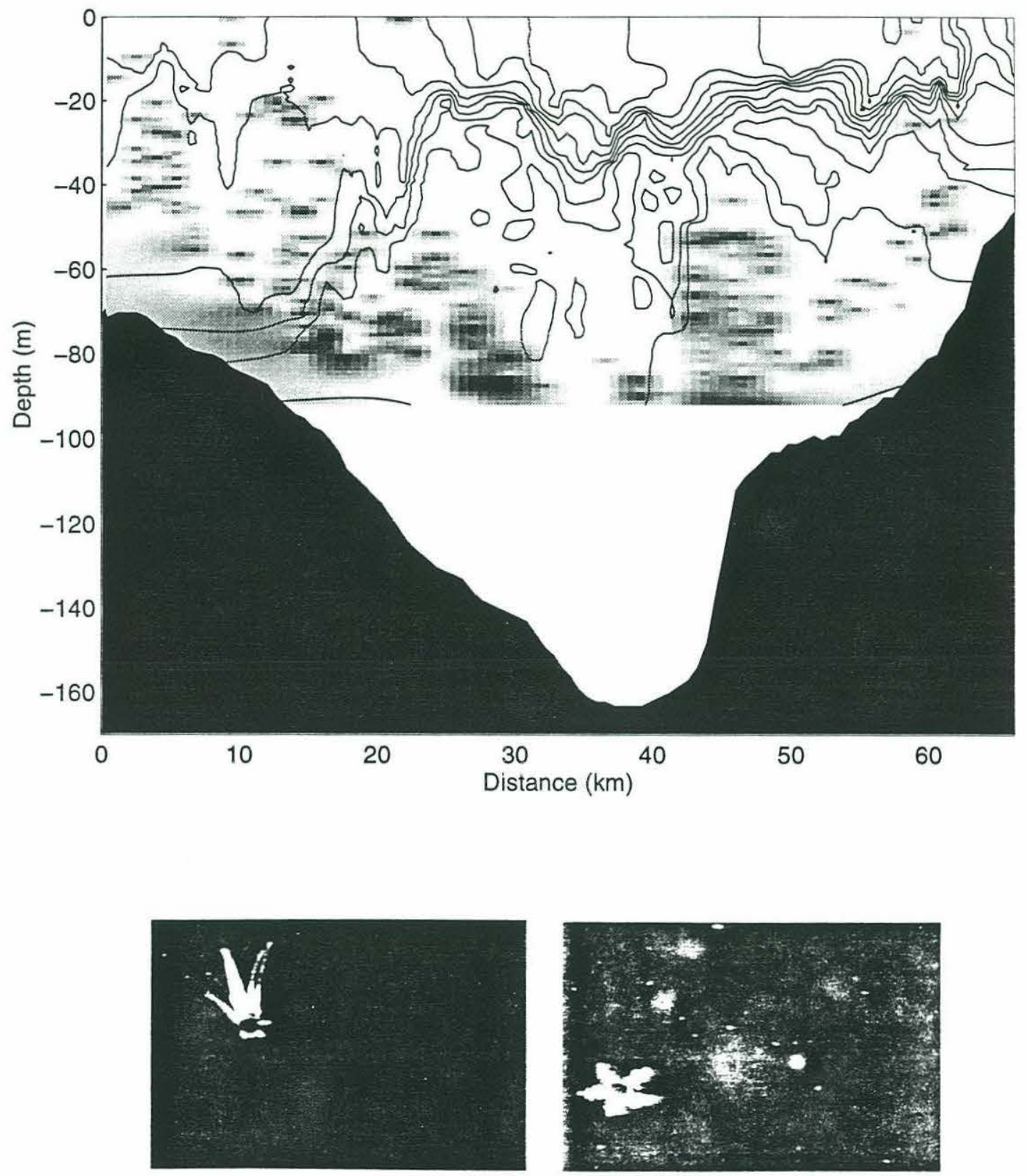

Figure 3.9 continued: Part F. Ophiuroid juveniles. 

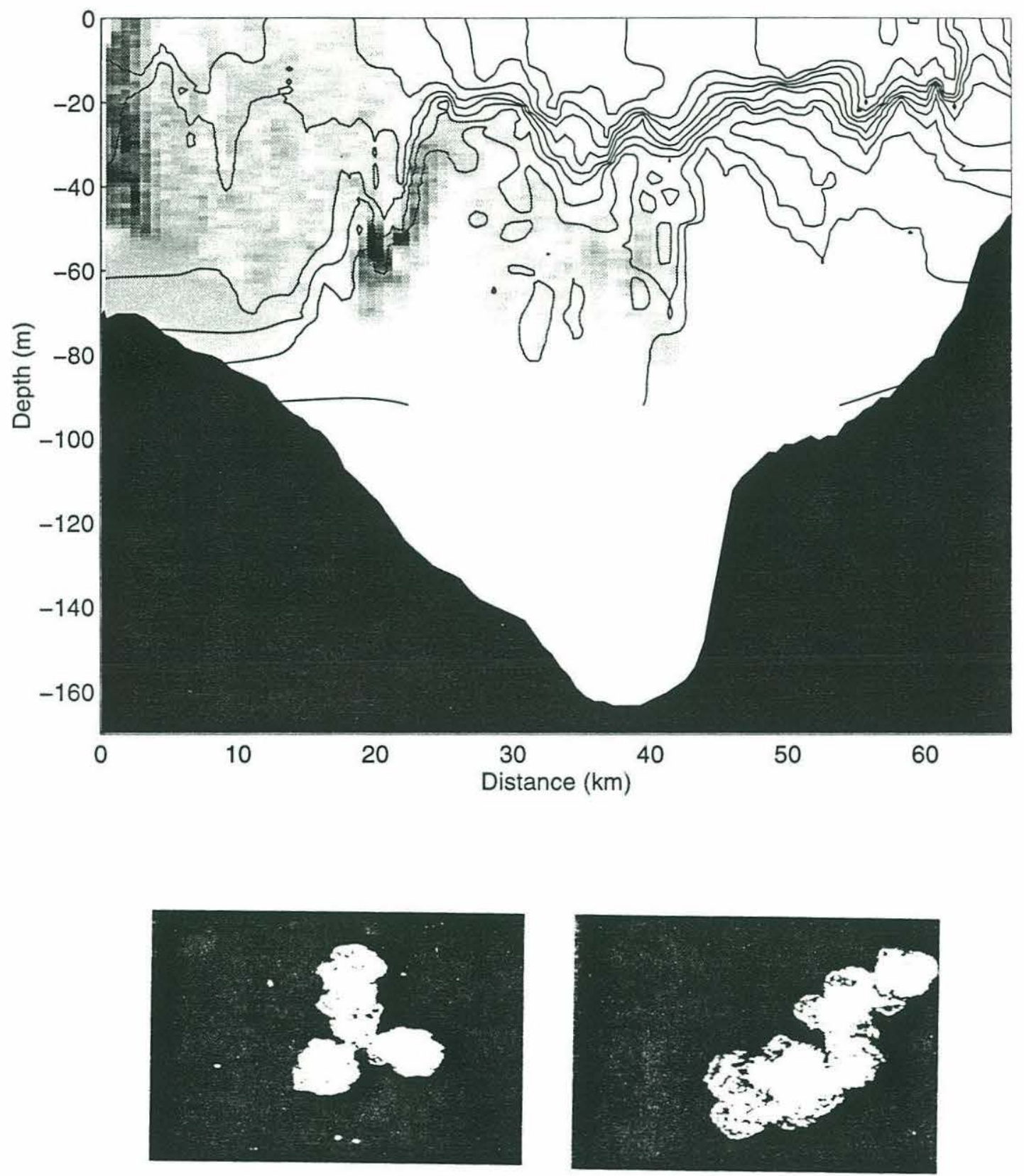

Figure 3.9 continued: Part G. Colonial diatom Chaetocerous socialis. 

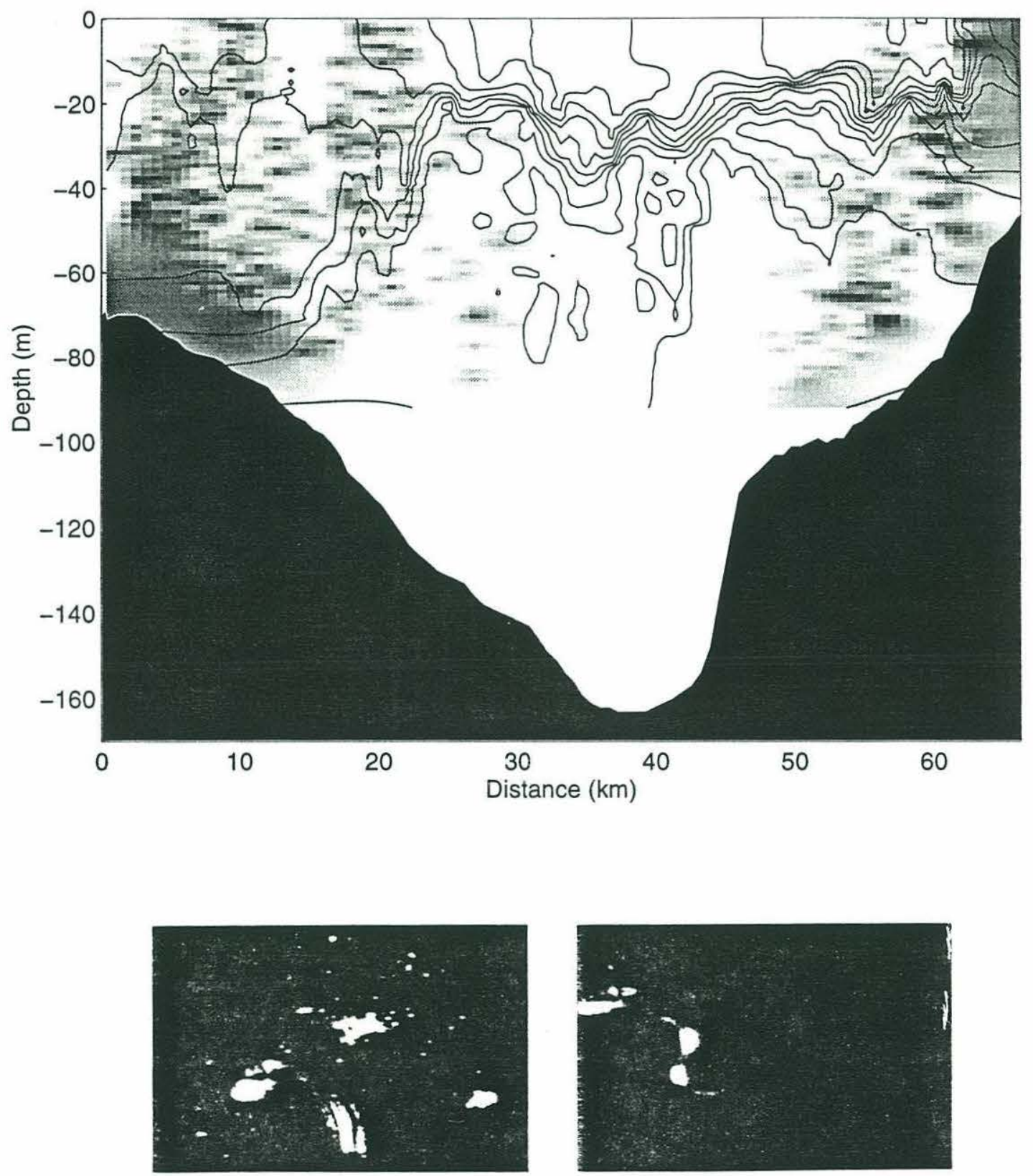

Figure 3.9 continued: Part H. Larvacians. 

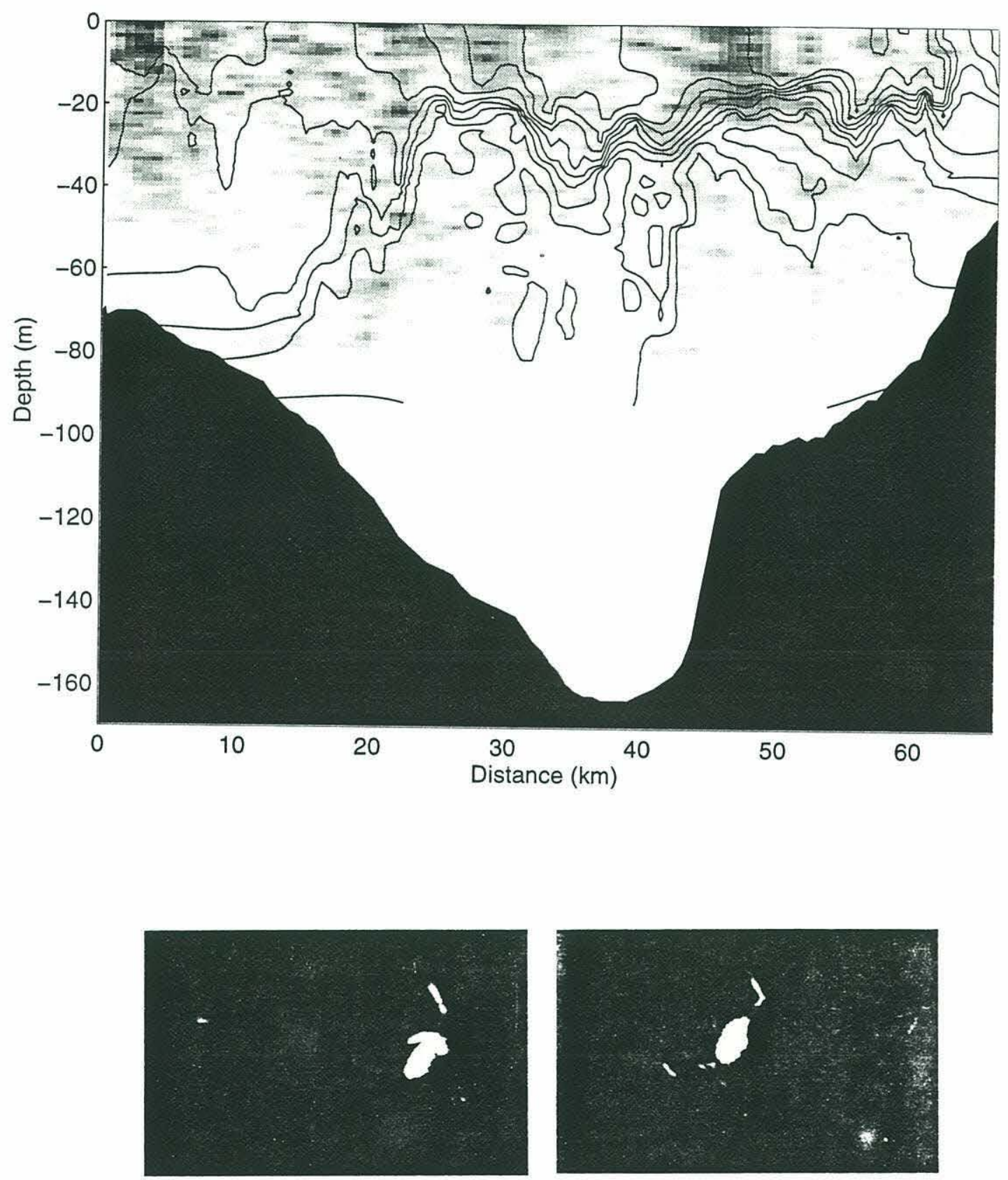

Figure 3.9 continued: Part I. Other copepods. 

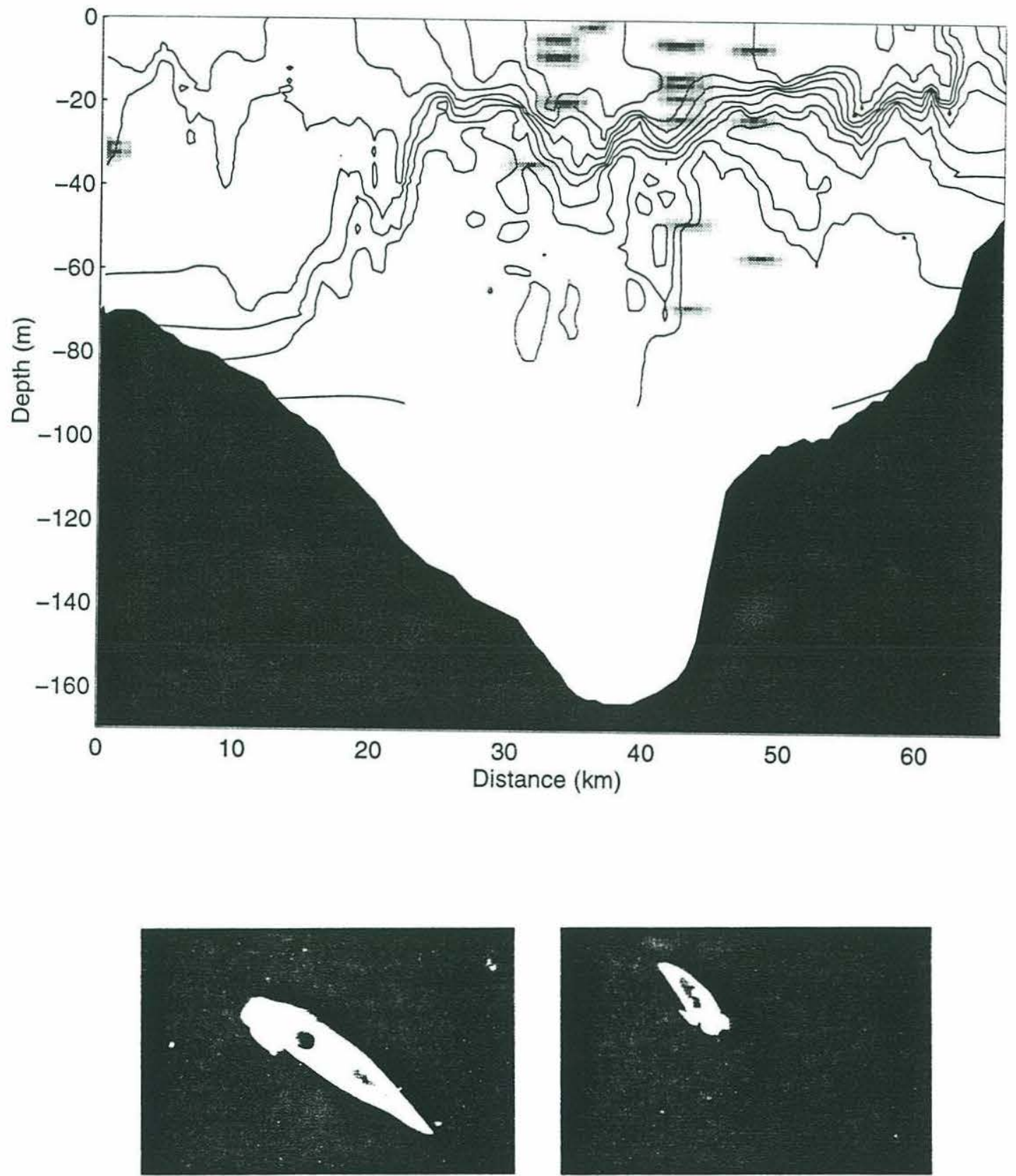

Figure 3.9 continued: Part J. Pteropod Clione sp. 

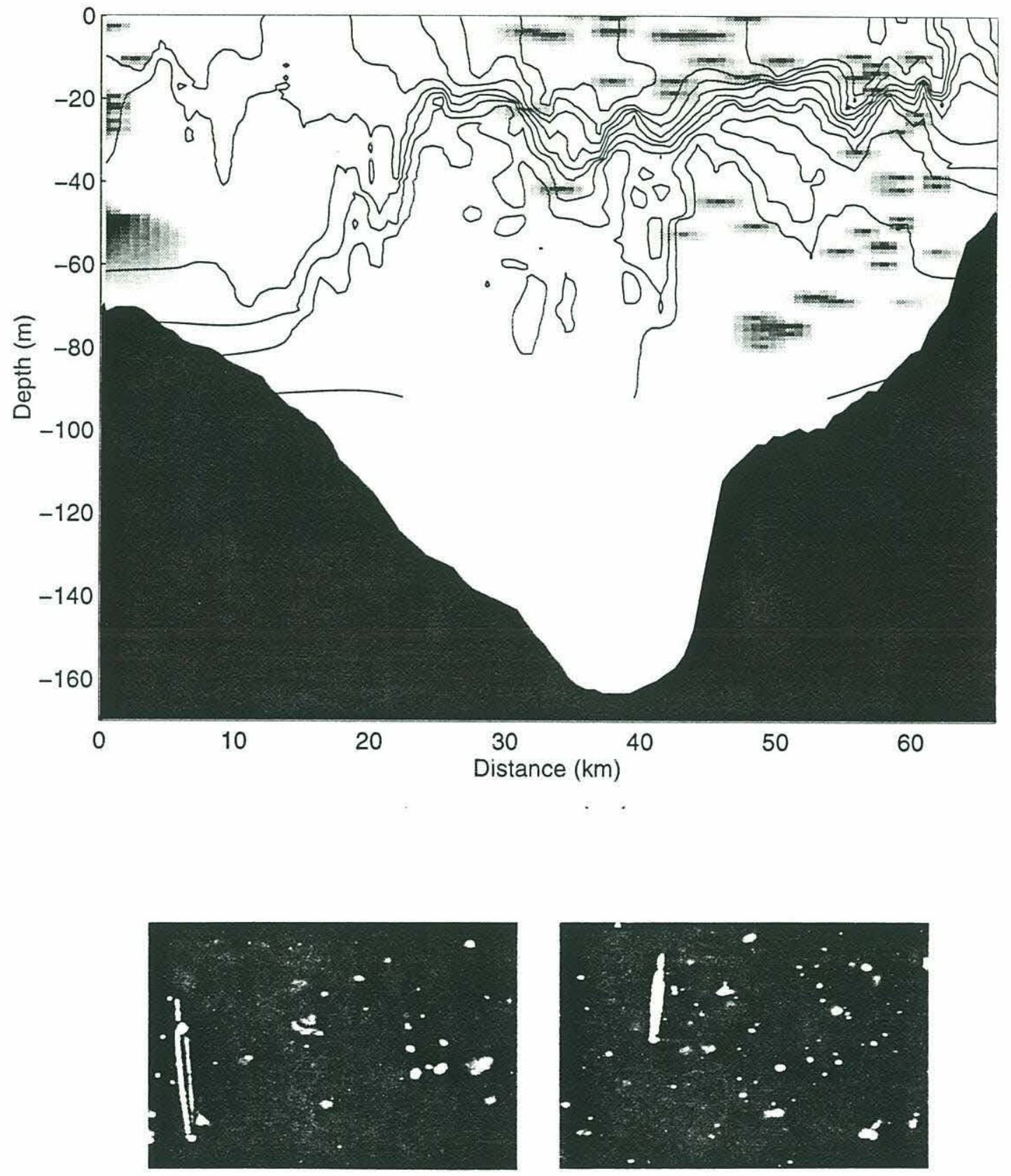

Figure 3.9 continued: Part K. Chaetognaths. 

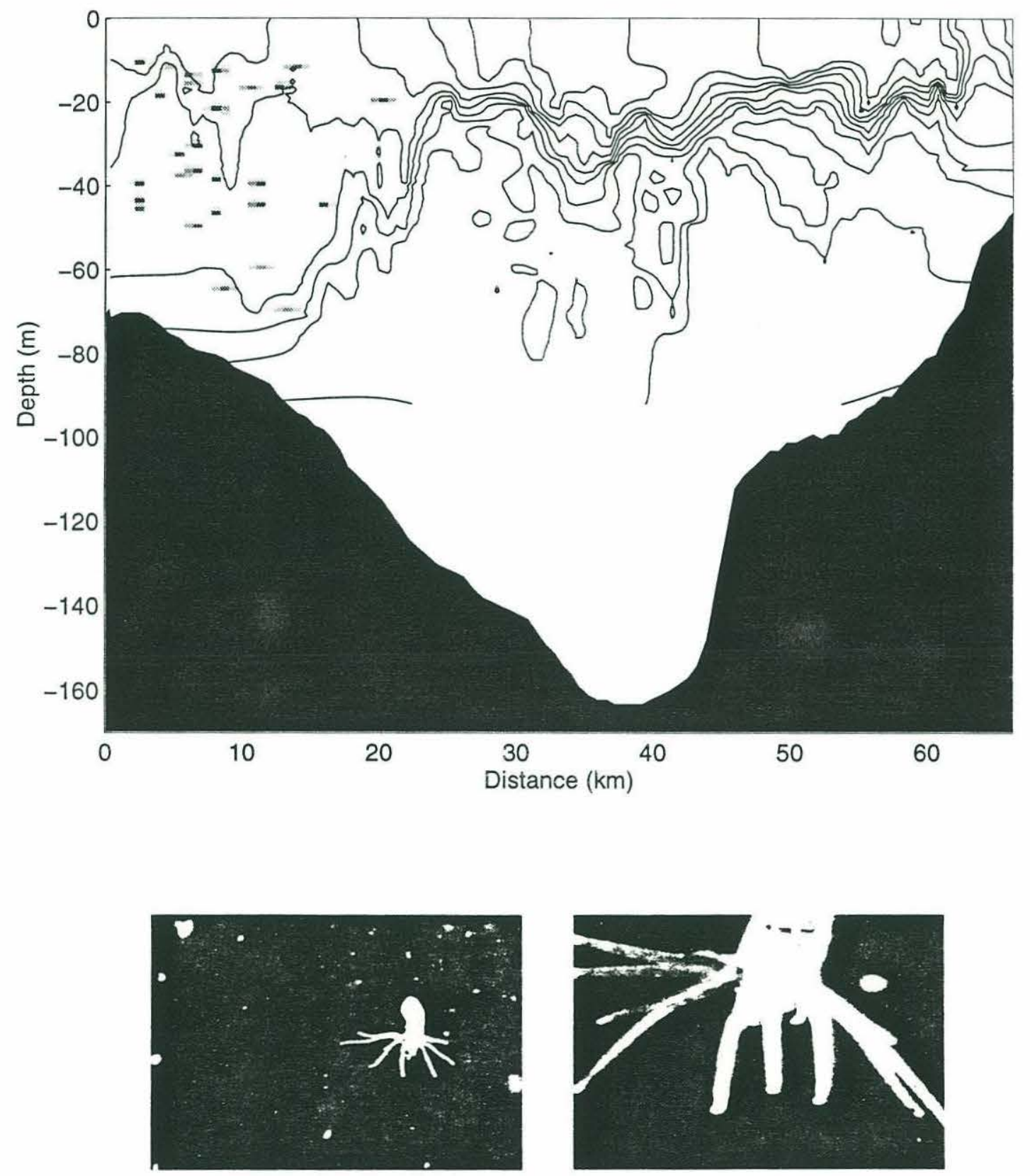

Figure 3.9 continued: Part L. Larvae of Cerianthis sp. 

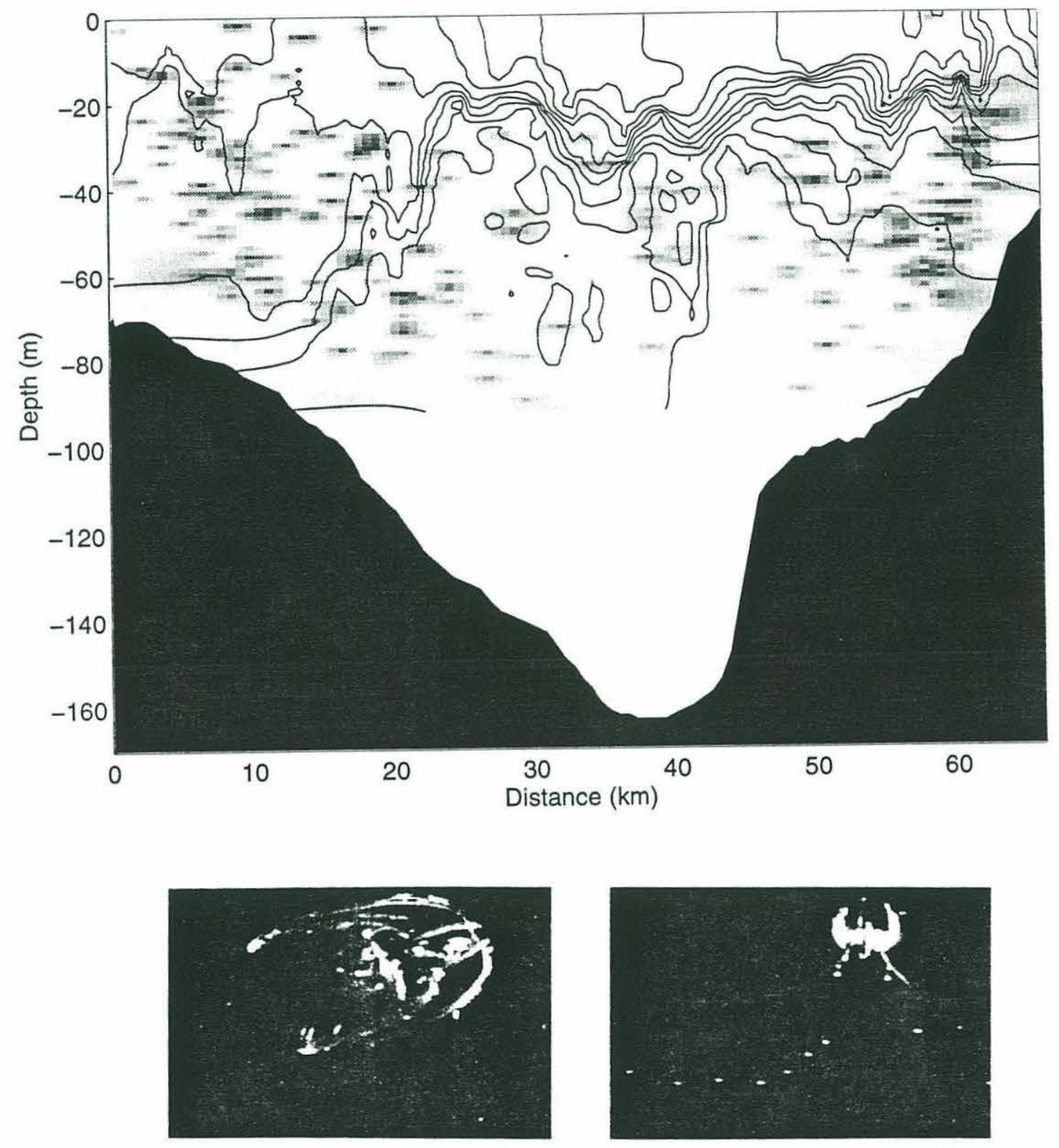

Figure 3.9 continued: Part M. Ctenophores. 

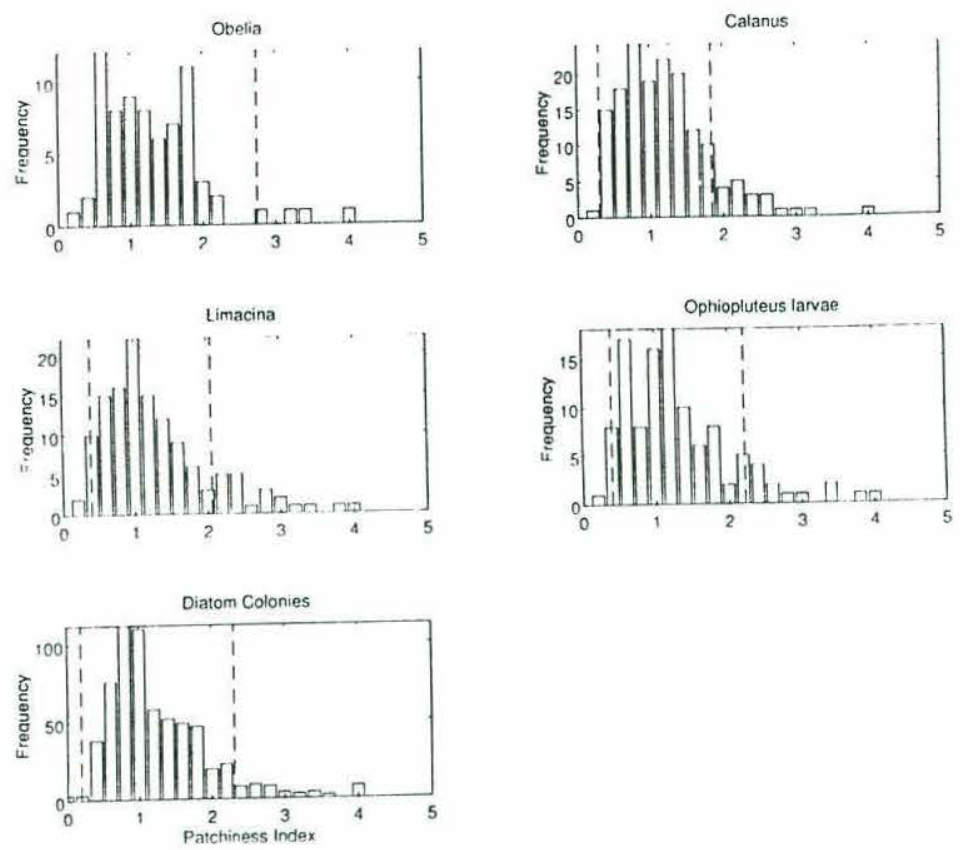

Figure 3.10: Frequency histograms for the taxon-specific micro-scale Patchiness Index (PI) across VPR 22 generated for each grid cell traversed by the VPR. 95\% confidence intervals are shown as vertical dashed lines. Bins above and below the confidence interval show aggregated and uniform distributions, respectively.
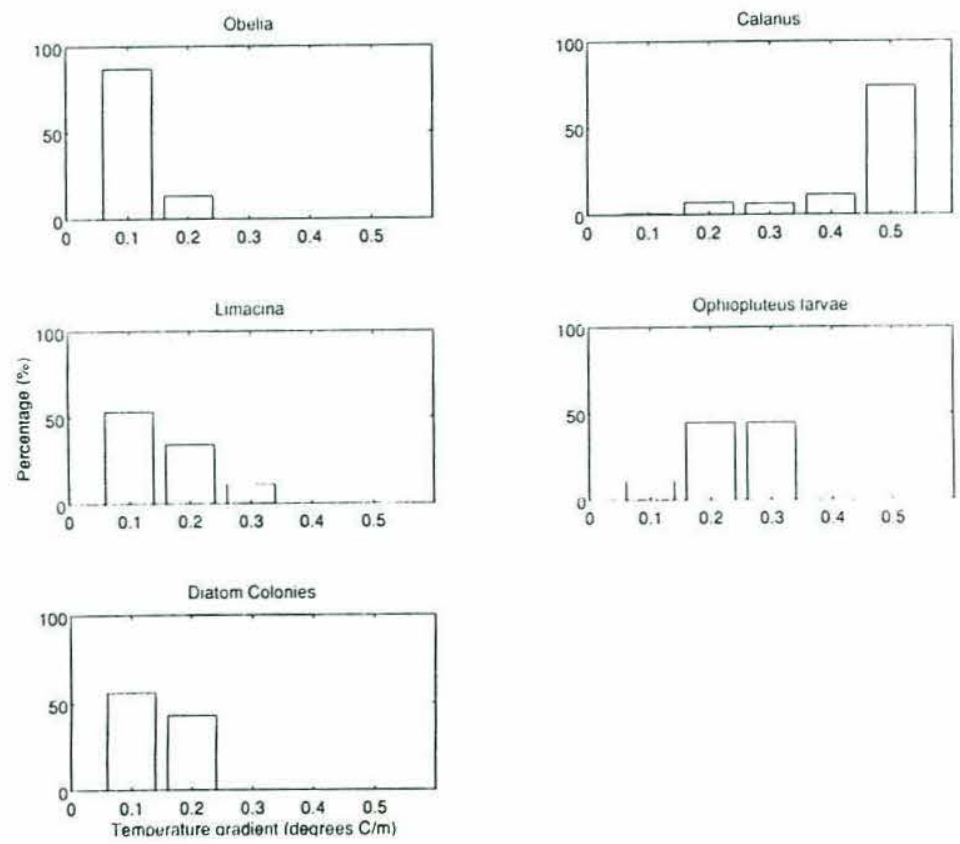

Figure 3.11: Percentage of the aggregated organisms in a given population in relation to the vertical gradient in temperature calculated at $1 \mathrm{~m}$ intervals. Data are binned at intervals of $0.1^{\circ} \mathrm{C} / \mathrm{m}$. 
The micro-scale patchiness index (PI) showed that $94.5 \%$ of the medusa were randomly distributed across the entire transect (Figure 3.10 ). Only 5.5\% were aggregated and none were uniformly distributed. Of those medusa that were aggregated, the tendency was for aggregation within weak temperature gradients (Figure 3.12). Data for the other physical gradients showed similar results, and so only those for temperature are presented here.

Orientation of individual medusa appeared random with roughly equal possibility of finding animals in a mouth-up or mouth-down position. Sizes varied from 1 to $2.5 \mathrm{~mm}$ in diameter.

\section{Calanus sp. (Figure 3.9B)}

Life stages CV and adult Calanus finmarchicus were positively identified from the video images by virtue of their bifurcated antenules (length: 1.2 to $2 \mathrm{~mm}$ ). Younger stages (CI-CIV) were identified as Calanus sp. only. It is well known from net hauls that nearly all Calanus sp. in this region at this time of year are copepodite CIV-CVI (Davis, $1987 \mathrm{a}, \mathrm{b}$ ). For the purpose of obtaining the distributional pattern and average concentration for this genus, all life stages were pooled.

In general, Calanus sp. was observed both within and above the thermocline to the west of the mixing front in the CSW1, CSW2, and CSW3. A sharp boundary between CSW3, Plume Surface Water (PSW), and PIW-influenced water indicated that few Calanus sp. were in the relatively warm and fresh water influenced by river runoff. A clearly defined patch of Calanus sp. was observed within the theromocline about $45 \mathrm{~km}$ from the beginning of the transect. Concentrations exceeding $2.5 / 1$ on the average were found between 15 and $20 \mathrm{~m}$ in depth for a distance of about $2 \mathrm{~km}$. In the region of this patch, maximum number of Calanus sp. observed in a single field from Camera 2 was 8 , indicating a local concentration of about 285/1. 
The micro-scale patchiness index showed that $76.9 \%$ of the Calanus sp. were randomly distributed, $15.6 \%$ were aggregated, and $7.5 \%$ were uniformly distributed (Figure 3.10). Those that were aggregated tended to aggregate in the strongest temperature gradients (Figure 3.12), which corresponded to the thermocline at about $30 \mathrm{~km}$ into the transect.

Body orientation of individual Calanus sp. was, for the most part, either in the head-up or head-down position; observations of individuals in a horizontal position with their body axis either orthogonal or parallel to the camera's view were rare.

\section{Limacina retroversa (Figure 3.9C,D)}

The highly refractive shells of the pteropod Limacina retroversa allowed for rapid identification of this spheroid-like organism. The number of shell whorls ranged between two and six as body size increased from 0.5 to $2 \mathrm{~mm}$. L. retroversa were found primarily above the thermocline in dense aggregations bounded by the $8.5^{\circ} \mathrm{C}$ temperature contour to the west of the mixing front, corresponding to water types CSW1 and CSW2, but not CSW3. The concentration at the centroids of these aggregations exceeded $7 / 1$ and were located well within these water masses rather than near the boundaries. Similar high densities were recorded just below the air-water interface to a depth of $0.5 \mathrm{~m}$. Close to the surface, adult L. retroversa were observed releasing veligers in a cloud around themselves. Over 370 veligers (ca. $200 \mu \mathrm{m}$ in length) were counted in a single video field of Camera 4, thus yielding a local concentration in excess of $600 / \mathrm{ml}$.

Micro-scale distributions were $75.4 \%$ random, $15.3 \%$ aggregated, and $9.3 \%$ uniform (Figure 3.10). The predominant number of aggregated Limacina retroversa were found in the weakest temperature gradients (Figure 3.12) coresponding to the centers of water masses CSW1 and CSW2. 
Body orientation was observed always with the shell below the parapodia relative to the gravity vector. The parapodia, however, were found in varying positions throughout the effective and return strokes of the swimming cycle.

\section{Ophiopluteus larvae (Figure 3.9E)}

Ophiopluteus larvae were identified by their unequal arm length compared with equal arm lengths found in echinopluteus larvae. It is not known what species these larvae represent, but a number of brittle stars (e.g., Ophiura sarsi) and basket stars are present in the Gulf of Maine and Georges Bank region (see Theroux and Grosslein, 1987). When individuals were observed to be undergoing metamorphosis (shortening of arms toward the main body), they were placed into a separate juvenile category.

In contrast to the hydrozoan medusae, which occurred in the tidally mixed area of Georges Bank, ophiopluteus larvae were restricted to the deeper, cooler waters of the Gulf of Maine, and their distributions followed the base of the thermocline. More specifically, they were distributed to the west of the mixing front and below the thermocline in the Surface Water (SW) mixed with CBW and interleaved SW/CBW and SW/MIW. The eastern boundary of the larval population was between the MIW and Cold Coastal Water. Although few larvae were observed in the CCW, relatively high numbers (0.9/1) were found between CCW and PIW-influenced water on the west side of the channel.

Micro-scale distributions of ophiopluteus larvae were $82.9 \%$ random, $13.5 \%$ aggregated, and $3.6 \%$ uniform (Figure 3.10 ). When aggregated, larvae tended to be

found in relatively strong temperature gradients (Fig 12) at the interfaces between water masses. 
Orientation of individual larvae was virtually constant in the arms-up position. Very little deviation from this orientation was observed regardless of the hydrographic conditions.

\section{Juvenile Ophiuroids (Figure 3.9F)}

Metamorphosing juvenile Ophiuroids were found well up into the water column, but in general they were distributed at a greater depth than their larval counterparts. Interestingly, low numbers $(0.01 / 1)$ were found in regions where larvae were virtually absent such as the MIW, CCW, WBW1 and WBW2 on the east side of the channel.

\section{Diatom Colonies (Figure 3.9G)}

Colonies of the centric diatom Chaetocerous socialis were observed in great abundance in specific regions of the channel. The VPR images of the colonies showed globular forms ranging in diameter from 0.5 to $1 \mathrm{~mm}$. Groups of colonies exceeded $5 \mathrm{~mm}$ in maximum dimension. Fine structure within the colonies was difficult to see without further image processing. Application of a Sobel filter ( $7 \times 7$ kernel) revealed detailed structure consisting of diatom chains formed into $\mathrm{S}$ patterns throughout an amorphous gelatinous matrix. Although no water samples were taken on cruise EN237 to verify the identification of this diatom, subsequent cruises to Georges Bank with the VPR have revealed similar forms in abundance. Direct sampling with Niskin bottles during those cruises, followed by on-board microscopic examination of the colonies, has confirmed their taxonomic position as colonies of Chaetocerous socialis.

Colonies were abundant (200-300/1) on the eastern side of the channel extending from the surface to the bottom (WBSW1, WBSW2, WBW1, and WBW2). Within the mixing front, and particularly at a nearby region where isotherms slope sharply in the vertical (depth $=55 \mathrm{~m}$, distance $=20 \mathrm{~km}$ ), the concentration of colonies, 
averaged over 1 -m (depth) by $600-\mathrm{m}$ (distance) bins, exceeded 600/1. Ri in this region tended to be high, suggesting great vertical stability. The VPR video screens displaying images in real time on the ship literally turned white for a few seconds as the VPR traversed this patch. While in the patch, the maximum number of colonies observed in the Camera 4 FOV was three, giving a local concentration of $5 / \mathrm{ml}$. The boundaries of the patch were very sharp: the concentration fell by a factor of 100 within $0.5 \mathrm{~m}$ above and $5 \mathrm{~m}$ below the patch. The diatom patch was encompassed within the water mass identified as SW/CBW. Colonies were also observed at the boundaries between SW/CBW and SW/MIW, and in the region of interleaving between SW/CBW and SW/MIW, but not in the MIW itself. Few colonies were found in the CCW mass to the east (although scattered observations showed low numbers in the intermixed region between the CCW and PIW).

The micro-scale patchiness index revealed the majority (92.3\%) of diatom colonies to be random in their distributions (Figure 3.10 ). Only $7.2 \%$ were aggregated and $0.5 \%$ were uniform. The few that were aggregated were found in the temperature inversion (medium to low temperature gradient; Figure 3.12) within the mixing front.

\section{Larvacea (Figure $3.9 \mathrm{H}$ )}

The larvacean Oikopleura sp. was found encased in a gelatinous house in the majority of observations. Since positive identification was dependent, in part, on the presence of the house, only those within a house are reported here. Larvaceans were distributed in a pattern similar to that of the ctenophores: Relatively high concentrations on both the west and east sides of the channel with few in the center. On the east side of the channel, they were found in the WBW1 and WBW2 regions with a few scattered near the surface in the WBSW1 and WBSW2. On the west side, Larvaceans ranged 
throughout the water column between the PSW at the surface, the PIW-influenced water 20 to $60 \mathrm{~m}$ in depth, and into the CCW below $60 \mathrm{~m}$.

No preferred body orientation was observed for Oikopleura sp.

\section{Other Copepods (Figure 3.9I)}

This category included the remaining species of copepods found along with small and immature stages of Calanus sp. and Pseudocalanus sp. that, for various reasons, were not always identified to genus. Additional copepod species included Acartia sp., Eucalanus sp., Metridia sp., Neocalanus sp., Paracalanus sp., Temora sp., and Oithona sp. These groups were most abundant in the well-mixed regions WBSW1 and WBSW2, WBW1 and WBW2, within $20 \mathrm{~m}$ of the surface in the CSW1, CSW2 and 3 water masses, and in the PIW-influenced region between 10 and $30 \mathrm{~m}$ depth on the eastern boundary of the channel. As for Calanus sp. and Pseudocalanus sp., these copepods were also rare in the deep MIW and CCW.

Body orientation in Oithona sp. was always in a head-down position. No specific orientations were noted for the other species.

\section{Pseudocalanus sp. (females)}

Female Pseudocalanus sp. (length: 0.9 to $1.5 \mathrm{~mm}$ ) were identified by the tight constriction at the urosome and the presence of egg (embryo) sacs attached to the abdomen. The number of embryos in the sac could be counted in most images yielding an average of $13(\mathrm{n}=108, \mathrm{SD}=5)$ per female. Compared with Calanus sp., the abundance of Pseudocalanus sp. females was low with only scattered observations throughout WBW, CSW, and CCW. A single dense patch was found near the surface in the well-mixed region in which the local concentration exceeded $3 / \mathrm{ml}$. 
Body orientation appeared random with no preferential position relative to gravity or the camera axis.

Clione sp. (Figure 3.9J)

The large ( $2 \mathrm{~cm}$ in length) heteropod Clione sp. was found in low abundance in the regions of CSW1 and CSW2. Although only scattered observations were made, they were generally found in the same regions as Limacina retroversa above the thermocline between 30 and $50 \mathrm{~km}$ from the beginning of the transect.

There was no preferred body orientation in the water column. In a few video images, a mucous web was clearly seen trailing either behind or to the side of individual Clione sp. Single Limacina retroversa appeared to be entangled within the web.

\section{Chaetognatha (Figure 3.9K)}

The chaetognath Sagitta sp. was rare in most of the channel with only a few individuals observed during the latter half of the transect. From about $32 \mathrm{~km}$ into the transect, Sagitta sp. ranged between the surface and $80 \mathrm{~m}$.

Invariably, Sagitta sp. was found in either a head-up or head-down orientation.

\section{Anthozoa (Figure 3.9L)}

Larvae of the anthozoan Cerianthus sp. were identified by virtue of their concentric rings of tentacles and a body size of about $10 \mathrm{~mm}$ (Leloup, 1964). The distribution of Cerianthus sp. larvae was virtually identical to that of Obelia sp., but its abundance was considerably lower with a maximum average concentration of $50 / \mathrm{m}^{3}$. 
All 79 observations in Camera 2 showed these larvae positioned in the tentacle-down orientation.

\section{Ctenophora (Figure 3.9M)}

The lobate ctenophore Mnemiopsis sp. was scattered throughout the water column on both the western and eastern sides of the channel. On the western side of the channel, individuals were observed on the bank generally below $10 \mathrm{~m}$ in depth scattered in the WBW1 water mass. No major concentrations were associated with the mixing front. There was a clear absence of ctenophores in the surface waters (CSW1, CSW2, CSW3, and PSW) above the thermocline. On the western side of the channel, ctenophores were found in the PIW-influenced region where maximum concentrations exceeded $250 / \mathrm{m}^{3}$. Body size ranged from 15 to $>30 \mathrm{~mm}$ in diameter.

No preferred body orientation of Meniopsis sp. relative to the gravity vector was apparent. The ciliated comb plates, however, were observed to be beating on one side only, as indicated by the presence of a metachronal wave. The side with beating comb plates was always on the underside of the animal when its body was rotated in one direction or another relative to the camera axis. As discussed by Moss and Tamm (1986), this activity would tend to re-orient the animal to its vertical position.

The cydippid ctenophore Pleurobrachia sp. was rare with only a few observations in the PIW-influenced region at a depth of 30 to $40 \mathrm{~m}$ (data not shown). All 25 observations showed Pleurobrachia sp. to be in an upright posture (mouth down, apical sense organ up) with tentacles trailing to the side. Body size ranged from 8 to $12 \mathrm{~mm}$ in diameter. 


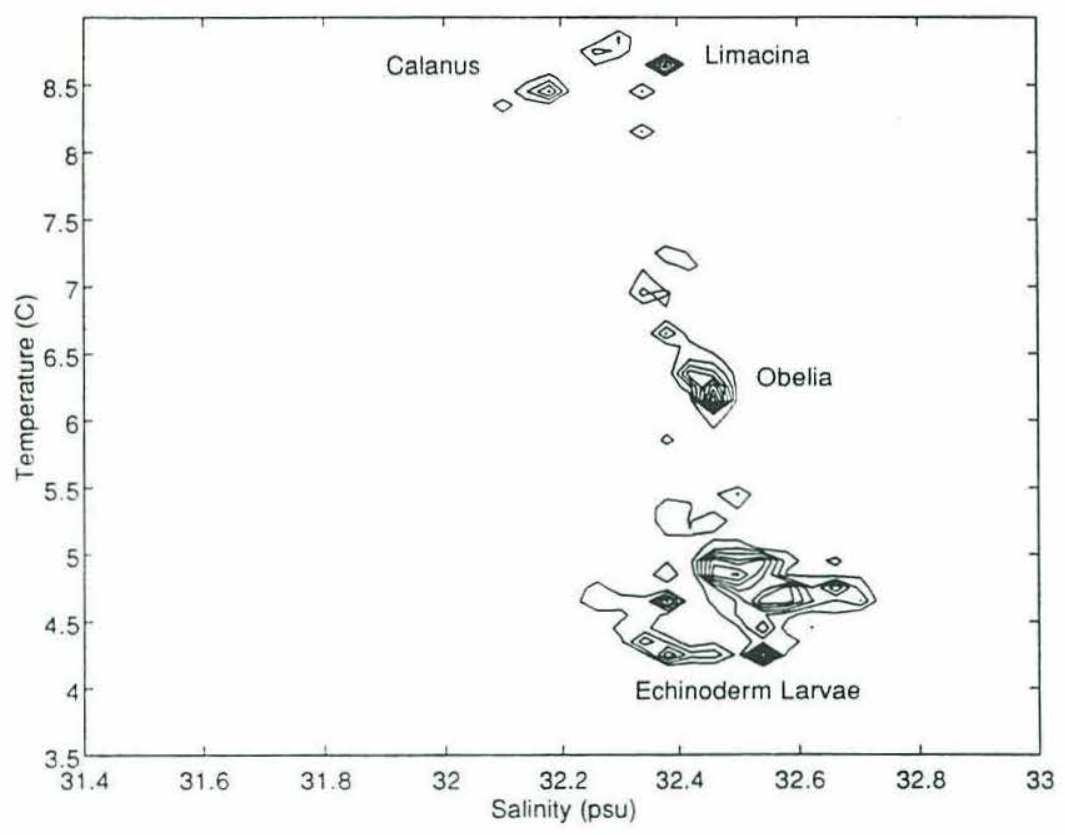

Figure 3.12: Temperature-Salinity-Plankton (T-S-P) diagram showing the clustering of five plankton species as a function of the local $\mathrm{T}$ and $\mathrm{S}$.

\subsubsection{T-S-P Diagrams}

The ability to assign characteristics of the physical environment to individual plankton enabled us to create temperature-salinity-plankton (T-S-P) diagrams showing the relationship between plankton distributions and water-mass structure at the individual level (Figure 3.12). When Figure 3.12 is compared with Figure 3.6, it is clear that some taxa (e.g., Limacina sp., ophiopluteus larvae, Obelia sp.) exhibited well defined boundaries related to a particular water mass, while others (e.g., Calanus sp.) were scattered among and between water masses. As will be discussed later, this may be due to an interplay between the mobility of the plankton and the vertical stability of the water. 


\subsection{Discussion}

This study demonstrates a close association of plankton communities with water mass structure and distribution on scales of $<1 \mathrm{~m}$ to $70 \mathrm{~km}$. The extent to which a given water mass contains a plankton assemblage is species-specific, with stronger boundary conditions being imposed on those organisms that are less active. When the actively swimming pteropods Limacina retroversa are constrained within a water mass, they tend to concentrate at the center of the water parcel rather than near any one boundary, and they tend to be aggregated at small spatial scales. The copepod Calanus finmarchicus, however, was aggregated only in the thermocline. Conversely, concentrations of the more passive forms such as Obelia sp. and Ophiopleuteus larvae tend to be greatest near boundaries and density interfaces, while their micro-scale distributions are more random. Taken together with water-column stability (as indicated by Richardson number), this suggests that weak swimmers tend to become concentrated in regions of high vertical stability (at edges of water masses or in density gradients) while more active plankton are able to aggregate either in regions of high vertical stability or relatively low stability (center of water masses).

The unique two-dimensional view of the GSC provided in this paper shows with high resolution the existence of a patchwork or mosaic of water masses. The complexity of the mosaic is due in part to interactions among the four distinct hydrographic regimes that converge in the northern Great South Channel: 1) the well-mixed Georges Bank crest water, 2) the Gulf of Maine system, 3) water overlying Nantucket Shoals, and 4) water overlying the continental shelf and slope.

The first major hydrographic feature we shall discuss is the well-mixed Georges Bank water, which travels in a clockwise gyre around Georges Bank, flowing northward on the eastern side of the GSC. The plankton community in the well-mixed Bank Water was characterized by freely drifting hydrozoans (both colonial hydranths 
and medusae of Obelia sp.), Larvaceans, the colonial diatom Chaetocerous socialis, ctenophores, larvae of the burrowing anthozoan Cerianthus sp. and scattered copepods. The western boundary of the Georges Bank water, the front between WBW2 and the region of MIW and mixed SW/MIW, coincides with a marked boundary in community structure. Obelia sp. medusae and cerianthid larvae were clearly bounded on the western side by the front while the larvaceans and ctenophores appeared on both sides of the channel. Bigelow (1926) discussed the presence of colonial hydrozoans in the water column that were concentrated in frontal regions at the interface of well-mixed and stratified waters in the Gulf of Maine. Although these predominantly benthic forms may be scoured and resuspended from the bottom, as thought by Bigelow (1926), recent evidence suggests the hydroids are growing, feeding, and reproducing in the water column (L. Madin, personal communication) and thus may be less transient than expected.

Although adult burrowing anthozoans are fairly common in the deep basins of the Gulf of Maine (Theroux and Grosslein, 1987), cerianthid larvae have not been reported from plankton tows taken in this area. Perhaps this is because of damage to their relatively soft and fragile bodies by conventional sampling gear. Their tentacledown orientation even in the regions of high potential shear instability $(\mathrm{Ri}<0.25)$ in the well-mixed area, suggests the existence of a strong torque induced by a center of gravity close to the tentacular region.

There are only a few references to the occurrence and distribution of Chaetocerous socialis in Gulf of Maine and Georges Bank region. Bigelow (1926) reported this colonial diatom to be the dominant phytoplankton species during the months of March and May in the well-mixed area, while Falkowski and von Bock (1979) calculated the abundance of C. socialis to be $26 \%$ of the phytoplankton community in March. More recent observations of $C$. socialis in the western Gulf of Maine include Townsend et al. (1992) who reported colonies forming blooms in which chlorophyll a 
values exceeded $5 \mu \mathrm{g} / 1$ during the month of April. On Georges Bank, recent reports of C. socialis are lacking except for observations made with the VPR throughout cruises EN237 in May of 1992 and CI94-07 in May of 1994. During both cruises, C. socialis occurred in great abundance along the northern and southern flanks in a subsurface chlorophyll maximum immediately below the pycnocline. Fluorometer readings exceeded $10 \mu \mathrm{g} \mathrm{Chl} a / 1$ while the video monitors turned white as the VPR traversed the diatom patches. Durbin et al. (1995a) reported the GSC in May, 1989, to be dominated by large diatoms including Rhizosolenia hebetata, Chaetocerous concavicornis, C. convolutus and Thalassiosira nordenskioldii, but they did not identify C. socialis in the SCOPEX studies (E. Durbin, personal communication). One explanation for this is the observation made by Bigelow (1926) that when C. socialis was present in the water column, the plankton nets became covered in a slimy film, reducing their ability to filter small particles. The non-invasive sampling of the VPR proved useful in obtaining accurate estimates of population abundance and distribution for this important diatom.

In the central regions of the GSC, the larval population was bounded vertically by the thermocline and the interface between MIW and SW/MIW, while the MIW contained virtually no larvae. Coincident with the distribution of Ophiopluteus larvae in the central region of the GSC was a relatively low level of diatom colonies (Chaetocerous socialis) punctuated by extreme concentrations within the mixing front. Before we examine the source of the larval and diatom populations, we must first consider the origins of the water mass in which they are embedded.

Judging by T-S properties alone, CCW mixed with surface water could provide the bulk of the water we have designated as SW/CBW. For this to be the case, however, the plume of CCW flowing south along the western side of the GSC would have to turn as it reached the sill, following the topography until it flowed northward along the eastern side of the GSC, back towards the Gulf of Maine. In this scenario 
the CCW would mix tidally with surface water as it passed near the shallow GSC sill, producing, for example, the mixed surface water/cold water that is visible from about 30 to $60 \mathrm{~m}$ in depth between 20 and $40 \mathrm{~km}$ along the transect. A flaw in this scenario is that the sill of the GSC is about $70 \mathrm{~m}$ deep, and the mixed surface water/cold water is nearly all found above this depth. It seems unlikely that any CCW above $70 \mathrm{~m}$ would not simply pass over the sill of the GSC and thus exit the GSC/Gulf of Maine system.

In addition, the distribution of ophiopluteus larvae and colonial diatoms lead us to believe that the CCW is not the source of this cold water. Extremely high concentrations of diatom colonies were found in the mixed surface water/cold water, yet the CCW itself was nearly devoid of diatom colonies, and the surface waters of the central and western GSC contained virtually none. Perhaps the cold water comes from some source outside the Gulf of Maine, and enters via the eastern GSC. One candidate for such a source is the so-called Cold Band, a filament of cold water found on the south flank of Georges Bank during the spring, summer and early fall (Flagg, 1987). VPR transect 16 was made across the south flank of Georges Bank (Fig. 1) two days before the section we present in this paper (Norrbin et al., submitted). In the section called Tow 4, the Cold Band is visible as a temperature minimum between about 30 and $60 \mathrm{~m}$ deep. T-S diagrams for individual vertical legs of that VPR transect show that the Cold Band does indeed have T-S properties consistent with the cold water that is one ingredient of the mixed surface water/cold water found in VPR 22 across the GSC (Norrbin et al., submitted). As shown in Figure 3.6, the Cold Band Water (CBW) has temperatures between about 3.75 and $4^{\circ} \mathrm{C}$ and salinities between about 32.3 and 32.5 psu. The Cold Band also contains high concentrations of diatom colonies (maximum 30/1) and ophiopluteus larvae (maximum 11/1)(Norrbin et al., submitted), so it could be a partial source for the diatoms and larvae found in the mixed surface water/cold water in VPR 22. 


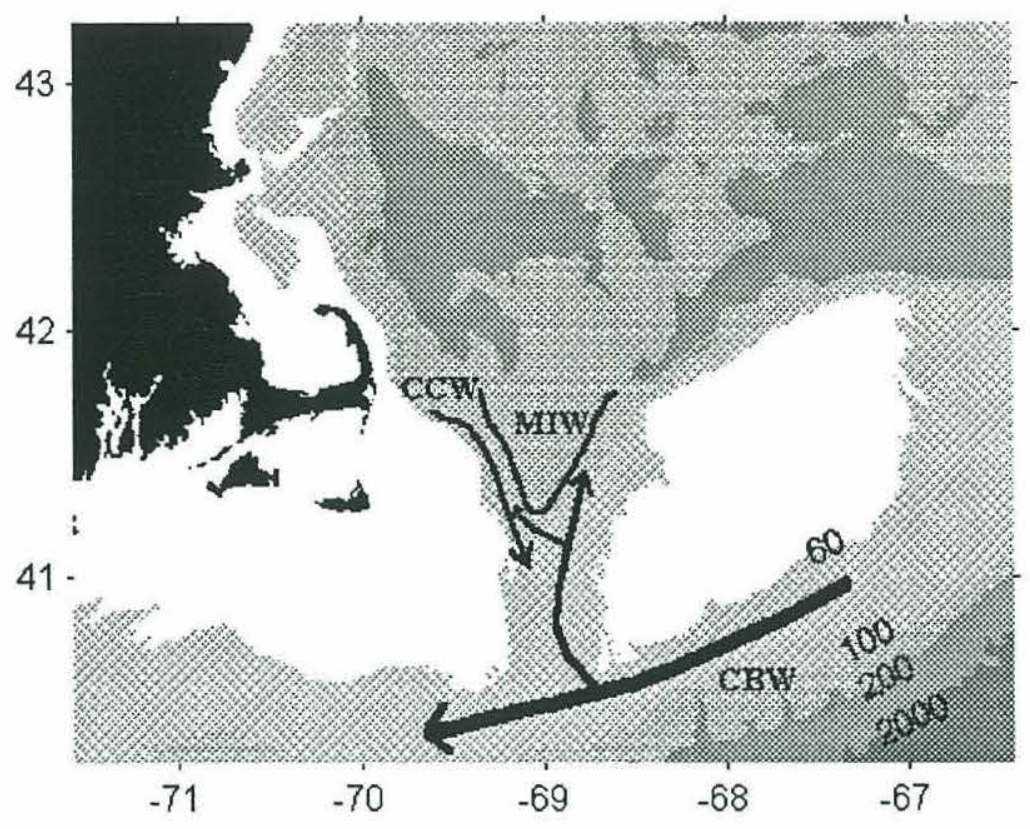

Figure 3.13: Cartoon depicting implied flow occurring in the Great South Channel (GSC) during transect VPR 22. As Cold Bank Water (CBW) flows southwestward along south flank of Georges Bank, some water flows northward into the GSC, mixing with Maine Intermediate Water (MIW) and Cold Surface Water (CSW). A tongue of Cold Coastal Water (CCW) moves south along the western rim of the GSC and onto Nantucket Shoals. Deep MIW below the sill of GSC moves south along the western edge of GSC turning to the north to follow topography of the western flank of Georges Bank. This kinematic picture is consistent with direct measurements in this region reported by Chen et al. (1995), and Manning and Beardsley (1995).

The kinematic picture we are thus suggesting (Figure 3.13) shows the middepths of the north-central GSC occupied by a core of nearly stationary MIW and mixed SW/MIW. On the western side of the GSC a plume of CCW flows southward past the MIW and crosses over the sill of the GSC. On the eastern side of the GSC, some of the water from the Cold Band is diverted from its general southwestward flow and crosses over the sill of the GSC, partially mixing with surface water there. When it reaches the core of the MIW and mixed SW/MIW, the CBW/SW mixture divides: some of it flows northward in a thin jet between the WBW2 and the core of SW/MIW, and some of it flows northward to the west of that core, interleaving with the SW/MIW mixture as it progresses. This would explain how diatom colonies came to be distributed both east and west of the MIW and SW/MIW mixture, but it 
does not explain the dense concentration found in the mixing front. (This diversion of the CBW need not be a steady phenomenon; we suggest only that it was occurring at the time these observations were made.)

Aggregations of phytoplankton in fronts can be due to a combination of rapid growth, reduced grazing pressure, and physical concentration (Owen, 1981). Given the size of the Chaetocerous socialis colonies ( $>1 \mathrm{~mm}$ ), grazing by all but the largest herbivores is not a consideration. Furthermore, the only zooplankton found in abundance in the region of the front were ophiopluteus larvae, which feed only on cells 10 $\mu \mathrm{m}$ or less in diameter (Strathmann, 1987). Thus grazing pressure on the colonies was probably low. Cell growth may have been fueled by a pool of relatively high levels of ammonia and nitrate, which was found at the base of the front in the 1988 and 1989 SCOPEX cruises by Durbin et al. (1995a). Although no data are available on the photosynthesis versus light-intensity thresholds for this colonial form, many diatoms can be low-light adapted and form blooms below the pycnocline or at depth. Townsend et al. (1992) calculated the critical depth (the depth at which photosynthesis exceeds respiration) to be at $43 \mathrm{~m}$ in the western Gulf of Maine in April 1992 when Chaetocerous sp. dominated the water column. We should expect, therefore, that at least some growth if not rapid growth would be occurring while the colonies were in the frontal region. Furthermore, physical concentration of colonies in the front may have occurred through the interaction of downwelling currents and potentially buoyant cells. Some large cell masses have been observed to form gas bubbles internally (probably supersaturated $\mathrm{O}_{2}$ ) causing them to become positively buoyant (Riebesell, 1992). The result of positively buoyant cells in a downwelling current would be to concentrate them along the length of the front (Franks, 1992; Epstein et al., 1993; Chapter 4 of this thesis), which is consistent with the distribution observed here. Microscopic examination of Chaetocerous socialis colonies obtained on a recent cruise to Georges Bank in May, 1994 (CI94-07) showed that most colonies had a large $(>100 \mu \mathrm{m})$ inclusion in the center of the cell mass. Whether this was a gas bubble 
or a solid body is unknown. Further studies on the physiology and growth kinetics of $C$. socialis need to be done before the mechanism or mechanisms of concentration at fronts is elucidated.

The remarkably well defined boundaries of the ophiopluteus distribution could have been produced by processes similar to those controlling the distribution of the diatom colonies. Larvae transported from the southern flank of Georges Bank in the Cold Band water would be distributed to the east and west of the coneshaped SW/MIW core. The T-S plots show interleaving between the SW/MIW and SW/CBW and SW/MIW, but this appears not to influence the larval distribution when the T-S-P plots are compared (i.e, no larvae were found in the SW/MIW core). Furthermore, the thermocline provided an upper boundary to the larval population, constraining them to the colder, more dense CBW and away from the surface CSW. Why are these boundaries so marked? Are the larvae depth-keeping and unable or unwilling to penetrate into the SW/MIW, MIW, and CSW1? Ophiopluteus larvae have relatively slow swimming speeds (ca. $0.1 \mathrm{~mm} / \mathrm{s}$ ) compared with the much faster sinking speeds $(2-4 \mathrm{~mm} / \mathrm{s})$ (Konstantinova, 1966; Emlet, 1983), and are probably weak vertical migrators due to their apparent insensitivity to light (Mladenov and Chia, 1982). However, they should be able to keep their own depth, especially since the water column appears reasonably stable in the region where the larvae are distributed ( $\mathrm{Ri}>5$ on the average). The unidirectional orientation of the larval body in all our observations is consistent with the idea of a relatively quiescent environment. Lack of penetration by the larvae through the thermocline and into the CSW1 could be caused by sensitivity to temperature, but why the larvae were not moving into the SW/MIW when the only significant gradient present was that of salinity is unknown. Working in the Kiel Bight, Banse (1964) noted that echinoderm larvae did not make excursions through the pycnocline and hypothesized that the larvae were "captured" in the water mass into which they were spawned. Sensitivity to salinity is possible, but the direct effects of changing kinematic viscosity with temperature and salinity 
on locomotory behavior in invertebrate larvae need closer attention before conclusions may be drawn (Gallager et al., submitted).

Equally interesting is the distribution of ophiuroids metamorphosing into the juvenile stage. The juvenile distribution appears as the inverse of the larval distribution (i.e., juveniles are found in abundance only in regions where larvae are not). Although we cannot find a description of planktonic metamorphosis in ophiuroids in the Gulf of Maine, juveniles have been observed from plankton samples collected from depth off the coast of New Hampshire (R. Olsen, personal communication). In our study, juveniles were found in water masses below those containing the larval populations. Furthermore, some juveniles were observed in the well-mixed region to the east of the mixing front in the virtual absence of larvae. A few explanations may be advanced to explain this distribution: Metamorphosing juveniles may cease swimming and fall through the water column, advancing developmentally to the point at which we staged them as juveniles from the video images. This does not explain, however, the sharp boundaries between larvae and juveniles which appears to coincide with our classification of water masses. Nor does it explain how juveniles appear to the east of the mixing front in the absence of larvae in the water column. Significant cross-frontal transport is possible where a tidal mixing front intersects the bottom (Owen, 1981). Perhaps cross-frontal transport coupled with downwelling along the front and recirculation up the sloping bottom produced the distributions reported here. Rapid transitions of temperature, salinity, or some other environmental constituent at the interface between water masses could provide the metamorphic cue triggering rapid advancement into the juvenile stage. This would result in larval stages being distributed in the central portions of water masses and metamorphosing juveniles at the edges. Alternatively, one could imagine that the larval population was at one time more or less uniformity distributed throughout the water column, including in the CCW, MIW and WBW water masses. Some environmental or biochemical constituent of the CCW, MIW and WBW water masses then triggered initiation 
of the metamorphic process. The result would be more developmentally advanced organisms in certain water masses and less advanced organisms in others. A final explanation may be that the larvae and juveniles are from different cohorts or even different species being transported differentially. In view of the previous discussion on the origins of the water masses, the idea that larvae were triggered to metamorphose at the interface between the CBW and SW/MIW seems most plausible.

A third hydrographic region traversed in this VPR section was the western GSC. The two groups of organisms most abundant in these waters were copepods, particularly Calanus sp., and the pteropod Limacina retroversa. L. retroversa was found in the water masses we call CSW1 and CSW2 but not in CSW3, whereas Calanus sp. appeared scattered throughout CSW1 with a major aggregation extending from CSW3 into the thermocline.

High but variable concentrations of $L$. retroversa are common in the waters of the Gulf of Maine during late spring (Bigelow, 1926; Redfield, 1939). One population is believed to immigrate into the Gulf of Maine off the Scotian Shelf in December, and another appears in April (Redfield, 1939). Although growth and developmental rates for $L$. retroversa are unknown, it seems consistent that the gravid adult pteropods we observed spawning in the top few $\mathrm{cm}$ of the water column were immigrants to the Gulf of Maine while the resulting progeny were part of the second population appearing in the spring as discussed by Redfield (1939). Our observations also suggest these pteropods aggregate at the air/water interface at night for reproductive purposes, which is consistent with Redfield's observation that $L$. retroversa is a strong swimmer and vertical migrator from within the thermocline during the day to the surface at night.

The horizontal and vertical constraints placed on the pteropod population by the boundaries of CSW1 and CSW2 were remarkable. Concentrations averaged vertically over $1 \mathrm{~m}$ fell by a factor of 10 within a few meters of the $8.5^{\circ}$ isotherm. 
Like most zooplankton, $L$. retroversa probably has little control over its horizontal movement, being transported passively within a water parcel. In addition, although it is a strong swimmer with swimming speeds exceeding $10 \mathrm{~cm} / \mathrm{s}$ and fall velocities ranging from 3 to $8 \mathrm{~cm} / \mathrm{s}$ depending on size (Gallager, unpublished observations on shipboard), L. retroversa appeared to be constrained vertically at the base of the surface water overlaying the thermocline. Unfortunately, we do not know the distribution of this pteropod during the day, but data from Redfield (1939) suggests it probably does not penetrate much deeper than the thermocline. Aggregated or clumped distributions of $L$. retrovers $a$ at the micro-scale demonstrate how interactions between individuals are possible in certain regions of the water column.

The GSC is known for its high abundance of Calanus finmarchicus during the spring (Bigelow, 1926; Wishner et al., 1988) which attracts large numbers of right whales to the area at this time of the year (Wishner et al., 1988; Beardsley et al., 1995 [Chapter 2 of this thesis] ). C. finmarchicus did not appear as constrained horizontally by water parcels as did Limacina retroversa, although the major copepod aggregations occurred to the west of the mixing front. Of particular interest was a patch exceeding a concentration of $3 / 1$ for a distance of about five $\mathrm{km}$ extending from within the thermocline to the surface. Similar patch dimensions for C. finmarchicus in the GSC were described by Wishner et al. (1988) but their highest concentrations exceeded 40/1. As in the latter study, most copepods were CIV, suggesting a climax community preparing for diapause (Davis, 1987). The western edge of the patch appears bounded by CSW2 while the eastern edge is abrupt within CSW3 without clear relationship to physical features. Wishner et al. (1988) discussed the various biological reasons for formation of a patch such as that seen here, including aggregation in regions of high productivity, swarming by the use of mechanical and chemosensory communication, and predation. Without data on chlorophyll levels in the immediate vicinity of the patch, it is difficult to say if food was a motivation for formation of the patch. Chlorophyll levels in the center of the patch described by 
Wishner et al. (1988) were low, suggesting either intense grazing by zooplankton or the termination of the spring bloom. The location of our transect VPR 22 and its hydrographic features are similar to that of transect D of the last leg of the SCOPEX cruise (Durbin et al., 1995a) in June, 1989 . In the SCOPEX study, a sharp pycnocline at a depth of 15 to $20 \mathrm{~m}$ marked the boundary between low nutrients $\left(\mathrm{NO}_{3}<\right.$ $0.25 \mu \mathrm{M}, \mathrm{NH}_{4}<0.25 \mu \mathrm{M}, \mathrm{PO}_{4}<0.3 \mu \mathrm{M}, \mathrm{SiO}_{2}<1.0 \mu \mathrm{M}$ ) and chlorophyll (Chl $a$ $<1 \mu \mathrm{g} / 1)$ levels above, compared with a subsurface maxima for these variables just below the pycnocline $\left(\mathrm{NO}_{3}>2.0 \mu \mathrm{M}, \mathrm{NH}_{4}>2.0 \mu \mathrm{M}, \mathrm{PO}_{4}>0.8 \mu \mathrm{M}, \mathrm{SiO}_{2}>2.0\right.$ $\mu \mathrm{M}$, Chl $a>3 \mu \mathrm{g} / 1$ ). Durbin et al. (1995b) found Calanus finmarchicus above the pycnocline to be food-limited and in generally poor condition, leading the authors to conclude that the low chlorophyll levels were a result of hydrographic and nutrient interactions rather than grazing by the copepods.

Another possible mechanism for formation of the C. finmarchicus patch found in this study is physical concentration by internal waves at density interfaces, such as at the thermocline (Haury et al, 1983). If C. finmarchicus sink into the thermocline during the day and are concentrated by internal wave activity, migration to the surface as night approaches could occur in a tightly constrained patch. Internal waves are known to exist in this area at this time of the year, but confirmation of their existence in our study is lacking. Wishner et al. (1988) indicated that diurnal vertical migration in the population they studied was weak, and so it is hard to speculate on the effect of internal waves without daytime information from our transect. However, our data on micro-scale patchiness suggests Calanus sp. was aggregating in regions of the water column where static stability was greatest. This is consistent with the idea that biological control of aggregation (swimming behavior) can dominate background physical mixing processes in regions of strong density gradients.

The final major hydrographic feature encountered during this transect was the surface plume of relatively fresh water in the western GSC that is believed to 
originate as river runoff. The VPR transect extended only about five $\mathrm{km}$ into this water mass. Larvaceans, ctenophores, pteropods and chaetognaths were common in this water mass and are known to inhabit this region at this time of the year (Bigelow, 1926).

\subsection{Conclusions}

Our analysis of transect VPR 22 over a distance of $62 \mathrm{~km}$ demonstrates the fine detail of biological and physical information that can be obtained using the VPR. The GSC is a complex area both hydrographically and biologically, but the biological structure can be correlated to the hydrography over a wide range of spatial scales. Strikingly distinct distributions of plankton are bounded by specific water masses, which appear to provide impenetrable barriers both horizontally and vertically to both active and less mobile plankton. While coarse-scale distributions are a function of hydrograhic conditions, fine- and micro- scale distributions appear related to the plankton's ability to aggregate in relation to background mixing intensity. Strong swimmers such as Calanus finmarchicus form dense clusters in regions where static stability of the water column is high, but are distributed randomly in regions were stability is low and the potential for mixing is higher. Conversely, another strong swimmer, Limacina retroversa, appeared to be contained and aggregated in the center of a water mass which flowed in fingerlike projections over cooler, more dense water. The mixing front between the well-mixed Georges Bank water and the mixture of MIW and surface water isolated a water mass apparently originating from the southern flank of Georges Bank in which diatom colonies bloomed over what was most likely a relatively short time period. The residence period for retention of water in this front is unknown, but could be estimated in the future from repeated observations over the course of a few days. The distribution of metamorphosing ophiuroids 
at the base of the mixing front suggests these hydrographic features are important for influencing the distribution of benthic invertebrates, and they may be responsible for enhanced populations of certain species found around Georges Bank along the 70-m isobath (Theroux and Grosslein, 1987; Sinclair, 1988). 


\section{Chapter 4}

\section{Flow-Induced Aggregation of}

\section{Zooplankton at a Front: a}

\section{Two-Dimensional Eulerian}

\section{Numerical Model}

\subsection{Introduction}

What causes dense aggregations of zooplankton in the Great South Channel, such as those described in Chapters 2 and 3 ? In particular, what mechanisms bring about the dense patches of the copepod Calanus finmarchicus that are found in the Great South Channel during the late spring, and that were the focus of the SCOPEX program? Chapter 2 suggests that the very densest aggregations observed during SCOPEX were caused, in part, by some behavior on the part of the animals (such as swarming), but behavior alone cannot explain the patches' existence: typical horizontal water velocities in the Great South Channel are much larger than the animals' 
characteristic swimming speeds, and so it is unreasonable to suppose that copepods form patches by swimming large distances against or across the horizontal flow of the water. Certainly swarming may act to increase the concentration of organisms in a pre-existing patch if animals tend to swim toward their near neighbors, but what causes a patch to form at all?

One clue may lie in the locations of the observed patches. During SCOPEX, Calanus patches and whale sightings (which can indicate the existence of Calanus patches) tended to occur near salinity fronts associated with the low-salinity plume flowing southward along the western side of the Great South Channel (Chen, 1992; see figure 2.1). Could phenomena associated with the motion of this plume lead to the formation of dense patches of copepods? This suggestion, which was put forward by Beardsley and Limeburner (1987 SCOPEX proposal), seems quite plausible. Elevated concentrations of zooplankton are often observed near fronts and river plumes (see, for example, Olson et al., 1994; Govoni and Grimes, 1992; Mackas and Louttit, 1988), and a number of mechanisms have been proposed to explain this phenomenon (e.g. Okubo, 1978; Olson and Backus, 1985; Franks, 1992). In this chapter I present a two-dimensional, Eulerian numerical model of one such mechanism: small-scale convergence in the surface flow, combined with depth-keeping swimming behavior on the part of the animals.

Section 4.2 describes this mechanism, which, following R. Beardsley (personal communication), I shall refer to as "small-scale subduction." Section 4.3 shows an example of data that seem to be consistent with the action of the mechanism: a dense aggregation of Calanus near a front observed during SCOPEX. Section 4.4 describes the mechanics of the model itself. Section 4.5 discusses the velocity fields I shall be using and shows output from a few sample runs of the model made under various conditions. Section 4.6 discusses and explores the model's parameter space, and presents the results of a number of model runs. Finally, Section 4.7 discusses 

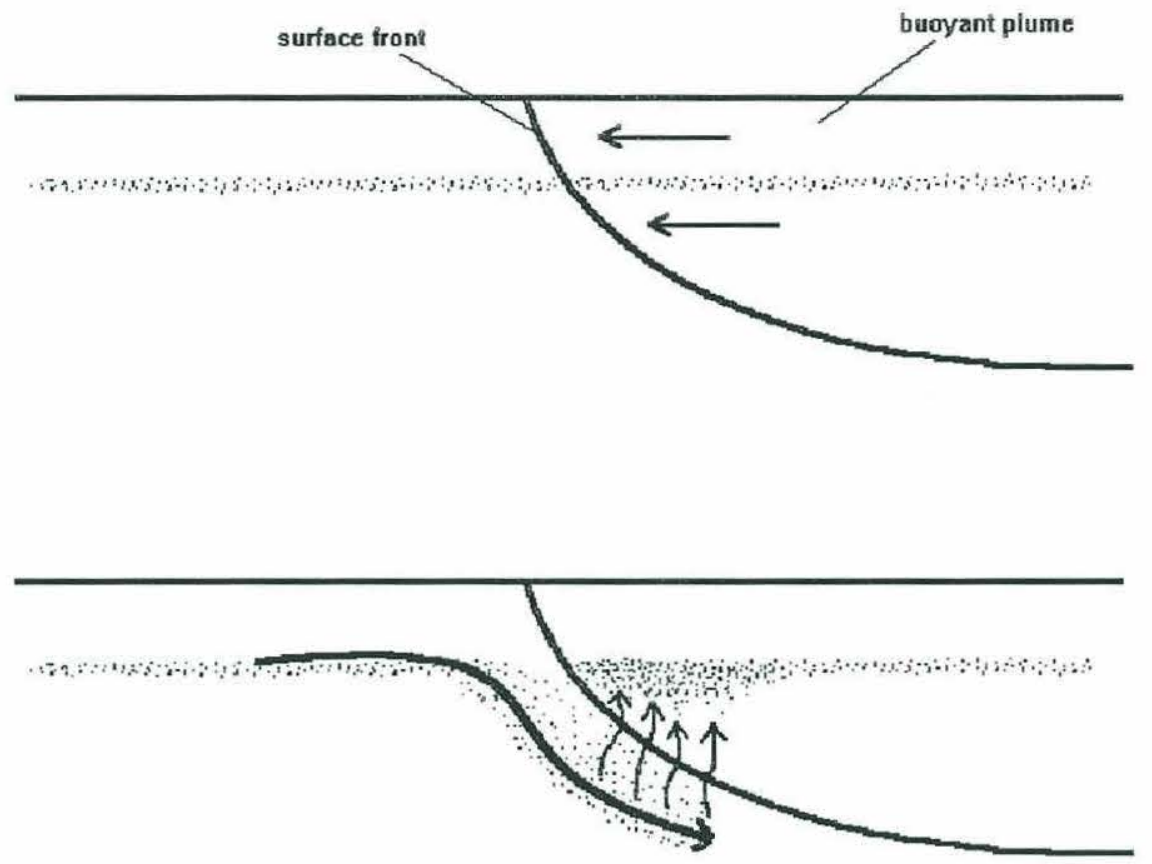

Figure 4.1: Schematic of the small-scale subduction mechanism. A buoyant plume (top) flows over heavier water containing plankton that for some reason swim to maintain a constant depth. As the plankton are swept beneath the plume (bottom, transformed to plume coordinates), they swim up, accumulating in a dense patch behind the plume's leading edge.

some alternative, slightly more realistic, velocity fields and briefly compares output from the model with the SCOPEX data shown in Section 4.3.

\subsection{The Small-Scale Subduction Mechanism}

The small-scale subduction mechanism is depicted schematically in Figure 4.1. In this example, a buoyant plume flows over denser water inhabited by organisms that for some reason are attempting to maintain a constant depth. Such organisms could include various species of phytoplankton that float passively towards the surface, in effect attempting to maintain a constant depth of 0 meters. They could also include zooplankton swimming actively toward the surface or toward some intermediate depth. The model described in this chapter can be used to simulate any of these cases; 
here I shall concentrate on the case of zooplankton that swim actively to maintain a particular target depth-the mathematically most general (although biologically more complicated) case. In the case of floating or surface-seeking organisms, the target depth would simply be the surface itself.

As dense water is subducted beneath the moving plume, the organisms are carried downward, to a level below their target depth. In response they swim upward into the plume water. As the plume advances, additional organisms are swept beneath it, and they too swim upward into the same region of buoyant water. The result is a dense aggregation of plankton somewhat behind the density front that characterizes the plume's leading edge.

The small-scale subduction mechanism is similar to the mechanism invoked by Olson and Backus (1985) to explain unusually high concentrations of a cold-water fish, Benthosema glaciale, in and around a warm-core ring. They note that cold surface water surrounding such a ring can be swept inward toward the edge of the ring, creating a local horizontal convergence there. Since the flow must remain threedimensionally nondivergent, the impinging cold water is swept downward at the ring's edge. Olson and Backus hypothesize that fish within the cold water then swim upward to maintain their depth, causing an accumulation of fish as additional individuals continue to be carried in toward the ring. They go on to model analytically the rate at which fish should accumulate (given certain assumptions) and the time-evolution of the concentration of fish in a two-dimensional section made across the edge of the ring. They hypothesize that inwardly-spiralling streamers may carry some of the fish into the ring's interior.

Franks (1992) presents a two-dimensional, Langrangian numerical model of a similar mechanism. In Franks's model, an initially uniform distribution of organisms is embedded in a convergent or divergent flow field surrounding a front that slants downward diagonally. Franks shows the organisms' distribution after a certain time 
interval for a variety of behavioral patterns: depth-keeping, floating, periodic vertical migration, and passive advection by the surrounding fluid. In the depth-keeping case, the organisms accumulate on the "lighter" side of a convergent frontal flow field.

The numerical model I shall present here relies on fluid velocities and swimming behavior modelled after those used by Franks, but, like the analytical model of Olson and Backus, it describes the movement of organisms from an Eulerian perspective. One advantage of this approach is that it enables the effects of physical diffusion to be included explicitly. As I shall show, diffusion can play an extremely important role in shaping the eventual distribution of organisms, as well as in determining the extent to which an initial distribution of organisms becomes concentrated in a convergent frontal flow field. Before I discuss the model in any detail, however, I shall first describe observations of one case in which the small-scale subduction mechanism seems to be acting.

\subsection{Aggregation Near a Front Observed during SCOPEX}

On June 2, 1989, the R/V Endeavor was conducting a small-scale physical/biological survey as part of the SCOPEX ' 89 cruise program. During the course of the survey, a surface salinity front happened to pass through the study area (see Figure 4.2). As the front passed, a towed acoustic profiler operating at $200 \mathrm{kHz}$ (described in Chapter 2 and in Macaulay et al., 1995) detected high levels of biomass on the buoyant side of the front between depths of about 5 and 13 meters. (No acoustic data were taken above 4 meters depth.) Figure 4.3 shows the relevant acoustic data, taken between SCOPEX '89 CTD stations 129 and 130. Net tows in the survey area

revealed that the biomass in the upper water column at that time and place consisted 

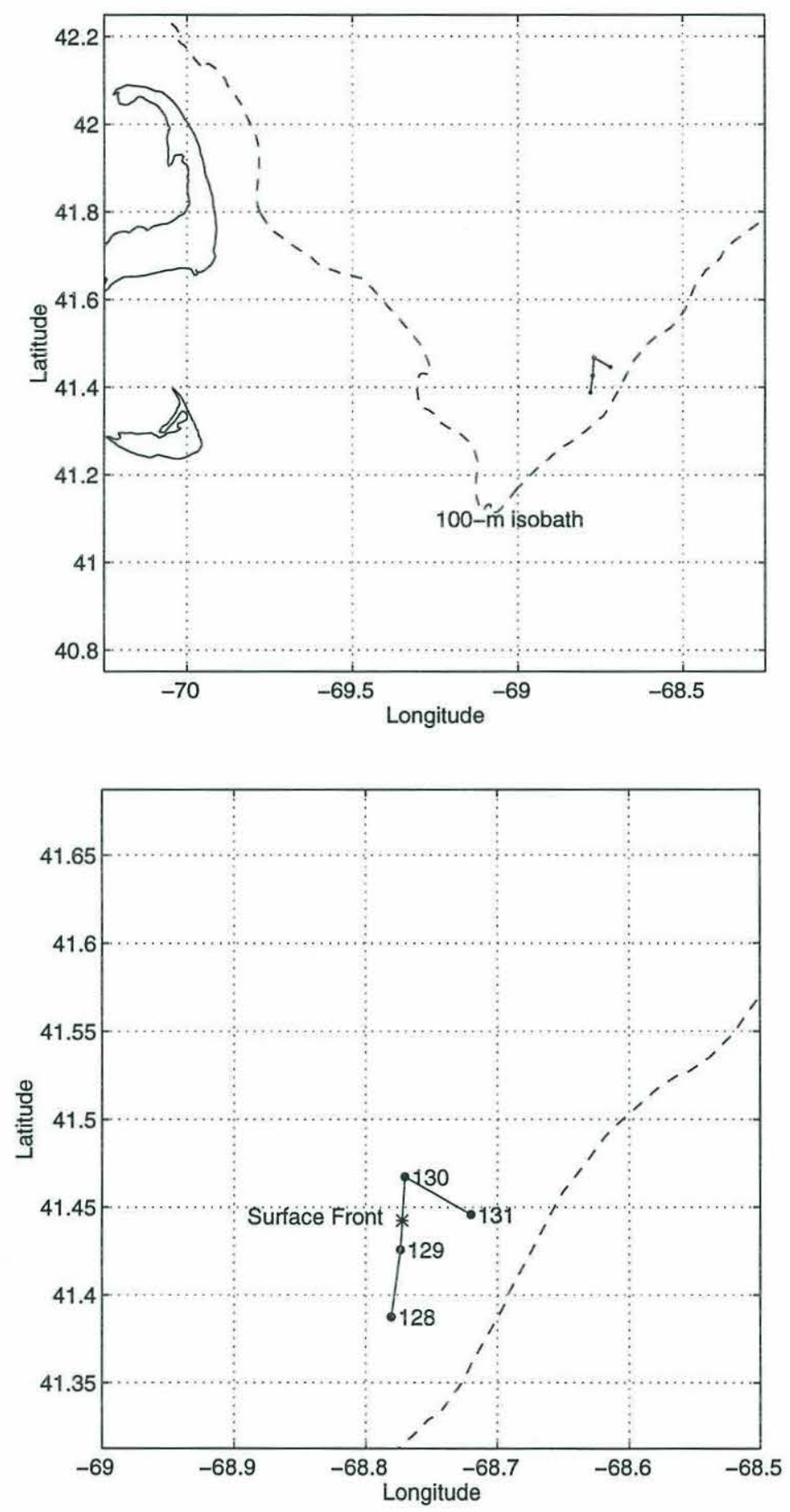

Figure 4.2: Site of SCOPEX small-scale survey made on June 2, 1989 (top). Positions of CTD stations 128-131 are marked in a close-up view (bottom), as is the approximate position of the surface front observed during the survey. 


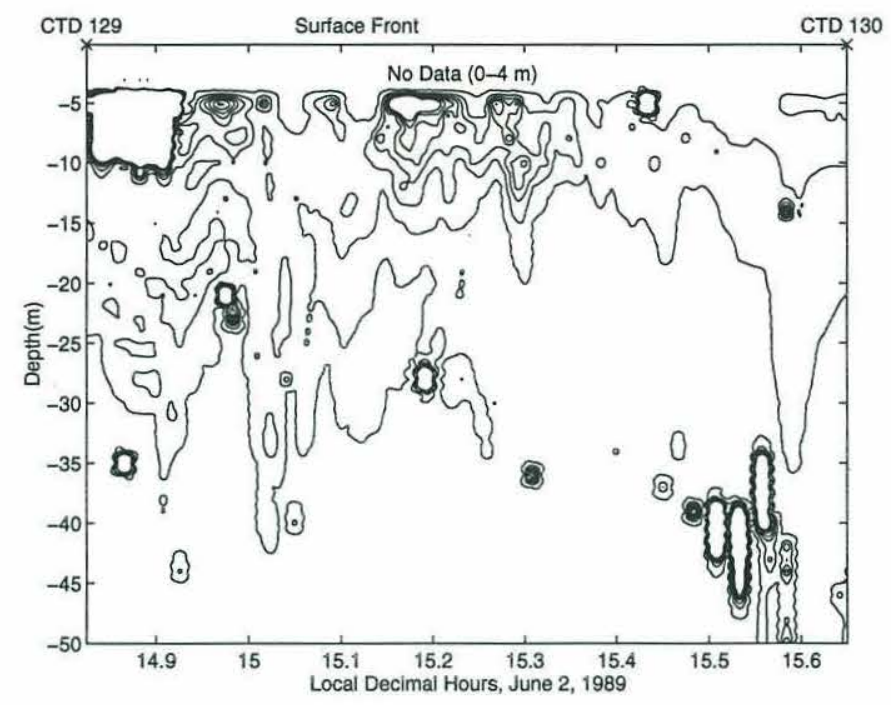

Figure 4.3: Acoustic data taken across a small-scale salinity front during SCOPEX. The front was encountered at approximately local decimal hour 15.1, between CTD stations 129 and 130; a strong biomass signal is visible soon afterward. Note the weaker but thicker layer of biomass on the denser side of the front (left-hand side in this image). Strong peaks at depth around local decimal hour 15.5 are probably fish. Strong signal at about local decimal hour $14.85-14.9$ is noise associated with the recovery of CTD 129. Contours represent estimated biomass concentrations of $1,9,17,25,33,41$ and $49 \mathrm{~g} / \mathrm{m}^{3}$.

nearly entirely of Calanus, and so the elevated levels of biomass detected acoustically can be interpreted to be a dense Calanus patch. Note that the biomass levels in the patch are highest at shallow depths and towards the leading edge of the front, with some of the animals spread out below the region of highest concentration and others spread out behind it (that is, away from the leading edge of the front and towards the more buoyant water-to the right in the figure). Note also the weaker but thicker layer of plankton just on the denser side of the front. In Section 4.7, I shall compare this distribution pattern to patterns produced by the model to be presented later in this chapter.

During this segment of SCOPEX '89, Calanus were observed to be remaining at the same depth for many hours (Wishner et al., 1995), and so one ingredient of the small-scale subduction mechanism-depth-keeping on the part of an organismseems to be present. Is the other ingredient-subduction of denser water underneath 


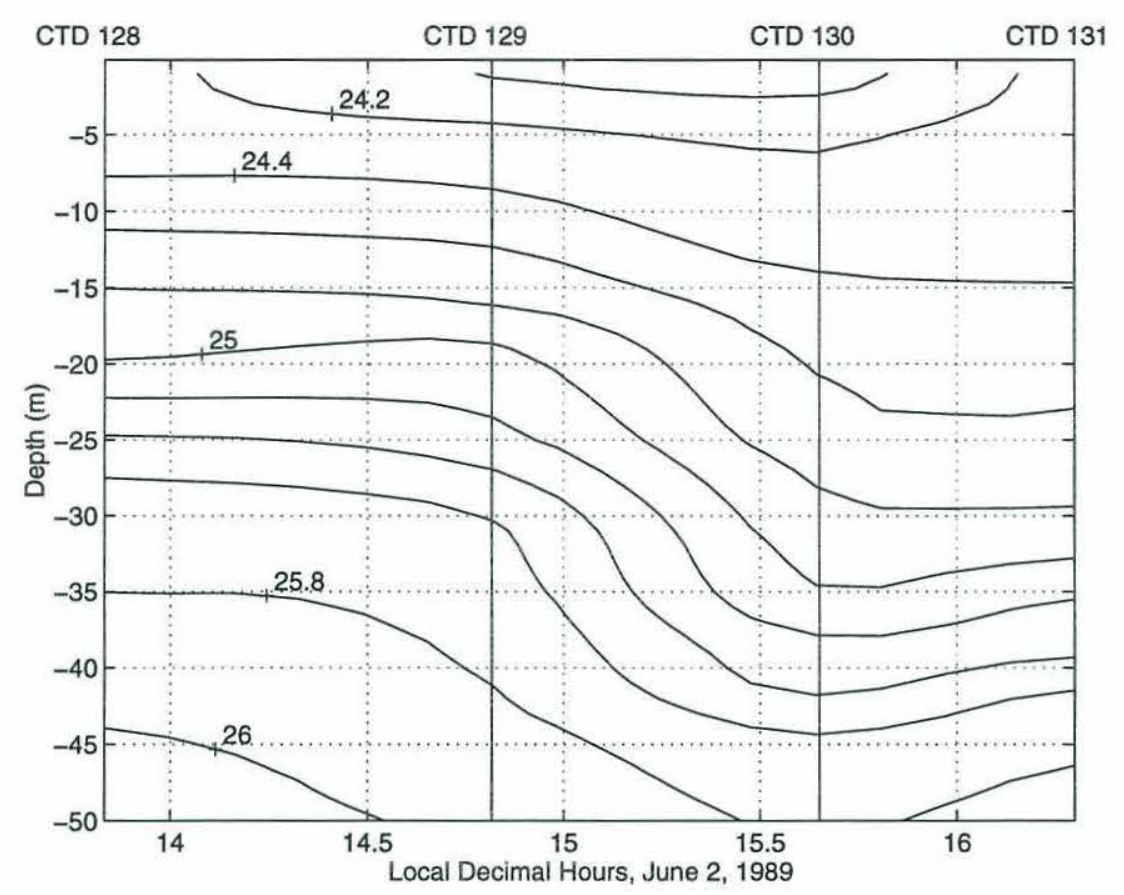

Figure 4.4: Contours of $\sigma_{t}$ in the region of the front observed on June 2, 1989. The front was encountered between CTD stations 129 and 130 .

more buoyant water-present as well? Based on somewhat limited physical data, it appears that subduction was indeed occurring in this case.

Figure 4.4 shows contours of $\sigma_{t}$ between CTD stations 128 and 131. Between stations 129 and 130 (the region shown in Figure 4.3), the contour lines do trend downward, as would be expected during subduction. Contours of temperature (Figure 4.5, top), salinity (Figure 4.5, bottom), light transmission (Figure 4.6, top) and fluorescence (Figure 4.6, bottom) show the same trend. (CTD instrumentation for these sections was as described in Chapter 2.)

From the acoustic section shown in Figure 4.3, it appears that the denser water is redirected downward by about 15 meters as it is subducted below the layer of buoyant water. (The layer of biomass is centered at about ten meters depth on the less dense side of the front-to the right in the figure-whereas the thin layer that seems to be pushed downward near the leading edge of the front-at about 15.15 

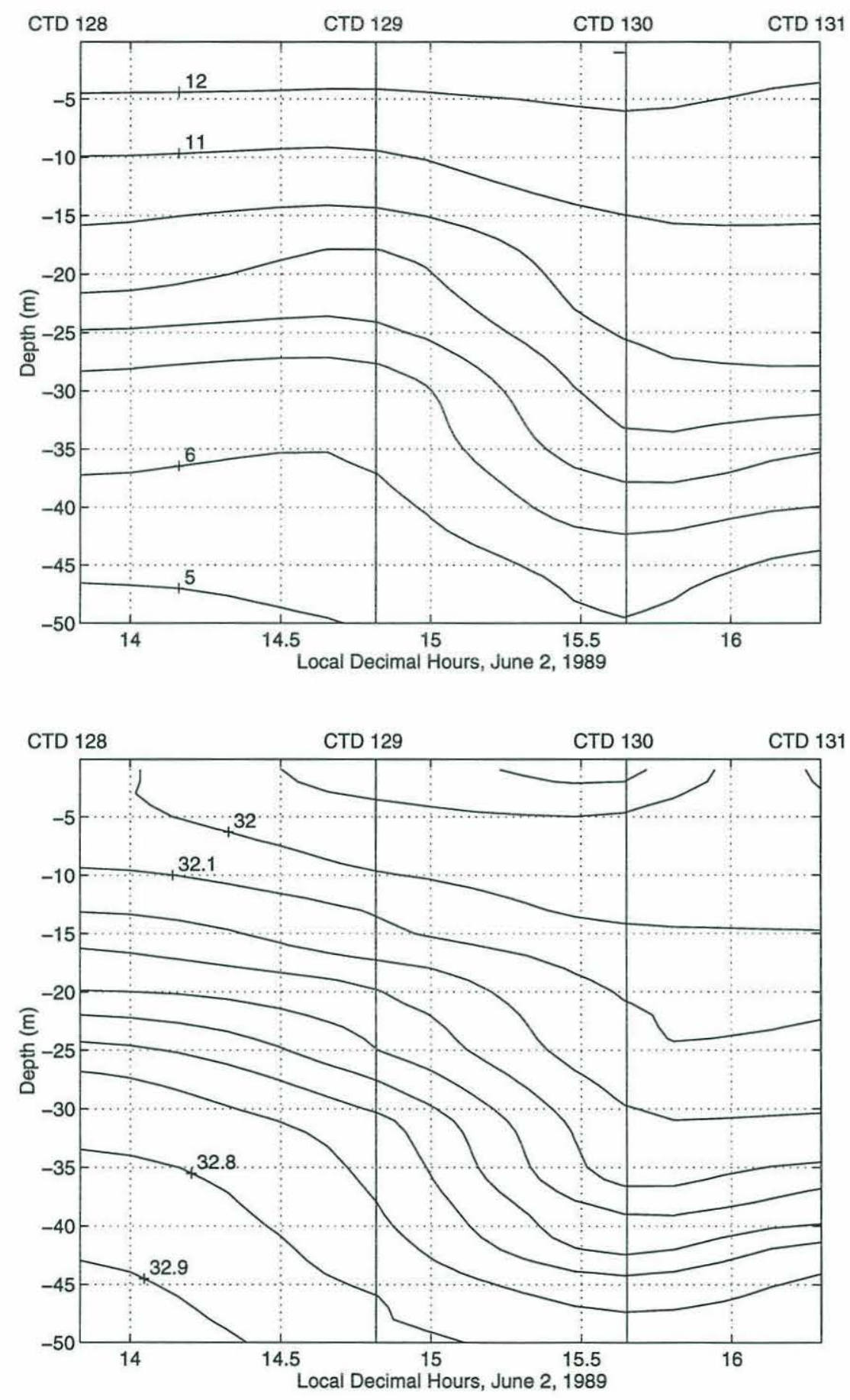

Figure 4.5: Contours of temperature $\left({ }^{\circ} \mathrm{C}\right.$, top) and salinity (psu, bottom) observed in the region of the front observed on June 2, 1989. 

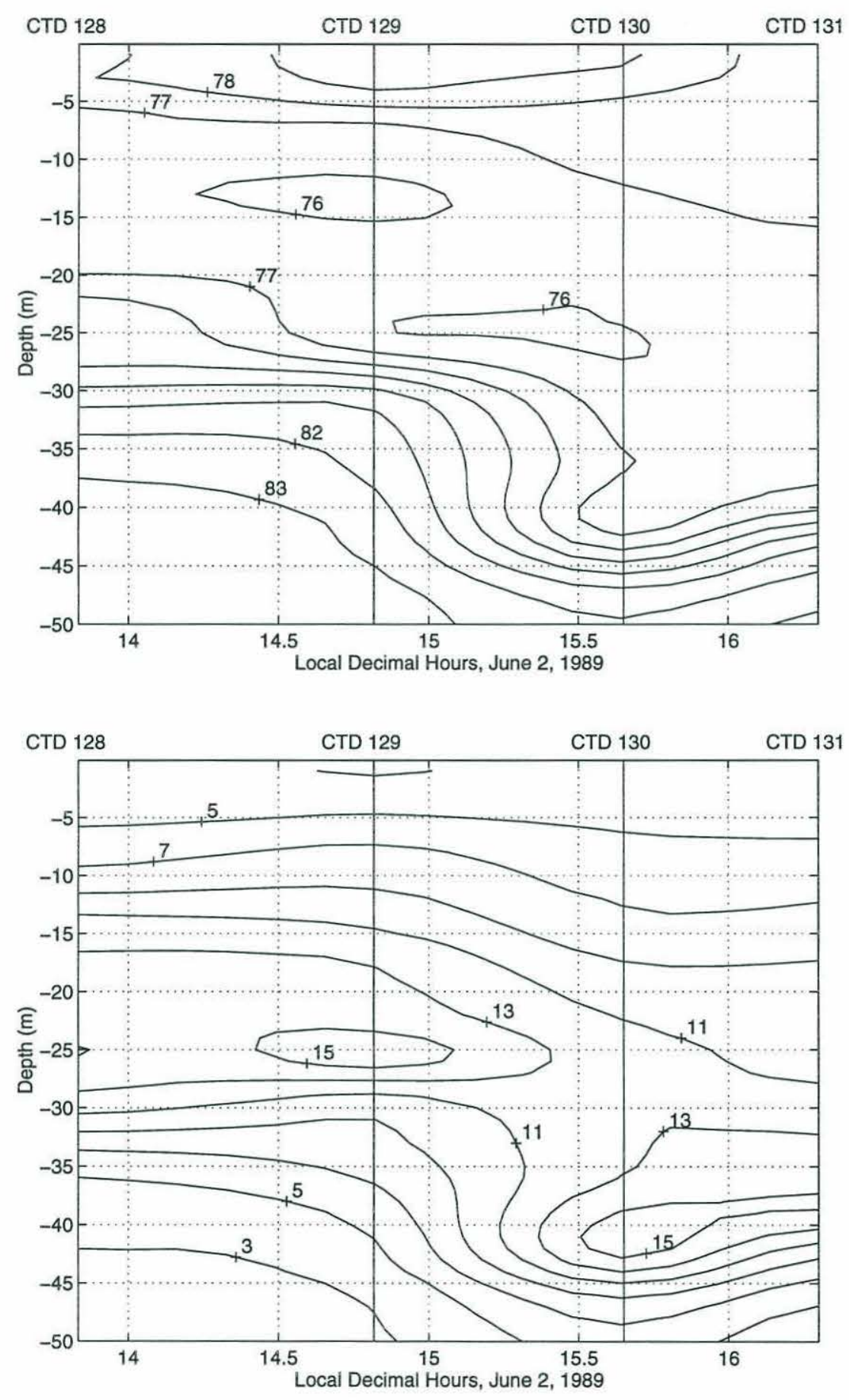

Figure 4.6: Contours of light transmission (\% transmitted, top) and fluorescence (\%, bottom) observed in the region of the front observed on June 2, 1989. 
local decimal hours in the figure-is centered at about 25 meters.) If subduction is really taking place, one would expect that water found at station 129 would have the same physical properties as water found 15 meters deeper at station 130 . Figures 4.7, 4.8 and 4.9 show that this is indeed the case. These figures show profiles of $\sigma_{t}$, temperature, salinity, light transmission and fluorescence for station 130, plotted on the same axes as profiles from station 129; in the figures, the profiles from station 129 have been offset downward by 15 meters in order to compare the water found at station 129 with the water found 15 meters deeper at station 130 . The resemblances are striking, especially in the plots of light transmission and fluorescence, where sharp peaks in the profiles line up almost precisely. The upper ten meters or so of the

profiles from station 129 do differ from the corresponding water at station 130 . These differences may be attributable to surface processes that took place between the time the water was subducted and the time it was observed, to processes associated with the subduction itself, or perhaps to some non-two-dimensional process.

These data do not show definitively that subduction was taking place, or that the dense patch of Calanus is due to the small-scale subduction mechanism. They are consistent with the action of this mechanism, however. One goal in creating a numerical model of the mechanism is to be able to identifiy the characteristics one might expect of a dense patch of organisms created by small-scale subduction. As I shall describe in Section 4.7, the patch shown here does have some of those characteristics. In the next section, I shall describe the details of the model itself; later sections show the results of running the model under various conditions.

\subsection{The Model}

The model I present here is based on the regularly-spaced grid shown in Figure 4.10. Organisms are modelled as a dimensionless "concentration", which is ad- 

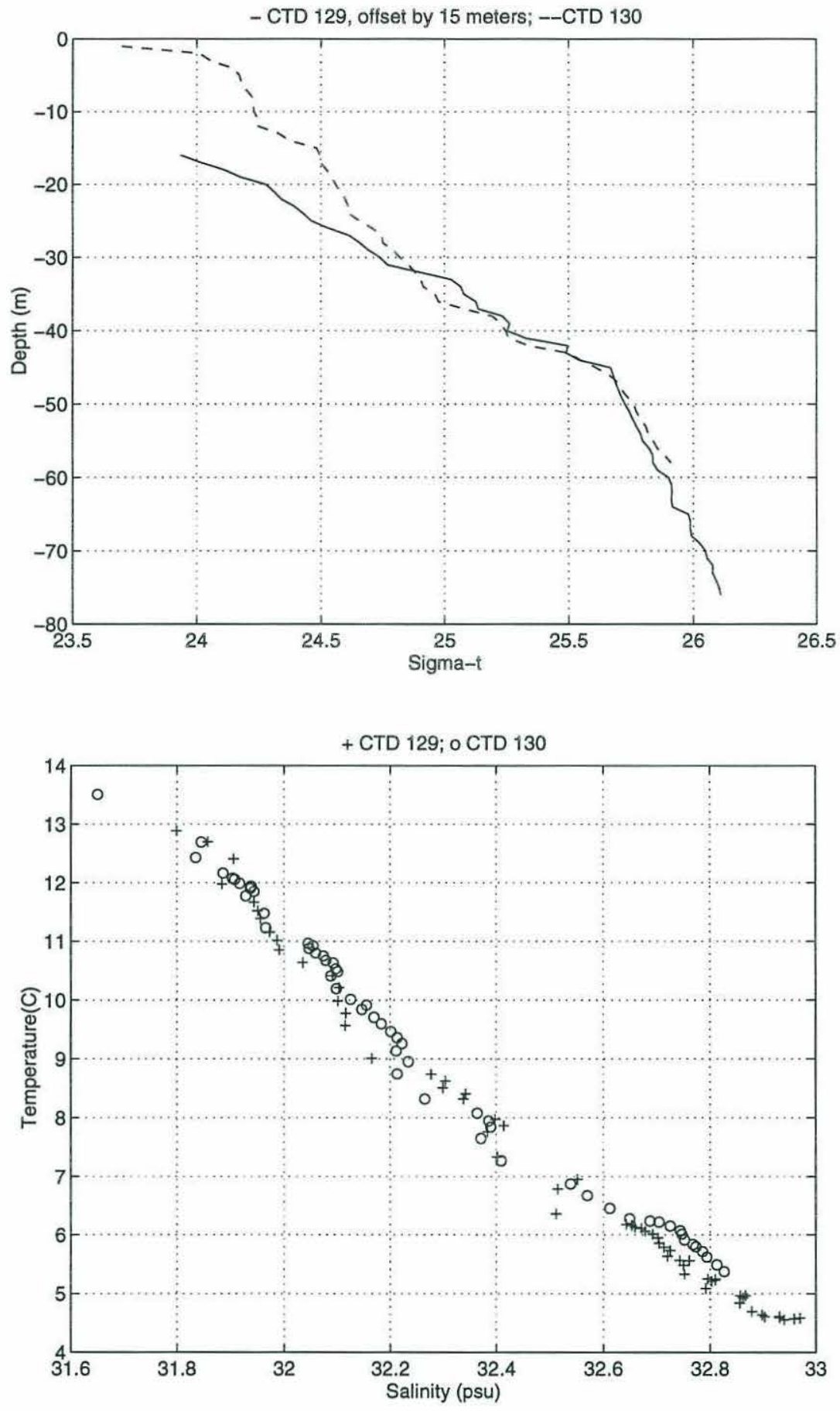

Figure 4.7: Profiles of $\sigma_{t}$ (top) from CTD stations 129 (solid) and 130 (dashed). In this plot, the profile from station 129 has been offset downward by 15 meters; except for the surface layer, water at station 129 has much the same properties as water found 15 meters deeper at station 130 . T-S diagram (bottom) for stations $129(+)$ and $130(0)$. 

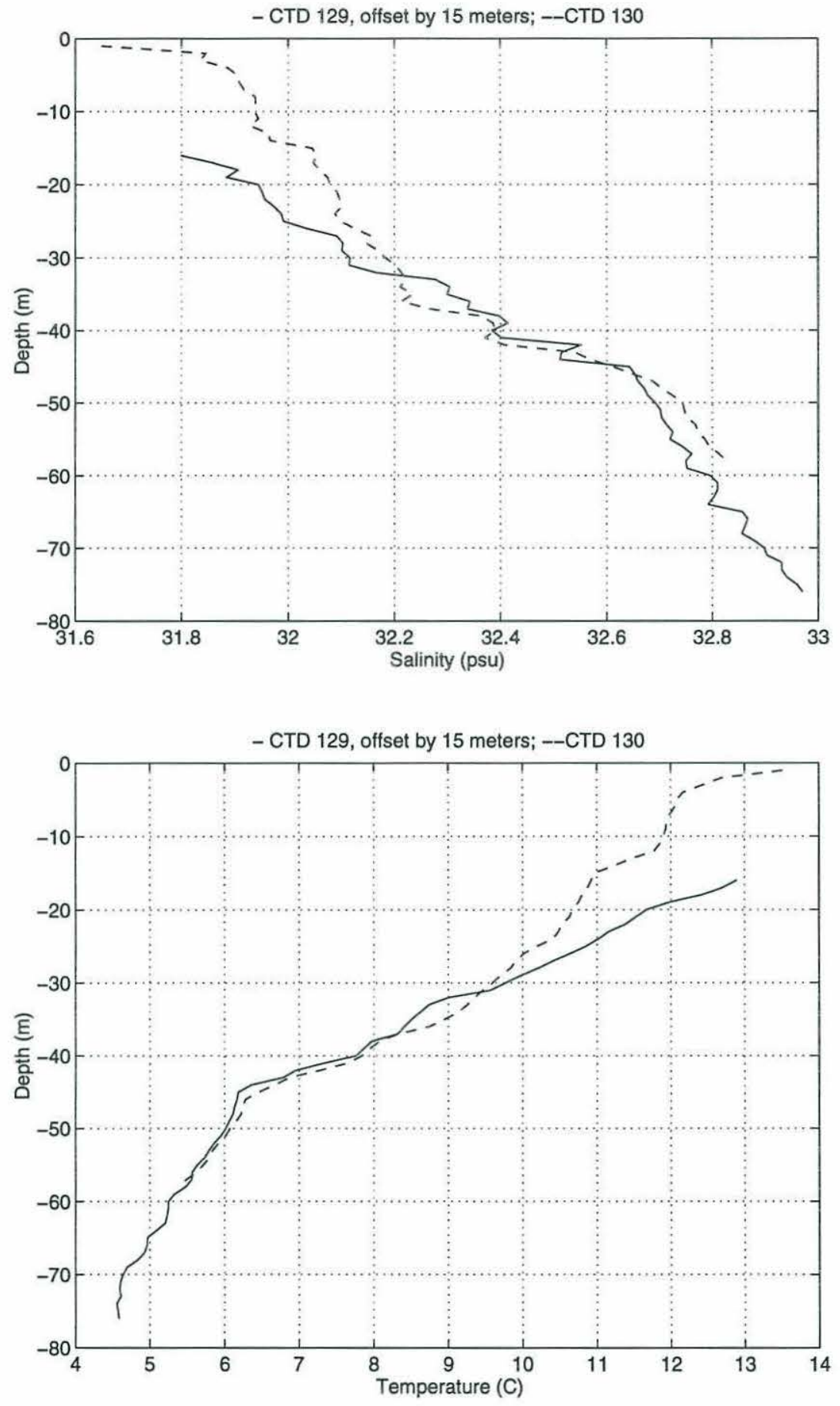

Figure 4.8: Profiles of salinity (top) and temperature (bottom) from stations 129 (solid) and 130 (dashed). As in Figure 4.7, the profiles from station 129 have been offset downward by 15 meters. 

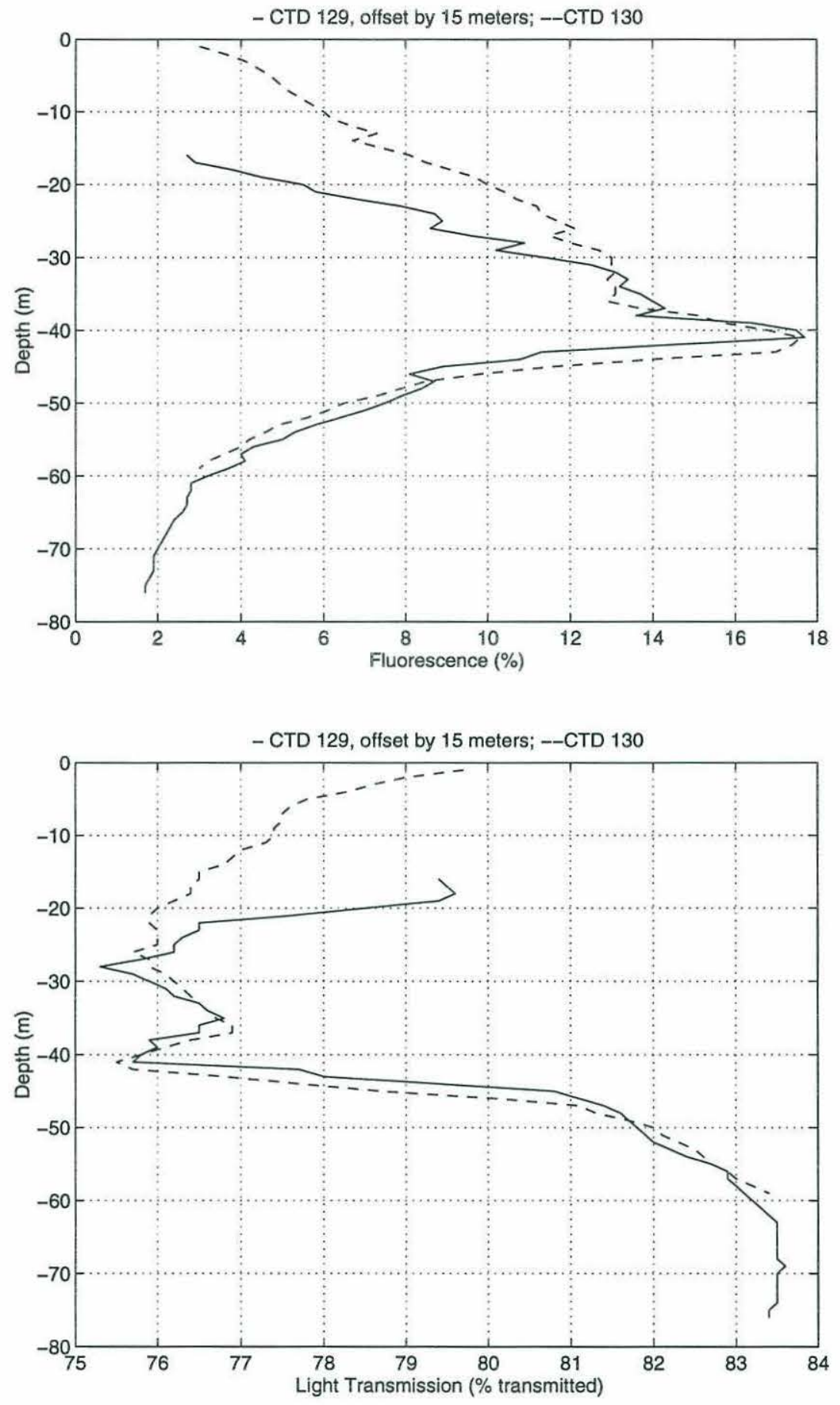

Figure 4.9: Profiles of fluorescence (top) and light transmission (bottom) from stations 129 (solid) and 130 (dashed). As in Figures 4.7 and 4.8, the profiles from station 129 have been offset downward by 15 meters. 

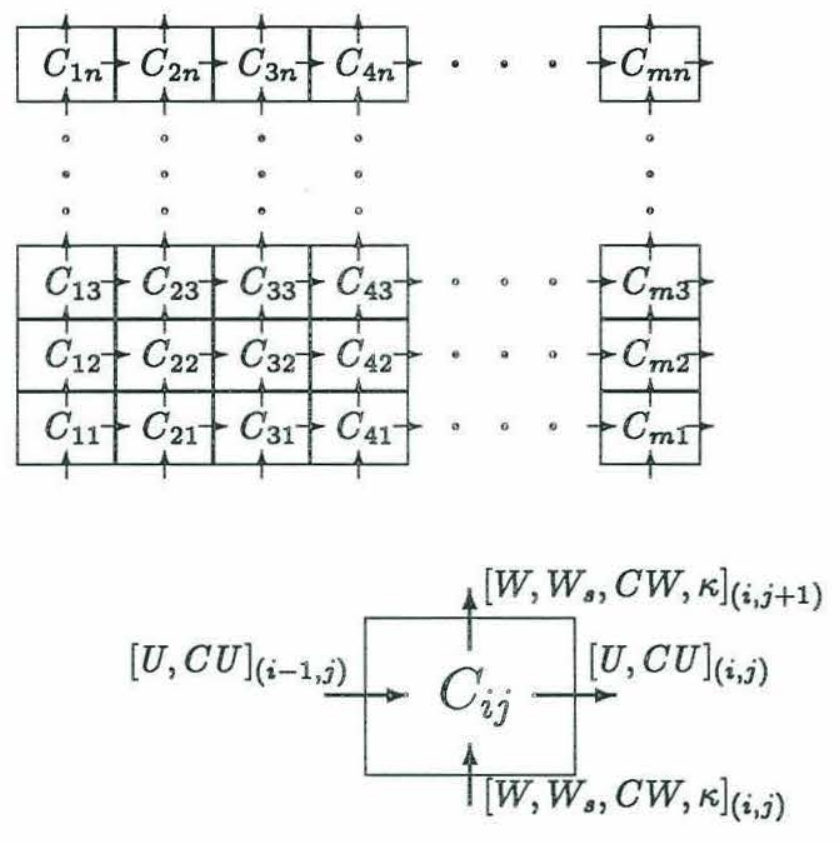

Figure 4.10: Grid for the model described in this chapter. Concentration of plankton $(C)$ is defined at the center of each gridcell. Water velocities $(U, W)$, swimming velocity $\left(W_{s}\right)$ and vertical diffusion coefficients $(\kappa)$ are defined at gridcell walls, as are advected quantities of concentration $(C U, C W)$.

vected and diffused through the grid according to the equation:

$$
\frac{\partial C}{\partial t}=-\frac{\partial}{\partial z}\left(C \cdot\left(W_{f l u i d}+W_{s w i m}\right)\right)-\frac{\partial}{\partial x}\left(C \cdot U_{f l u i d}\right)+\frac{\partial}{\partial z}\left(\kappa \frac{\partial C}{\partial z}\right)
$$

where $C$ is the concentration of plankton at a given location, $W_{\text {fluid }}$ is the vertical component of the fluid's velocity, $W_{\text {swim }}$ is the animals' vertical swimming speed, $U_{\text {fluid }}$ is the horizontal component of the fluid's velocity, and $\kappa$ is the vertical diffusion coefficient. The animals swim vertically with speeds that depend only on depth, although the form of that depth-dependence may take into account such factors as the vertical variation in light level or in the concentration of some prey organism. To determine the rate at which animals are advected, this swimming speed is added to the water's velocity, which is time-invariant. The water's coefficient of vertical diffusion (which may vary throughout the grid) is also time-invariant. It is assumed that the animals' horizontal swimming speed is insignificant compared to the fluid's horizontal velocity. Although horizontal diffusion may be important in certain situations where 
small-scale subduction occurs, it is ignored in the model I shall discuss here. (For a brief discussion of the way diffusion is treated in the model, see Appendix A.)

Concentration is defined at the center of each gridcell. Horizontal velocities are defined at the cells' horizontal faces, and vertical velocities (both swimming velocities and fluid velocities) are defined at the top and bottom faces of each cell. Diffusion is Laplacian. In order to determine the quantity of concentration advected from cell to cell, concentration must be estimated at the points for which velocity is known (i.e. the gridcell faces). This is done by the two-dimensional QUICK scheme (Quadratic Upstream Interpolation for Convective Kinematics) described by Leonard (1979a, 1979b, 1988), in order to avoid the spatial oscillations and instabilities that can affect models based on central-difference algorithms when advection is much greater than diffusion. (For descriptions of the one- and two-dimensional QUICK algorithms, see Appendix B.)

The boundary condition at the water's upper surface is no-flux. The bottom boundary condition, achieved through the use of two pseudo-layers below the bottom layer, is $\frac{\partial C}{\partial z}=0$, in order to eliminate the effects of spurious diffusion through the bottom of the array while still permitting animals to be advected downward out of the array. Wherever the water's flow field is inward at the sides of the model array, the boundary condition is $\frac{\partial C}{\partial t}=0$. Under this condition, any feature at the edge of the array is effectively infinite in extent, since organisms that are advected from the edge into the array's interior are immediately replaced by the same quantity of organisms at the same depth at the array's edge. This is useful for modelling, for example, an infinite, uniform layer of plankton. (The initial concentration can, of course, be set to zero at the boundary, in order to prevent any unwanted organisms from entering the array through its sides.) Where the flow field is outward at the sides of the array, an inactive pseudo-layer is employed to give the boundary condition $\frac{\partial C}{\partial x}=0$. 
The model is written in the Matlab programming and display language. Some portions of the model code were adapted from a model developed by Geyer (1993), although the code has been altered substantially in order to adjust for differences between the environment modelled in that paper and the environment modelled here. The most significant difference is that in this environment advection is important in both the vertical and the horizontal directions, whereas in Geyer (1993) vertical advection is much weaker than vertical diffusion. For that reason, the model presented here employs the QUICK method in both the vertical and horizontal directions. In addition, this model employs the fully two-dimensional QUICK algorithm, in order to reproduce two-dimensional advection more accurately.

\subsection{Velocity Fields and Sample Runs}

In most of the model runs I shall show in this chapter, the fluid's velocity field and the depth-dependence of the animals' swimming are modelled after those suggested by Franks (1992). (See Figure 4.11.) The flow field represents a highly simplified convergent front, in which the line of convergence slopes beneath the fluid on one side of the array, which I shall refer to as the "buoyant" or "less dense" side (although dynamic quantities such as density are not considered in constructing the velocity field). This can be viewed as a simplified model of the buoyant plume shown in Figure 4.1; in this analogy, the grid coordinates should be viewed as travelling with the plume, so that fluid velocities do not change over time in the grid/plume coordinate system. The animals' swimming-speed profile follows a hyperbolic-tangent curve, so that animals far from their target depth ( $Z_{0}$ in the figure) swim towards it rapidly, whereas animals near the target depth do not swim as quickly but still seek the target depth. The fluid follows streamlines defined by:

$$
\psi=\psi_{0} \cdot z \cdot \tanh \xi
$$



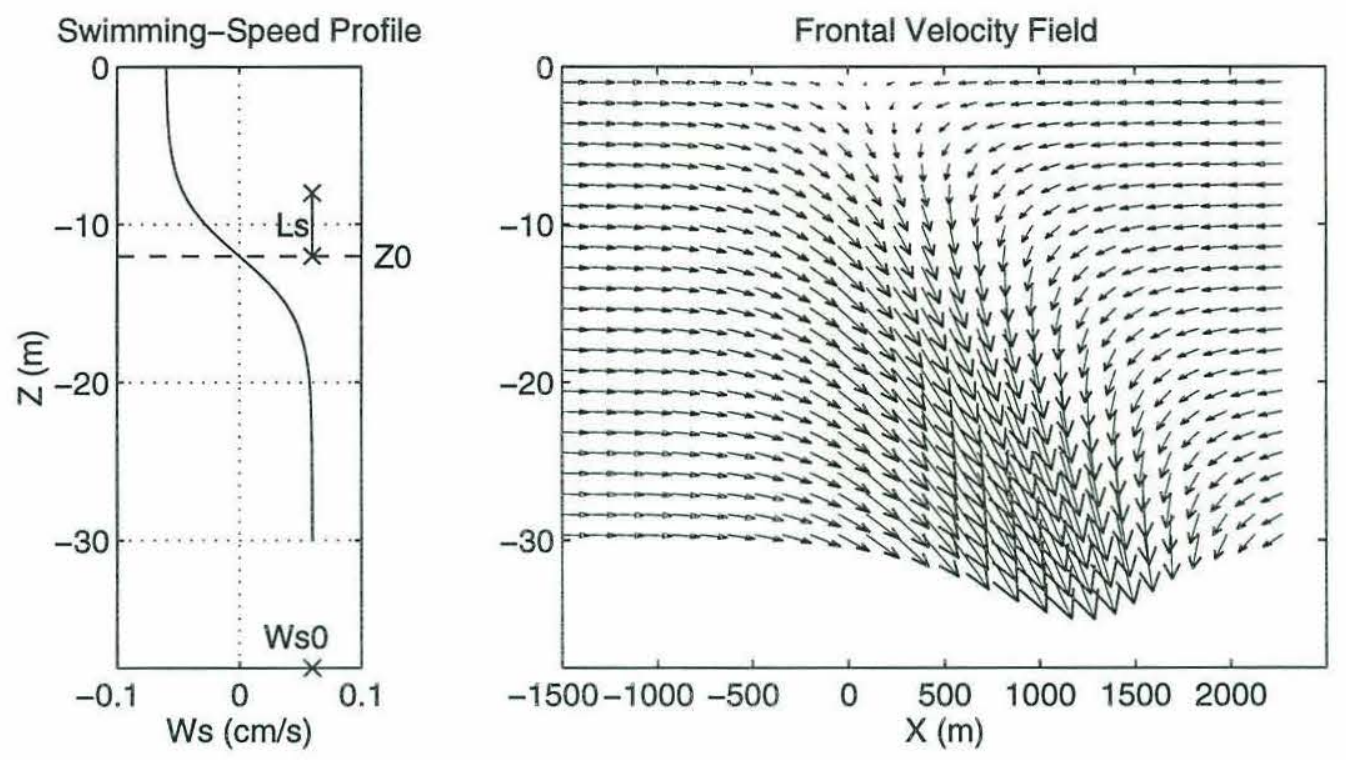

Figure 4.11: Swimming speed (left) and water velocity (right) used in the model runs presented in this chapter. Modelled after those suggested by Franks (1992). As marked in the left-hand figure, $W_{s 0}$ is the organisms' maximum swimming speed, $Z_{0}$ is the depth toward which they are swimming, and $L_{s}$ is a length scale of the swimming-speed profile.

where $\xi=\left(\frac{x}{r}+\frac{z}{h_{0}}\right)$, with $z \equiv 0$ at the surface and $z<0$ at depth, so that:

$$
U_{\text {fluid }}=U_{0} \tanh \xi+U_{0} \frac{z}{h_{0}} \cdot\left(1-(\tanh \xi)^{2}\right)
$$

and

$$
W_{\text {fluid }}=-U_{0} \frac{z}{r} \cdot\left(1-(\tanh \xi)^{2}\right)
$$

In Figure 4.11, $h_{0}=21.2 \mathrm{~m}$ and $r=750 \mathrm{~m}$. The animals' swimming speed is given by:

$$
W_{s}=-W_{s 0} \tanh \left(\frac{\left(z-Z_{0}\right)}{L_{s}}\right),
$$

where $Z_{0}$ is the depth towards which the animals are swimming and $L_{s}$ is the length scale of the animals' swimming-speed profile. In all the cases shown here the vertical diffusion coefficient, $\kappa$, is kept constant throughout the grid.

Figure 4.12 shows the results of a typical model run. The four plots at the top 

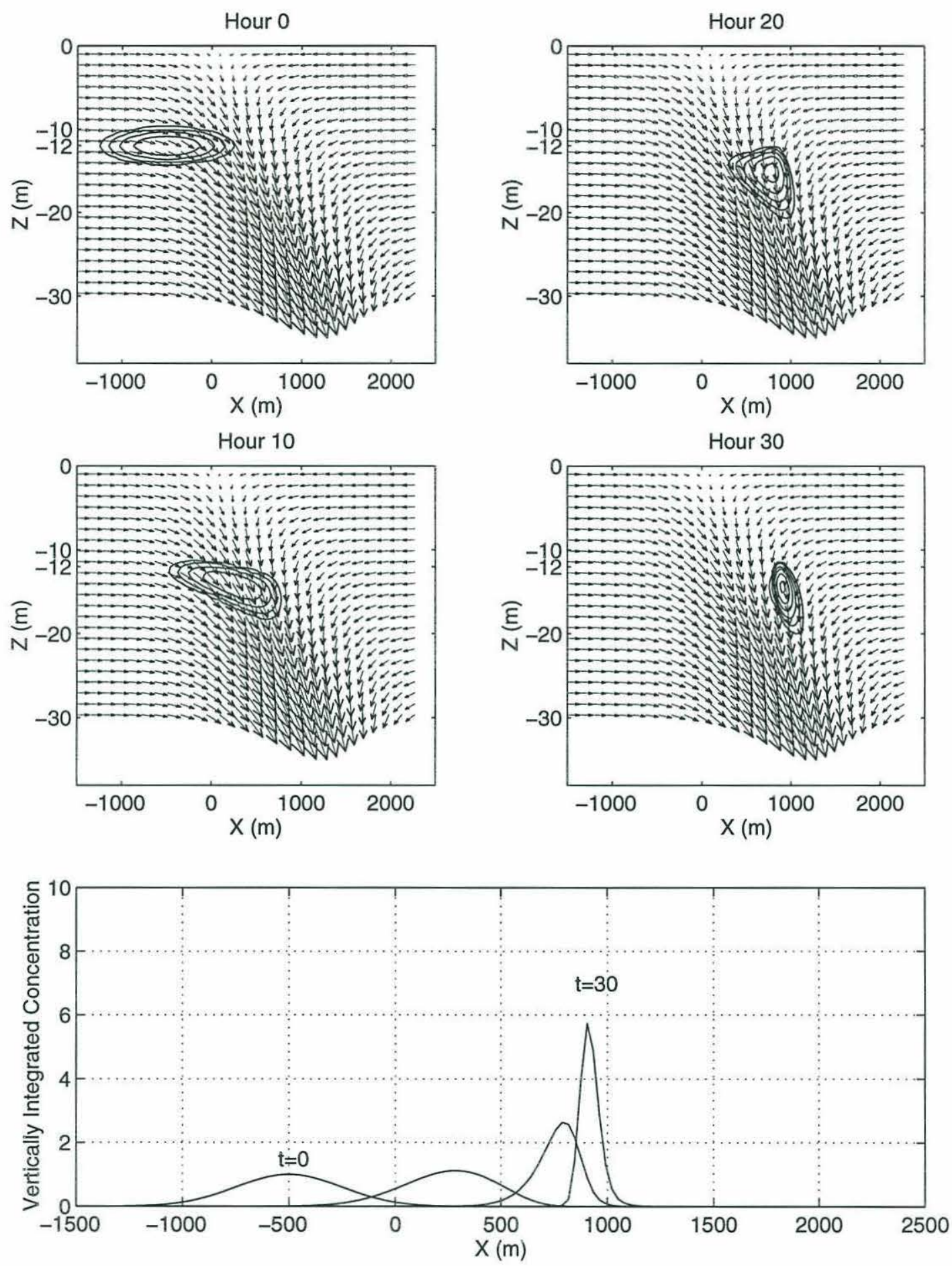

Figure 4.12: Typical model run. Initial plankton distribution is shown, along with the distributions after 10,20, and 30 model hours. Concentration is contoured logarithmically: each contour represents an increase in concentration by a factor of $\sqrt{10}$. The bottom part of the figure shows vertically integrated concentration at each of the displayed times, plotted as a function of horizontal position. 
of the figure show the initial distribution of organisms and the distributions after 10, 20 , and 30 hours of model time. Concentration is contoured logarithmically, so that each contour line represents an increase in concentration by a factor of $\sqrt{10}$. The initial concentration is arranged in such a way that if the water were not in motion, the organisms' vertical swimmng toward their target depth $\left(Z_{0}\right)$ would be exactly balanced by vertical diffusion away from the maximum in plankton concentration at $Z_{0}$. In the horizontal, the initial distribution follows a smooth Gaussian curve. The plot across the bottom of the figure shows the vertically integrated concentration at each of the displayed times, plotted as a function of horizontal position. The curves have been normalized so that the maximum vertically integrated concentration at time $t=0$ is equal to unity.

In this example, the animals' target depth is $Z_{0}=-12$ meters, and their maximum vertical swimming speed $\left(W_{s 0}\right)$ is $0.06 \mathrm{~cm} / \mathrm{s} . U_{0}$, the water's horizontal speed at $x=\infty$, is $2.12 \mathrm{~cm} / \mathrm{s}$. The mean downward velocity component of the water in the model array is $0.016 \mathrm{~cm} / \mathrm{s}$, and the water's maximum downward vertical component (at the bottom of the array) is $0.085 \mathrm{~cm} / \mathrm{s}$. The vertical diffusion coefficient is 0.74 $\mathrm{cm}^{2} / \mathrm{s}$. At the beginning of the run, the animals are distributed broadly on the dense side of the front. As they are swept beneath the lighter water, however, they swim upward, crossing the front and aggregating in a dense patch on the lighter side of the front at a depth somewhat below their target depth. In this and future plots, I shall call the point where final plankton concentration is highest the "accumulation point".

To illustrate the effect of the animals' vertical swimming, Figure 4.13 shows what happens if the water velocity and diffusion coefficient are kept the same but the animals do not swim at all. In this case the animals do not aggregate. Instead, they are carried downward and out of the model array, acting as almost passive tracers of the flow field (although diffusion causes the distribution of organisms to spread 

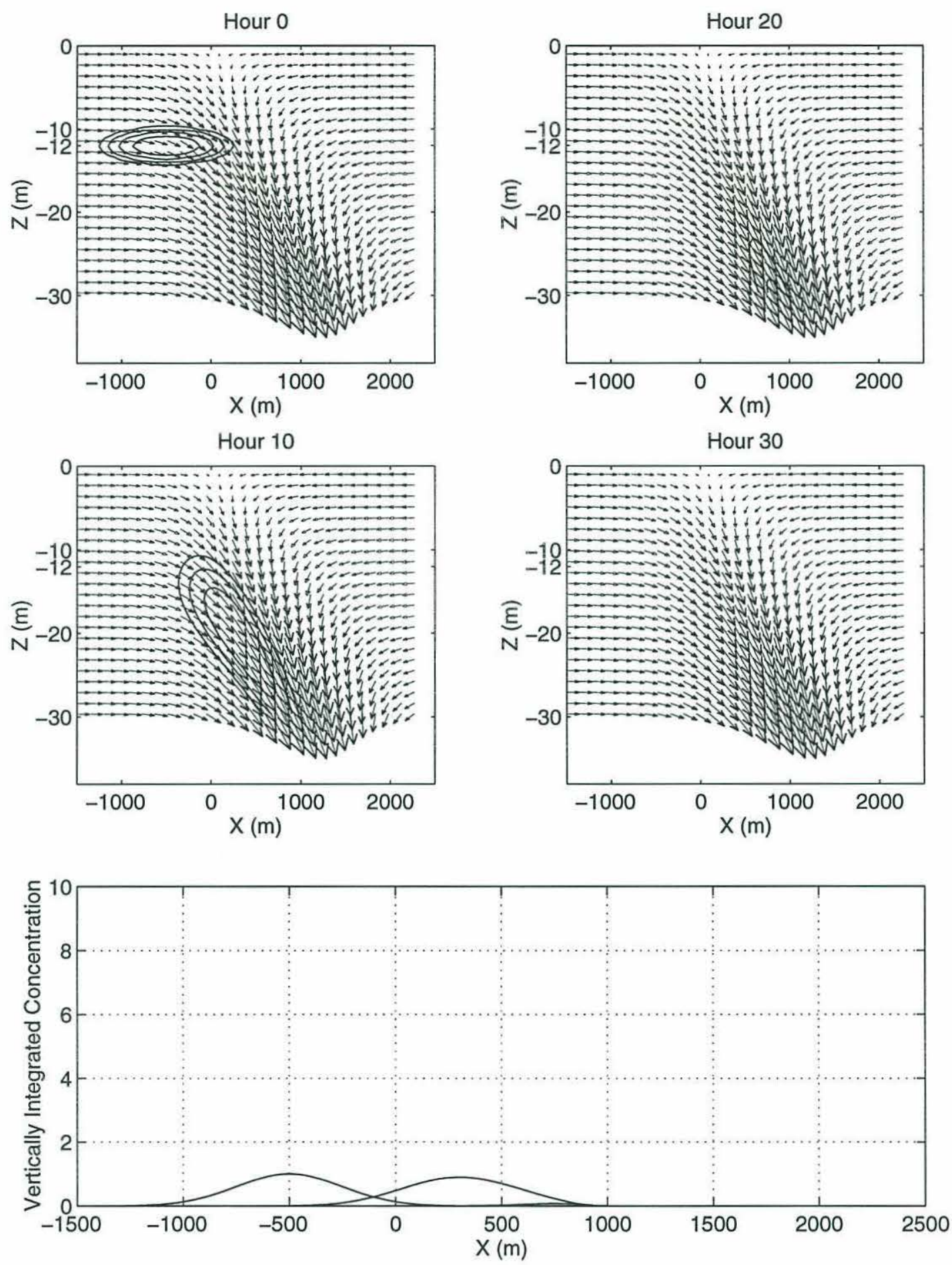

Figure 4.13: Run in which plankton swimming speed is set to zero. The animals are advected down and out of the model array. 
slightly in the vertical). The animals never cross to the "light" side of the front, except for some slight spreading across the boundary due to diffusion.

Figures 4.14 and 4.15 show the model's behavior in two other situations: when the animals' target depth is near the surface, and when the animals are initially distributed in an infinite, uniform layer. When the target depth is near the surface, the effect of the front is much the same as when the animals are trying to swim to some intermediate depth. In the case shown, the target depth is $Z_{0}=-1$ meter. As before, the animals aggregate on the lighter side of the front at a depth just below their target depth. This case is analogous to the mechanism proposed by Yoder et al. (1994) to explain extremely high concentrations of buoyant diatoms observed in a "line in the sea" visible in 1992 photographs taken from the space shuttle Atlantis. In the case of an infinite layer (Figure 4.15), the animals aggregate approximately where they aggregated in the example shown in Figure 4.12, and the layer is slightly deformed in the region of the front.

\subsection{Parameter Space}

How sensitive is the eventual distribution of plankton to various characteristics of the flow field and the animals' vertical swimming profile? To what extent do such factors as swimming speed, water velocity and the vertical diffusion coefficient affect how (or whether) plankton aggregate in the presence of a small-scale surface front? In this section I shall address such questions by nondimensionalizing various model parameters and exploring how changes in the nondimensional parameters affect the final distribution of plankton. I shall pay particular attention to the role played by vertical diffusion in determining both the degree to which plankton aggregate and the shape of the final aggregation. 


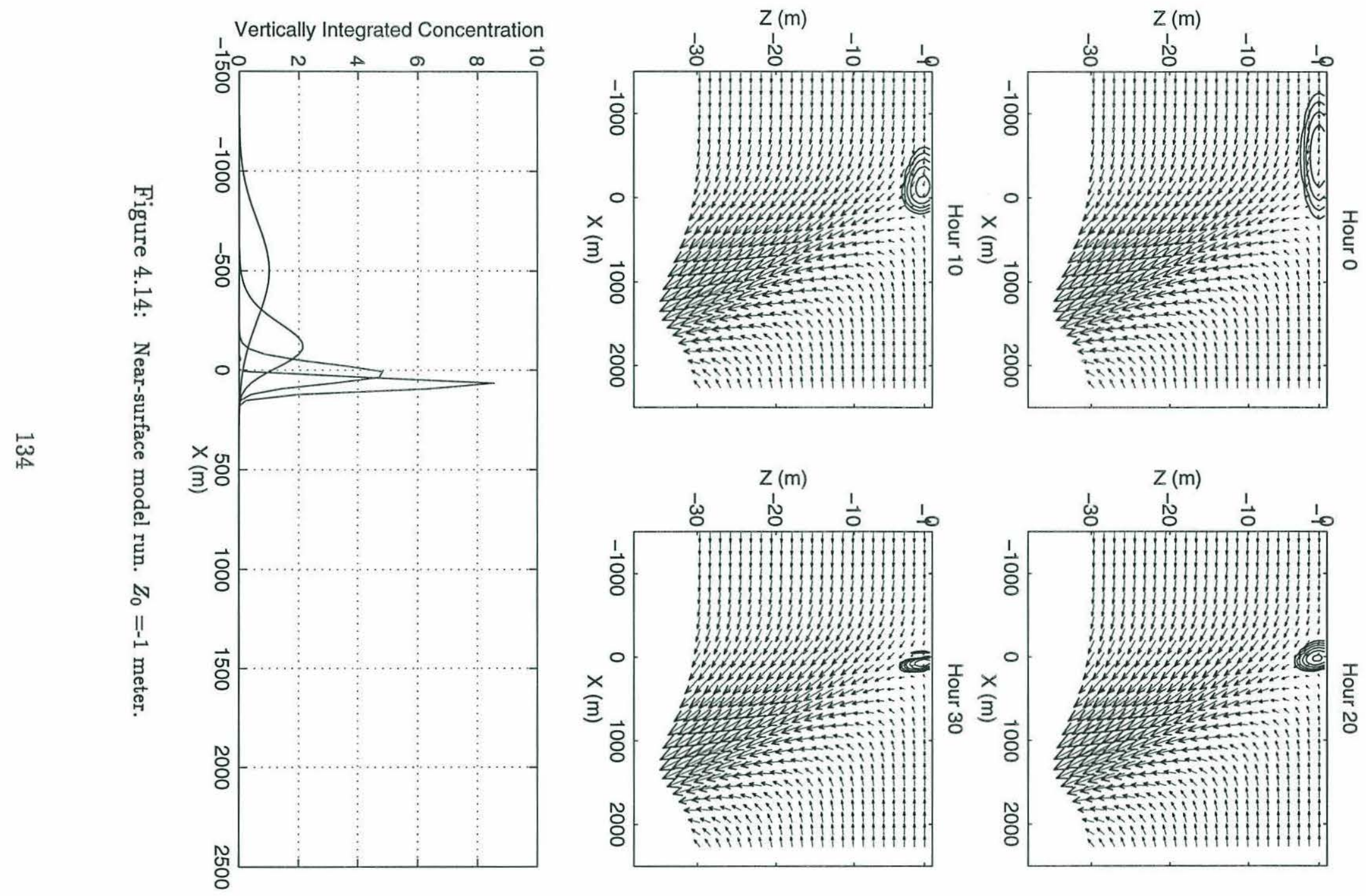



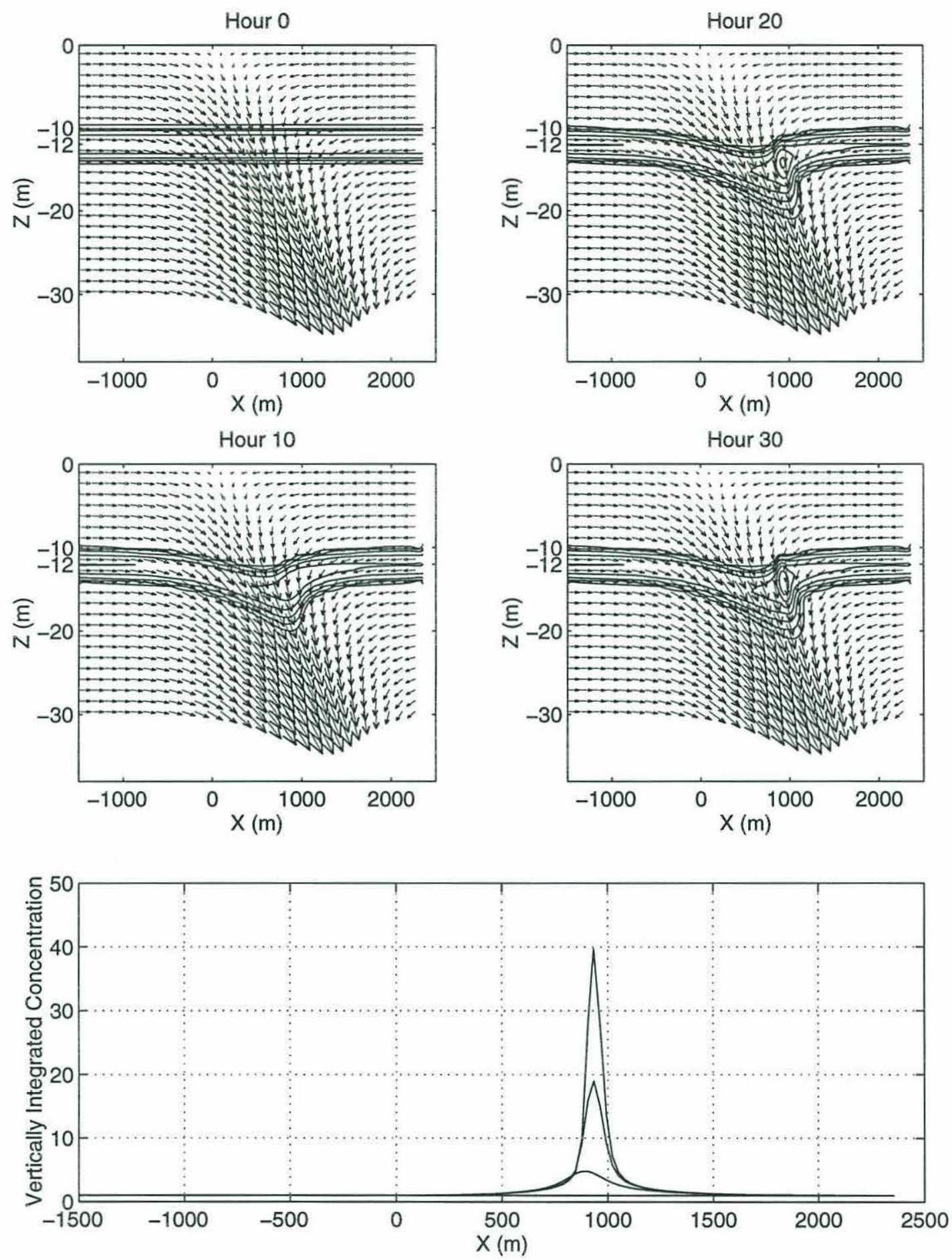

Figure 4.15: Model run with plankton initially distributed in an infinite, uniform layer. The boundary conditions are set so that as plankton are advected from the boundary into the model array they are replaced by an equal quantity of plankton at the boundary. Note that the scale in the bottom part of the figure is expanded compared to previous figures. 


\subsubsection{The Diffusion Length Scale}

One effect of strong vertical diffusion is to cause a layer of plankton in the water to become thicker-to spread out in the vertical as a result of mixing. The thickness of the plankton layer in turn affects the animals' swimming behavior, since animals far from their target depth, $Z_{0}$, may swim more vigorously than animals near $Z_{0}$. The effect is not necessarily simple: the degree to which animals swim more vigorously as they are diffused away from $Z_{0}$ can itself be a function of the animals' distance from $Z_{0}$, depending on the shape of their swimming-speed profile. This effect is illustrated schematically in Figure 4.16, which shows "thin", "intermediate" and "thick" plankton layers superposed on a hyperbolic-tangent swimming-speed profile. In the thin layer, nearly all of the animals are found in a region in which their swimming speed depends approximately linearly on their distance from $Z_{0}$. In the thick layer, many animals are found in a region far from $Z_{0}$, in which their swimming speed is nearly constant with depth because they are already swimming at their highest sustainable speed. In the intermediate layer, many animals-particularly those near the top and bottom edges of the layer-are found in the transitional zone between these two regions. (Although the hyperbolic-tangent swimming-speed profile provides a good example of the interplay between layer thickness and swimming speed, this kind of interplay should occur for any animal whose swimming-speed profile is nonlinear with depth, whether or not that profile approximates a hyperbolic tangent.)

In order to quantify the relationship between layer thickness and swimming speed, let us define the "diffusion length scale", which I shall call $L_{\kappa}$, to be the "thickness" of the layer of plankton that would form if diffusion were the only factor preventing all of the plankton from reaching their target depth. More precisely, let $L_{\kappa}$ be the e-folding scale for plankton concentration in the situation in which the water velocity is uniformly zero, but the animals still swim toward $Z_{0}$ and diffusion still tends to spread out the distribution of animals in the vertical. 

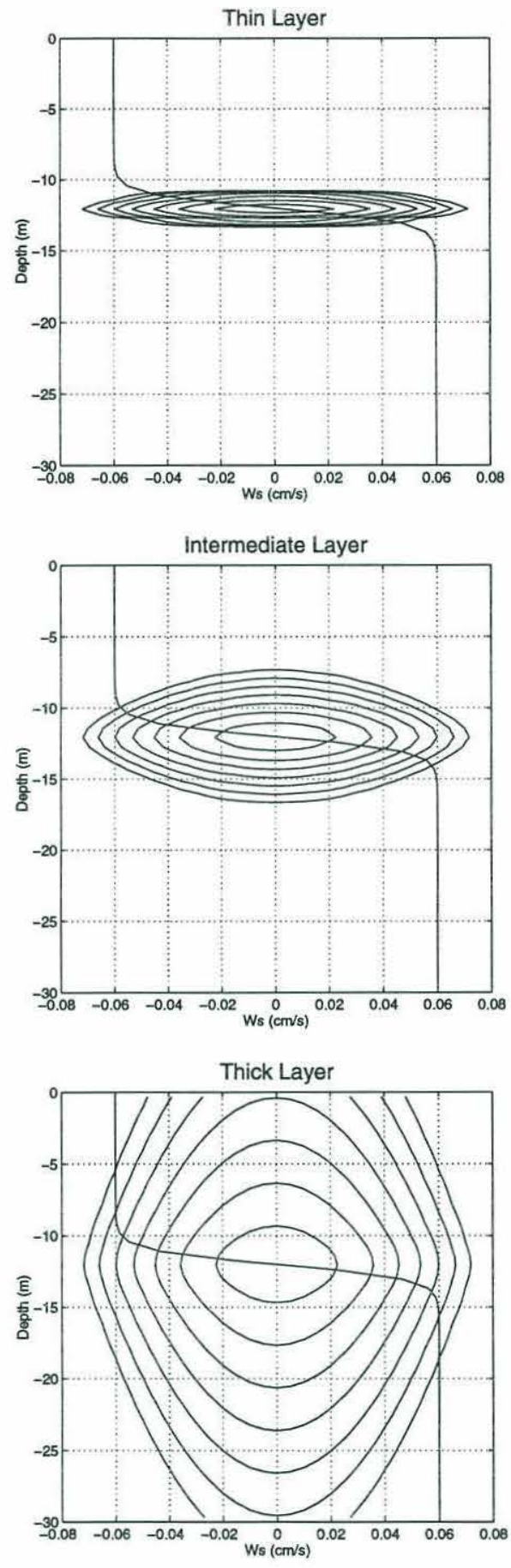

Figure 4.16: Plankton layers of varying thickness, superposed on plots of a hyperbolic-tangent swimming-speed profile. Most animals in the thin layer (top) are found in a region in which their swimming speed depends linearly on distance from their target depth. In the thick layer (bottom) many animals are found far from the target depth, and so their swimming speed is nearly constant with depth. In the intermediate layer (middle), animals near the top and bottom of the layer are found in a transitional zone between these two regions. 
Let us now derive an expression for the value of $L_{\kappa}$. If the velocity of the water were uniformly zero, the change in plankton concentration in any small volume of water would be determined by a balance between swimming and diffusion:

$$
\frac{\partial C}{\partial t}+\frac{\partial\left(C \cdot W_{s}\right)}{\partial z}=\frac{\partial}{\partial z}\left(\kappa \frac{\partial C}{\partial z}\right),
$$

where $W_{s}$ is the animals' swimming speed at depth $z$. If the distribution of organisms is in equilibrium, $\frac{\partial C}{\partial t} \equiv 0$ and therefore, integrating once, we have:

$$
\frac{1}{C} \frac{\partial C}{\partial z}=\frac{W_{s}}{\kappa}+\text { const. }
$$

At the animals' target depth, however, $W_{s}=0$ and $C$ is at a maximum, so $\frac{\partial C}{\partial z}=0$; hence the constant of integration must equal zero as well. Integrating again, we therefore have:

$$
\ln C=\int \frac{W_{s}}{\kappa} d z+\text { const. }
$$

and so

$$
C=C_{0} \cdot e^{\int \frac{W_{a}}{\kappa} d z} .
$$

In the model presented here, $\kappa$ is constant in $z$ and

$$
W_{s}=-W_{s 0} \tanh \left(\frac{\left(z-Z_{0}\right)}{L_{s}}\right) \text {. }
$$

And since

$$
\int \tanh \zeta d \zeta=\ln (\cosh \zeta)
$$


we have

$$
\begin{aligned}
C & =C_{0} \cdot e^{-\left(\frac{W_{s 0} L_{s}}{\kappa} \cdot \ln \left(\cosh \left(\frac{z-Z_{0}}{Z_{s}}\right)\right)\right)} \\
& =C_{\text {max }} \cdot\left(\cosh \left(\frac{\left(z-Z_{0}\right)}{L_{s}}\right)\right)^{-\frac{L_{s} W_{s}}{\kappa}} .
\end{aligned}
$$

Defining $L_{\kappa}$ as $\left(z-Z_{0}\right)$ such that $\frac{C(z)}{C_{m a s}}=e^{-1}$, we have:

$$
e^{-1}=\left(\cosh \left(\frac{L_{\kappa}}{L_{s}}\right)\right)^{-\frac{L_{s} W_{s}}{\kappa}}
$$

and so, finally:

$$
L_{\kappa}=L_{s} \cdot \cosh ^{-1}\left(e^{\frac{\kappa}{L_{s} W_{s 0}}}\right)
$$

\section{Limiting Cases}

In itself, this expression is not immediately illuminating. How does $L_{\kappa}$ vary as $\kappa$, $W_{s 0}$ and $L_{s}$ change? To shed some light on this question, let us consider two limiting cases. In the first case suppose diffusion is very strong, so that the plankton layer is very thick. Then $L_{s}$ would be very small compared to $L_{\kappa}$, and so most of the animals in the layer would almost always be swimming toward the target depth at their maximum speed, $W_{s 0}$. I shall call this the "diffusion-dominated" case. In this case, the animals' swimming-speed profile approaches a step function: 


$$
W_{s}= \begin{cases}-W_{s 0} & \text { for } z>Z_{0} \\ W_{s 0} & \text { for } z<Z_{0}\end{cases}
$$

Substituting this into Equation 4.9, we find

$$
C=C_{\max } \cdot e^{-\left(\frac{\left.W_{s 0\left(z-Z_{0}\right)}\right)}{\kappa} .\right.}
$$

Recalling that $L_{\kappa}=\left(z-Z_{0}\right)$ such that $\frac{C(z)}{C_{m a x}}=e^{-1}$, we find that:

$$
L_{\kappa}(\text { diff })=\frac{\kappa}{W_{s 0}} .
$$

In the other limiting case, suppose diffusion is weak, so that $L_{s}$ is very large compared to $L_{\kappa}$. Then the layer of plankton is very thin relative to the structure of the animals' swimming-speed profile. (See, for example, the top panel of Figure 4.16.) Indeed, if $L_{\kappa}$ is small enough, the animals' swimming-speed profile will be essentially linear throughout the layer:

$$
W_{s}=-W_{s 0} \cdot \frac{\left(z-Z_{0}\right)}{L_{s}} .
$$

Again substituting into Equation 4.9, we now have:

$$
C=C_{\max } \cdot e^{-\left(\frac{W_{s 0}\left(z-Z_{0}\right)^{2}}{2 L_{s} \kappa}\right)},
$$

and so

$$
L_{\kappa}(\operatorname{lin})=\sqrt{\frac{2 \kappa L_{s}}{W_{s 0}}} .
$$




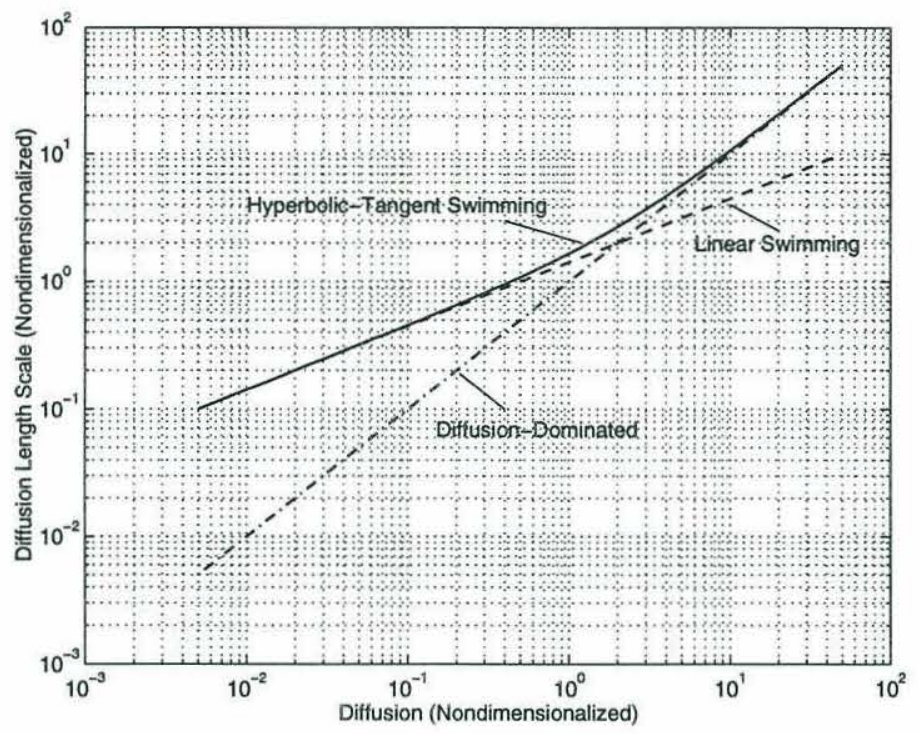

Figure 4.17: Nondimensionalized diffusion length scale $\left(\frac{L_{\kappa}}{L_{s}}\right)$ plotted versus nondimensionalized diffusion $\left(\frac{\kappa}{W_{s 0} \cdot L_{s}}\right)$. The solid line represents $\frac{L_{k}}{L_{s}}$ for the case in which the animals' swimming-speed profile is a hyperbolic tangent. The dashed line shows the "linear swimming" limiting case, and the dashdot line shows the "diffusion-dominated" limiting case. For low values of nondimensionalized diffusion, $\frac{L_{k}}{L_{s}}$ approaches the $\frac{L_{k}}{L_{v}}$ of the linear-swimming case; for high values of diffusion, $\frac{L_{\kappa}}{L_{*}}$ approaches the $\frac{L_{\kappa}}{L_{*}}$ of the diffusion-dominated case.

I shall call this the "linear-swimming" case.

How do these limiting cases compare to the actual value of $L_{\kappa}$ ? When diffusion is very weak-when $\kappa$ is small-we would expect that $L_{\kappa}$ would behave like $L_{\kappa}(\operatorname{lin})$. On the other hand, when diffusion is very strong-i.e. when $\kappa$ is very large-we would expect $L_{\kappa}$ to behave very much like $L_{\kappa}($ diff $)$.

This is precisely how $L_{\kappa}$ behaves. Figure 4.17 shows a nondimensionalized $L_{\kappa}$ plotted versus a nondimensionalized $\kappa$. The two limiting cases, $\frac{L_{\kappa}(\text { diff })}{L_{s}}$ and $\frac{L_{\kappa}(\text { lin })}{L_{s}}$, are plotted as well. For values of $\frac{L_{\kappa}}{L_{s}}$ below about 1 (i.e., in the case of weak diffusion), we see that the value of $\frac{L_{\kappa}}{L_{s}}$ is very close to $\frac{L_{\kappa}(l i n)}{L_{s}}$. In other words, the thickness of an undisturbed layer of plankton is much as it would be if the swimming-speed profile were linear in $\left(z-Z_{0}\right)$. For values of $\frac{L_{\kappa}}{L_{s}}$ above about 10 (i.e., in the case of strong 
diffusion), the value of $\frac{L_{\kappa}}{L_{s}}$ is very close to the value of $\frac{L_{\kappa}(\text { diff })}{L_{s}}$. In this case, the layer of plankton is shaped roughly as it would be if the swimming-speed profile were a step function. For intermediate values of $\frac{L_{\kappa}}{L_{s}}$, the specific details of the hyperbolic-tangent swimming-speed profile are important in determining the thickness of the equilibrium layer of plankton.

\section{Three Regimes}

In effect, then, depending on the value of $\frac{L_{\kappa}}{L_{s}}$, the situation we are modelling can fall into one of three distinct regimes: diffusion-dominated (large $\frac{L_{\kappa}}{L_{s}}, \frac{\kappa}{W_{s 0} \cdot L_{s}} \geq 10$ ), linear-swimming (small $\frac{L_{\kappa}}{L_{s}}, \frac{\kappa}{W_{s 0} \cdot L_{s}} \leq 4 \times 10^{-1}$ ), and an intermediate case. Typical profiles of swimming speed and plankton concentration for each of the three regimes are shown in Figure 4.18.

Which of these regimes are we likely to observe in the real ocean? Suppose the organism under consideration can migrate vertically about 100 meters in roughly three hours, making its maximum sustained vertical swimming speed (which is not necessarily equal to its maximum speed over short distances) approximately $10^{-2} \mathrm{~m} / \mathrm{s}$. Also suppose that an isolated individual would be "comfortable" in a vertical range a meter or so thick; that is, suppose the scale distance of its swimming-speed profile, $L_{s}$, is of order unity. Such an organism would fall into the linear-swimming regime (which I shall call "Regime I") for values of $\kappa$ less than about $\left(4 \times 10^{-1}\right) \times\left(10^{-2}\right) \times(1)$, or $\kappa<4 \times 10^{-3} \mathrm{~m}^{2} / \mathrm{s}$, or about $40 \mathrm{~cm}^{2} / \mathrm{s}$. One would not expect to find values of $\kappa$ this high in an open-ocean situation in which small-scale fronts could exist: such a high value of $\kappa$ corresponds to mixing phenomena that could homogenize a 5 -meter-thick layer in roughly three hours. And if the animals under consideration can sustain speeds greater than $1 \mathrm{~cm} / \mathrm{s}$ or are comfortable in a depth range greater than 1 meter, still greater values of $\kappa$ would be required before we would consider the organism to 

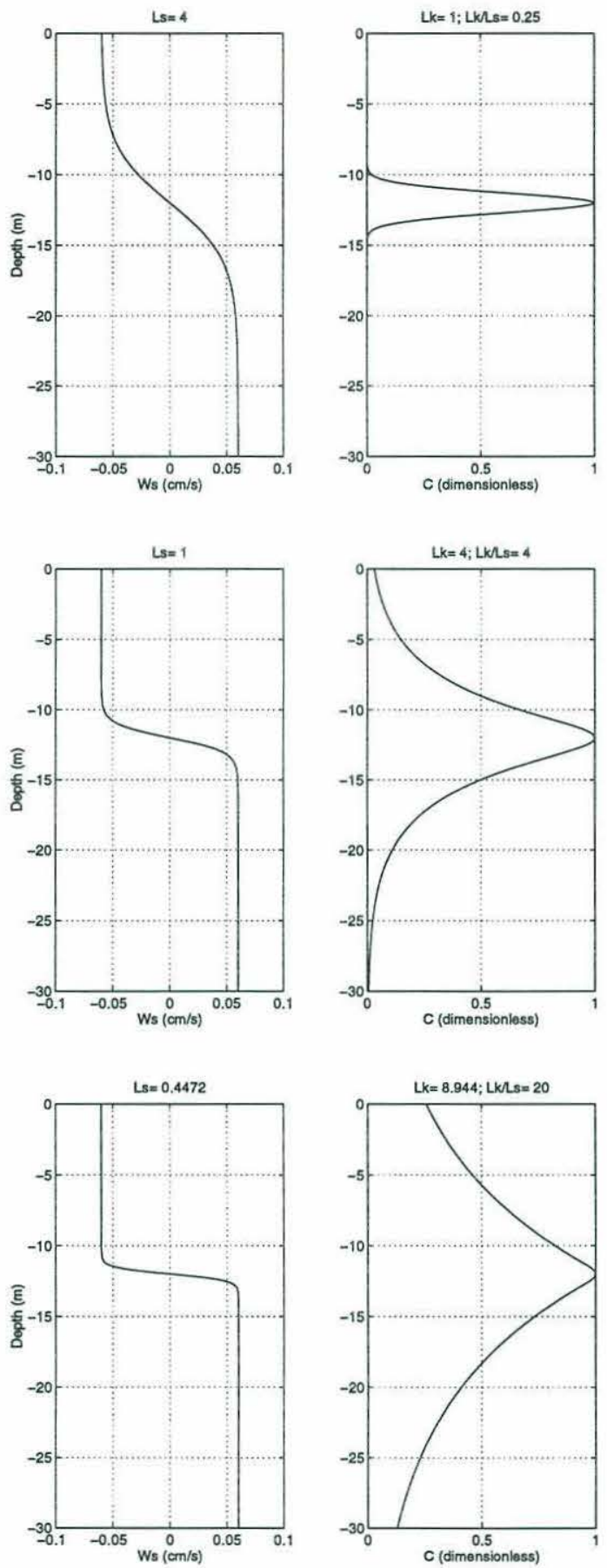

Figure 4.18: For each of the three regimes of $\frac{L_{\kappa}}{L_{s}}$, a profile of plankton swimming speed is shown next to a profile of plankton concentration in an equilibrium layer of plankton (a layer in which diffusion in the fluid exactly balances swimming by the plankton). Regime I, the linearswimming regime, is at the top; Regime II, the intermediate regime, is in the middle; Regime III, the diffusion-dominated regime, is at the bottom. 
be in the intermediate regime (which I shall call "Regime II"). Hence Regime I is the most likely regime for actively swimming plankton.

For less active organisms, however, it may not be unrealistic to consider Regime II. For example, an organism that has a maximum sustained vertical swimming speed of about $0.5 \mathrm{~mm} / \mathrm{s}$ and is comfortable in a depth range of order 1 meter thick would require a $\kappa$ of only about $2 \times 10^{-4} \mathrm{~m}^{2} / \mathrm{s}$, or about $2 \mathrm{~cm}^{2} / \mathrm{s}$ in order to be in Regime II. A species of slightly buoyant phytoplankton that floats passively (and slowly) to the surface could fall into Regime II even more easily. It thus seems worthwhile to consider Regime II in our examination of the model's parameter space. Regime III, on the other hand, represents situations so diffusive that the small-scale density fronts necessary for the small-scale subduction mechanism probably could not exist. For the remainder of this chapter, therefore, I shall concentrate on Regimes I and II

\subsubsection{Nondimensional Parameters}

We are now ready to nondimensionalize the model's fundamental parameters. Leaving aside the essential structure of the frontal flow field, there are five independent dimensional parameters to consider:

$W_{s 0}$, the animals' maximum swimming speed;

$L_{s}, \quad$ the length scale of the animals' swimming-speed profile;

$Z_{0}$, the depth to which the animals are trying to swim;

$U_{0}$, the scale velocity of the water in the front; and

$L_{\kappa}$, the vertical-diffusion length scale.

Given five dimensional parameters and two fundamental quantities (distance and time), it should be possible to derive $(5-2)=3$ independent dimensionless 
parameters (Buckingham, 1915). The three dimensionless parameters I shall discuss here are:

$\frac{L_{\kappa}}{L_{s}}$, the ratio of the vertical-diffusion length scale to the length scale of the animals' swimming-speed profile;

$-\frac{U_{0}}{W_{s 0}}$, the ratio of the water's scale velocity to the animals' maximum swimming speed; and

$\frac{-Z_{0}}{\sqrt{L_{\kappa} \cdot L_{s}}}$, the animals' target depth divided by the square root of the product of the diffusion length scale and the swimming-speed length scale.

In attempting to understand how these parameters control the aggregation of plankton at a front, I shall consider not only the size and shape of the eventual plankton distribution, but also a more quantifiable characteristic, which I shall call the "Aggregation Index":

$\frac{\max \left(\int C_{f} d z\right)}{\max \left(\int C_{0} d z\right)}$, the maximum value of $\int C d z$ after the model has run for a set period of time, divided by the maximum value of $\int C d z$ for the initial distribution.

The Aggregation Index quantifies a feature that could in principle be measured for a real plankton patch in the ocean: the degree to which the maximum concentration of plankton in the patch increases as a surface front traverses the patch. Values of normalized vertically integrated concentration, $\frac{\int C d z}{\max \left(\int C_{0} d z\right)}$, are plotted as a function of horizontal position $(x)$ for each of the timesteps shown in the figures that present the results of individual model runs.

As we have seen, the first of the model's dimensionless parameters, $\frac{L_{\kappa}}{L_{s}}$, determines the swimming behavior of animals at the top and bottom of the plankton layer: it determines whether those animals' swimming speed will be linear, constant, 
or more complicated with depth. As a result, it determines which of the three fundamental regimes best describes a given situation. The value of the second parameter, $-\frac{U_{0}}{W_{s 0}}$, determines how rapidly water in the front flows in relation to the speed with which the plankton can swim, and hence determines whether organisms can maintain their vertical position or will be swept down and away by the flow field. (Although $U_{0}$ represents a horizontal velocity, it is proportional to the water's vertical velocityif $U_{0}$ is increased, the water's vertical velocity at every point increases proportionally.) I shall call this parameter the model's "Velocity Ratio".

The third parameter, $\frac{-Z_{0}}{\sqrt{L_{\kappa} \cdot L_{o}}}$, determines the degree to which the plankton distribution will pull itself into a thin layer when subjected to distorting forces such as vertical shear in the surrounding flow field. When $L_{s}$ is large, for example (making $\frac{-Z_{0}}{\sqrt{L_{\kappa} \cdot L_{s}}}$ small), animals can be advected very far below $Z_{0}$ before they will begin to swim back up strongly. Similarly, when $L_{\kappa}$ is large, animals that do swim back up toward the target depth are more likely to be diffused downward again. Hence a small value of $\frac{-Z_{0}}{\sqrt{L_{\kappa} \cdot L_{s}}}$ leads to a plankton layer that is easily deformed. Conversely, small values of these parameters (i.e., large values of $\frac{-Z_{0}}{\sqrt{L_{\kappa} \cdot L_{s}}}$ ) cause animals to swim back toward $Z_{0}$ and then to stay there, even under the influence of strong vertical shear. I shall therefore call this parameter the model's "Elasticity". (In this study, I shall vary Elasticity primarily by varying the product $L_{\kappa} \cdot L_{s}$, rather than by varying $Z_{0}$; varying $Z_{0}$ changes the depth at which organisms accumulate, but it does not have as dramatic an effect on the nature of the final plankton patch as changing $L_{\kappa} \cdot L_{s}$ does.)

One may ask why the vertical thickness of the equilibrium layer (a quantity affected by both $\frac{L_{\kappa}}{L_{s}}$ and $\frac{-Z_{0}}{\sqrt{L_{\kappa} \cdot L_{s}}}$ ) is important. From the point of view of a feeding whale (or an oceanographer towing a net), the thickness of a plankton layer is perhaps not as important as its horizontal extent and the peak concentration within the layer. As we shall see, however, both of those variables are strongly affected by the vertical 
thickness of the equilibrium layer. If the initial layer of plankton is very thin, then as the plankton are swept beneath the buoyant water most of them will eventually swim upward to accumulate at a single point. If the layer is very thick, however, vertical shear in the water velocity (both the horizontal and the vertical components) can carry animals far away from each other horizontally, resulting in a broader, less highly concentrated patch. Animals at the edges of the patch will certainly be carried back toward the accumulation point by the convergent flow of water, but as they accumulate there the effects of high diffusion and low initial swimming speed (i.e., of high $\frac{L_{\kappa}}{L_{s}}$ or low Elasticity) will cause them to spread out again in the vertical; animals that are forced downward by this process will be carried off again toward the edges of the patch by the strong horizontal velocity in the waters below.

\section{Varying the Parameters}

To see the effects of changing the various nondimensional parameters, let us look at the results of a few model runs. First, let us consider the result of increasing $\frac{L_{k}}{L_{a}}$, the dimensionless parameter that determines which of the three regimes characterizes a given run. Figure 4.19 shows the result of gradually increasing $\frac{L_{k}}{L_{s}}$ while keeping the other nondimensional parameters constant. This sequence of runs extends from $\frac{L_{\kappa}}{L_{s}}=0.125$ to $\frac{L_{\kappa}}{L_{s}}=4$ : from the linear-swimming regime (Regime I, Figures 4.19A-D) through the intermediate regime (Regime II, Figures $4.19 \mathrm{E}-\mathrm{F}$ ). Increasing $\frac{L_{k}}{L_{s}}$ has two primary effects: it decreases the peak concentration of plankton by causing the patch to spread in both the horizontal and the vertical directions, and it causes a "tail" of plankton to form in the direction from which the buoyant plume is flowing (to the right, in the figures) at about the level of $Z_{0}$.

The plankton patches formed in these runs do have certain features in common: the highest concentrations of plankton are found near the front itself, with a trailing edge of plankton below the accumulation point; also, the horizontal gradient 

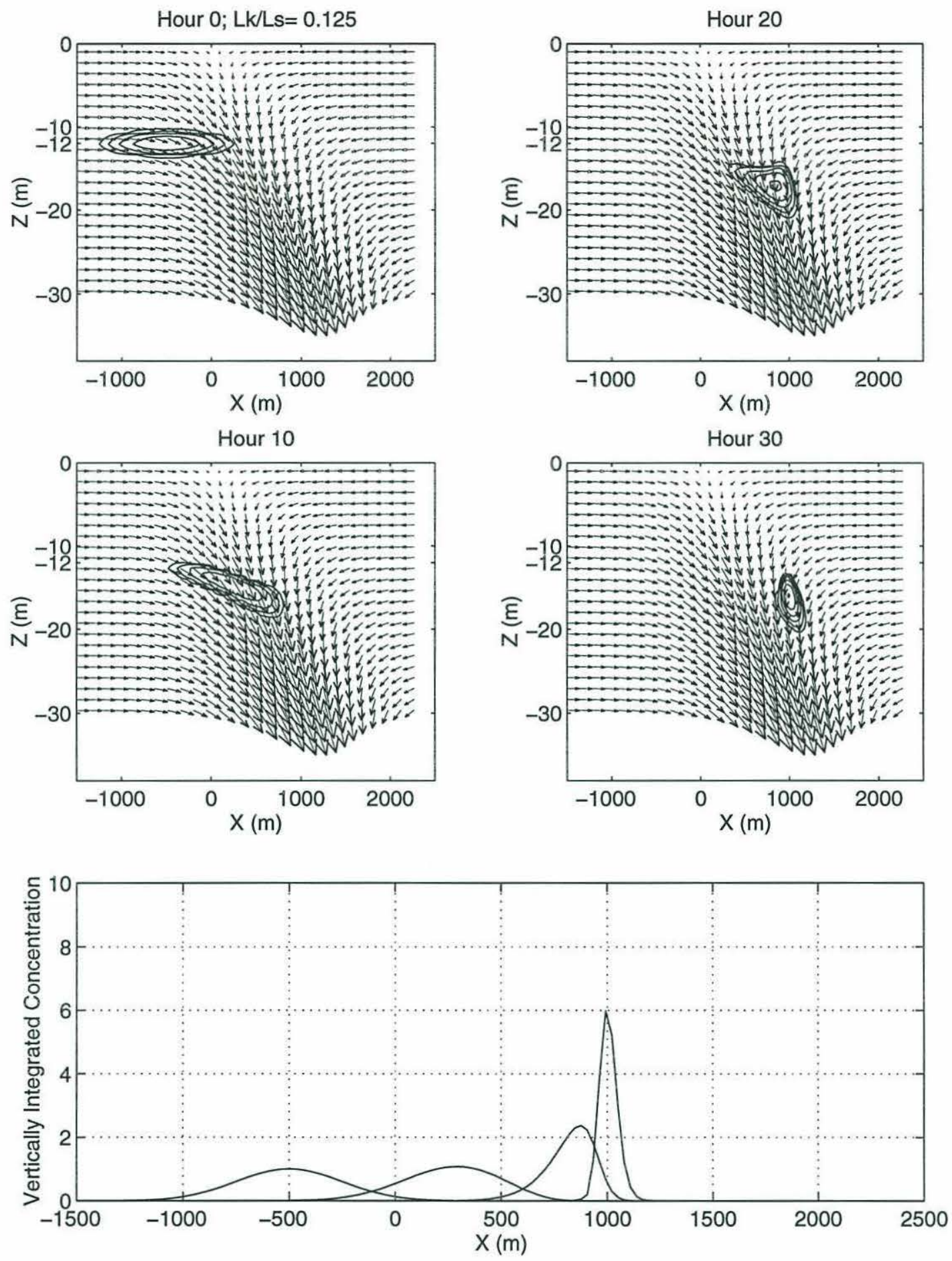

Figure 4.19: Part A. The effect of changing $\frac{L_{\kappa}}{L_{*}}$ while keeping the other dimensionless parameters constant. In this series, $\frac{L_{\kappa}}{L}$, is varied from the range representing Regime I (Figures $4.19 \mathrm{~A}-\mathrm{D}$ ) through the range representing Regime II (Figures 4.19 E-F). In part A, shown here, $\frac{L_{\kappa}}{L \text {; }}=0.125$, which is in Regime I. 

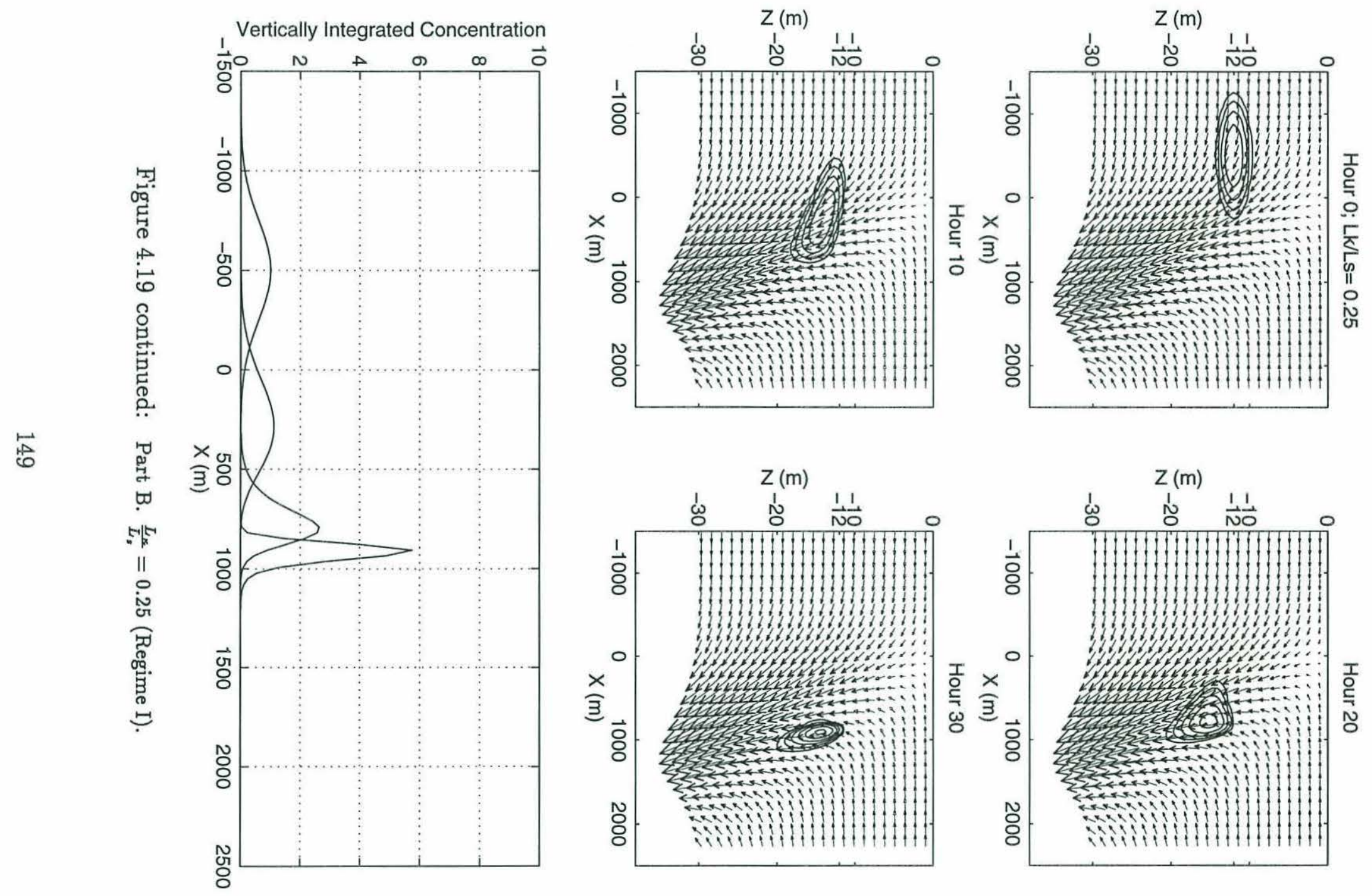

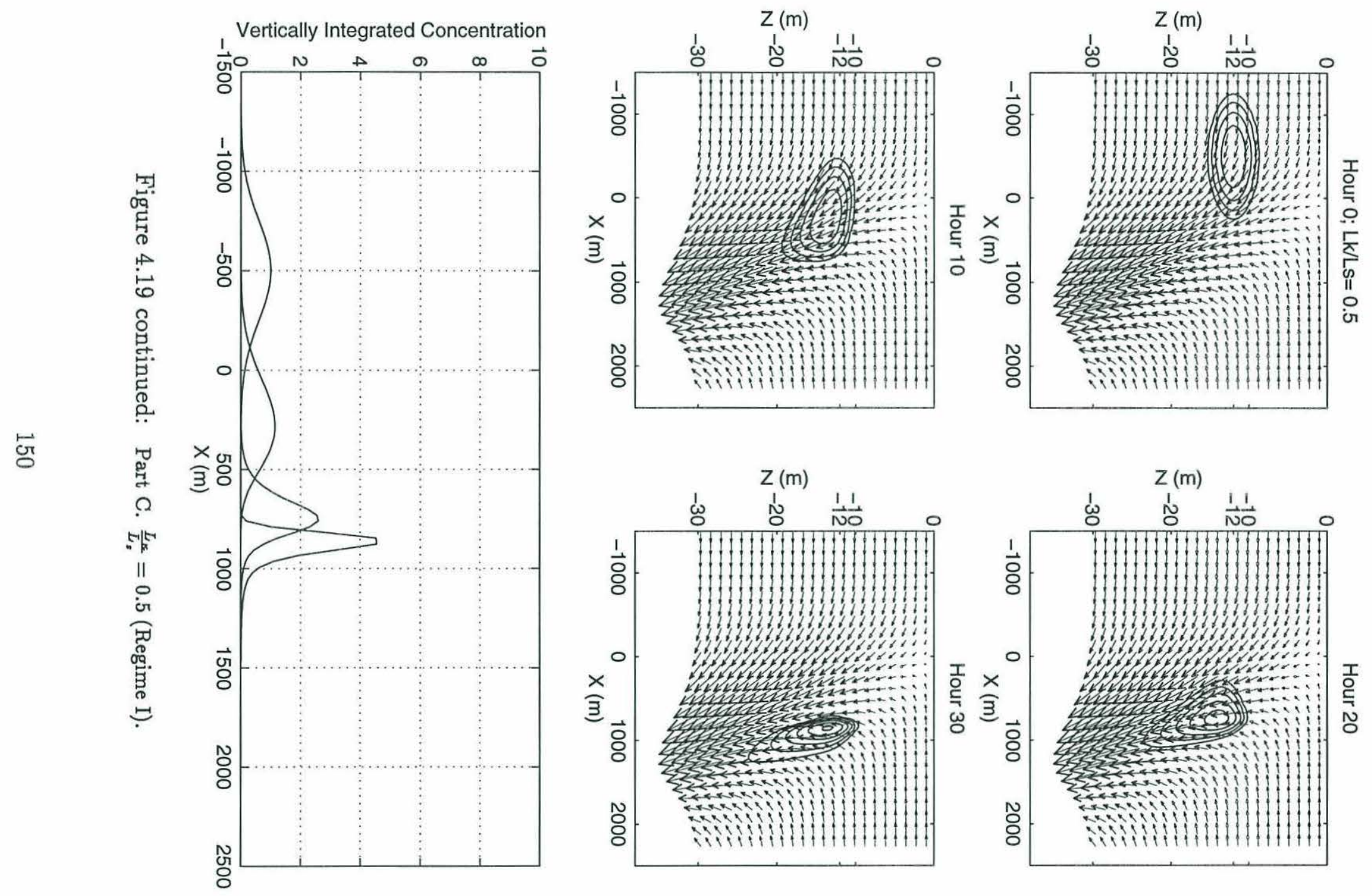

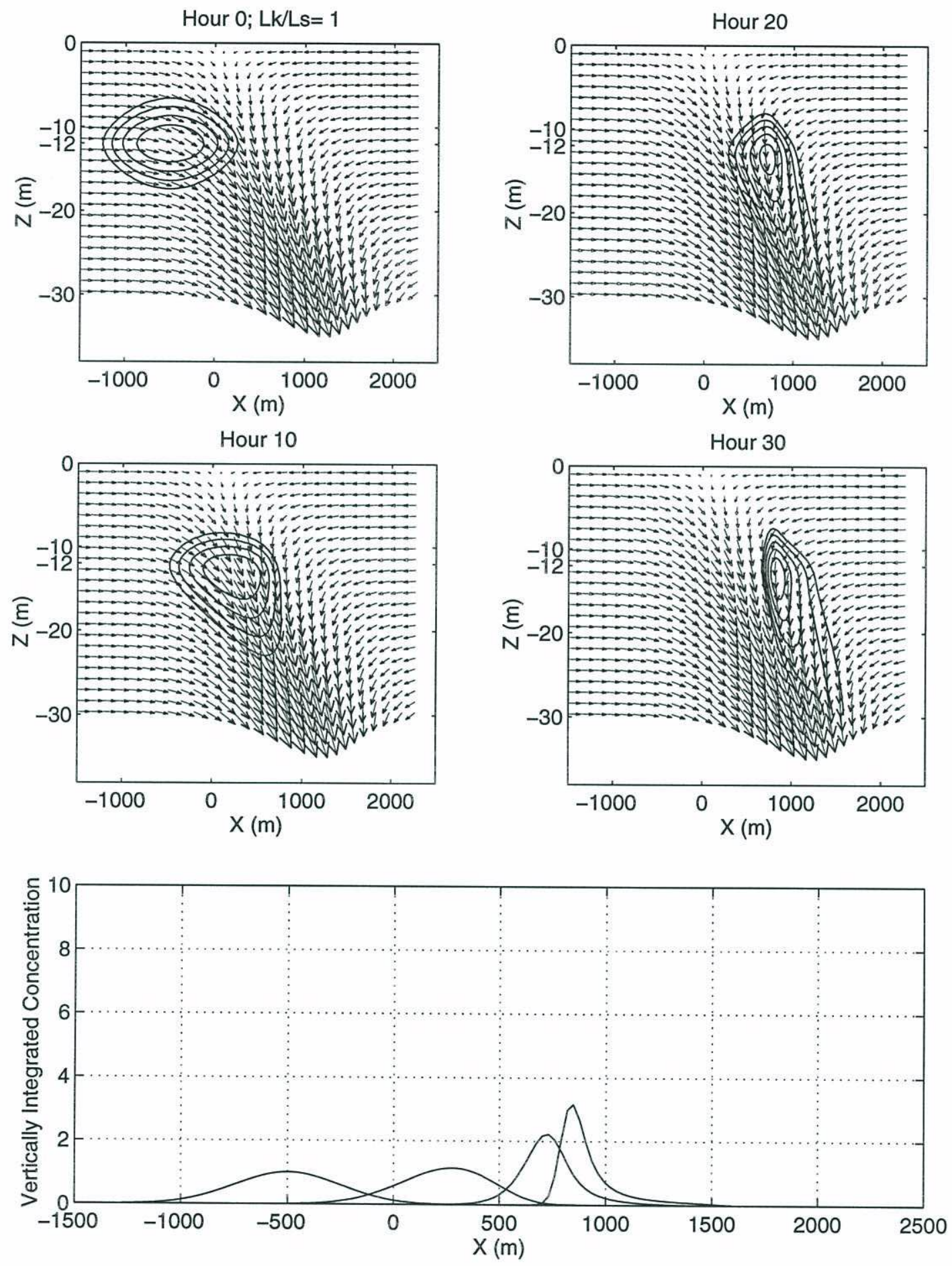

Figure 4.19 continued: Part D. $\frac{L_{k}}{L_{s}}=1.0$ (Regime I). 

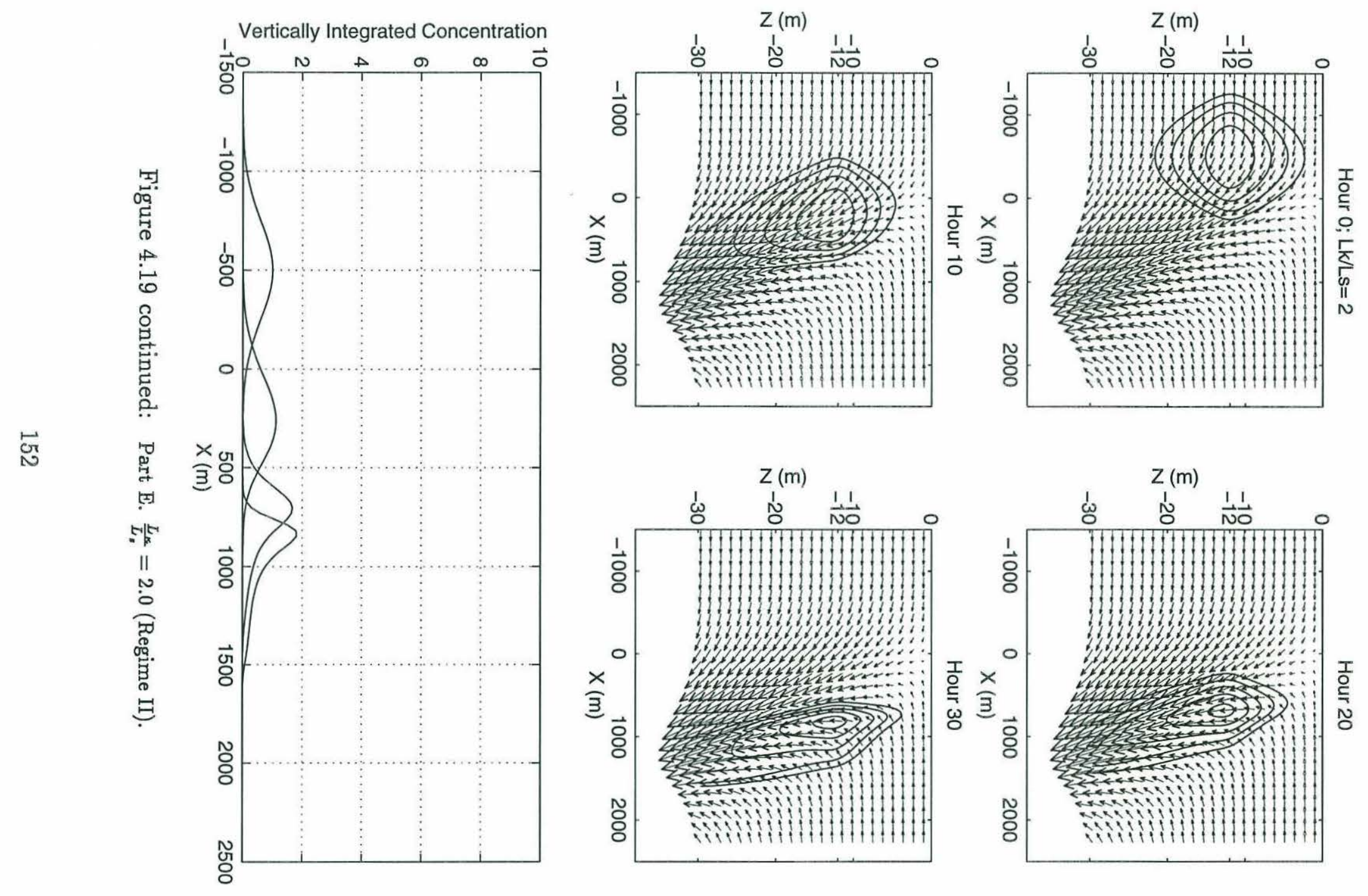

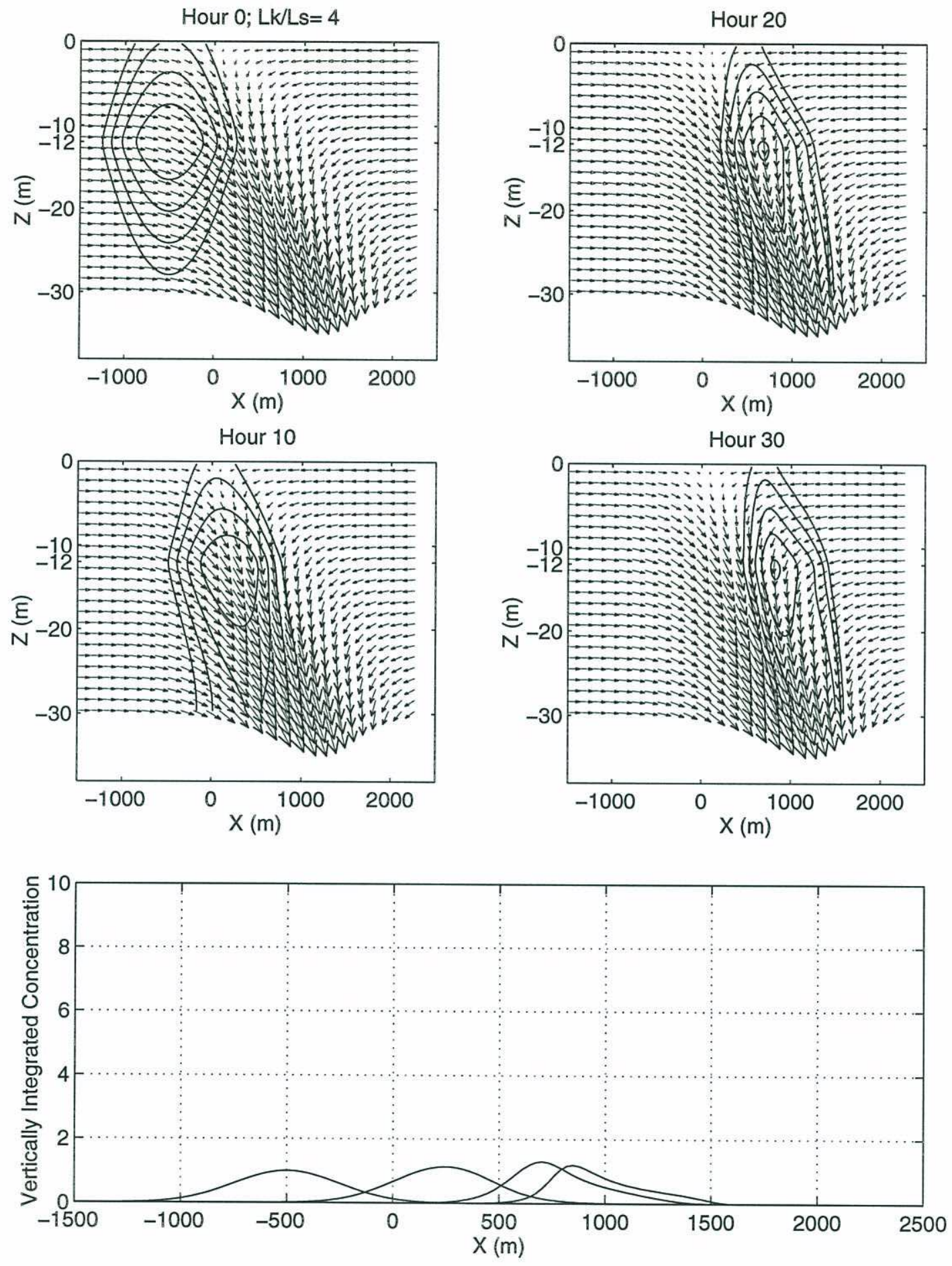

Figure 4.19 continued: Part F. $\frac{L_{k}}{L_{s}}=4.0$ (Regime II). 
of concentration is sharpest on the left-hand side of the patch (i.e. near the front), and the vertical gradient of concentration is sharpest at the top of the patch.

As $\frac{L_{\kappa}}{L_{s}}$ is increased, however, the character of the resulting plankton patch changes. Most obviously, the peak concentration of the final distibution (and the value of the Aggregation Index, $\left.\frac{\max \left(\int C_{f} d z\right)}{\max \left(\int C_{0} d z\right)}\right)$ falls. This is because as diffusion comes to dominate, the animals are more likely to spread downward from the accumulation point into the front itself, and then to be swept down and toward the right-hand side of the array.

Moreover, the shape of the patch changes as well: as $\frac{L_{\kappa}}{L_{s}}$ is increased, the plankton patch acquires a distinct "tail" to the right of the peak concentration (i.e., in the direction from which the buoyant plume is flowing) at a depth of approximately $Z_{0}$. This is because the animals that are carried downward and to the right eventually swim back up again toward $Z_{0}$. The water's horizontal velocity at that level does carry them back toward the accumulation point; when they arrive there, however, the resulting local increase in plankton concentration causes more animals to diffuse downward into the front, and the cycle begins again as those animals are first carried to the right and then swim back up towards $Z_{0}$.

Next let us examine the effect of decreasing the model's Elasticity. Figure 4.20 shows typical velocity and equilibrium-concentration profiles for three values of Elasticity. Figure 4.21 shows the effect of increasing $\frac{-Z_{0}}{\sqrt{L_{\kappa} \cdot L_{s}}}$ while keeping other nondimensional parameters constant in Regime I.

As Figure 4.21 shows, decreasing the model's Elasticity, like increasing $\frac{L_{\kappa}}{L_{s}}$, decreases the final peak concentration and the value of the Aggregation Index. In addition, decreasing the Elasticity causes the plankton patch to become distorted into a lozenge-like shape aligned roughly parallel to the slope of the front. Unlike the cases of high $\frac{L_{K}}{L_{s}}$, no trailing edge of plankton forms to the right of the peak (i.e., in the 

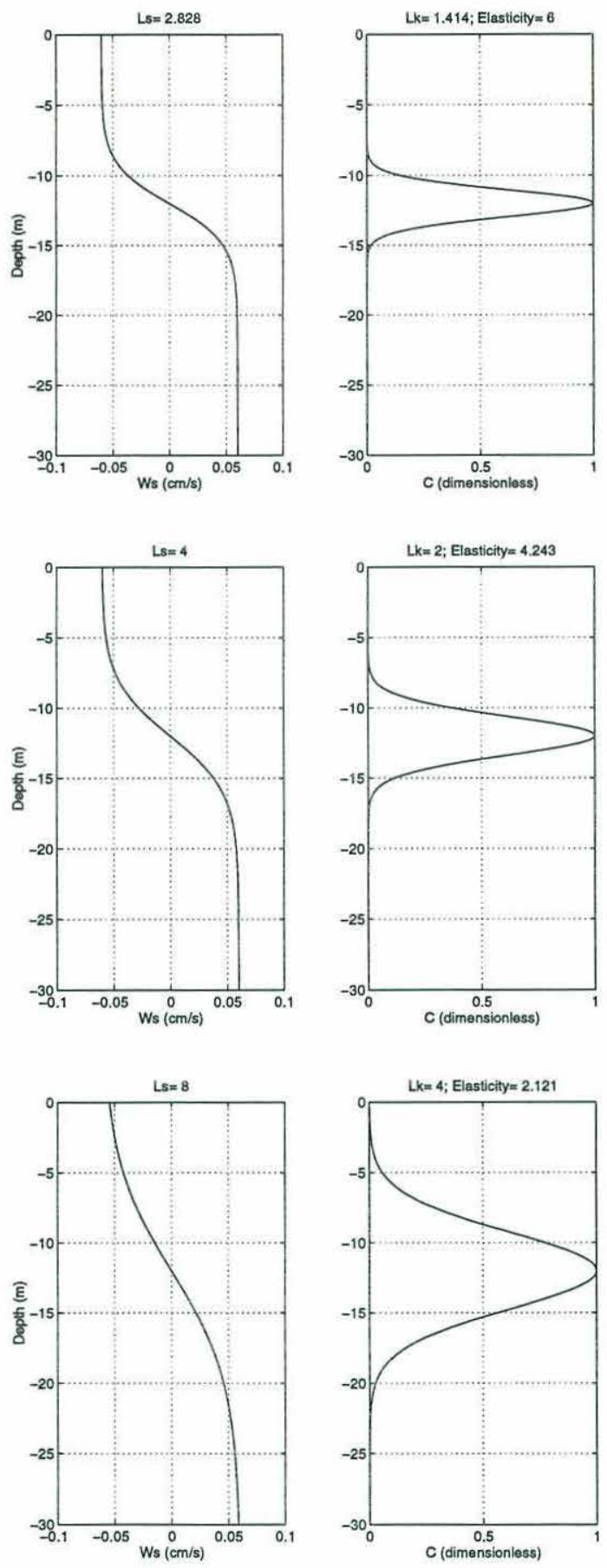

Figure 4.20: Profiles of swimming speed and equilibrium concentration for a range of values of Elasticity $\left(\frac{-Z_{0}}{\sqrt{L_{\kappa} \cdot L_{s}}}\right)$. All cases in this illustration are in Regime I (linear-swimming) of $\frac{L_{\kappa}}{L_{x}}$. In this figure, the value of the Elasticity is varied from 6 (top) to 4.2 (middle) to 2.1 (bottom). In all cases, $\frac{L_{x}}{L_{x}}=0.5$ 

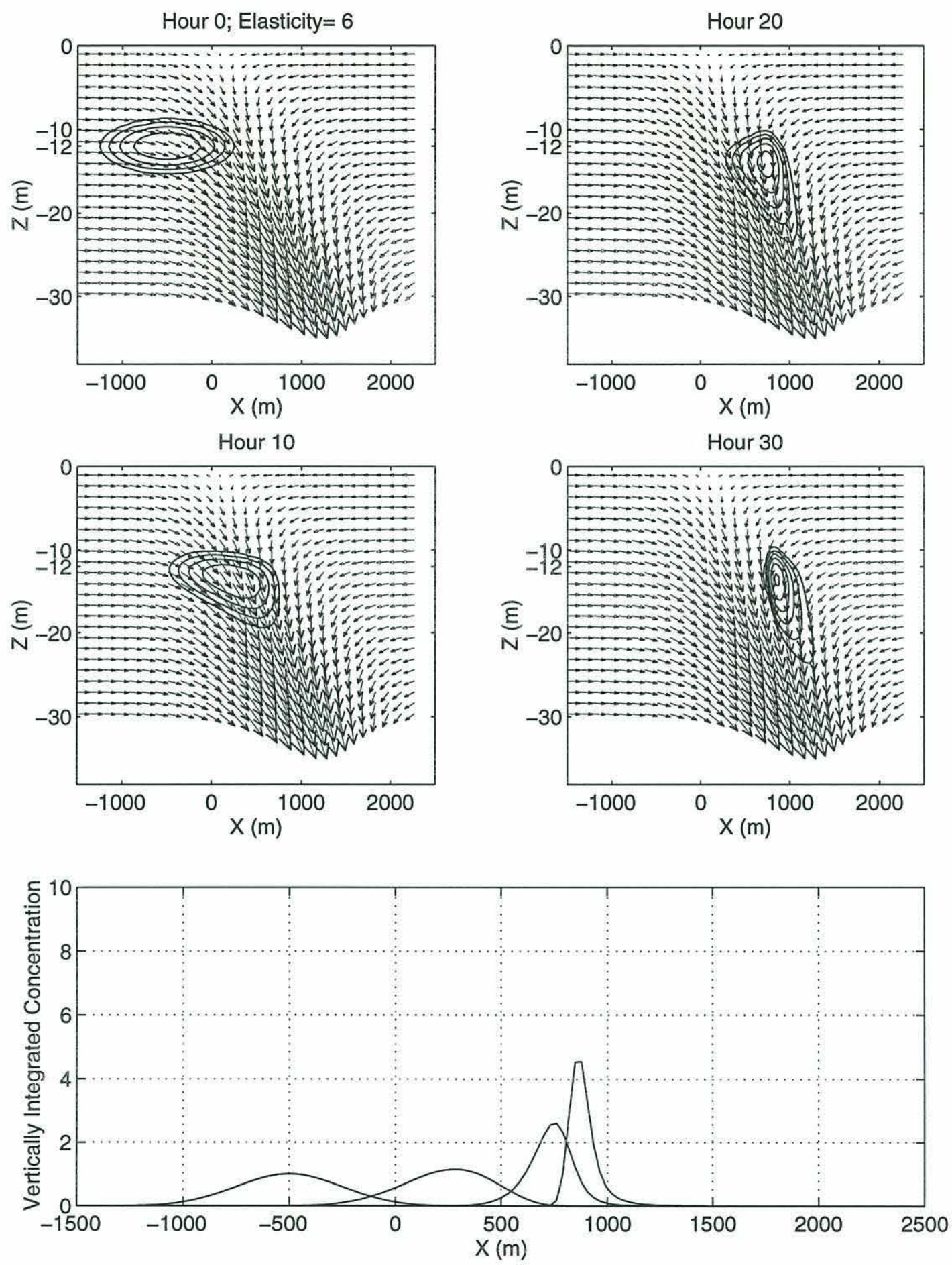

Figure 4.21: Part A. Effect of decreasing Elasticity $\left(\frac{-Z_{0}}{\sqrt{L_{\kappa} \cdot L_{s}}}\right)$ in Regime I. This series of model runs (this and following pages) corresponds to the series of profiles shown in Figure 4.20, for which $\frac{L_{\kappa}}{L_{s}}=0.5$. In Part A, shown here, Elasticity $=6$. 

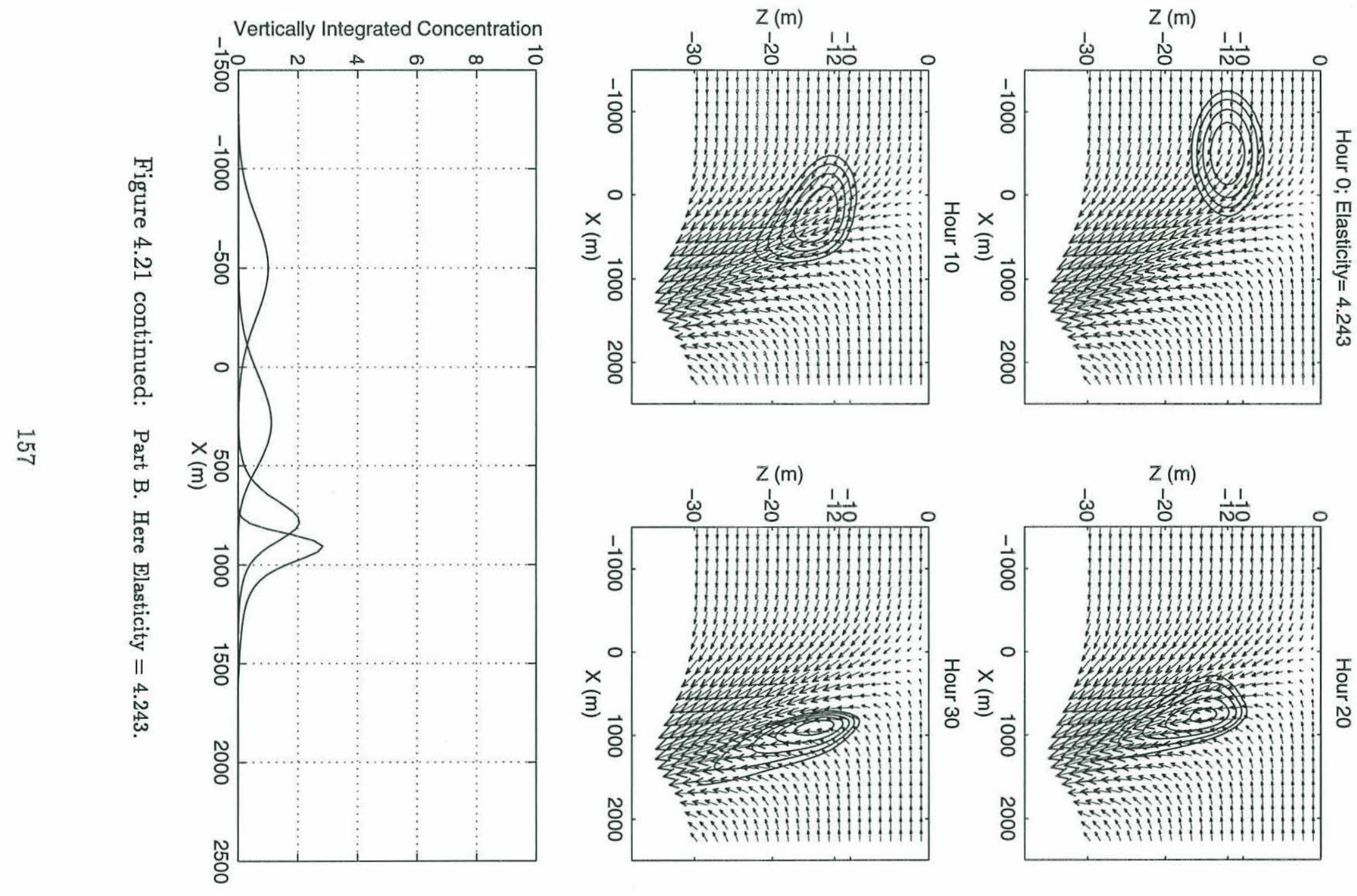

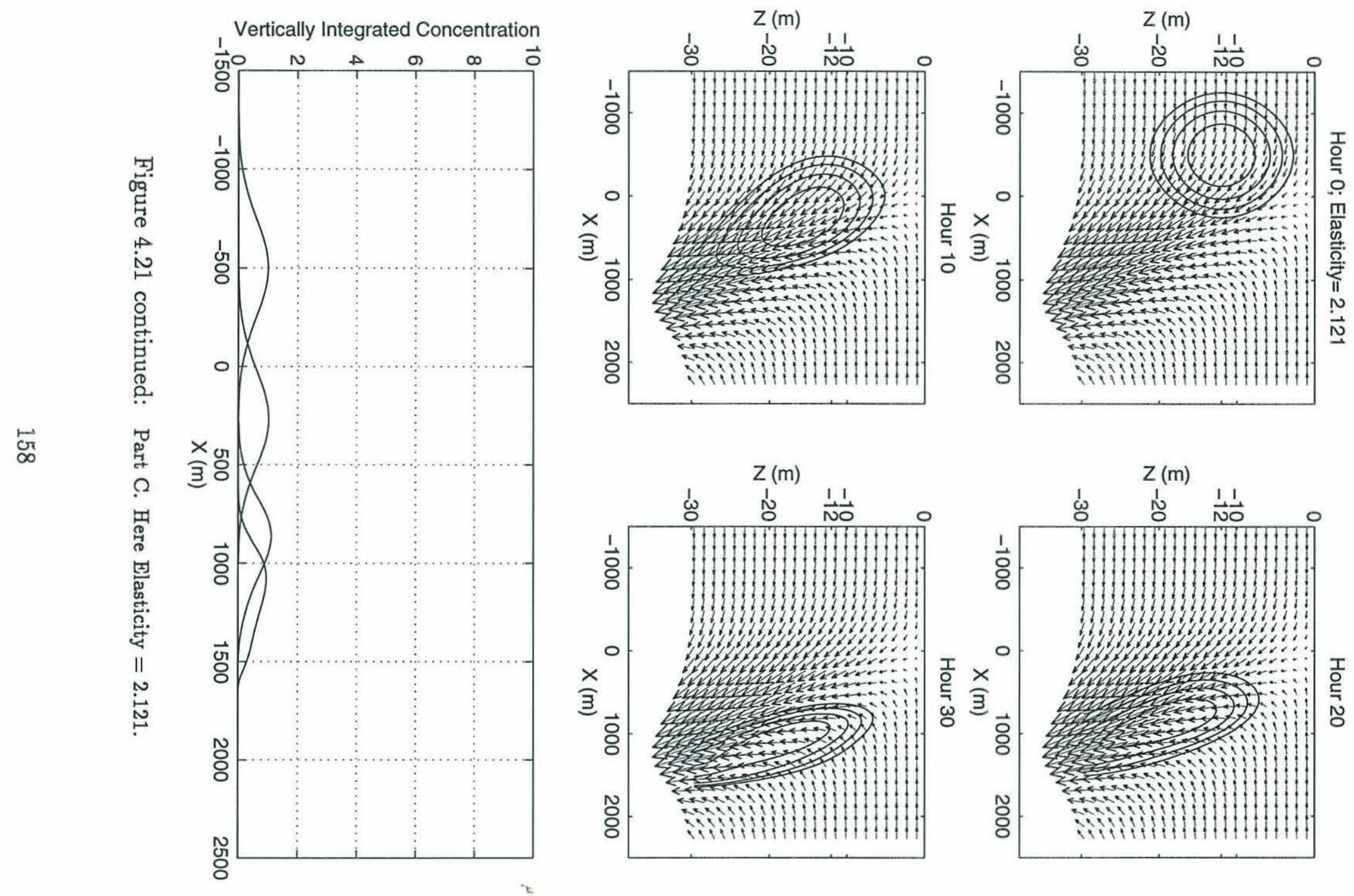
buoyant plume). Because both $L_{\kappa}$ and $L_{s}$ have been increased in these cases (while their ratio has been kept constant), animals that have been diffused even relatively far below $Z_{0}$ have not yet reached their maximum swimming speed, and so they do not swim rapidly up to form a trailing edge.

Finally, let us consider the effect of increasing the value of the Velocity Ratio $\left(-\frac{U_{0}}{W_{s 0}}\right)$. Figure 4.22 shows a series of runs in which the Velocity Ratio was increased in four even intervals while the other nondimensional parameters were kept constant. The results are much as one would expect. When the Velocity Ratio is quite low (i.e., when fluid velocities associated with the front are low), the plankton patch is not exposed to enough of the small-scale subduction process to form very dense aggregations. As the Velocity Ratio is increased, at first the patch aggregates more strongly. Eventually, however, the frontal velocity becomes so high that the plankton are simply washed out of the frontal area, unable to swim rapidly enough to overcome the strong downwelling velocity.

\subsubsection{Regime Diagrams}

The results of a number of model runs are summarized in Figures 4.23 and 4.24. The top panel of Figure 4.23 shows contoured values of the Aggregation Index after 36 hours of model time for a series of runs in Regime I $\left(\frac{L_{k}}{L_{s}}=0.25\right)$; the bottom panel of the figure shows contoured values of the Aggregation Index after 36 hours of model time for a series of runs in Regime II $\left(\frac{L_{\kappa}}{L_{s}}=2.0\right)$. Figure 4.24 shows a threedimensional schematic of the results of varying all three of the model's nondimensional parameters.

In both regimes, increasing the model's Elasticity always increases the value of the Aggregation Index: a highly Elastic plankton patch represents the ideal environment for the small-scale subduction mechanism, because plankton that are subducted 

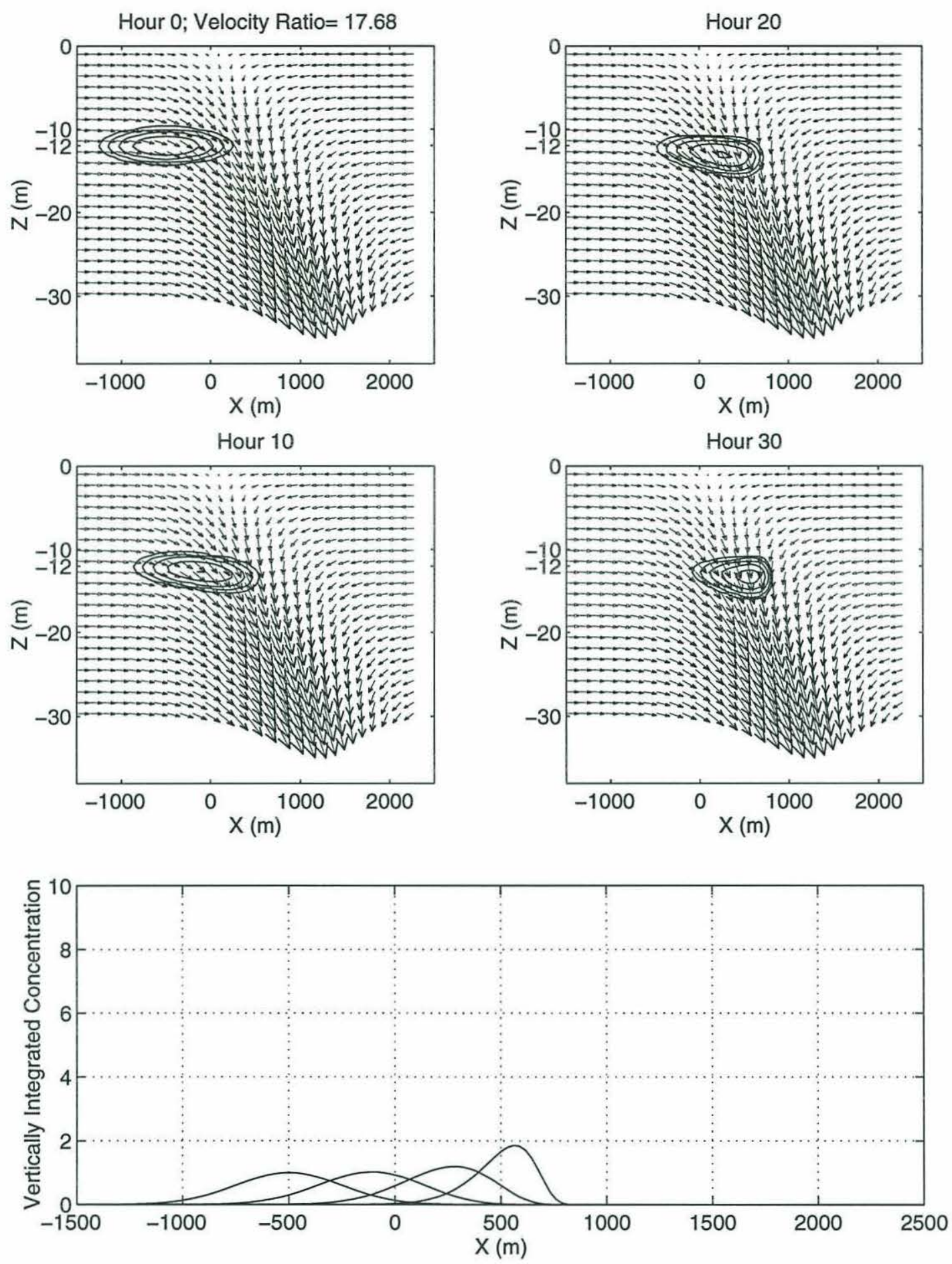

Figure 4.22: Part A. Effect of increasing Velocity Ratio $\left(-\frac{U_{0}}{W_{* 0}}\right)$ in Regime I. In this series, the Velocity ratio is increased in four even intervals from 17.7 to 70.7 . In all cases, $\frac{L_{k}}{L_{s}}=0.25$. In Part A, shown on this page, Velocity Ratio $=17.7$. 

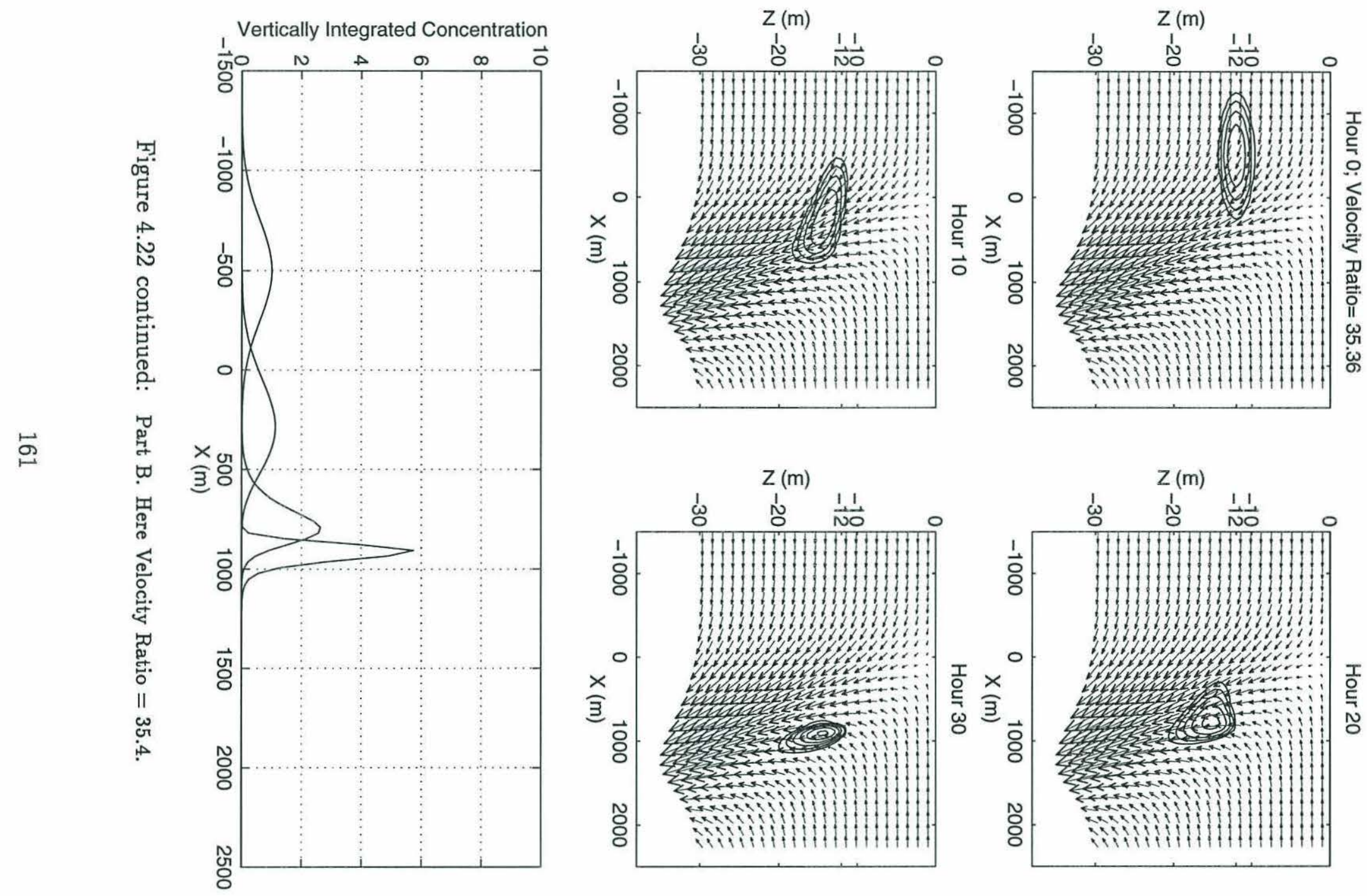

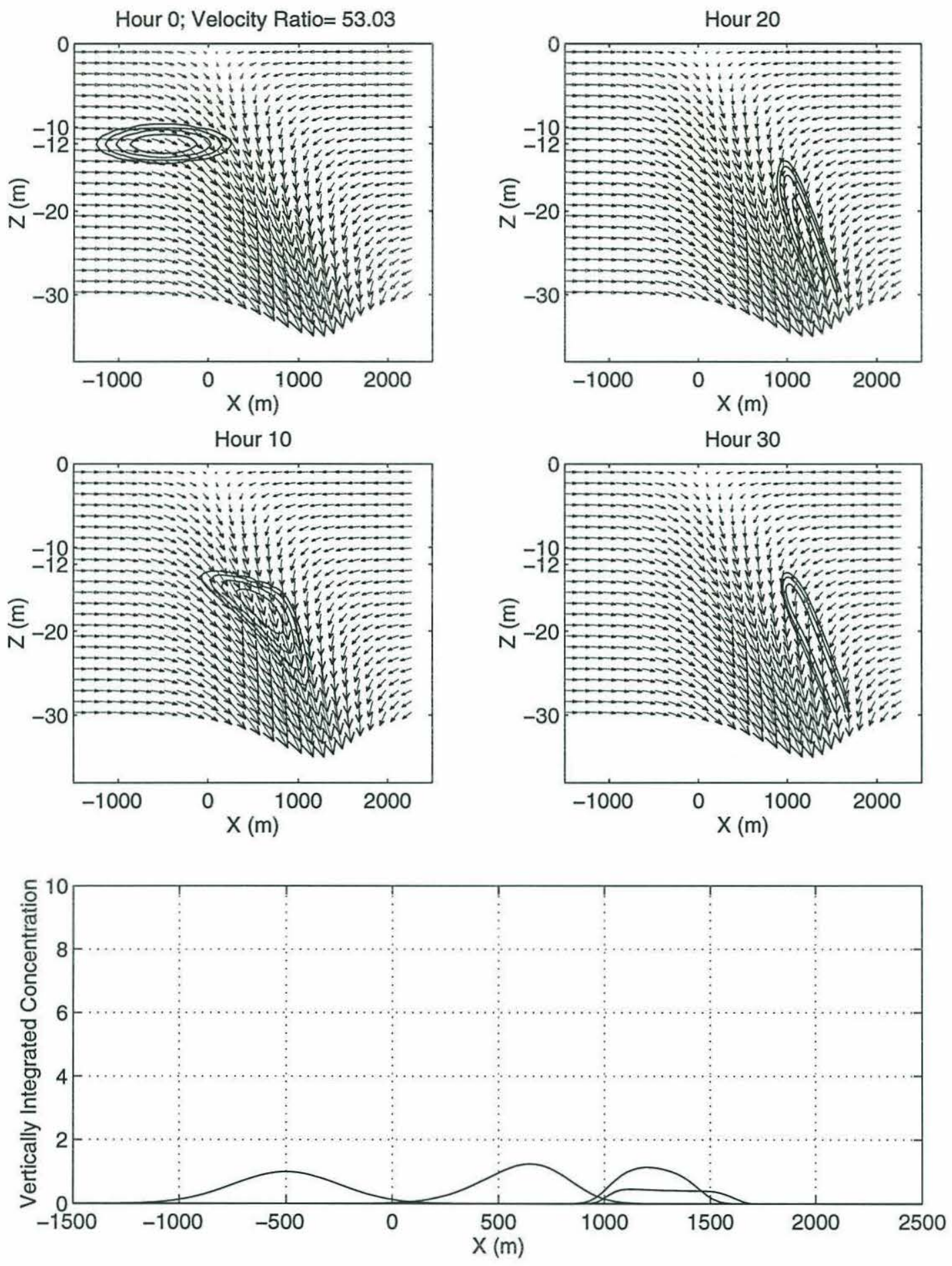

Figure 4.22 continued: Part C. Here Velocity Ratio $=53.0$. 

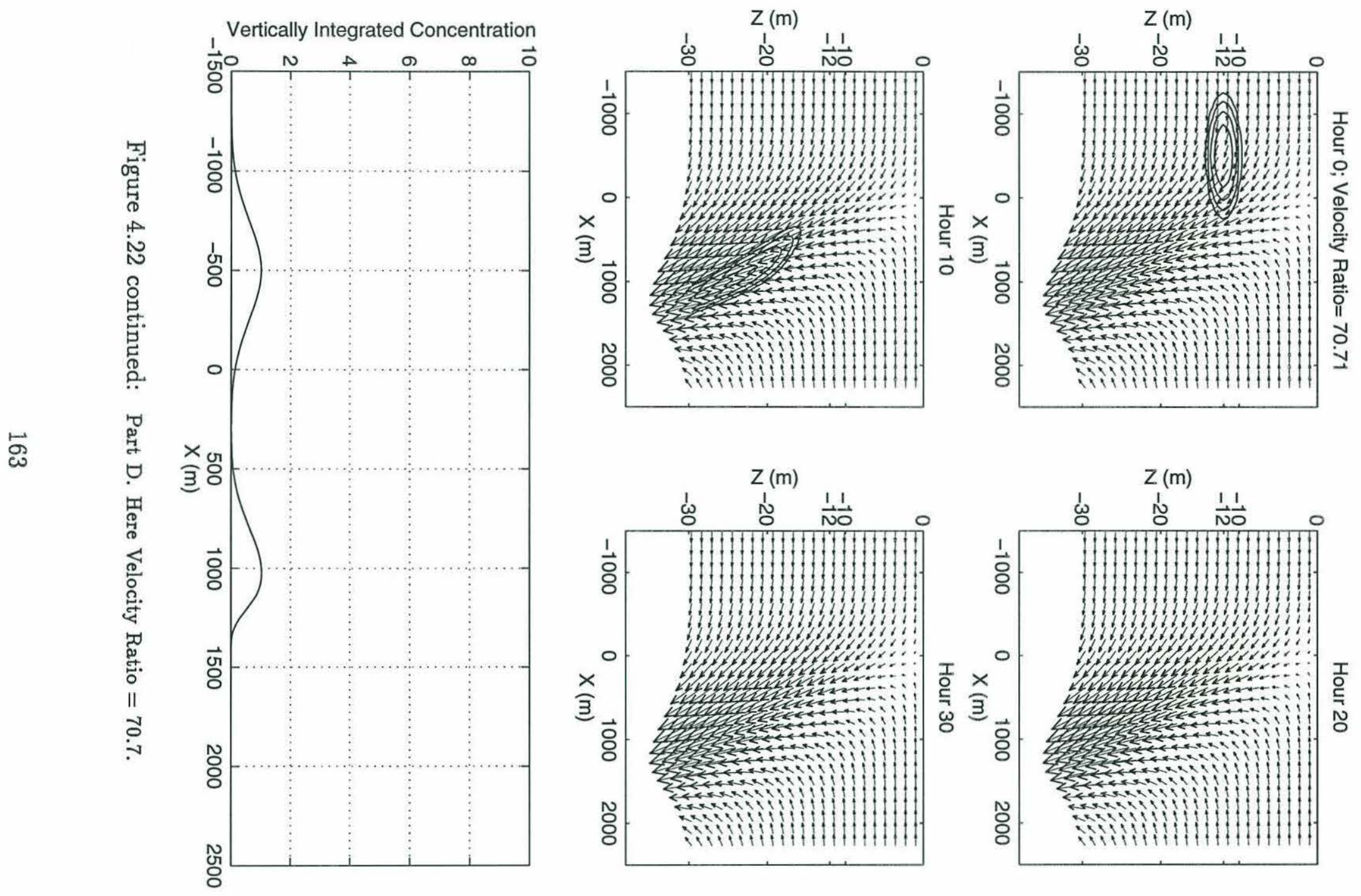

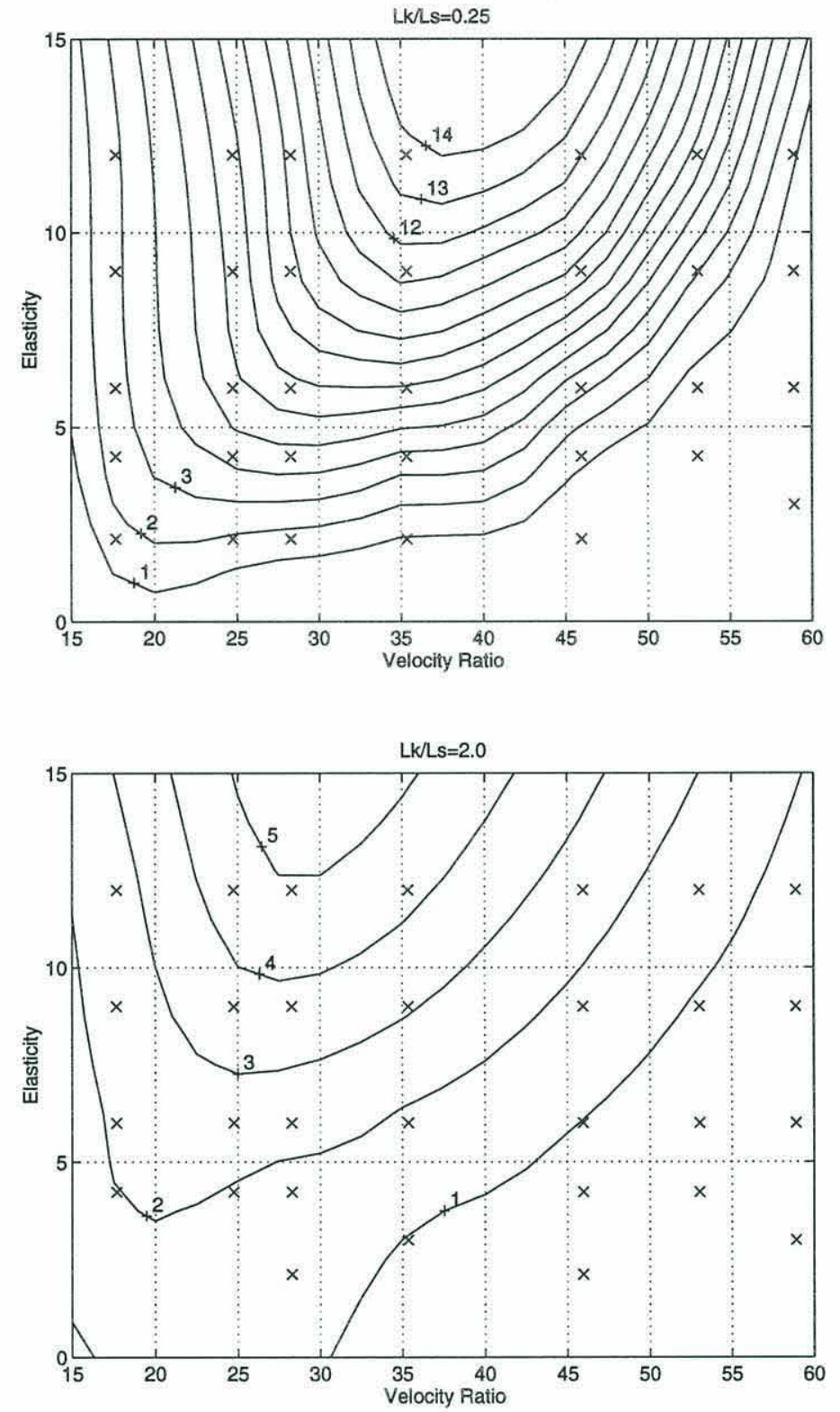

Figure 4.23: Regime diagrams. Contours represent the value of the Aggregation Index after 36 hours of model time $\left(\frac{\max \left(\int C_{36} d z\right)}{\max \left(\int C_{0} d z\right)}\right)$ for runs in Regime I (top, $\frac{L_{k}}{L_{s}}=0.25$ ) and Regime II (bottom, $\left.\frac{L_{\kappa}}{L_{s}}=2.0\right)$. Each $X$ indicates the values of Elasticity and Velocity Ratio for one model run. 


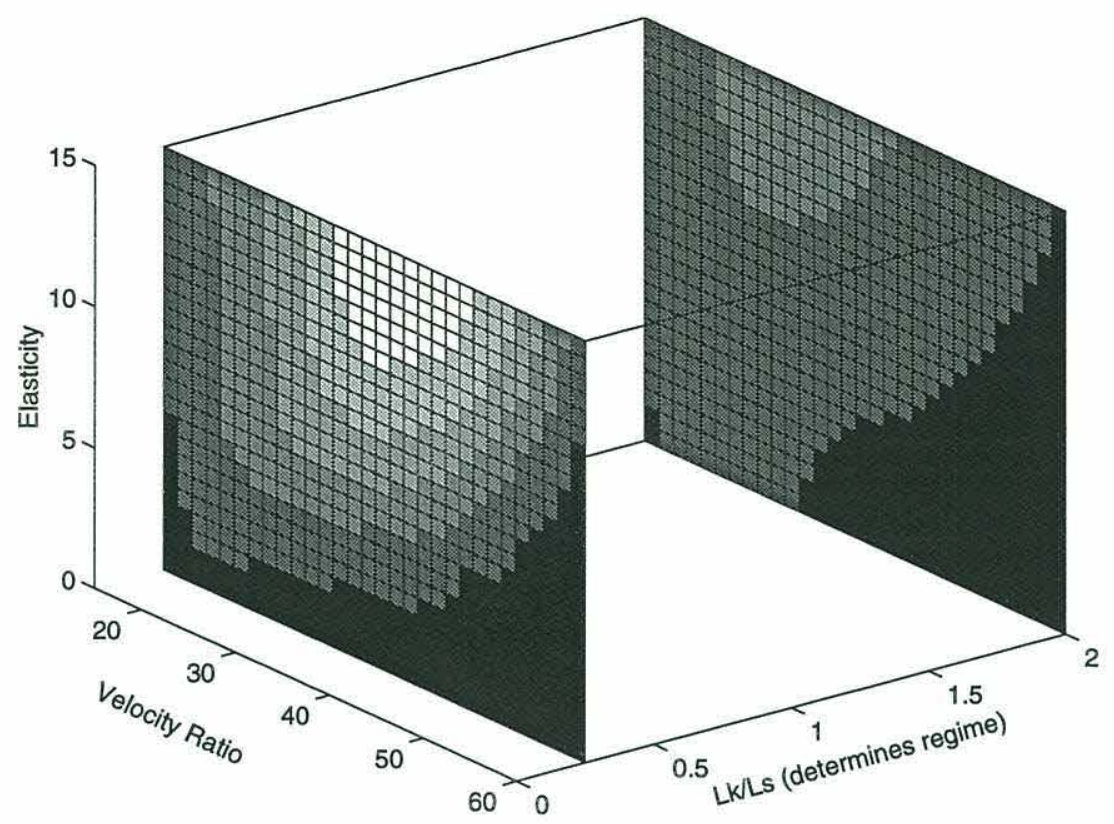

Figure 4.24: Three-dimensional schematic showing the results of varying all three of the model's dimensionless parameters. Shaded regions represent different values of the Aggregation Index $\left(\frac{\max \left(\int C_{36} d z\right)}{\max \left(\int C_{0} d z\right)}\right.$ after 36 hours of model time. Lighter shades represent higher values of the Aggregation Index.

beneath a plume swim rapidly up to the accumulation point and, once they have gotten there, tend not to be spread out by diffusion.

Increasing the Velocity Ratio (in either regime) from a very low value first increases the Aggregation Index, because a very slow frontal process does not have enough time in 36 hours to cause much aggregation. After a certain optimal Velocity Ratio, however, the Aggregation Index drops off sharply if the Velocity Ratio is increased further, as plankton are washed down and out of the frontal region.

Finally, Regime I shows higher overall values of the Aggregation Index than Regime II, because the higher values of diffusion in Regime II spread the plankton distribution in the vertical, making it more susceptible to being spread horizontally by vertically-sheared frontal currents. Interestingly, the optimal Velocity Ratio for a given value of Elasticity (that is, the Velocity Ratio that leads to the highest value 
of the Aggregation Index), is lower in Regime II than in Regime I. This also makes

sense: In Regime II a greater proportion of the plankton are diffused into the highly sheared frontal region, and so they require lower frontal velocities (i.e., lower Velocity Ratio) if they are not to be washed out or advected far away from the accumulation point. The tradeoff here is between slow frontal velocities (which reduce the effective aggregating power of the small-scale subduction mechanism) and high frontal shear (which further spreads out a highly diffused plankton layer).

\subsection{Curved Fronts}

One goal of constructing the model presented here is to compare model results directly with data, in order to understand the factors shaping the characteristics of real plankton patches. Unfortunately, the degree to which that is possible with the model runs presented so far is limited, because the model flow field shown so far does not resemble a physical plume very closely. The greatest difference is that a typical buoyancy plume curves so that the buoyant fluid forms a shallow layer (see, for example, the plume sketched in Figure 4.1), whereas the modelled front descends in a straight diagonal line. It would be useful to run the numerical model using a curved frontal flow field.

One step in that direction is relatively straightforward to make. As R. Beardsley has observed (personal communication), the frontal flow field presented earlier in this chapter is actually one of a class of flow fields having streamfunctions of the form:

$$
\psi=\psi_{0} \cdot z \cdot \tanh \xi
$$

with

$$
\xi=\left(\frac{x}{r}-\left(\frac{|z|}{h_{0}}\right)^{m}\right) .
$$



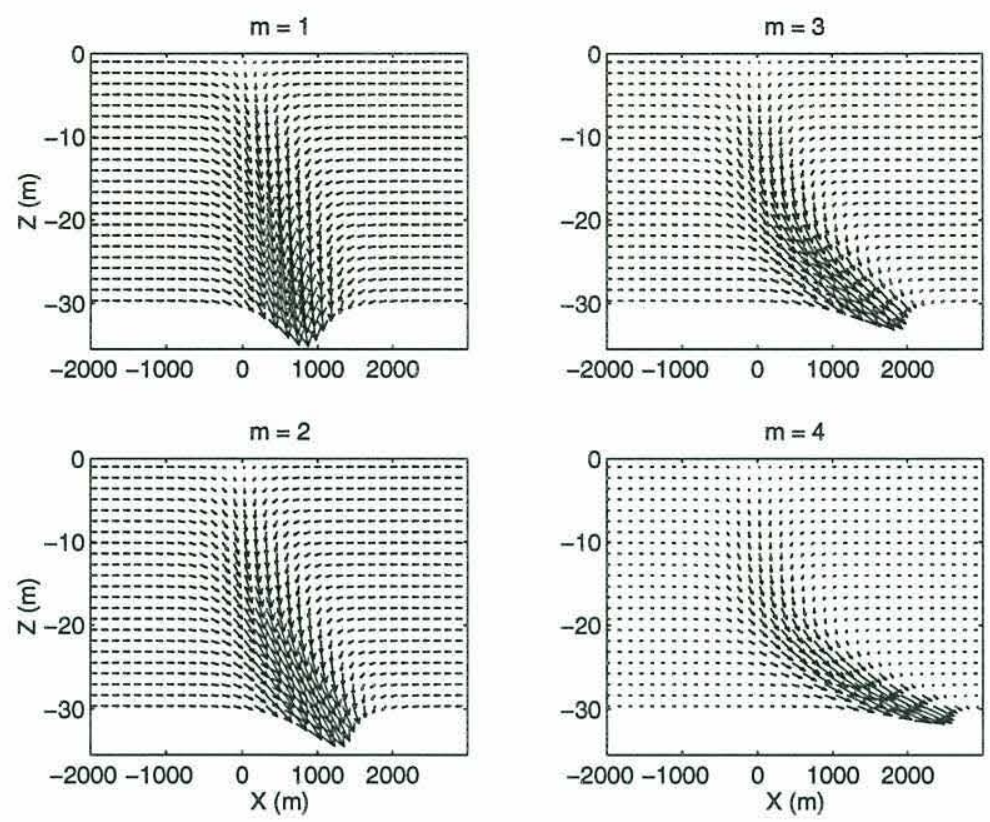

Figure 4.25: Curved fronts produced by varying the value of $m$ in the streamfunction $\psi=\psi_{0} \cdot z \cdot \tanh \xi$, with $\xi=\left(\frac{x}{r}-\left(\frac{|z|}{h_{0}}\right)^{m}\right)$.

Here, the value of $m$ sets the curvature of the front. In the frontal flow field used so far, $m$ has been set to unity. Figure 4.25 shows how the structure of the front varies for various values of $m$.

Figure 4.26 shows the output of runs in Regime I (Figure 4.26A) and Regime II (Figure 4.26B) with $m=3$. As in the $m=1$ runs shown earlier, the greatest concentration of plankton is near the front itself, the sharpest horizontal gradient in concentration is between the accumulation point and the front, and the sharpest vertical gradient in concentration is directly above the accumulation point. On the other hand, the $m=3$ runs have a more pronounced "tail" of plankton extending into the buoyant plume. This is as we would expect, since the high velocities in the frontal region of an $m=3$ front curve more sharply underneath the plume, carrying each animal farther into the plume before it can swim up toward $Z_{0}$. 

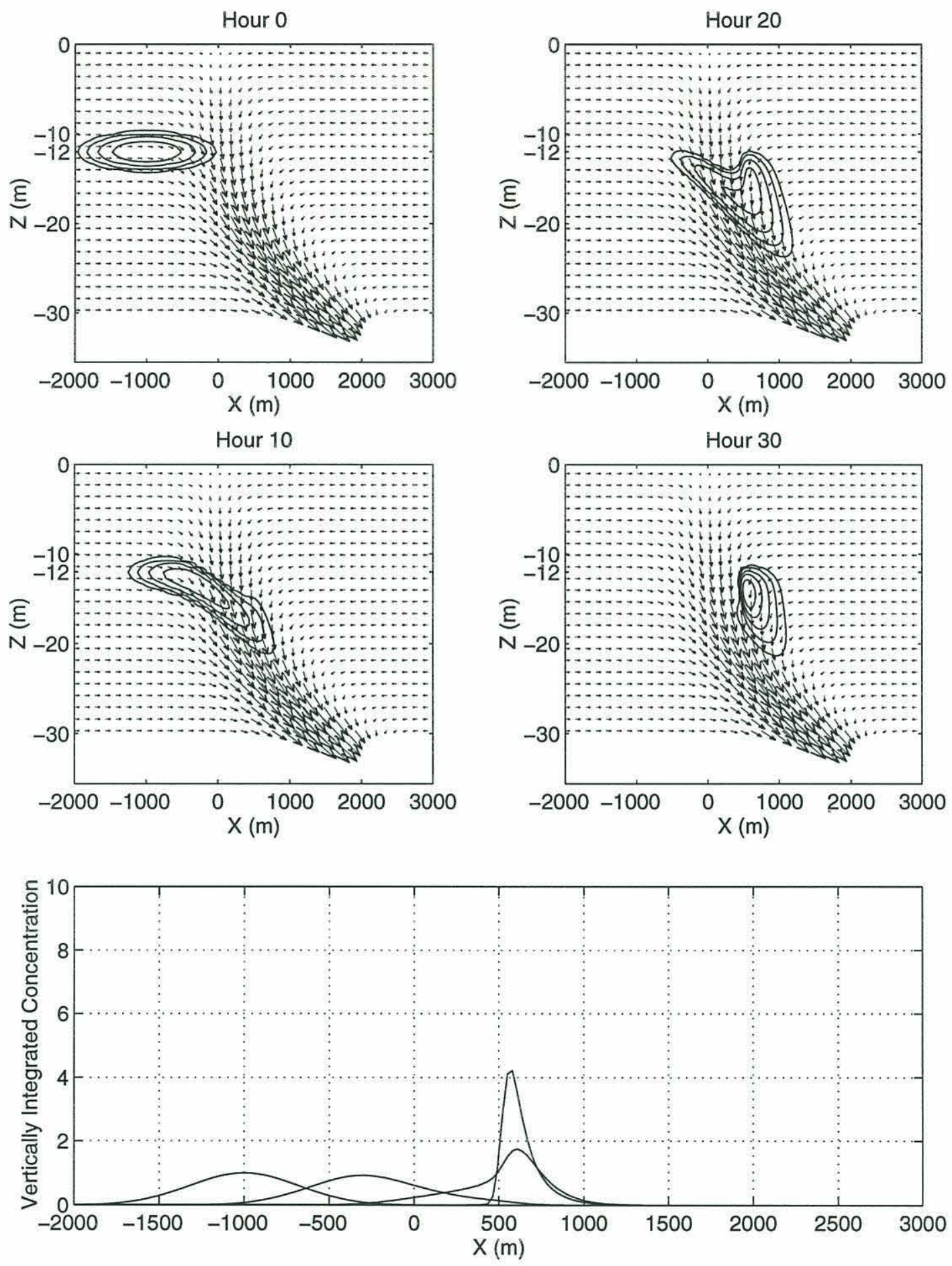

Figure 4.26: Part A. Model Run in Regime I with $m=3$. Note expanded horizontal scale relative to previous plots. 

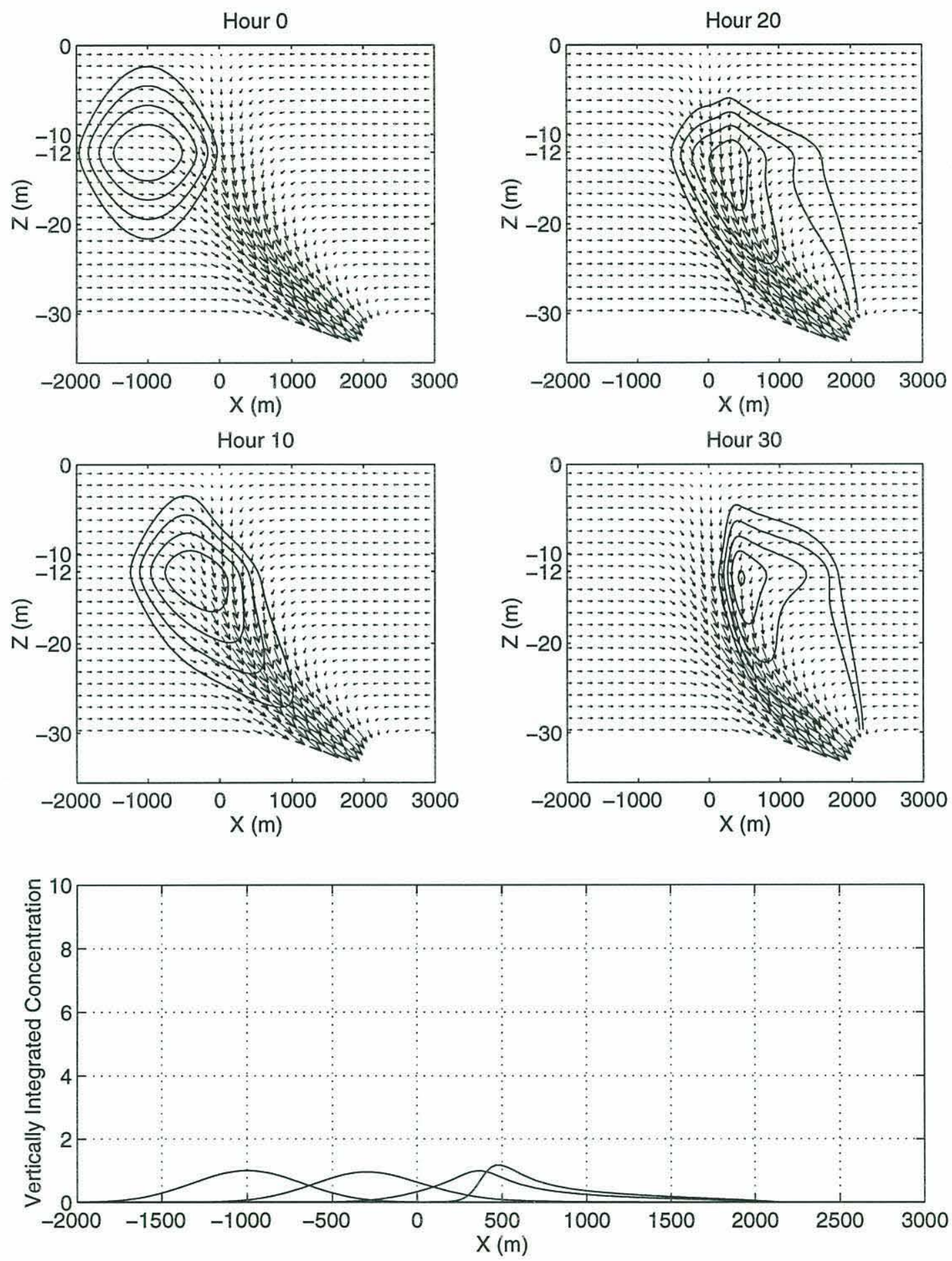

Figure 4.26 continued: Part B. Model run in Regime II with $m=3$ 


\subsubsection{Comparison between Model Results and SCOPEX Data}

Finally, let us briefly compare output from the model with the plankton patch observed near a small-scale density front during SCOPEX. The top panel of Figure 4.27 shows the SCOPEX acoustic data taken near that front. The bottom panel of Figure 4.27 shows the model output after running for 28 hours of model time with $\frac{L_{\kappa}}{L_{s}}=0.25$ (Regime I), Velocity Ratio $=50$, Elasticity $=9$, and $m=3$. (In dimensional numbers: The fluid's scale velocity, $U_{0}=3 \mathrm{~cm} / \mathrm{s}$; the diffusion, $\kappa=0.5 \mathrm{~cm}^{2} / \mathrm{s}$; the scale distance of the animals' swimming-speed profile, $L_{s}=2.7 \mathrm{~m}$; the animals' maximum vertical swiming speed, $W_{s 0}=.06 \mathrm{~cm} / \mathrm{s}$; and the thickness of an equilibrium layer of plankton, $L_{\kappa}=0.7 \mathrm{~m}$.) The model patch is similar to the observed plankton patch in at least some qualitative aspects: the sharp gradient in concentration to the left of the region of highest concentration; the trailing edge of plankton to the right and at the same depth as the region of highest concentration; and the gradual decrease in concentration below the patch.

It is not really possible to make a more detailed comparison between the results of running the numerical model and actual at-sea data for at least two reasons: first, it is difficult to find data taken with high enough resolution-and soon enough after the passage of a front-to compare structures in detail; second, and perhaps more importantly, the frontal flow fields used here, even the fields with $m \neq 1$, are not accurate representations of the actual physical flow field in the region of a buoyant plume. This second problem can perhaps be addressed relatively easily without changing the basic code of the model. It is merely necessary to specify some more realistic frontal velocity field, such as that proposed by Garvine (1974). 

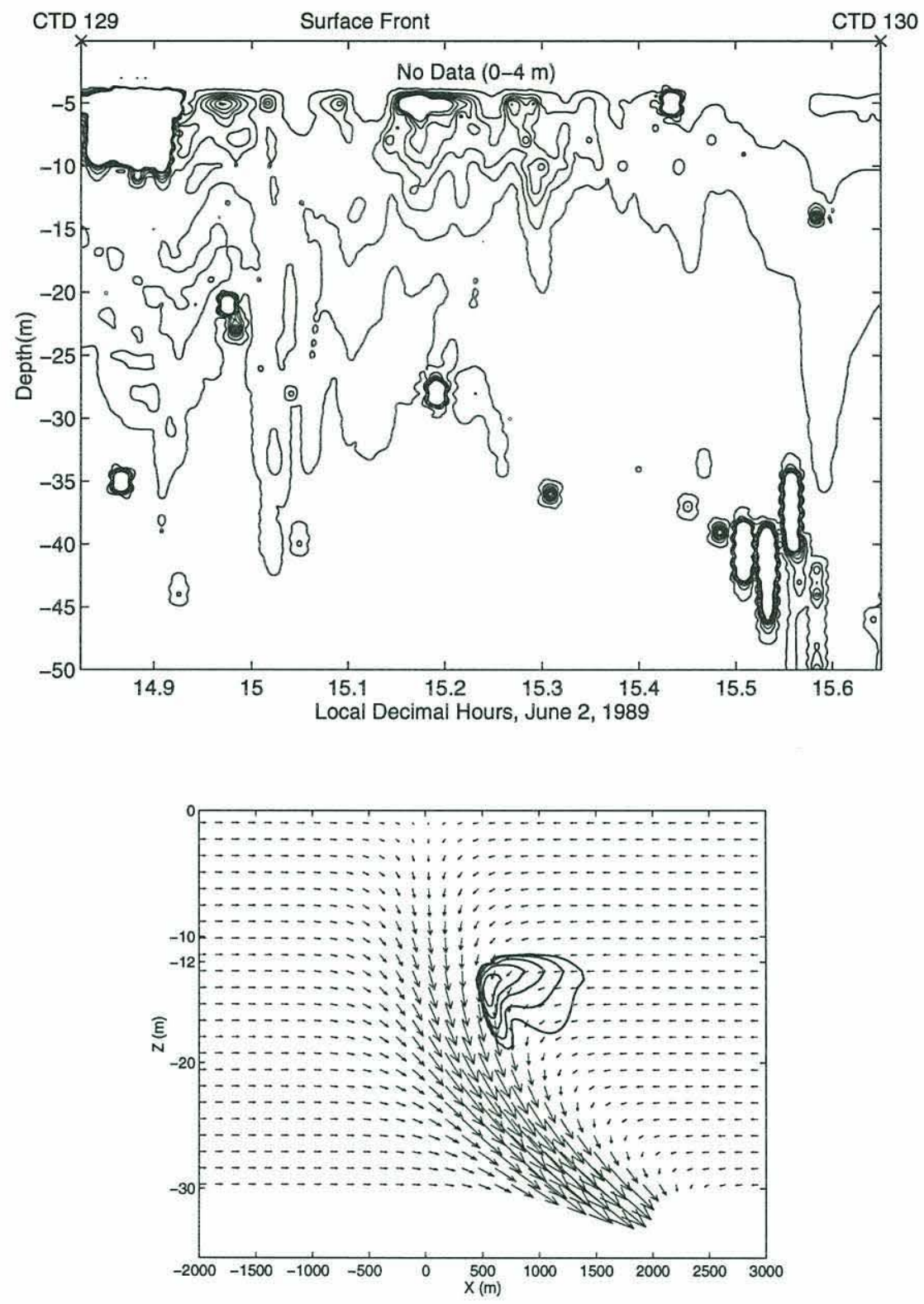

Figure 4.27: Model run similar in some respects to Figure 4.3. Compare the sharp gradient to the left of the accumulation point, and the broad "tail" to the right and below. 


\subsection{Conclusion}

The model shown here demonstrates one mechanism by which small-scale physical processes, combined with biological behavior, can cause zooplankton to aggregate at a front. This may be one of the mechanisms responsible for forming dense patches of Calanus in the Great South Channel, such as those observed during SCOPEX. The Eulerian structure of the model makes it possible to understand the interplay between the roles of diffusion, water velocity, swimming speed and the length scale of the swimming-speed profile in determining the final shape (and degree of concentration) of the patch formed.

One way of analyzing this interplay is through the use of the model's characteristic nondimensional parameters: $\frac{L_{\kappa}}{L_{s}}$, which determines the swimming behavior of the plankton near the top and bottom of the patch; Elasticity, which governs the degree to which a plankton patch tends to form a thin, horizontal layer even under the distorting influence of a vertically-sheared flow field; and Velocity Ratio, which governs the tradeoff between the tendency of plankton to be dispersed or washed out

by a rapid flow field and the inability of the small-scale subduction mechanism to operate efficiently when the frontal velocity field is slow.

The work shown here has two primary limitations. The first-the fact that the simulated front is not physically realistic — can be addressed by adapting a more realistic flow field without changing the essential structure of the model. The second, and more fundamental, limitation is that in the model as it is currently constructed, all velocities must be steady state. Being able to model changing water velocities would make the model much more flexible and capable of simulating much more realistic situations, such as tidal flow fields and fronts that change in intensity over time. In addition, being able to change the animals' swimming speed during a model run would make it possible to simulate such phenomena as diel vertical migration; 
one could imagine, for example, a uniform layer of plankton at depth rising into a frontal flow field, remaining there for a few hours, and then migrating downward again, slightly aggregated by the front. It should be possible in the future to address this question without making too extensive a change to the structure of the model, by adapting from the QUICK algorithm to the QUICKEST algorithm (Leonard, 1988), which is designed to simulate unsteady flow. 


\section{Chapter 5}

\section{Conclusion}

The individual studies that make up this thesis take distinctly different, but complementary, approaches to understanding the dense aggregations of zooplankton that form in the Great South Channel: a close examination of two specific plankton patches (Chapter 2); a highly detailed description of a transect through the larger environment in which the zooplankton aggregations exist (Chapter 3); and a numerical exploration of one small-scale mechanism that may be at the heart of the patch-formation process itself (Chapter 4). In this chapter I shall review the primary results of each study, and I shall describe some of the many questions that are left unanswered.

\subsection{Individual Plankton Patches}

Chapter 2 looks at individual patches of the copepod Calanus finmarchicus from the point of view of a predator-the North Atlantic right whale. To carry out this study, the R/V Endeavor followed each of two right whales as they fed on Calanus patches at separate sites in the Great South Channel. As it followed each whale, the ship gathered data from CTD tow-yos, MOCNESS tows, a 150-kHz ADCP, and a 
towed acoustic profiler operating at 120 and $200 \mathrm{kHz}$. Acoustic estimates of biomass concentration were correlated with the results of MOCNESS tows that had been made while the acoustic data were being taken. In addition, "noise," or scatter, in data from the CTD-mounted transmissometer was correlated with acoustic biomass estimates, making it possible to use one measure of that scatter (the rms deviation from a smooth background curve) as a proxy for acoustic biomass data in places where the acoustic data were corrupted. Using this combination of data, it was possible to derive a biological description of the plankton patches. Data from the ADCP were used to estimate the speed through the water at which one whale swam while feeding (approximately $1.2 \mathrm{~m} / \mathrm{s}$ ) and to set a lower limit on the north-south extent of one patch $(5.3 \mathrm{~km})$.

The primary strength of this study lies in its use of multiple instruments and observations to draw a single coherent picture of the observed Calanus patches. One important result is the estimate that one whale stopped feeding and turned around when the copepod concentration dropped below about $1.5-4.5 \times 10^{3}$ copepods $/ \mathrm{m}^{3}$, or $1-3 \mathrm{~g} / \mathrm{m}^{3}$. This is consistent with earlier estimates (based on the energetics and hydrodynamics of whale feeding) of the minimum density of prey a whale must ingest in order not to lose energy by attempting to feed. Another important result was the discovery of an extremely high concentration of copepods in one patch: $3.3 \times 10^{5}$ copepods $/ \mathrm{m}^{3}$. If a right whale could find a patch that was this highly concentrated throughout, it could satisfy its entire annual energy requirement in only two days of continuous feeding.

The greatest limitations of this work originate primarily in the limitations of the sampling gear. Net tows give specific information concerning species, life-stage, and size distributions, but they are limited in their vertical coverage (they can sample only one depth at a time) and they integrate over long horizontal distances. Acoustic instrumentation does sample multiple depth bins simultaneously, and samples much 
more closely in the horizontal than nets do, but it provides no information on the nature of the organisms being observed. And neither kind of instrument is deployed at exactly the same time or place as the instruments gathering physical data. The transmissometer, on the other hand, can be deployed together with the CTD, but it provides nowhere near the specificity or accuracy of nets or acoustic instruments. That it was possible to integrate data from three such disparate sources is largely due to the specific conditions that happened to hold at the time of sampling, and especially to the fact that the biomass present near the surface at that time consisted almost entirely of one species of copepod, with most individuals in one of only two life stages. If that had not been the case, it is highly unlikely that transmissometer data would have given any useful indication of the concentration of copepods; it would also have been extremely difficult to intercalibrate acoustic echo-strength data with species-specific data from MOCNESS tows.

\subsection{One Transect in Detail}

The Video Plankton Recorder, as discussed in Chapter 3, provides data with great specificity and detail. Indeed, it gives almost too much information to be assimilated in one study. The VPR provides data on the genus or species (and often the gender), size, life-stage, depth, and orientation in space of individual organisms, together with CTD data taken at almost precisely the same time and place. The instrument's inherent resolution is very good (60 fields per second from each of four cameras, and 4-second averages of CTD data), and that resolution can be taken advantage of in a number of ways: the instrument can be towed at a single depth, for

example, in order to achieve very good horizontal resolution; alternatively, it can be tow-yoed in order to resolve a two-dimensional section. 
From the perspective of this thesis, one of the most important elements of Chapter 3 is the "mosaic" of water types shown in Figure 3.7. Although this is a necessarily time-aliased view of one cross-section of the Great South Channel, the high resolution of the VPR data provides a unique picture of the small-scale variability of the water there. Moreover, this mosaic correlates extremely well with much of the biological data concerning the spatial distribution of various species and age-classes: members of certain species were found to be contained almost entirely within particular water types, and in one case (the Ophiuroids), larvae and metamorphosing juveniles were found to be divided into separate water types depending on their lifestage. Another important result of this study is the finding that weakly-swimming animals tended to aggregate in regions of high physical stability (as indicated by gradient Richardson number), and that strongly-swimming animals aggregated either in regions of low vertical stability (as in the case of the pteropod Limacina retroversa) or in regions of high vertical stability (as in the case of the copepod Calanus finmarchicus). In addition, certain correlations between physical data and biological data concerning the distribution of one organism (the colonial diatom Chaetocerous socialis) provided important information concerning the origin of one water type, and thus helped to resolve the kinematic picture of the region.

The primary limitation of this dataset has to do with temporal scales: the data represent only a single transect across a region known for high temporal variability and strong tidal currents. The section took eight hours to complete-a significant fraction of the tidal cycle - and so it is very difficult to eliminate the effects of aliasing when comparing data taken at opposite ends of the transect. 


\subsection{Model of a Mechanism}

The numerical model presented in Chapter 4 provides an effective simulation of the "small-scale subduction" mechanism, a small-scale, physical-biological process that can create dense patches of zooplankton. By varying certain parameters of the model, it is possible to gain some intuition into the ways vertical diffusion, water velocity, and details of the organisms' swimming-speed profile can affect the eventual distribution of organisms.

In the small-scale subduction mechanism, a buoyant plume flows over denser water containing organisms that for some reason swim vertically in order to maintain a particular depth. As dense water is subducted beneath the plume, the organisms in the dense water swim up into the plume water, accumulating near the front that characterizes the plume's leading edge. Chapter 4 shows an example of SCOPEX data that is consistent with the action of this mechanism, and then presents a twodimensional, steady-state (in water velocity), Eulerian model of the mechanism.

The SCOPEX data show a highly concentrated patch of Calanus on the less dense side of a surface salinity front; the front was probably associated with the springtime low-salinity plume advancing across the northern Great South Channel at the time. Physical data taken near the front are consistent with the suggestion that dense water was being subducted under lighter water as the front advanced, and net tows made in the area indicated that the Calanus there seemed to be remaining at the same depth for long periods of time (depth-keeping). Since the biological and physical conditions necessary for the formation of plankton patches by the smallscale subduction mechanism were both present, and since the location of the patch is consistent with the action of that mechanism, it is likely that small-scale subduction played a role in the formation of that patch. 
The numerical model was constructed to simulate the formation of highly concentrated plankton patches by small-scale subduction, and to explore ways in which varying the physical or biological conditions in the region of a small-scale front can change the shape and maximum plankton concentration of the patches that are formed. Plankton are modelled as a dimensionless "concentration"; the flow of plankton through the model grid is controlled by a balance between the animals' vertical swimming (which varies as a function of depth) and advection and diffusion by the surrounding fluid. Advection is simulated by the two-dimensional QUICK algorithm proposed by Leonard (1979a, 1979b, 1988), in order to avoid certain instabilities that can affect central-difference-based algorithms in highly advective situations. The model produces concentrated plankton patches resembling the patches one would expect to be produced by small-scale subduction. In a typical case, the vertically integrated concentration of an initial distribution of plankton increases by an order of magnitude after 30 hours of model time.

The model is characterized by three dimensionless parameters, which determine both the degree to which plankton aggregate and the overall shape (in two dimensions) of the eventual plankton patch. Those parameters are: $\frac{L_{k}}{L_{s}}$, where $L_{s}$ is a characteristic length scale of the animals' swimming-speed profile and $L_{\kappa}$ is the "thickness" of the plankton layer that would form if vertical diffusion exactly balanced the animals' swimming (i.e., if the surrounding fluid were motionless); Elasticity, a measure of the degree to which a plankton patch re-forms into a thin layer after having been distorted by the surrounding currents; and Velocity Ratio, the ratio of the water's scale velocity to the animals' maximum vertical swimming speed.

The first of these parameters, $\frac{L_{\kappa}}{L_{a}}$, determines a key characteristic of the model: the swimming behavior of animals at the top and bottom of the plankton layer. For high values of $\frac{L_{k}}{L_{s}}$, animals are diffused strongly in the vertical, but once they have been displaced by even a relatively small distance, they attempt to swim back to their 
"target depth" at nearly their maximum sustainable speed. As $\frac{L_{\kappa}}{L_{s}}$ is increased, the plankton distribution acquires a distinct "tail" in the direction of the buoyant plume, centered at approximately the animals' target depth. This is because for high values of $\frac{L_{k}}{L_{s}}$, any plankton that accumulate near the front are diffused downward and into a region where the surrounding water velocity carries them rapidly in the direction from which the plume is flowing; as they are carried into the plume, however, they swim up rapidly toward their target depth, forming a weak layer there.

The second of these parameters, the Elasticity, controls the degree to which the frontal flow field distorts the plankton distribution. As the Elasticity is decreased, the plankton distribution forms a lozenge-like shape aligned with the strongest frontal velocities. The third parameter, the Velocity Ratio, controls the tradeoff between water velocities that are too slow for the small-scale subduction mechanism to work effectively and velocities that are so fast that plankton are washed down and out of the front before they can accumulate. For each combination of values of the other two parameters, there is an optimal value of Velocity Ratio that maximizes the final concentration in the patch.

The model's greatest limitations are its time-invariance and the unrealistic structure of the front that is modelled. Both of these limitations can be addressed within the essential structure of the model, but in order to model a realistic frontal field it will be necessary to obtain good data concerning the nature of the fronts that may be responsible for the formation of Calanus patches in the Great South Channel. Another limitation is uncertainty concerning the actual swimming behavior of depthkeeping plankton. Again, this limitation can best be addressed by obtaining good observational data of plankton behavior. 


\subsection{Questions}

The studies presented here represent only very early steps toward understanding the dense aggregations of zooplankton found in the Great South Channel during the late spring and early summer. Each study answers only a small part of the question it addresses, and each raises new questions on the way to that partial answer. In a sense, then, one common theme of these studies is ignorance.

For example, Chapter 2 estimates that the north-south extent of one patch of Calanus was at least $5.3 \mathrm{~km}$. Is this typical of the size of Calanus patches in the northern Great South Channel? And how much does knowing this one dimension tell us about the overall area of the patch-after all, the whale could have been swimming along the patch's longest (or shortest) axis. Furthermore, what is the typical concentration of Calanus in a patch? Studies that rely on whales to find Calanus patches will most likely be biased towards the densest aggregations, since that is surely where the whales prefer to feed. How common are patches containing such high concentrations of copepods as were found in this patch, and how common are less dense patches?

Moreover, how does the concentration of copepods vary within a single patch? The SCOPEX acoustic data (Figure 2.6) show that biomass concentration varies greatly on the smallest horizontal scales measured. For example, the highest concentration of copepods found by the acoustic profiler (about 5 meters deep at approximately 1400 meters along the tow-yo) is only one "ping" (30 seconds) after a location at which the profiler registered essentially zero copepod biomass at the same depth. The Video Plankton Recorder data discussed in Chapter 3 show strong variability on even smaller scales - in some sense, on the smallest scales for which zooplankton concentration can be defined. How does variability on large scales (the existence of the patches themselves) relate to variability on the smallest scales (clusters of individual 
plankton)? Is there a definable "spectrum" of variability in plankton concentration? How much of this variability is due to physical-biological processes, such as that modelled in Chapter 4, and how much is due simply to some behavior (such as small-scale swarming) on the part of the plankton?

The model presented in Chapter 4 shows one way in which plankton patches can form at small-scale fronts (such as the salinity fronts found in the Great South Channel), but it too raises a number of questions. The model shows that the size, shape and peak concentration of a patch depend strongly on the swimming behavior of the animals aggregated there, yet very little is known about the depth-keeping or surface-seeking behavior of zooplankton in the Great South Channel. Which plankton species swim to maintain depth (or to stay near the surface), when (and why) do they do so, and how do their swimming speeds vary with distance from their desired depth? Certainly the presence of small-scale salinity fronts in the Great South Channel is a seasonal phenomenon; is depth-keeping in some species also a seasonal phenomenon, as suggested by the observations of Durbin et al. (1995a)? If so, how much of the animals' depth-keeping behavior occurs at a time when these fronts are present?

Another key factor in determining the characteristics of patches formed by small-scale subduction is the shape and velocity profile of the front itself. The curved fronts shown in Section 4.7 are a first approximation to the frontal flow fields that might be found at small-scale salinity fronts in the Great South Channel, but they are clearly not a realistic representation. What does the velocity field look like at the leading edge of a buoyant plume? How does this velocity field change over time? How strong, and how varied in space, are the horizontal and vertical diffusivity fields in the vicinity of plume-related fronts?

On a larger scale, the VPR transect discussed in Chapter 3 shows in some detail the biological and physical properties of water in the broad region in which the plankton patches form. How variable are these properties in time and space? How 
do the water types shown in Figure 3.7 form, circulate, and disperse? How does the distribution of plankton change as the distribution of water types changes, and how frequently are they as well correlated as in the section discussed here? Where in the Great South Channel is the biology best correlated with the physics, and where is the correlation weakest? How does that pattern itself change over time?

Many of the questions I have raised here are well suited to being addressed by the techniques described earlier in this thesis. Certainly it would be useful to make a number of VPR transects across a few sections of the Great South Channel over the course of a few days or weeks, preferably at the highest speed possible (to reduce time-aliasing of the data). Repeated VPR sections and grid patterns conducted across a small-scale salinity front could be made in order to resolve the physical structure of the front. If the sections were carried out for several days at a time, it would be possible to trace not only the front's temporal evolution, but also the changing distribution of plankton near the front. Similar grids conducted near existing plankton patches (perhaps located by tracking feeding right whales) could determine the size scale of the patches themselves, the variability of plankton concentration on many scales within a patch, and the way these characteristics change over time. Study of the biological distributions found in these grids could help answer questions about the animals' vertical swimming behavior. The resulting data concerning the shape of the front and the behavior of the animals could then serve as input into a numerical model, and simulated patches produced by the model could then be compared with patches actually observed in the Great South Channel. 


\section{Appendix A}

\section{Horizontal and Vertical Diffusion}

\section{A.1 Homogeneity of Vertical Diffusion}

The assumption that the vertical diffusion coefficient is constant over the model domain is certainly unrealistic, but I believe it does not affect the model's overall results in a critical way. The strength of the vertical diffusion coefficient is most important at the accumulation point, where vertical diffusion determines whether the plankton that accumulate there will remain in a thin clump or will become spread out vertically. Plankton that are dispersed vertically by diffusion will then be dispersed horizontally by vertically-sheared currents in the front (see Figure 4.19). At the accumulation point, which is within the body of the buoyant plume, the vertical diffusion coefficient is not likely to vary a great deal.

Indeed, the place where the vertical diffusion coefficient is most likely to vary strongly is in the front itself, because it is there that the velocity and density fields change most rapidly with distance. Within the front, however, I do not believe

that diffusion is an important part of the balance that determines $\frac{\partial C}{\partial t}$, the change in concentration over time at each grid-point. Rather, I believe the most important 
balance is between advection by the fluid, $\frac{\partial}{\partial z}\left(C \cdot W_{\text {fluid }}\right)+\frac{\partial}{\partial x}\left(C \cdot U_{\text {fluid }}\right)$, and swimming by the animals, $\frac{\partial}{\partial z}\left(C \cdot W_{\text {swim }}\right)$ (see Equation 4.1). Evidence for this is found in Figure 4.13, in which the animals do not swim at all. In this case, the animals are advected rapidly out of the model domain and the effects of vertical diffusion are barely noticeable. It is only when swimming balances advection that animals cross the frontal boundary appreciably.

\section{A.2 Horizontal Diffusion}

How reasonable is it to ignore the effects of horizontal diffusion in the model? In this section I shall present a simple scaling argument indicating that, in the cases I have treated, horizontal diffusion is probably insignificant in relation to horizontal advection. Even so, the question is close enough that horizontal diffusion should probably be included in future versions of the model.

If horizontal diffusion is not ignored, then Equation 4.1 becomes:

$$
\frac{\partial C}{\partial t}=-\frac{\partial}{\partial z}\left(C \cdot\left(W_{\text {fluid }}+W_{\text {swim }}\right)\right)-\frac{\partial}{\partial x}\left(C \cdot U_{\text {fluid }}\right)+\frac{\partial}{\partial z}\left(\kappa_{V} \frac{\partial C}{\partial z}\right)+\frac{\partial}{\partial x}\left(\kappa_{H} \frac{\partial C}{\partial x}\right)
$$

where $\kappa_{V}$ is a vertical diffusion coefficient and $\kappa_{H}$ is a horizontal diffusion coefficient. In order for horizontal diffusion to be at least as important as horizontal advection, we then require that

$$
\left|\frac{\partial}{\partial x}\left(C \cdot U_{\text {fluid }}\right)\right| \leq\left|\frac{\partial}{\partial x}\left(\kappa_{H} \frac{\partial C}{\partial x}\right)\right|
$$

or

$$
\frac{C \cdot U}{L} \leq \frac{\kappa_{H} \cdot C}{L^{2}}
$$

or

$$
U \leq \frac{\kappa_{H}}{L}
$$




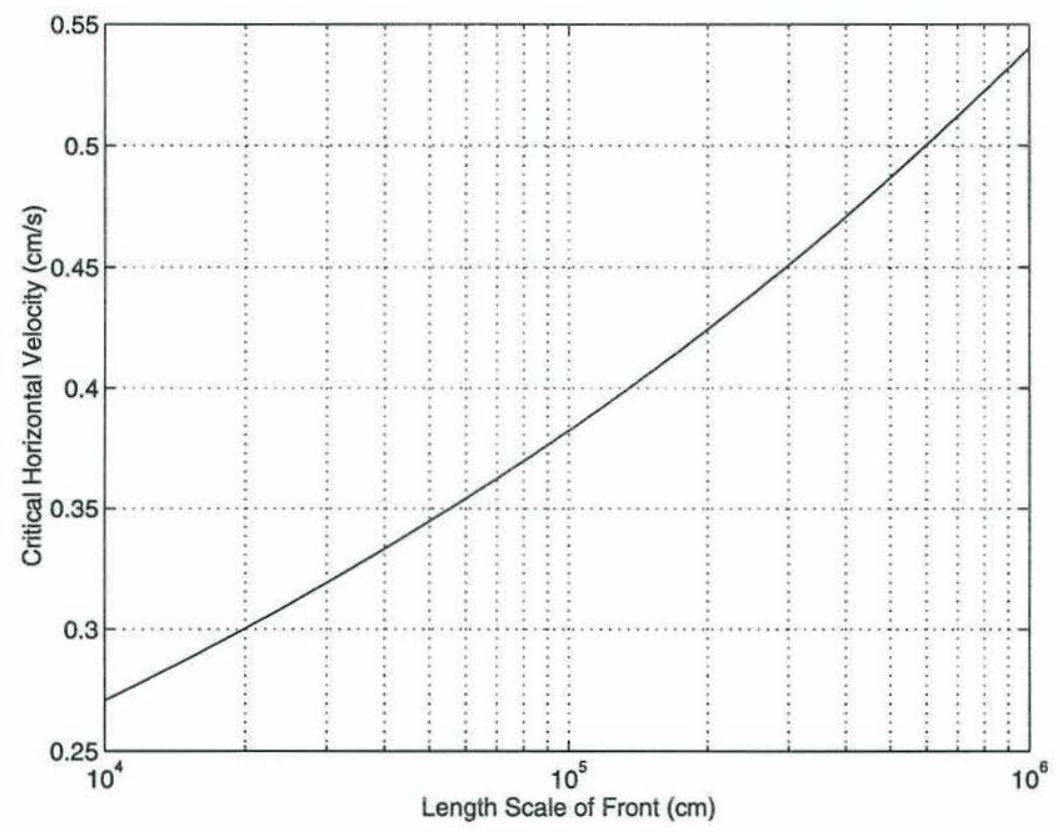

Figure A.1: Critical horizontal velocity plotted as a function of frontal length scale. Horizontal diffusion is significant for fronts in which the horizontal scale velocity is roughly equal to or below the critical horizontal velocity.

where $L$ is a characteristic length scale of the front and $U$ is a characteristic horizontal scale velocity.

Okubo (1971) presents the following empirical relation between effective horizontal diffusivity and the length scale of the system under consideration:

$$
\kappa_{H}=0.0103 \times L^{1.15},
$$

where $\kappa_{H}$ is given in $\mathrm{cm}^{2} / \mathrm{s}$ and $\mathrm{L}$ is given in $\mathrm{cm}$. Okubo (1976) modifies this formula on theoretical grounds, to give:

$$
\kappa_{H}=0.0680 \times L^{1.15},
$$

and so we can eliminate $\kappa_{H}$ from Equation A.3 to arrive at:

$$
U_{\text {crit }} \leq 0.068 \times L^{0.15} \text {. }
$$


Values of this critical horizontal scale velocity are plotted in Figure A.1 for fronts ranging in size from $100 \mathrm{~m}$ to $10 \mathrm{~km}$. For the fronts treated in this thesis, $L$ ranges from 500 to $750 \mathrm{~m}$, giving a critical horizontal scale velocity of about 0.37 $\mathrm{cm} / \mathrm{s}$. This is an order of magnitude smaller than the fluid velocities modelled, and so it is probably reasonable to conclude that in these cases horizontal diffusion would have only a second-order effect. 


\section{Appendix B}

\section{The One- and Two-dimensional QUICK Algorithms}

In the one-dimensional QUICK method, quantities of concentration $(C)$ at a gridcell face are estimated by taking the average of the concentration at the gridcells on either side of the face, and then correcting it with a "curvature" term that takes into account the gridcell "upstream" of those cells (see Figure B.1):

$$
C U_{i}=C_{\text {linear }}-\frac{1}{8} \mathcal{C U R V} \cdot(\Delta x)^{2},
$$

where $C U_{i}$ is the estimated value of concentration at the gridcell face between cells $i$ and $i+1$, and

$$
C_{\text {linear }}=\frac{1}{2}\left(C_{i}+C_{(i+1)}\right)
$$

with

$$
\mathcal{C U R V}= \begin{cases}\frac{C_{(i-1)}-2 C_{i}+C_{(i+1)}}{(\Delta x)^{2}} & \text { for } U_{i}>0 \\ \frac{C_{(i+2)}-2 C_{(i+1)}+C_{i}}{(\Delta x)^{2}} & \text { for } U_{i}<0\end{cases}
$$

where $U_{i}$ is the velocity at the gridcell face between cells $i$ and $i+1$. 


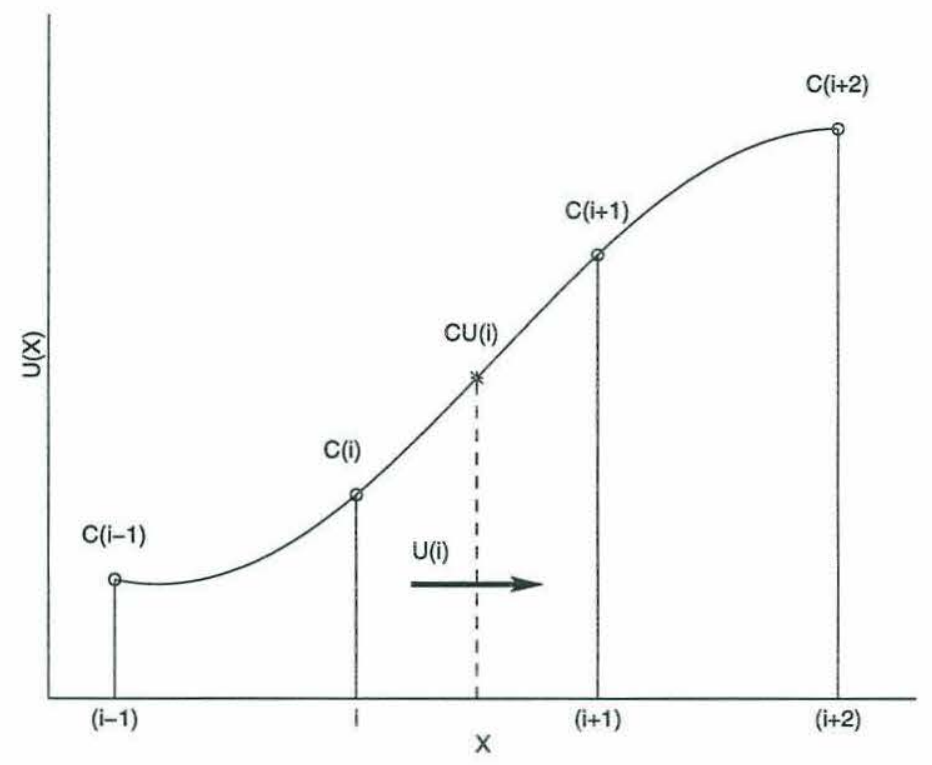

Figure B.1: Grid for the one-dimensional QUICK method. As explained in the text, $C U_{i}$, the estimated value of $C$ between grid points (i) and (i+1), depends on the direction of the velocity vector $\left(U_{i}\right)$ at the cell wall between those points (after Leonard, 1988).

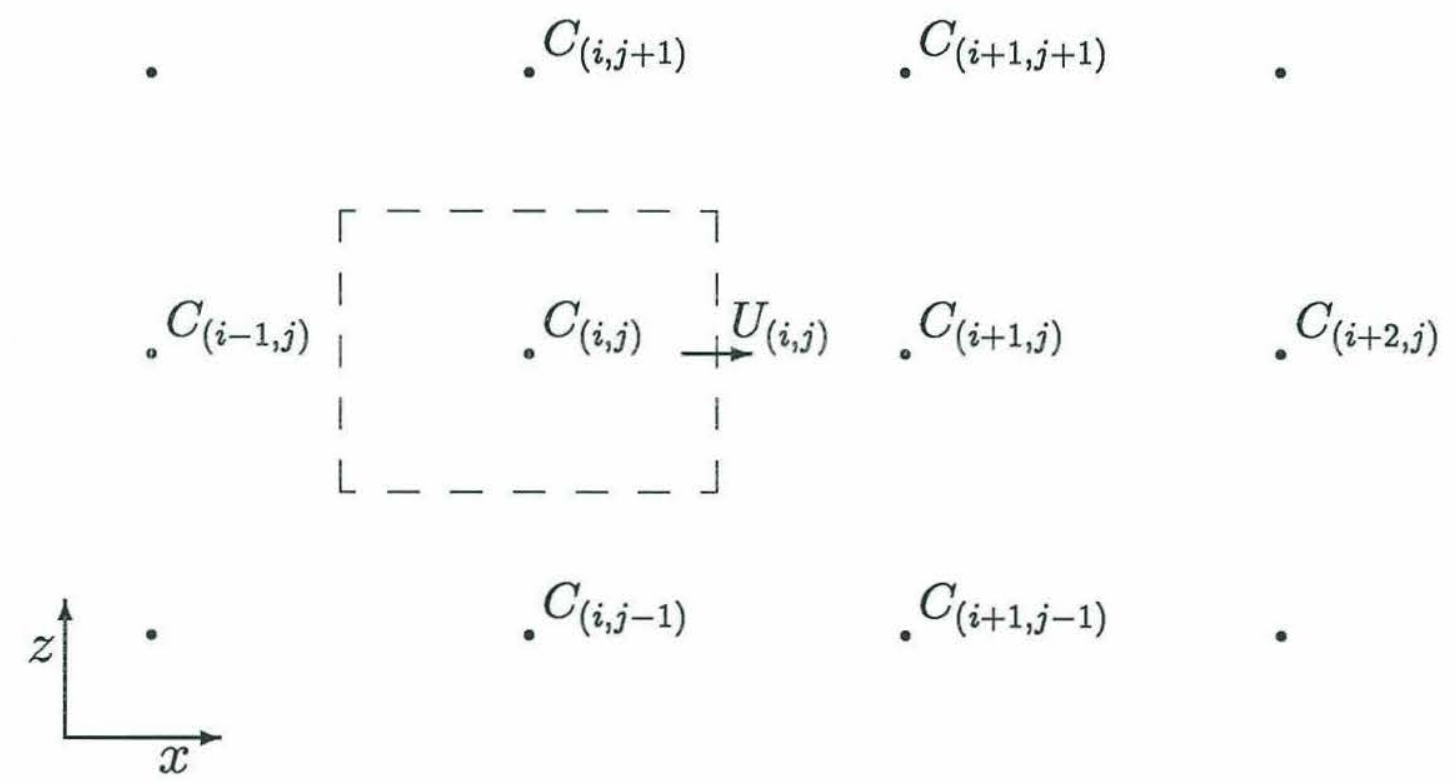

Figure B.2: Grid for the two-dimensional QUICK method (after Leonard, 1988). 
The Two-dimensional QUICK method is similar, except that a second curvature term is included in order to account for variation in the value of $C$ over a gridcell face (see Figure B.2). Hence:

$$
C U_{(i, j)}=C_{\text {linear }}-\frac{1}{8} \mathcal{C U R \mathcal { N } N} \cdot(\Delta x)^{2}+\frac{1}{24} \mathcal{C U R V \mathcal { T }} \cdot(\Delta z)^{2}
$$

where

$$
C_{\text {linear }}=\frac{1}{2}\left(C_{(i, j)}+C_{(i+1, j)}\right)
$$

and

$$
\left.\begin{array}{l}
\mathcal{C U R \mathcal { N } N}=\frac{C_{(i-1, j)}-2 C_{(i, j)}+C_{(i+1, j)}}{(\Delta x)^{2}} \\
\mathcal{C U R V \mathcal { T }}=\frac{C_{(i, j+1)}-2 C_{(i, j)}+C_{(i, j-1)}}{(\Delta z)^{2}}
\end{array}\right\} \text { for } U_{(i, j)}>0
$$

or

$$
\left.\begin{array}{l}
\mathcal{C U R V \mathcal { N }}=\frac{C_{(i+2, j)}-2 C_{(i+1, j)}+C_{(i, j)}}{(\Delta x)^{2}} \\
\mathcal{C U R V \mathcal { T }}=\frac{C_{(i+1, j+1)}-2 C_{(i+1, j)}+C_{(i+1, j-1)}}{(\Delta z)^{2}}
\end{array}\right\} \text { for } U_{(i, j)}<0
$$




\section{REFERENCES}

Bigelow, H. B., 1926. Plankton of the offshore waters of the Gulf of Maine. Bull. Bureau Fisheries, 40, 1-509.

Bigelow, H. B., 1927. Physical oceanography of the Gulf of Maine. Bull. Bureau Fisheries, 40, 511-1027.

Burd, B. J., and R. E. Thomson, 1993. Flow volume calculations based on threedimensional current and net orientation data. Deep-Sea Res., 40, 1141-1153.

Butman, B. and R. C. Beardsley, 1987. Long-term observations on the southern flank of Georges Bank: Seasonal cycle of currents, temperature, stratification, and wind stress. J. Phys. Oceanogr., 17, 367-384.

Cassie, R. M., 1959. Some correlation in replicate plankton samples. N. Z. J. Sci., 2, 473-484.

Cassie, R. M., 1960. Factors influencing the distribution pattern of plankton in the mixing zone between oceanic and harbour waters. N. Z. J. Sci., 3, 26-50.

Cetacean and Turtle Assessment Program (CETAP), 1982. A characterization of marine mammals and turtles in the Mid-and North-Atlantic areas of the U. $S$. outer continental shelf, final report. Contract no. AA551-CT8-48. Bureau of Land Management, U. S. Dept. of the Interior, Washington, DC, 586 pp. (NTIS no. PB83-215 855).

Chen, C., 1992. Variability of Currents in Great South Channel and Over Georges Bank: Observation and Modeling. Ph.D. Thesis. MIT/WHOI, WHOI-92-20.

Chen, C., R. C. Beardsley, and R. Limeburner, 1995a. Variability of water properties in late spring in the northern Great South Channel. Cont. Shelf Res., 15(4/5), 415-431.

Chen, C., R. C. Beardsley, and R. Limeburner, 1995b. Variability of currents in late spring in the northern Great South Channel. Cont. Shelf Res., 15(4/5), 451-473.

Comita, G. W., S. M. Marshall, and A. P. Orr, 1966. On the biology of Calanus finmarchicus, XIII. Seasonal change in weight, calorific value and organic matter. J. Mar. Biol. Assoc. U.K., 46, 1-17.

Crone, M. J. and S. D. Kraus (eds.), 1990. Right Whales (Eubalaena glacialis) in the Western North Atlantic: A Catalog of Identified Individuals. New England Aquarium, Boston, MA, 223 pp. 
Cushing, D. H., 1961. Patchiness. ICES Rapp. Proc. Verb., 153, 152-163.

Davis, C. S., 1987. Zooplankton life cycles. In: Georges Bank, R. H. Backus (ed), MIT Press, Cambridge, MA, pp. 256-267.

Davis, C. S., S. M. Gallager, M. S. Burman, L. R. Haury, and J. R. Strickler, 1992a. The video plankton recorder (VPR): design and initial results. Archiv fur Hydrobiologie, Beihefte, Ergebnisse'der Limnologie, 36, 67-81.

Davis, C. S., S. M. Gallager, and A. Solow, 1992b. Microaggregations of oceanic plankton observed by towed video microscopy. Science, 257, 230-232.

Denman, K. L. and D. L. Mackas, 1977. Collection and analysis of underway data and related physical measurements. In: Spatial Pattern in Plankton Communities, J. H. Steele (ed), Plenum Press, NY. pp. 85-110.

Denman, K. L. and T. M. Powell, 1984. Effects of physical processes on planktonic ecosystems in the coastal ocean. Oceanogr. Mar. Biol. Ann. Rev., 22, 125-168.

Durbin, E. G., R. G. Campbell, S. L. Gilman, and A. G. Durbin, 1995a. Diel feeding behavior and ingestion rate in the copepod Calanus finmarchicus in the southern Gulf of Maine during late spring. Cont. Shelf Res., 15(4/5), 539-570.

Durbin, E. G., and A. G. Durbin, 1983. Energy and nitrogen budgets for the Atlantic menhaden, Brevoortia tyrannus (Pisces: Clupeidae), a filter-feeding planktivore. Fish. Bull., 81, 177-199.

Durbin, E. G., A. G. Durbin, and R. C. Beardsley, 1995b. Springtime nutrient and chlorophyll $a$ concentrations in the southwestern Gulf of Maine. Cont. Shelf. Res., 15(4/5), 433-450.

Durbin, E. G., S. L. Gilman, R. G. Campbell, and A. G. Durbin, 1995c. Abundance, biomass, vertical migration and estimated development rate of the copepod Calanus finmarchicus in the southern Gulf of Maine during late spring. Cont. Shelf Res., 15(4/5), 571-591.

Emlet, R. B. 1983, Locomotion, drag, and the rigid skeleton of larval echinoderms. Biol. Bull., 164, 433-445.

Epstein, A. W., R. C. Beardsley, and M. C. Macaulay, 1993. Mechanisms of flowinduced aggregation and concentration of zooplankton at fronts. Larval Ecology Meetings; Stony Brook, NY, August, 1993.

Falkowski, P. and K. von Bock, 1979. Atlantic coastal experiment: Phytoplankton species composition. Brookhaven National Laboratory Associated Universities. Inc. Report BNL-26335 USDOE. 266 pp. 
Flagg, C. N, 1987. Hydrographic structure and variability. In: Georges Bank, R. H. Backus (ed), MIT Press, Cambridge, MA, pp. 108-124.

Franks, P. J. S., 1992. Sink or swim: accumulation of biomass at fronts. Mar. Ecol. Prog. Ser., 82, 1-12.

Gallager, S. M., J. L. Manuel, D. A. Manning and R. O'Dor, submitted. Ontogenetic changes in the vertical distribution of scallop larvae Placopecten magellanicus in $9 \mathrm{~m}$ deep mesocosms as a function of light, food, and temperature. Mar. Biol., submitted.

Garrett, C. J. R, J. R. Keeley, and D. A. Greenberg, 1978. Tidal mixing versus thermal stratification in the Bay of Fundy and Gulf of Maine. AtmosphereOcean, 16, 403-423.

Garvine, R. W., 1974. Dynamics of small-scale oceanic fronts. J. Phys. Oc., 4, 557-569.

Gaskin, D. E., 1987. Updated status of the right whale, Eubalaena glacialis, in Canada. Can. Field-Nat., 101(2), 295-309.

Gaskin, D. E., 1991. An update on the status of the right whale, Eubalaena glacialis, in Canada. Can. Field-Nat., 105(2), 198-205.

Geyer, W. R., 1993. The importance of suppression of turbulence by stratification on the estuarine turbidity maximum. Estuaries, 16, 113-125.

Govoni, J. J., and C. B. Grimes, 1992: The surface accumulation of larval fishes by hydrodynamic convergence within the Mississippi River plume front. Cont. Shelf Res., 12, 1265-1276.

Hardy, A. C. and E. R. Gunther, 1935. The plankton of the south Georgia whaling grounds and adjacent waters. 1926-1927.

Haury, L. R. 1976. A comparison of zooplankton patterns in the California Current and North Pacific central gyre. Mar. Biol., 37, 159-167.

Haury, L. R. , P. H. Wiebe, M. H. Orr, and M. G. Briscoe, 1983. Tidally generated high-frequency internal wave packets and their effects on plankton in Massachusetts Bay. J. Mar. Res., 41, 65-112.

Hopkins, T. S. and N. Garfield, 1979. Gulf of Maine Intermediate Water. J. Mar. Res., 37, 103-139.

Hopkins, T. S., and N. Garfield, 1981. Physical origins of Georges Bank water. J. Mar. Res., 39, 465-500. 
Kenney, R. D., M. A. M. Hyman, R. E. Owen, G. P. Scott, and H. E.Winn, 1986. Estimation of prey densities required by western North Atlantic right whales. Mar. Mamm. Sci., 2, 1-13.

Kenney, R. D., H. E. Winn, and M. C. Macaulay, 1995. Cetaceans in the Great South Channel, 1979-1989: Right Whale (Eubalaena glacialis). Cont. Shelf Res. 14(4/5), 385-414.

Kenney, R. D. and K. F. Wishner, 1995. The South Channel Ocean Productivity Experiment. Cont. Shelf Res., 14(4/5), 373-384.

Konstantinova, M. I., 1966, Characteristics of movement of pelagic larvae of marine invertebrates. Dokl. Akad. Nauk. SSSR, 170, 726-729.

Kraus, S. D., K. E. Moore, C. A. Price, M. J. Crone, W. A. Watkins, H. E. Winn, and J. H. Prescott, 1986. The use of photographs to identify individual North Atlantic right whales (Eubalaena glacialis). Rep. Int. Whal. Comm. Spec. Iss., 10, 145-151.

Leising, A. W., 1994. The personal space of copepods. EOS, Proceedings of the American Geophysical Union, 75(3), 195 (abstract).

Lelpoup, E, 1964. Larves de Cerianthaires. Discovery Reports, 33, 251-307.

Leonard, B. P., 1979a. A survey of finite differences of opinion on numerical muddling of the incomprehensible defective confusion equation. In: Finite Element Methods for Convection Dominated Flows, T. J. R. Hughes (ed), Am. Soc. Mech. Eng., New York.

Leonard, B. P., 1979b. A stable and accurate convective modelling procedure based on quadratic upstream interpolation. Comp. Meth. in Appl. Mech. and Eng., 19, 59-98.

Leonard, B. P., 1988. Elliptic systems: finite-difference method IV. In: Handbook of Numerical Heat Transfer, W. J. Minkowycz, E. M. Sparrow, G. E. Schneider, and R. H. Pletcher (eds), John Wiley \& Sons, Inc., New York.

Limeburner, R., and R. C. Beardsley, 1982. The seasonal hydrography and circulation over Nantucket Shoals. J. Mar. Res., 40 (suppl.), 371-406.

Limeburner, R. and R. C. Beardsley, 1989. Lagrangian circulation in the Great South Channel and on Georges Bank during summer. In: Proceedings of the third Georges Bank Research Workshop. Bedford Institute of Oceanography, $29 \mathrm{pp}$. 
Macaulay, M. C., K. F. Wishner, and K. L. Daly, 1995. Acoustic scattering from zooplankton and micronekton in relation to a whale feeding site near Georges Bank and Cape Cod. Cont. Shelf Res., 15(4/5), 509-537.

Mackas, D. L., K. L. Denman and M. R. Abbott, 1985. Plankton patchiness: biology in the physical vernacular. Bull. Mar. Sci., 37(2), 652-674.

Mackas, D. L. and G. C. Louttit, 1988. Aggregation of the copepod Neocalanus plumchrus at the margin of the Fraser River plume in the strait of Georgia. Bull. Mar. Sci., 43(3), 810-824.

Marine Zooplankton Colloquium. 1989. Future marine zooplankton research-a perspective. Mar. Ecol. Progr. Ser., 55, 192:206.

Matthews, L. H. 1938. Notes on the southern right whale, Eubaleana australis. Disc. Rep., 17, 169-182.

Mayo, C. A. and L. Goldman, 1992. Right whale foraging and the plankton resources in Cape Cod and Massachusetts Bays. In: J. Hain (ed), The Right Whale in the Western North Atlantic: A Science and Management Workshop. NEFSC Ref. Doc. 92-05. National Marine Fisheries Service, Northeast Fisheries Science Center, Conservation and Utilization Division, Woods Hole, MA, pp. 43-44

Mayo, C. A. and L. Goldman, in preparation. Food consumption and caloric intake of a right whale, Eubalaena glacialis, in Cape Cod Bay.

Mayo, C. A. and M. K. Marx, 1990. Feeding behavior of northern right whales, Eubalaena glacialis, in Cape Cod Bay, and associated zooplankton characteristics. Can. J. Zool., 68, 2214-2220.

McGowan, J. A. 1974, The nature of marine ecosystems. In: C. B. Miller (ed), The biology of the Pacific Ocean. OSU Press, Corvallis, OR, pp. 9-28.

McGowan, J. A. 1967, Distributional atlas of pelagic molluscs in the California Current region. CalCOFI Atlas No. 6, State of California Research Committee.

Michel, H. B. and M. Foyo, 1976. Caribbean Zooplankton. Part I. Siphonophora, Heteropoda, Copepods, Euphausiacea, Chaetognatha and Salpidae. ONR, Library of Congress \#76-211-43.

Mladenov, P. V. and F. S. Chia, 1982. Development, settling behavior, metamorphosis and pentacrinoid feeding and growth of the feather star Florometra serratissima. Mar. Biol., 73, 309-323.

Moss, A. G., and S. L. Tamm. 1986. Electrophysiological control of ciliary motor responses in the ctenophore Pleurobrachia. J. Comp. Physiol., 158, 311-330. 
Murison, L. D., and D. E. Gaskin, 1989. The distribution of right whales and zooplankton in the Bay of Fundy, Canada. Can. J. Zool., 67, 1411-1420.

Nemoto, T., 1970. Feeding patterns of baleen whales in the ocean. In: Marine Food Chains, J. H. Steele (ed), University of California Press, Berkeley, CA, pp. 241-252.

Neumann, G., and W. J. Pierson, 1966. Principles of Physical Oceanography. Prentice-Hall, Inc. Englewood Cliffs, NJ, p. 400.

Norrbin, M. F., C. S. Davis and S. M. Gallager, submitted. Differences in fine-scale structure and composition of zooplankton between mixed and stratified regions of Georges Bank. Deep Sea Res., submitted.

Okubo, A., 1971. Oceanic diffusion diagrams. Deep-Sea Res., 18, 789-802.

Okubo, A., 1976. Remarks on the use of 'diffusion diagrams' in modeling scaledependent diffusion. Deep-Sea Res., 23, 1213-1214.

Okubo, A., 1978. Advection-diffusion in the presence of surface convergence. In: Coastal Processes, M. J. Bowman and W. E. Esaias (eds), Springer-Verlag, New York.

Olson, D. B., and R. H. Backus, 1985. The concentrating of organisms at fronts: a cold-water fish and a warm-core ring. J. Mar. Res., 43, 113-137.

Olson, D. B., G. L. Hitchcock, A. J. Mariano, C. J. Ashjian, G. Peng, R. W. Nero, and G. P. Podesta, 1994. Life on the edge: marine life and fronts. Oceanography, 7, 52-60.

Omura, H., S. Ohsumi, T. Nemoto, K, Nasu, and T. Kasuya, 1969. Black right whales in the North Pacific. Sci. Rep. Whales Res. Inst., 21, 1-96.

O'Reilly, J. E., C. Evans-Zetlin, and D. A. Busch, 1987. Primary Production. In: Georges Bank, R. H. Backus (ed), MIT Press, Cambridge, MA, pp. 220-233.

Owen, R. W., 1981. Fronts and eddies in the sea: mechanisms, interactions and biological effects. In: Analysis of marine ecosystems, A. R. Longhurst (ed), Academis Press, London, pp. 197-233.

Pivorunas, A., 1979. Feeding mechanisms of baleen whales. Am. Sci., 67, 432-440.

Redfield, A. C., 1939. The history of a population of Limacina retroversa during its drift across the Gulf of Maine. Biological Bull., 76, 26-47. 
Schoenherr, J. R., and K. F. Wishner, 1990. Abundance and distribution of the copepod Calanus finmarchicus in the Great South Channel (MOCNESS tows). Final Data Report for EN-174, EN-176, and EN-196. Unpublished manuscript.

Scott, G. P., R. D. Kenney, R. E. Owen, M. A. M. Hyman, and H. E. Winn, 1985. Biological and physical oceanographic correlatives to cetacean density distribution in the Great South Channel. Document C.M.1985/N:6/Ref:L. International Council for the Exploration of the Sea, Copenhagen, 36 pp.

Sinclair, M., 1988. Marine populations: An essay on population regulation and speciation, Dept. Fish. Oceans. Can., 252 pp.

Steele, J. H., 1976. Some comments on plankton patchiness. In: Spatial Pattern in Plankton Communities, J. H. Steele (ed), Plenum Press, NY, pp. 1-20.

Strathmann, R. R., 1987. Larval Feeding. In: Reproduction of marine Invertebrates, pp. 465-549.

Theroux, R., and M. Grosslein, 1987. Benthic Fauna. In: Georges Bank, R. H. Backus (ed), MIT Press, Cambridge, MA, pp.283-295.

Tomilin, A. G., 1957. Mammals of the U.S.S.R. and Adjacent Countries, Volume IX, Cetacea. Translation no. 1124, Israel Program for Scientific Translation, Jerusalem (1967), 738 pp.

Townsend, D. W., M. D. Keller, M. E. Sieracki, and S. G. Ackleson, 1992. Spring phytoplankton blooms in the absence of vertical water column stratification. Nature, 360, 59-62.

Watkins, W. A. and W. E. Schevill, 1976. Right whale feeding and baleen rattle. J. Mamm., 57(1), 58-66.

Watkins, W. A. and W. E. Schevill, 1979. Aerial observation of feeding behavior in four baleen whales: Eubalaena glacialis, Balaenoptera borealis, Megaptera novaeangliae, and Balaenoptera physalus. J. Mamm., 60, 155-163.

Wessel, P., and W. H. F. Smith, 1991. Free software helps map and display data. EOS Trans. AGU, 72, 441.

Wiebe, P. H., K. H. Burt, S. H. Boyd, and A. W. Morton, 1976. A multiple opening/closing net and environmental sensing system for sampling zooplankton. J. Mar. Res., 34, 313-326.

Wiebe, P. W., E. M. Hulbert, E. J. Carpenter, A. E. Cahn, G. P. Knapp, S. H. Boyd, P. B. Ortner and J. L. Cox, 1976. Gulf Stream cold core rings: large 
scale interaction sites for open ocean plankton communities. Deep-Sea Res., 223, 695-710.

Wiebe, P. H., A. W. Morton, A. M. Bradley, R. H. Backus, J. E. Craddock, V. Barber, T. J. Cowles, G. R. Flierl, 1985. New developments in the MOCNESS, an apparatus for sampling zooplankton and micronekton. Mar. Biol., 87, 313323.

Winn, H. E., J. D. Goodyear, R. D. Kenney, and R. O. Petricig, 1995. Dive patterns of tagged right whales in the Great South Channel. Cont. Shelf Res., 14(4/5), 593-611.

Wishner, K., E. Durbin, A. Durbin, M. Macaulay, H. Winn, and R. Kenney, 1988. Copepod patches and right whales in the Great South Channel off New England. Bull. Mar. Sci., 43(3), 825-844.

Wishner, K. F., J. R. Schoenherr, R. C. Beardsley, and C. Chen, 1995. Abundance, distribution, and population structure of the copepod Calanus finmarchicus in a springtime right whale feeding area in the southwestern Gulf of Maine. Cont. Shelf Res., 15(4/5), 475-507.

Yoder, J.A., S. G. Ackelson, R. T. Barber, P. Flament, and W. M. Balch, 1994. A line in the sea. Nature, 371, 689-692. 